\title{
OTIMIZAÇÃO DE SEÇÕES TRANSVERSAIS DE CONCRETO ARMADO SUJEITAS À FLEXÃO - APLICAÇÃo A PAVIMENTOS
}

Autor: ENG. RODRIGO DE CARVALHO SOARES

Orientadora: Profa. Dra. ANA LÚCIA H.C. EL DEBS 


\section{OTIMIZAÇÃO DE SEÇÕES TRANSVERSAIS DE CONCRETO ARMADO SUJEITAS À FLEXÃO - APLICAÇÃO A PAVIMENTOS}

\section{RODRIGO DE CARVALHO SOARES}

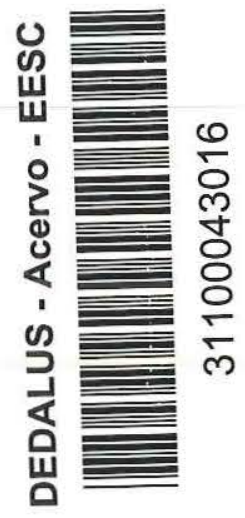

Dissertação apresentada à Escola de Engenharia de São Carlos da Universidade de São Paulo como parte dos requisitos para obtenção do título de "Mestre em Engenharia Civil".

Orientadora: Profa. Dra. ANA LÚCIA H.C. EL DEBS

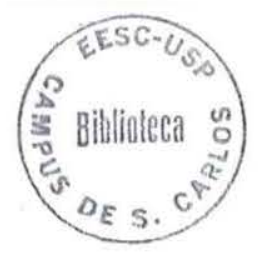

São Carlos 
Class.

cult. 5704

Soares, Rodrigo de Carvalho
Otimização de seçães transversais de concreto armado sujeitas à flexão: aplicação a pavimentos / Rodrigo de Carvalho Soares. -- São Carlos, 1997. $145 \mathrm{p}$.

Dissertação (Mestrado) -- Escola de Engenharia de São CarlosUniversidade de São Paulo, 1997.

Orientador: Prof ${ }^{a}$. Dra . Ana Lúcia H.C. El Debs

1. Otimização estrutural. 2. Concreto armado. 3. Grelhas. I. Titulo. 
A meu pai Zoroastro, minha mãe Rita e meus irmãos Ana e Tiago. 


\section{AGRADECIMENTOS}

À Professora Dr. Ana Lúcia H.C. El Debs pela orientação de extrema competência, confiança no meu trabalho e amizade.

Aos professores do Departamento de Engenharia de Estruturas da ESSC pelos conhecimentos transmitidos e amizade.

Aos funcionários do Departamento de Engenharia de Estruturas pelo apoio e aconchego.

Ao amigo e colega Eduardo Walter pelas contribuições profissionais e companheirismo destes dois anos de mestrado e da própria graduação.

À amiga Conceição de Maria (Mana) pela correção do texto e principalmente pelo apoio emocional e incentivo profissional sem os quais teria sido bem mais difícil completar esta tarefa.

Ao meu pai pelo apoio de todas as formas, e a minha mãe, em memória, que também com certeza de onde estiver estar ao meu lado.

Aos familiares que sempre me incentivaram ao aprendizado.

Aos amigos e colegas do Departamento pelo carinho e sabedoria que sempre transmitiram.

Ao professor e amigo Dr. Silvio Romero Frej da Fonseca Lima, da Universidade Federal de Pernambuco, pelo apoio, incentivo e confiança na minha vinda ao mestrado.

Ao professor Dr. Bernardo Horowitz, da Universidade Federal de Pernambuco, pela contribuição no presente trabalho.

À CNPq. pelo apoio financeiro, sem o qual não seria possível a realização desta monografia.

À FAPESP pelo apoio financeiro, sem o qual não seria possível a realização desta monografia. 


\section{SUMÁRIO}

LISTA DE SÍMBOLOS

LISTA DE TABELAS .......................................................................................... iii

LISTA DE QUADROS ......................................................................................... iv

LISTA DE GRÁFICOS ..................................................................................... iv

LISTA DE FIGURAS ............................................................................................... vi

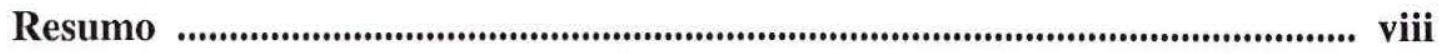

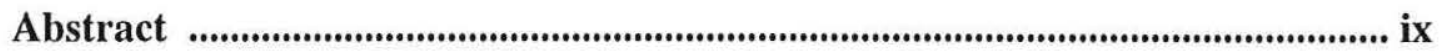

1 Introdução

1.1 Situação do Problema ......................................................................................... 1

1.2 Proposta do Trabalho .............................................................................................. 3

2 Histórico

2.1 História da Otimização Matemática ................................................................ 5

2.2 Tipos de Problemas na Otimização Estrutural ........................................... 13

3 Condições Físicas do Problema

3.1 Situação do Problema ............................................................................... 15

3.2 Variáveis a Serem Otimizadas ............................................................. 15

3.3 Restrições .............................................................................................. 16

3.4 Variáveis Específicas do Problema .............................................................. 17

3.5 Solicitações .................................................................................................. 18

4 Fundamentos da Otimização Matemática

4.1 Preâmbulo ............................................................................................... 19

4.2 Justificativa do Método Utilizado ......................................................... 20

4.3 Conceitos Matemáticos ......................................................................... 21

5 Formulação Matemática para Minimização da Seção Transversal de uma Viga

5.1 Localização do Problema no Campo da Otimização ............................... 39

5.2 Formulação da Função Objetivo e Restrições ......................................... 40

5.3 Resolução do Problema ................................................................................. 43

5.4 Solução do Sistema de Equaç̃̃es .................................................................. 46 
5.5 Verificação dos Resultados Obtidos ......................................................... 47

5.6 Verificação da Consistência dos Resultados ............................................. 52

6 Solução Extendida às Seções Transversais de Grelhas

6.1 Introdução .................................................................................................... 54

6.2 Embasamento Matemático ................................................................................. 54

6.2.1 Formulação do Problema ................................................................. 55

6.3 Procedimentos utilizados no "Software" ................................................... 58

6.3.1 Cálculo da Flecha ............................................................................. 58

6.3.1.1 Aplicação da Analogia de Mohr para Vãos Apoiados nas

Extremidades .......................................................................... 61

6.3.1.2 Aplicação da Analogia de Mohr para Vãos em Balanço .. 62

6.3.2 Fluência ...................................................................................... 63

6.3.3 Esforços Solicitantes .............................................................................. 64

6.4 Obtenção da Seção Ótima ........................................................................ 64

6.5 Precisão dos Resultados .................................................................................... 65

7 Momento de Inércia

7.1 Introdução ........................................................................................................... 67

7.2 Momento Crítico de Fissuração ……………………………………………... 68

7.3 Momento de Inércia à Flexão ...................................................................... 69

7.3.1 Momento de Inércia Segundo BRANSON ................................... 70

7.4 Análise Numérica do Coeficiente " $\mathrm{m}$ " ........................................................ 72

7.4.1 Exemplo - Viga Biapoiada .................................................................. 74

7.4.2 Exemplo - Viga com 2 Tramos ....................................................... 76

7.4.3 Exemplo - Viga com 3 Tramos .......................................................... 78

7.4.4 Exemplo - Viga em Balanço com 2 Tramos .................................. 79

7.5 Cálculo do Momento de Inércia à Torção .................................................... 82

8 Experimentação Numérica

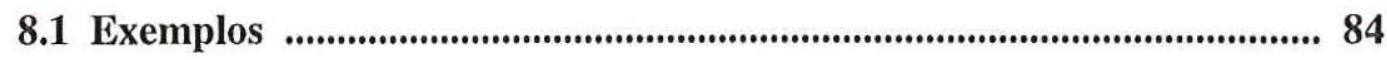

8.1.1 Exemplo - Viga Biapoiada .................................................................. 86

8.1.2 Exemplo - Viga com 3 Tramos .................................................. 87

8.1.3 Exemplo - Grelha Composta por 9 Vigas ..................................... 88 
8.1.4 Exemplo - Pavimento Composto por 7 Vigas ............................... 91

8.1.5 Exemplo - Pavimento Composto por 9 Vigas ................................. 94

8.1.6 Exemplo - Pavimento Composto por 13 Vigas .............................. 99

8.2 Comparação com Estruturas Existentes ..................................................... 107

8.2.1 Edifício LIBERAL OFFICE ........................................................ 107

8.2.1 Edifício LAGO AZUL ....................................................................... 116

8.2.1 Edifício RESIDENCIAL ................................................... 125

9 Conclusão

9.1 Conclusões do Trabalho ................................................................................... 136

9.2 Propostas para Pesquisas Futuras .......................................................... 140

Referências Bibliográficas .................................................................................... 142

Apêndice I : Fluxograma 


\section{LISTA DE SÍMBOLOS}

$\varepsilon_{\mathrm{c}}$ - deformação da fibra comprimida do concreto;

$\varepsilon_{\mathrm{s}}$ - deformação da fibra tracionada do aço;

$\rho_{\mathrm{s}}$ - peso específico do aço;

$\mathrm{A}_{\mathrm{s}}$ ' - área de aço trabalhando à compressão;

$\mathrm{A}_{\mathrm{s}}$ - área de aço trabalhando à tração;

$\mathrm{b}_{\mathrm{w}}$ - base da seção transversal;

$\mathrm{C}_{\mathrm{c}}$ - custo unitário do concreto;

$\mathrm{C}_{\mathrm{f}}$ - custo unitário da forma;

$\mathrm{C}_{\mathrm{s}}$ - custo unitário do aço;

d'- distância do centro de gravidade da área de aço comprimida à face do banzo comprimido;

d - altura útil da seção transversal;

$\mathrm{E}_{\mathrm{c}}$ - módulo de elasticidade longitudinal do concreto;

$\mathrm{E}_{\mathrm{s}}$ - módulo de elasticidade longitudinal do aço;

$\mathrm{F}_{\mathrm{c}}$ - força atuante no banzo comprimido da seção transversal de concreto;

$\mathrm{f}_{\mathrm{cd}}$ - resistência de cálculo do concreto à compressão;

$\mathrm{f}_{\mathrm{ck}}$ - resistência característica do concreto à compressão;

$\mathrm{F}_{\mathrm{sl}}$ - força atuante na área de aço comprimida;

$\mathrm{F}_{\mathrm{st}}$ - força atuante na área de aço tracionada;

$\mathrm{f}_{\mathrm{yd}}$ - resistência de cálculo do aço;

$\mathrm{f}_{\mathrm{yk}}$ - resistência característica do aço;

h - altura da seção transversal;

I - momento de inércia à flexão;

$\mathrm{I}_{0}$ - momento de inércia à flexão no Estádio I;

$\mathrm{I}_{2}$ - momento de inércia à flexão no Estádio II puro;

IServiço - momento de inércia à flexão no Estádio II;

M - momento fletor;

$\mathrm{M}_{\mathrm{d}}$ - momento fletor de cálculo;

$\mathrm{M}_{\mathrm{k}}$ - momento fletor característico; 
$\mathrm{M}_{\mathrm{r}}$ - momento resistente ou momento de fissuração;

$\mathrm{P}_{\mathrm{ac}}$ - limite máximo para a taxa geométrica da armadura;

q - ação transversal distribuída uniformemente no elemento;

Q - esforço cortante;

$\mathrm{X}$ - posição da linha neutra. 


\section{LISTA DE TABELAS}

Tabela 2.1 - Trabalhos sobre otimização estrutural .................................................6 6

Tabela 2.2 - Características principais da prática da otimização estrutural .............. 9

Tabela 2.3 - Identificação de fatores nos problemas estruturais ............................ 14

Tabela 5.1 - Resultados de otimização de seções transversais de uma viga biapoiada .................................................................................. 49

Tabela 7.1 - Coeficientes $\eta$ fornecidos pelo SÜSSEKIND para cálculo do momento de inércia à torção .......................................................................... 82

Tabela 7.2 - Coeficientes $\eta$ para determinar o momento de inércia à torção ........... 83

Tabela 8.1 - Resultados Numéricos das alturas ótimas de uma viga biapoiada ...... 86

Tabela 8.2-Resultados Numéricos das alturas ótimas de uma viga com três tramos

Tabela 8.3 - Resultados Numéricos das alturas ótimas de uma grelha composta por 9 vigas

Tabela 8.4 - Resultados Numéricos das alturas ótimas de um pavimento composto por 7 vigas.

Tabela 8.5 - Resultados Numéricos das alturas ótimas de um pavimento composto por 9 vigas 95

Tabela 8.6 - Resultados Numéricos das alturas ótimas de um pavimento composto por 13 vigas

Tabela 8.7 - Otimização das vigas de um pavimento com a variação das espessuras das placas 103

Tabela 8.8 - Variação dos resultados da otimização com o refinamento da malha de elementos finitos 105

Tabela 8.9 - Variação nas alturas das vigas do edifício Liberal Office 110

Tabela 8.10 - Análise das flechas das vigas do edifício Liberal Office 112

Tabela 8.10.1 - Comparação das flechas do edifício Liberal Office calculadas pelo GL5 e pelo SSPO

Tabela 8.11 - Variação nas alturas das vigas do edifício Lago Azul 118

Tabela 8.12 - Análise das flechas das vigas do edifício Lago Azul 120 
Tabela 8.13 - Análise do tempo de processamento e variação do custo da estrutura do edifício Lago Azul ..................................................................................................... 123

Tabela 8.11 - Variação nas alturas das vigas do edifício Residencial .................. 127

Tabela 8.12 - Análise das flechas das vigas do edifício Residencial ................... 129

Tabela 7.2 - Consumo de aço do edifício Residencial ........................................... 134

Tabela 7.2 - Consumo de concreto do edifício Residencial ................................. 134

Tabela 7.2 - Custo dos materiais do edifício Residencial ..................................... 135

\section{LISTA DE QUADROS}

Quadro 6.1 - Analogia de Mohr 60

\section{LISTA DE GRÁFICOS}

Gráfico 5.1 - Variação da altura da seção ótima com respectivo momento fletor solicitante - exemplo de uma viga biapoiada 50

Gráfico 5.2 - Variação do volume de concreto da seção ótima com respectivo momento fletor solicitante - exemplo de uma viga biapoiada ......... 50

Gráfico 5.3 - Variação da área de aço da seção ótima com respectivo momento fletor solicitante - exemplo de uma viga biapoiada ................................. 51

Gráfico 5.4 - Variação da flecha máxima com o momento fletor solicitante - exemplo de uma viga biapoiada 51

Gráfico 5.5 - Variação do custo da seção ótima com respectivo momento fletor solicitante - exemplo de uma viga biapoiada 52

Gráfico 5.6 - Representação da função objetivo sujeita as restrições para uma seção transversal - exemplo de uma viga biapoiada 53

Gráfico 7.1 - Momentos de inércia das alturas ótimas de uma viga biapoiada para diferentes modelos de consideração do I 74

Gráfico 7.2 - Análise da variação dos momentos de inércia dos elementos de uma viga biapoiada 75 
Gráfico 7.3 - Momentos de inércia das alturas ótimas de uma viga com dois tramos para diferentes modelos de consideração do I ................................. 76

Gráfico 7.4 - Análise da variação dos momentos de inércia dos elementos de uma viga com dois tramos 77

Gráfico 7.5 - Momentos de inércia das alturas ótimas de uma viga com três tramos para diferentes modelos de consideração do I

Gráfico 7.6 - Análise da variação dos momentos de inércia dos elementos de uma viga com três tramos 79

Gráfico 7.7 - Momentos de inércia das alturas ótimas de uma viga em balanço para diferentes modelos de consideração do I 80

Gráfico 7.8 - Análise da variação dos momentos de inércia dos elementos de uma viga em balanço 80

Gráfico 7.9 - Comparação de alturas ótimas de vigas para diferente modelagem do momento de inércia dos elementos discretos 81

Gráfico 8.1 - Análise de convergência de uma viga biapoiada 87

Gráfico 8.2 - Análise de convergência de uma viga com três tramos 87

Gráfico 8.3 - Análise de convergência das vigas com mais de um tramo de uma grelha composta por 9 vigas 90

Gráfico 8.4 - Análise de convergência das vigas com um tramo de uma grelha composta por 9 vigas 90

Gráfico 8.5 - Análise do custo de uma grelha composta por 9 vigas 91

Gráfico 8.6 - Análise de convergência das vigas com mais de um tramo de um pavimento composto por 7 vigas 93

Gráfico 8.7 - Análise de convergência das vigas com um tramo de um pavimento composto por 7 vigas 93

Gráfico 8.8 - Análise do custo de um pavimento composto por 7 vigas 94

Gráfico 8.9 - Análise de convergência das vigas com mais de um tramo de um pavimento composto por 9 vigas 97

Gráfico 8.10 - Análise de convergência das vigas com um tramo de um pavimento composto por 9 vigas 97

Gráfico 8.11 - Análise do custo de um pavimento composto por 9 vigas 98 
Gráfico 8.12 - Análise do custo de um pavimento composto por 9 vigas 100

Gráfico 8.13 - Análise de convergência das vigas com mais de um tramo de um pavimento composto por 13 vigas 100

Gráfico 8.14 - Mostra um "zoom" do gráfico 8.13 101

Gráfico 8.15 - Análise de convergência das vigas com um tramo de um pavimento composto por 13 vigas 101

Gráfico 8.16 - Mostra um "zoom” do gráfico 8.15 102

Gráfico 8.17 - Otimização das vigas de um pavimento com a variação das espessuras das placas 104

Gráfico 8.18 - Análise dos resultados da otimização com o refinamento da malha de elementos finitos - vigas com mais de um tramo 106

Gráfico 8.19 - Análise dos resultados da otimização com o refinamento da malha de elementos finitos - vigas com um tramo 106

Gráfico 8.20 - Análise de convergência do custo do edifício Lago azul 123

Gráfico 8.21 - Variação das alturas das vigas do edifício Lago azul 124

\section{LISTA DE FIGURAS}

Figura 4.1 - Interpretação gráfica dos multiplicadores de Lagrange - representação geométrica dos gradientes de um conjunto de funções

Figura 4.2 - Exemplos de regiões viáveis, conjunto de pontos factíveis para solução do problema de otimização 26

Figura 4.3 - Exemplos de pontos de mínimo de uma função de uma variável 27

Figura 4.4 - Exemplos de restrições ativas e inativas 28

Figura 4.5 - Exemplos de plano tangente 29

Figura 4.6 - Definição geométrica da matriz L restringida ao sub-espaço M, que é tangente à superfície de restrição 34

Figura 5.1 - Seção transversal sujeita à esforços de flexão 40

Figura 5.2 - Viga biapoiada 47 
Figura 6.1 - Flecha de um vão definida por diferença relativa de deslocamentos nodais

Figura 6.2 - Analogia de Mohr, condições de vinculação e carregamento para um tramo apoiado nas extremidades - estrutura real 61

Figura 6.3 - Analogia de Mohr, condições de vinculação e carregamento para um tramo apoiado nas extremidades - estrutura virtual

Figura 6.4 - Analogia de Mohr, condições de vinculação e carregamento para um tramo em balanço - estrutura real 62

Figura 6.5 - Analogia de Mohr, condições de vinculação e carregamento para um tramo em balanço - estrutura virtual 63

Figura 7.1 - Exemplo de viga biapoiada 74

Figura 7.2 - Exemplo de viga com dois tramos 76

Figura 7.3 - Exemplo de viga com três tramos 78

Figura 7.4 - Exemplo de viga em balanço 79

Figura 8.1 - Forma de uma grelha composta por 9 vigas 88

Figura 8.2 - Forma de um pavimento composto por 7 vigas 92

Figura 8.3 - Forma de um pavimento composto por 9 vigas 95

Figura 8.4 - Forma de um pavimento composto por 13 vigas 99

Figura 8.5 - Forma do edifício Liberal Office 109

Figura 8.6 - Curvas de isodeslocamentos do edifício Liberal Office 114

Figura 8.6 - Forma do edifício Lago Azul 117

Figura 8.7 - Forma do edifício Residencial 126

Figura 8.8 - Diagrama de deslocamento da grelha do edifício Residencial 132

Figura 8.9 - Diagrama de momentos fletores da grelha do edifício Residencial 133 


\section{RESUMO}

Nos tempos atuais, já existe um forte desenvolvimento computacional no que diz respeito a análise de estruturas com características geométricas, de cargas e vinculações previamente definidas. Assim como os processadores, tem-se investido bastante em pré e pós-processadores, os quais são responsáveis pela maior parte do tempo dedicado a um projeto. No entanto, pode-se dizer que a definição automática das características geométricas dos elementos estruturais deixa a desejar. Hoje, esta etapa ainda é feita pelo engenheiro, apenas com uma ajuda indireta da máquina. Este trabalho apresenta uma maneira ótima de fazer o pré-dimensionamento das vigas de um pavimento de concreto armado. Para isso, desenvolveu-se uma formulação de minimização do custo de uma seção transversal com a qual, através de um método de aproximações combinadas, obtém-se o mínimo custo do vigamento de um pavimento. As variáveis envolvidas na função que representa o custo são: a altura da viga e as áreas de aço. E as restrições do problema são: a taxa geométrica da armadura, a taxa de armadura de compressão em relação a de tração e a flecha máxima pré-estabelecida pelo usuário. 


\begin{abstract}
Nowadays, there is a continuous development in structural computational analysis for known geometrical, loading and boundary conditions. Much effort has been made on the pre and pos-processors, which is the main part of the time spent in designing. The automatic definition of the geometrical characteristics for the structural elements, however is poor yet. Today, this phase is still carried out by the engineer, only with an indirect machine help. This work presents an optimal method to automate the first draft design of the beams reinforced concrete floor. A formulation to achieve the cross-section minimum cost function is proposed and then extended to the whole floor by combined approximation methods. In order to obtain the cost function the following values have been considered: the beam depth and the steel area. As problem constraints, the steel geometric rate, the steel compression with the steel tension rate and the limit displacement have to be prescribed by the user.
\end{abstract}

Keyword: structural optimization, frame, reinforced concrete. 


\section{1 - INTRODUÇÃO}

\section{1 - Situação do Problema}

Definido o projeto arquitetônico, o engenheiro de estruturas tem a incumbência de lançar e dimensionar a estrutura da forma mais econômica possível, permanecendo dentro das especificações definidas por Normas e das limitações práticas que causam impossibilidade ou dificuldade de execução da obra.

Então, o primeiro passo de um projeto estrutural é o lançamento da estrutura. Para isso, o engenheiro deve determinar o posicionamento dos elementos estruturais e suas respectivas dimensões. Esta etapa do cálculo pode induzir a um melhor comportamento estrutural e consequentemente resultar numa estrutura mais econômica, que é um dos objetivos principais dos engenheiros.

Existe um número razoável de variáveis na determinação do posicionamento dos elementos estruturais, principalmente no que diz respeito aos pilares, dificultando ou inviabilizando a prática da programação matemática neste assunto. Além das características dos materiais, geométricas e das ações externas, a localização ideal dos pilares numa estrutura varia com o tipo de solo, processo construtivo, forma de execução, preço da mão-de-obra, preço das estruturas pré-moldadas, tempo disponível de construção, etc. Foram citadas algumas das variáveis decisivas na localização ótima dos pilares, valendo ressaltar que um fator relevante é a arquitetura. Além de todas as variáveis do projeto estrutural, o engenheiro se restringe ao projeto arquitetônico, sendo muito difícil a coincidência de idealização destes projetos. Devido a toda essa dificuldade, hoje em dia um dos poucos passos que é feito exclusivamente pelo homem, sem o auxílio do computador, é a determinação do posicionamento dos elementos estruturais, sendo esta distribuição dos elementos mais próxima da ótima quanto maior a experiência do engenheiro. Vale salientar que tudo que está sendo dito no presente trabalho refere-se a pavimentos estruturais de concreto armado.

Uma vez definida a localização dos pilares, vigas e lajes, parte-se para o predimensionamento dos elementos estruturais. Nesta etapa, o engenheiro de 
estruturas precisa ter um certo conhecimento do comportamento estrutural para determinar as dimensões dos elementos de maneira a obter um menor custo para a obra e respeitar prescrições feitas pela Norma. As dimensões dos elementos variam com as cargas, vãos, materiais, tipo estrutural, etc. Como será mostrado posteriormente, entre outros objetivos, este trabalho propõe uma maneira automática de determinar as dimensões das vigas que fazem parte de uma grelha; de uma forma prática, buscar-se-á um menor custo para o vigamento de um pavimento de concreto armado.

Conhecidos o posicionamento e as dimensões dos elementos estruturais (lajes, vigas e pilares), inicia-se uma nova fase: o processamento dos esforços e deslocamentos. Nesta etapa, cabe ao engenheiro decidir qual modelo de cálculo será utilizado (grelha, elementos finitos, etc.), sendo determinado qual modelo melhor se adequa a situação em função do grau de precisão desejado dos resultados. Para uma maior economia, nesta fase do projeto, pode-se levar em consideração a plastificação do material, que faz com que ocorra uma redistribuição dos esforços, resultando num melhor aproveitamento dos elementos estruturais. Esta fase de projeto já é bastante automatizada, sendo necessário ao projetista apenas a conferência dos resultados, verificando se a concepção de cálculo adotada está ou não coerente.

Se os resultados obtidos até esta etapa estão coerentes com os desejados pelo engenheiro de estruturas, passa-se ao dimensionamento dos elementos estruturais. Caso estes não sejam satisfatórios, redefinem-se as dimensões dos elementos e realizase um novo processamento. O dimensionamento dos elementos estruturais consiste na determinação das áreas de aço das seções submetidas aos esforços solicitantes. Este dimensionamento deve ser feito nos domínios 2 e 3, uma vez que no domínio 4 ocorre ruptura brusca da peça estrutural. De acordo com os esforços solicitantes e as dimensões preestabelecidas, entre outros fatores, a seção de aço é dimensionada, não sendo necessariamente a que torne a estrutura mais econômica. Enfim, encerra-se o procedimento de cálculo de um pavimento de concreto armado com a plotagem das pranchas de forma e de armação. 
Através do breve relato descrito acima, tentou-se mostrar o procedimento de cálculo de um projeto estrutural, e, entre as várias fases de cálculo, tentar-se-á inserir o presente trabalho.

Com o passar dos tempos, os engenheiros de estruturas buscam cada vez mais minimizar o tempo utilizado num projeto, visando a maiores condições de competitividade. Para reduzir este tempo, busca-se a automatização dos passos de desenvolvimento dos projetos. A respeito do cálculo dos esforços, dimensionamento e detalhamento das estruturas, a automatização já está bastante desenvolvida. Com relação a pré e pós-processadores, o desenvolvimento tem crescido bastante, e continuará por mais algum tempo, pois são responsáveis por boa parte do tempo empregado num projeto. Além disso, o forte estudo nesta área também se dá devido aos recursos que a computação gráfica agora está oferecendo. Entretanto, apesar de todo o desenvolvimento, há uma certa deficiência na automatização da determinação das características geométricas dos elementos estruturais, que é onde se insere este trabalho.

\section{2 - Proposta do Trabalho}

Pretende-se fazer um "software" que determine, automaticamente, e de maneira "ótima", as alturas das vigas de um pavimento de concreto armado, e faça o processamento da estrutura definitiva. Baseado numa formulação matemática desenvolvida pelo autor, o "software" determinará alturas para as vigas de forma a terem custo mínimo dentro de um campo prático da engenharia de estruturas. $\mathrm{O}$ equacionamento matemático do problema está sujeito a algumas restrições, tais como: equilíbrio dos esforços, percentagem da área de aço em relação à área da seção transversal de concreto, e percentagem da armadura de compressão em relação à armadura de tração. A respeito da restrição relacionada ao máximo deslocamento admissível, esta será imposta fora da formulação matemática. Com uma altura ótima da viga já definida pelo equacionamento matemático, será verificado se a flecha relativa a esta rigidez é admissível. Caso não seja, serão dados incrementos positivos na altura da viga até que a inércia desta seja coerente para uma flecha admissível. 
O custo a ser minimizado é colocado em função do volume de concreto, da área de formas e do peso do aço, sendo a função objetivo aplicada a cada viga do pavimento independentemente. A interação entre as vigas da estrutura é feita através de um processo iterativo, obtendo-se assim uma minimização do custo das vigas. Vale ressaltar que a formulação matemática foi feita para uma viga, e não para uma grelha. Sendo assim, é desconhecido se os resultados apresentados são os mesmos que para a minimização de uma grelha como uma estrutura única. Neste trabalho, parte-se do princípio que a minimização de um conjunto de vigas (grelha) é equivalente à minimização da grelha, sendo a interação entre as vigas feita pelas iterações internas do programa. Acredita-se que os resultados não sejam teoricamente os mesmos mas, para uma utilização prática, parece uma aproximação bastante razoável.

O processamento da estrutura é feito pelo método dos elementos finitos, uma vez que este proporciona resultados mais próximos do comportamento real da estrutura, e consequentemente mais confiáveis e econômicos. 


\section{2 - HISTÓRICO}

\section{1 - História da Otimização Matemática}

A teoria da otimização estrutural tem alcançado avanço considerável nas últimas três décadas conforme ilustrado pelo grande número de livros e artigos publicados sobre o assunto. Por outro lado, a utilização prática da otimização é comparavelmente modesta, e reservada a problemas específicos, resolvidos por especialistas em otimização. Baseado no estudo de um amplo catálogo, feito em 1992 por M. Z. Cohn, Fellow, Grierson, e A. S. Dinovitzer publicado no "Journal of Structural Engineering" em fevereiro de 1994, com cerca de 500 exemplos de otimização publicados, que abrange a história da otimização estrutural até 1992, e nas publicações a partir de 1992 até a atualidade, tentar-se-á mostrar uma breve história da otimização estrutural.

Livros e artigos compõem a maior parte das fontes bibliográficas. Mas as publicações em concreto armado e concreto protendido são, na maioria das vezes, encontradas em artigos isolados: não há muitos exemplos de otimização em concreto armado devido à sua heterogeneidade e anisotropia.

Na aplicação prática da otimização estrutural, estão citadas estruturas do tipo:

- treliças planas;

- vigas, colunas e cabos;

- "frames" " e arcos;

- treliças espaciais;

- placas, cascas e chapas.

No estudo de teoria e prática da otimização estrutural COHN (1994) estimase que os registros publicados em otimização estrutural podem ser encontrados em cerca de 150 livros e 2.500 artigos. A maioria das publicações aborda aspectos matemáticos da otimização. Através dos anos, esforços para aplicar técnicas de otimização a problemas de engenharia estrutural têm sido refletidos por numerosas publicações de revistas internacionais. Para maior compreensão do desenvolvimento

"estrutura aporticada, pórtico ou grelha 
da otimização estrutural, apresentam-se na tabela 2.1, em ordem cronológica, algumas dessas publicações.

\begin{tabular}{|c|c|c|}
\hline ANO & AUTOR & DESCRIÇÃO DO TRABALHO \\
\hline 1963 & Schmit e Mallett & 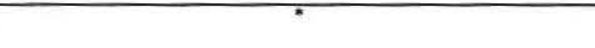 \\
\hline 1970 & Rozvany e Cohn & * \\
\hline 1971 & Lapay e Goble & * \\
\hline 1971 & Reinschmidt & * \\
\hline 1972 & Mau e Sexmith & * \\
\hline 1972 & Pedersen & * \\
\hline 1972 & Vanderplaats e Moses & * \\
\hline 1975 & Kirsch & * \\
\hline 1975 & Moses e Goble & * \\
\hline 1976 & Rosenblueth & * \\
\hline 1979 & Kirsch e Moses & * \\
\hline 1981 & Lev & * \\
\hline 1982 & Ashley & * \\
\hline 1982 & Vanderplaats & * \\
\hline 1983 & Templeman & * \\
\hline 1984 & Colnn e Mackal & * \\
\hline 1987 & Levy e Lev & * \\
\hline $3 / 1989$ & Amir e Hasegawa & Estrutura discreta mista não-linear \\
\hline $5 / 1989$ & Frangopol e Klisinski & Projeto ótimo de sistemas estruturais \\
\hline $6 / 1989$ & Hasegawa, Sakamoto e Sato & $\begin{array}{l}\text { Projeto elástico e plástico para carga } \\
\text { máxima }\end{array}$ \\
\hline $8 / 1990$ & Wei Z. e Ye S. & $\begin{array}{c}\text { Seção ótima para "frame" usando } \\
\text { programação geométrica }\end{array}$ \\
\hline $3 / 1991$ & Pezeshk e Hjelmstad & $\begin{array}{l}\text { Projeto ótimo de estruturas aporticadas } \\
\text { planas baseado no critério de estabilidade }\end{array}$ \\
\hline 1992 & Rajeev e Krishnamoorthy & * \\
\hline $7 / 1992$ & Kirsch e Topping & $\begin{array}{c}\text { Projeto de peso mínimo de topologia } \\
\text { estrutural }\end{array}$ \\
\hline $11 / 1992$ & Jenkins & $\begin{array}{l}\text { Em torno do projeto ótimo de estrutura } \\
\text { plana aporticada baseado no algoritmo } \\
\text { genético }\end{array}$ \\
\hline
\end{tabular}




\begin{tabular}{|c|c|c|}
\hline ANO & AUTOR & DESCRIÇÃO DO TRABALHO \\
\hline $11 / 1992$ & Chakrabarty & $\begin{array}{l}\text { Um modelo para projeto ótimo para viga } \\
\text { de concreto armado }\end{array}$ \\
\hline $3 / 1993$ & Lassen & $\begin{array}{c}\text { Projeto ótimo de estruturas } \\
\text { tridimensionais }\end{array}$ \\
\hline $7 / 1993$ & Horowitz & $\begin{array}{c}\text { Esforços em colunas esbeltas de } \\
\text { concreto sujeitas a flexão biaxial }\end{array}$ \\
\hline $7 / 1993$ & Ramos, Stange e Ing & $\begin{array}{l}\text { Um sistema para projeto ótimo de } \\
\text { estrutura de concreto armado }\end{array}$ \\
\hline $7 / 1993$ & Moharrami e Grierson & $\begin{array}{l}\text { Projeto automático de estruturas de } \\
\text { concreto armado }\end{array}$ \\
\hline $2 / 1994$ & $\begin{array}{c}\text { Grierson, Cohn, Fellow e } \\
\text { Dinovitzer }\end{array}$ & Aplicações da otimização estrutural \\
\hline $12 / 1994$ & Salloum e Siddiqi & $\begin{array}{l}\text { Projeto de custo ótimo de viga de concreto } \\
\text { armado }\end{array}$ \\
\hline $2 / 1995$ & Thanedar e Vanderplaats & $\begin{array}{c}\text { Inspeção de otimização de variável } \\
\text { discreta para projeto estrutural }\end{array}$ \\
\hline $5 / 1995$ & $\begin{array}{l}\text { Chun-Man, Grierson e } \\
\text { Sherbourne }\end{array}$ & $\begin{array}{c}\text { Projeto ótimo automático para construção } \\
\text { de estruturas aporticadas altas de aço }\end{array}$ \\
\hline $5 / 1995$ & Tseng, Wang e Ling & $\begin{array}{l}\text { Acrescentando o Método BRANCH- } \\
\text { BOUND para otimização estrutural }\end{array}$ \\
\hline
\end{tabular}

TABELA 2.1 - Trabalhos sobre otimização estrutural

Através de publicações do "Journal of Structural Engineering", de Congressos Internacionais e de publicações do Departamento de Estruturas da EESC - USP, foi feita uma pesquisa da prática da otimização estrutural entre 1992 e 1995, pois as publicações feitas antes de 1992 foram bastante exploradas por COHN et alii (1994). Alguns dos exemplos adquiridos neste estudo foram organizados em forma de tabela, a qual contém as características mais importantes para conhecimento do problema de otimização. Cada item descrito abaixo corresponde a uma coluna da tabela 2.2.

1. Descrição - treliça, viga, pórtico, grelha, etc.;

2. Data de publicação; 
3. Tamanho da estrutura: define o número de elementos da estrutura;

4. Incerteza: problema determinístico (D) ou problema probabilístico (P);

5. Nível de otimização: seção (SEC), membros (MEM), sistema estrutural especificado (SYS), ou topológicos (TOP) para sistemas estruturais não especificados;

6. Carregamento: estático (E) ou dinâmico (D);

7. Materiais: aço (S), concreto $(\mathrm{C})$, ou composto $(\mathrm{O})$;

8. Estado limite: estado limite último (U), estado limite de serviço (S) ou ambos (B);

9. Restrições: (9.1) tensão, (9.2) flecha ou rotação, (9.3) fadiga, (9.4) construtivo e (9.5) colapso global. Frequência relevante ou modo de vibração são listados como flecha ou restrições de estabilidade para problemas de carregamento dinâmico. Restrições em fissuração, instabilidade e dano local não foram verificadas nos trabalhos pesquisados. As restrições usadas em qualquer exemplo são identificadas por (C);

10.Função objetivo: única (U) ou múltipla (M);

11.Métodos computacionais: algoritmo e/ou 'software' conhecidos no campo da otimização estrutural. A seguir será listada a classificação dos métodos computacionais descritos na tabela abaixo:

- GP - programação geométrica (critério ótimo);

- SQP - programação quadrática sequencial (critério ótimo);

- OT - "optimal topologies" (critérios ótimos);

- MP - programação matemática;

- NLP - programação não-linear (programação matemática). 


\begin{tabular}{|c|c|c|c|c|c|c|c|c|c|c|c|c|c|c|}
\hline 1 & 2 & 3 & 4 & 5 & 6 & 7 & 8 & 9.1 & 9.2 & 9.3 & 9.4 & 9.5 & 10 & 11 \\
\hline placa & 89 & 1 & $\bar{D}$ & SYS & $\mathrm{E}$ & $\mathrm{O}$ & $\mathrm{S}$ & $\mathrm{C}$ & $\mathrm{C}$ & $\cdot$ & - & - & $\bar{U}$ & $\mathrm{AD}$ (all discrete) nlp \\
\hline viga & 89 & 1 & $\overline{\mathrm{D}}$ & SYS & $\mathrm{E}$ & $\mathrm{C}$ & $\mathrm{S}$ & $\mathrm{C}$ & - & $\mathrm{C}$ & - & - & $\mathrm{U}$ & $\mathrm{AD}$ \\
\hline pórtico plano & 89 & 15 & $\mathrm{D}$ & SYS & $\mathrm{E}$ & $\mathrm{s}$ & $\mathrm{S}$ & $\mathrm{C}$ & $\mathrm{C}$ & - & $\cdot$ & $\cdot$ & $\mathrm{U}$ & $\begin{array}{l}\text { AD, MD (mixed discrete), } \\
\text { AC (all continuous) nlp }\end{array}$ \\
\hline treliça & 89 & 10 & D & SYS & $\mathrm{E}$ & $\mathrm{S}$ & $\mathrm{U}$ & C & $\mathrm{C}$ & - & - & - & $\mathrm{U}$ & - \\
\hline treliça & 89 & 10 & $\mathrm{D}$ & SYS & $\mathrm{E}$ & $\mathrm{O}$ & $\mathrm{U}$ & $\mathrm{C}$ & - & - & - & - & $\mathrm{U}$ & - \\
\hline pórtico plano & 89 & 3 & $\mathrm{D}$ & SYS & E & $\mathrm{s}$ & $\mathrm{s}$ & $\mathrm{C}$ & $\mathrm{C}$ & $\mathrm{C}$ & $\mathrm{C}$ & $\mathrm{C}$ & $\mathrm{U}$ & - \\
\hline viga & 89 & 2 & $\mathrm{D}$ & SYS & E & $\mathrm{S}$ & $\mathrm{s}$ & $\mathrm{C}$ & $\mathrm{C}$ & - & - & - & $\mathrm{U}$ & - \\
\hline pórtico & 90 & 3 & $\bar{D}$ & SYS & $\mathrm{E}$ & $\mathrm{S}$ & $S$ & $\mathrm{C}$ & $\mathrm{C}$ & - & - & - & $\mathrm{U}$ & GP \\
\hline pórtico plano & 91 & 3 & $\bar{D}$ & TOP & D & $\mathrm{S}$ & $\mathrm{U}$ & $\mathrm{C}$ & - & $\mathrm{C}$ & - & -. & $\mathrm{U}$ & NLP \\
\hline treliça & 92 & 10 & $\mathrm{D}$ & SYS & $\mathrm{E}$ & $\mathrm{s}$ & $\mathrm{s}$ & $\mathrm{C}$ & $\mathrm{C}$ & - & - & - & $\mathrm{U}$ & OT - nlp \\
\hline treliça & 92 & 11 & D & SYS & $\mathrm{E}$ & $\mathrm{S}$ & $\mathrm{S}$ & C & $\mathrm{C}$ & - & - & - & $\mathrm{U}$ & OT \\
\hline treliça & 92 & 11 & $\mathrm{D}$ & SYS & $\mathrm{E}$ & $\mathrm{S}$ & $\mathrm{s}$ & $\mathrm{C}$ & $\mathrm{C}$ & - & - & - & $\mathrm{U}$ & OT \\
\hline treliça & 92 & 21 & D & SYS & $\mathrm{E}$ & $\mathrm{S}$ & $\mathrm{S}$ & $\mathrm{C}$ & $\mathrm{C}$ & - & - & - & $\mathrm{U}$ & OT \\
\hline viga & 92 & 1 & D & SYS & E & $\mathrm{C}$ & $\mathrm{s}$ & C & - & - & - & - & $\mathrm{U}$ & GNLP, SNLP -nlp \\
\hline $\begin{array}{c}\text { pórtico } \\
\text { tridimensional }\end{array}$ & 93 & 70 & $\mathrm{D}$ & SYS & $\mathrm{E}$ & $\mathrm{S}$ & $\mathrm{S}$ & $\mathrm{C}$ & - & - & - & $\mathrm{C}$ & $\mathrm{U}$ & NLP baseado em SQP \\
\hline treliça espacial & 93 & 31 & D & SYS & $\mathrm{E}$ & $\mathrm{S}$ & $\mathrm{S}$ & $\mathrm{C}$ & - & $\mathrm{C}$ & - & - & $\mathrm{U}$ & NLP baseado em SQP \\
\hline pórtico & 93 & 2 & D & SYS & $\mathrm{E}$ & $\mathrm{C}$ & $\mathrm{S}$ & $\mathrm{C}$ & - & $\mathrm{C}$ & - & - & $\mathrm{U}$ & MP processo iterativo \\
\hline pórtico plano & 93 & 15 & $\mathrm{D}$ & SYS & $\mathrm{E}$ & $\mathrm{C}$ & $\mathrm{S}$ & $\mathrm{C}$ & - & $\mathrm{C}$ & - & - & $\mathrm{U}$ & MP processo iterativo \\
\hline
\end{tabular}

TABELA 2.2 - Características principais da prática da otimização estrutural

Num total de 501 exemplos citados no catálogo COHN et alii (1994) e mais 18 na tabela $2.2,460(89 \%)$ são determinísticos e 59 (11\%) são probabilísticos, caracterizando assim os exemplos determinísticos como sendo dominantes no campo da otimização estrutural. Entre os exemplos de otimização apresentados como pórticos, grelhas e arcos, 71 (15\% dos exemplos determinísticos) são determinísticos e 27 (46\% dos exemplos probabilísticos) são probabilísticos. Além disso, entre as estruturas de aço há 415 (90\% dos exemplos determinísticos) exemplos de otimização determinística e 57 (97\% dos exemplos probabilísticos) de otimização probabilística.

A primeira decisão num projeto estrutural é considerar a escolha entre uma aproximação probabilística ou determinística. Entre os exemplos probabilísticos, há aproximadamente 27 "frames" ( $46 \%$ do total), dos quais metade são pórticos planos. Na otimização probabilística dos pórticos, o colapso plástico é geralmente o estado limite último que governa o problema, isto porque as falhas são facilmente identificadas e expressas como restrições lineares. Treliças planas estão em segundo no 'ranking' da frequência de otimização probabilística com aproximadamente 16 
(27\% do total) exemplos, com a maior parte projetada para restrições no estado em serviço (tensão).

Exemplos de otimização de chapas, estruturas de concreto ou com cargas dinâmicas, são escassos.

É interessante notar que exemplos de otimização para estados limite múltiplos (SLS ou ULS) são muito mais frequentes em projetos probabilísticos do que em projetos determinísticos ( $41 \%$ versus $4 \%$ ). Isto é de fácil entendimento, já que a natureza da análise probabilística baseia-se em causas implícitas, as quais são utilizadas para todas as combinações do estado limite.

Algumas dificuldades objetivas da otimização relacionam-se à questão de modelagem de carga, variações de materiais dependentes do tempo, e outras fontes de incerteza. É dificil, na prática, determinar uma estrutura ótima, uma vez que existem varias incertezas na modelagem das mesmas.

- Tipo Estrutural: A maior parte dos exemplos de otimização publicados referem-se a treliças planas, vigas, pórticos, grelhas, treliças espaciais e chapas. Dos 501 exemplos do catálogo COHN et alii (1994), existem 200 tipos de estruturas diferentes; isto significa uma média de 2,5 vezes a repetição de uma mesma estrutura. Além disso, apenas seis tipos de estruturas particulares representam cerca de $25 \%$ de todo o catálogo: treliça de 3 barras ocorre 23 vezes; treliça de 10 barras ocorre 23 vezes; pórtico plano com 3 tramos ocorre 25 vezes; viga simplesmente apoiada ocorre 26 vezes; viga em balanço ocorre 15 vezes; e treliça espacial de 25 barras ocorre 12 vezes. Entre os exemplos citados na tabela 2.2, três tipos de estruturas particulares representam $44 \%$ dos 18 exemplos tabelados: treliça com 10 barras ocorre 3 vezes; pórtico plano com três tramos ocorre 3 vezes; e viga simplesmente apoiada ocorre 2 vezes. A frequência do uso desses modelos é explicada pelo fato da solução já ser conhecida, o que é necessário para testar e comparar novos algoritmos;

- Nível de otimização: A maioria dos exemplos de otimização são de estruturas dadas ( $52 \%$ determinístico e $80 \%$ probabilístico). Projetos de seção e membros são 
de menor interesse para os engenheiros, e otimização de chapas ou sistemas são de complexidade excessiva na prática;

- Carregamento: A grande maioria de exemplos referem-se a um ou dois carregamentos estáticos (89\%). São poucos os casos de arranjo de carregamentos ou situações de carregamento mais complexas que encontraram seu caminho na otimização estrutural. O carregamento dinâmico, ilustrado em aproximadamente $11 \%$ dos exemplos pesquisados, está em crescimento no campo de estudos.

- Materiais: Com aproximadamente $92 \%$ dos exemplos pesquisados, o aço é de longe o material mais usado em exemplos de otimização, isto devido à facilidade de modelagem de suas propriedades, material elástico/plástico e homogêneo. Concreto e materiais compostos são menos ilustrados na literatura, e representam apenas $5 \%$ dos exemplos pesquisados.

- Função Objetivo: O número de exemplos de otimização com função objetivo única é bem maior do que o com função objetivo múltipla. Lembramos que nos projetos probabilísticos o número com função objetivo múltipla é maior do que nos projetos determinísticos (25\% versus $6 \%)$.

- Métodos Computacionais: Um maior número de exemplos utilizam 'softwares' comerciais de otimização, evitando o desperdício da duplicação de pacotes já existentes. Segundo COHN et alii (1994), 'softwares' feitos em elementos finitos e elementos de contorno são fundidos como pacotes de otimização de ótima eficiência. A programação matemática é largamente usada em estruturas de tamanho moderado quando as restrições podem ser linearizadas ou se podem usar técnicas aproximadas BORKOWSKI e JENDO (1990). Para problemas grandes ou complexos, são preferidos métodos de critério ótimo SAVE e PRAGER (1985), os quais se encontram dentro do campo da programação matemática. Os métodos de critério ótimo dividem o problema de otimização em subproblemas garantindo a convergência dos resultados. Finalmente, algoritmos genéticos mostram um bom potencial, mas estão apenas começando a serem aplicados em otimização estrutural.

Podem-se diferenciar algoritmos genéticos dos outros algoritmos e procedimentos de pesquisa de quatro maneiras GOLDBERG (1989): 
1. Algoritmos genéticos trabalham com um código de parâmetros fixos, não com parâmetros deles mesmos.

2. Algoritmos genéticos pesquisam uma população de pontos, não pontos isolados.

3. Algoritmos genéticos usam informações de funções objetivo, não de derivadas ou outros conhecimentos auxiliares.

4. Algoritmos genéticos usam regras de transição probabilísticas, não regras determinísticas.

A otimização de estruturas determinadas são mais largamente ilustradas do que otimização de seção, membros ou sistemas genéricos. A pequena parcela da vasta pesquisa produzida na otimização que é utilizada na prática de projetos estruturais, ainda não satisfaz às necessidades específicas do usuário. $\mathrm{O}$ número de publicações de exemplos de otimização estrutural durante os últimos trinta anos é muito pequeno quando comparado ao número de artigos e livros de otimização matemática. Os exemplos de otimização publicados nesta pesquisa ilustram ainda uma região limitada de problemas, na maior parte de interesse na engenharia acadêmica. Atualmente, como ilustrações mais aceitáveis na prática, os projetistas podem encontrar exemplos de treliças e pórticos, com objetivo único e otimização determinística.

Para a otimização se tornar mais atraente, os projetistas podem tomar como exemplo estruturas reais, com condições de carregamento nos estados limites. Quanto mais perto da estrutura real, menor fica o campo de soluções possíveis, aumenta o número de restrições, e a solução global converge mais rápido. Simplificando o trabalho do engenheiro e automatizando a maior parte das fases do projeto, a otimização torna-se uma eficiente ferramenta de projeto.

Ainda existe distância razoável entre o progresso da teoria de otimização e suas aplicações na prática da engenharia civil, como ASHLEY (1982), LEV (1981), e VANDERPLAATS (1982) têm notado. Este espaço não foi reduzido durante a última década, embora ocasionalmente sua existência, causas, e extensão tenham sido discutidas em vários encontros internacionais por GELLATLY e DUPRÉE (1976), HORNLEIN (1987), SOBIESKI et alii (1987), COHN (1993), entre outroṣ. Sugerese que a maior razão para o espaço entre a teoria e a prática da otimização estrutural é que a matemática é usada sem levar em conta o aspecto estrutural da otimização. 
Para diminuir este espaço, seria necessário utilizar as técnicas matemáticas junto com o problema explicitado fisicamente. A maioria dos trabalhos feitos é confinada a exemplos triviais, pretendendo apenas mostrar o sucesso de aplicação de um algoritmo particular. No uso acadêmico, a otimização pode ser utilizada para checar um algoritmo, mas não é apenas isso que os engenheiros precisam. Então, a distância entre aspectos teóricos e problemas práticos da otimização estrutural pode ser diminuída por limitações de variáveis, podendo trazer benefícios para a prática da engenharia estrutural .

\section{2 - Tipos de Problemas na Otimização Estrutural}

Pensando em projetos estruturais, é necessário que se respondam algumas das questões seguintes:

- Quais são as variáveis conhecidas numa estrutura real ?

- Quais são os objetivos práticos da otimização estrutural ?

- Quais exemplos publicados podem ser usados em projetos práticos?

- Quais são os artigos ou livros de onde vêm exemplos de otimização estrutural ?

Baseando-se em publicações recentes e na avaliação de um real estado-daprática, ou seja, na prática de projetos estruturais, tentar-se-á responder às questões explicitadas acima. A chave característica do estudo é a seguinte: seguindo a prática da engenharia, problemas são identificados primeiro por sua estrutura e depois pelas características matemáticas, com prioridade para a seleção de variáveis e para a modelagem da estrutura, e depois para sua solução algorítmica.

A otimização do projeto é proposta para considerar uma melhor estrutura do ponto de vista físico e econômico, visando a uma ou mais particularidades do problema.

Com relação ao projeto ótimo, problemas estruturais podem facilmente ser identificados por:

- Considerações de projeto ( determinística ou probabilística );

- Parâmetros e variáveis de projeto ( geometria, carregamento, materiais ); 
- Formulação do problema ( objetivo, estado limite, restrições ).

Para uma formulação ser concluída com êxito, a solução precisa ser encontrada por um algoritmo conveniente, via programação matemática, critério de optimalidade, ou algoritmos genéticos. Vários fatores na identificação do problema estrutural são detalhados na tabela 2.3 .

Um problema estrutural particular é definido quando entradas apropriadas em cada coluna da tabela 2.3 são selecionadas.

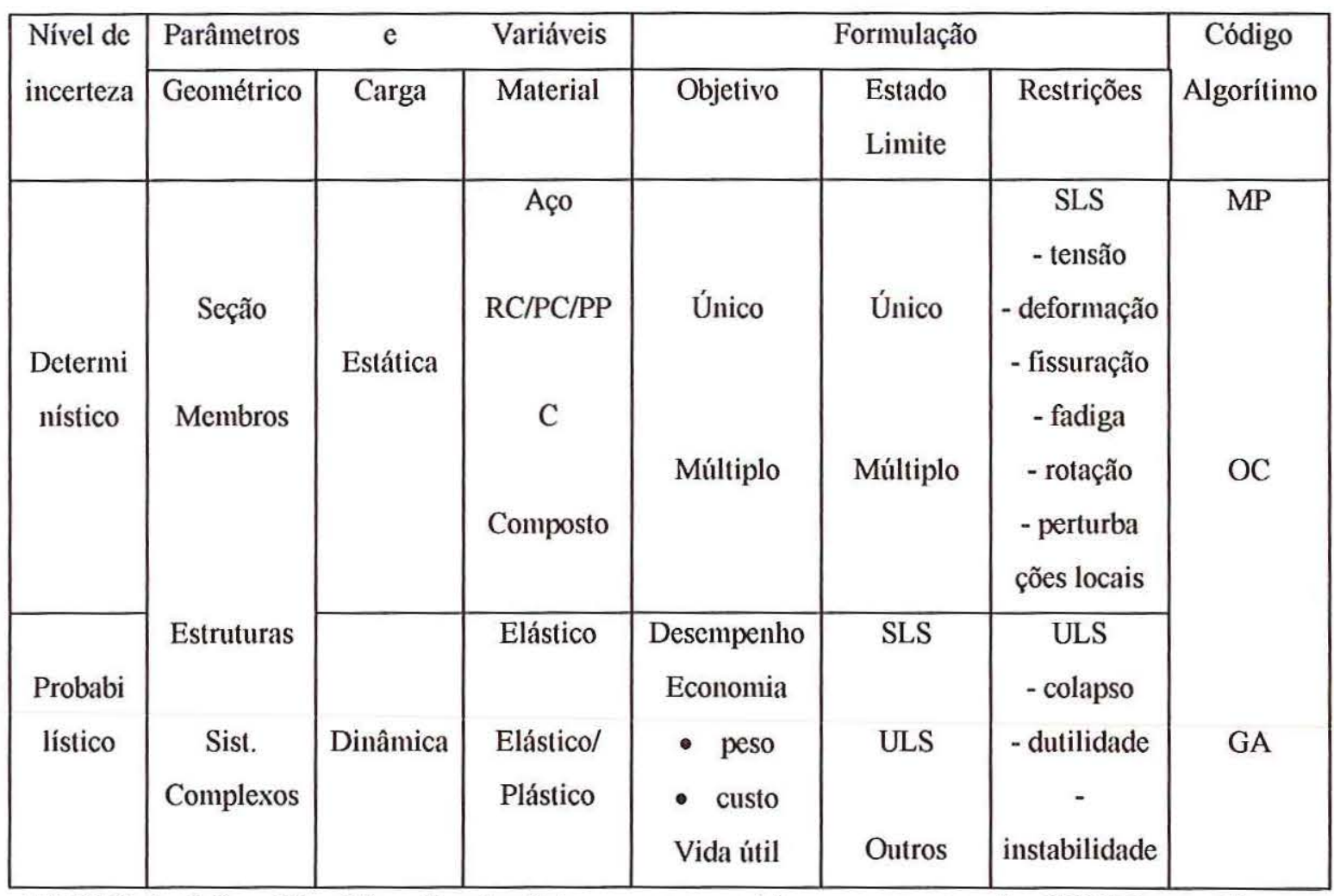

TABELA 2.3. Identificação de fatores nos problemas estruturais $\mathrm{COHN}$ et alii (1994). 


\section{3 - CONDIÇÕES FÍSICAS DO PROBLEMA}

\section{1 - Situação do Problema}

Como a programação não-linear apresenta várias soluções para o sistema de equações formulado pelo problema, torna-se complexa qualquer análise de resultados. Mas, quando as variáveis possuem características físicas, o objetivo do problema pode ser alcançado bem mais facilmente. No cálculo estrutural, pode-se dizer que todas as variáveis de projeto possuem este tipo de característica, o que, no ponto de vista do autor, é um caminho que deve ser explorado pelo pesquisador de otimização de estruturas. Acredita-se que as variáveis não devam ser analisadas isoladamente, e que a solução ótima faz parte de todo o conjunto de elementos que compõe a estrutura. Sendo assim, com técnicas matemáticas e uma boa concepção física das variáveis, a otimização de estruturas torna-se muito mais fácil e prazerosa.

Dentre os vários tipos estruturais, optou-se pela otimização do vigamento de um pavimento de concreto armado. Esta escolha foi feita devido à não existência de um programa com tais características, e à necessidade de se conhecerem as dimensões dos elementos de viga, o que, até a atualidade, é determinado pela prática do engenheiro. A noção das alturas das vigas a serem utilizadas em escritórios de cálculo foi adquirida no decorrer dos anos, com experiências anteriores, permanecendo ainda a necessidade de determiná-las matematicamente, que é o objetivo deste estudo.

A estrutura será calculada pelo método dos elementos finitos, podendo ser discretizada por elementos de barra e de placa, com a compatibilidade entre eles feita pelos deslocamentos dos nós em comum. Os elementos finitos de placa têm três graus de liberdade por nó, podendo este elemento ser triangular (DKT) ou quadrangular (DKQ), este último formado por quatro elementos finitos triangulares através de uma condensação estática. Os elementos finitos de barra são formados por dois nós com três graus de liberdade em cada nó.

\section{2 - Variáveis a Serem Otimizadas}


As variáveis a serem otimizadas serão as alturas das vigas e as áreas de aço das seções transversais obtidas pelo dimensionamento à flexão da maior solicitação de cada viga.

Uma restrição física de grande importância para a formulação é que todas as variáveis de projeto pertencem, ao menos teoricamente, ao conjunto dos números reais, e nenhuma delas pode ser negativa.

A respeito do tratamento dado à variável altura da viga, o valor ótimo será um qualquer dentro do campo real positivo. Na prática, a altura da viga é variável no conjunto dos inteiros, com um incremento pré-definido pelo engenheiro de estruturas. Na formulação, será calculada a altura ótima para uma função contínua, e depois de já conhecido o valor ótimo, este será apresentado ao engenheiro que determinará um valor inteiro quão próximo ele queira do valor ótimo. A altura da viga deve ser maior ou igual à apresentada pelo programa para evitar dimensionamento no domínio 4 ou flecha maior que a admissível por Norma.

As outras variáveis que serão otimizadas são as áreas de aço de tração e de compressão devidas ao esforço de flexão, que é consequência direta da altura da viga. Embora na prática estas variáveis não constituam uma função contínua, na maioria dos programas existentes, inclusive este, elas serão consideradas contínuas, pois a diferença no custo devido a esta descontinuidade não é de grande significado quando comparado ao trabalho que seria tratar as variáveis com otimização discreta.

\section{3 - Restrições}

Para maior facilidade de execução da obra, impôs-se uma restrição que limita em $50 \%$ a área de aço de compressão relativa à área de aço de tração. Esta percentagem foi atribuída devido à técnica construtiva usual, já que quando existe muita armadura trabalhando à compressão, torna-se dificil passar o vibrador, impossibilitando assim uma boa execução do concreto.

A máxima taxa geométrica deve ser definida pelo engenheiro de estruturas. Esta restrição foi estabelecida com o intuito de se evitar que existam seções 
transversais com área de aço exagerada, de tal forma que não seja possível posicionar a armadura coerentemente.

A seção transversal de concreto armado a ser otimizada será de forma retangular, que é usual e bastante genérica para pavimentos convencionais. Embora não seja objetivo do presente trabalho, em pavimentos constituídos de lajes maciças e vigas é bastante comum considerar a seção $\mathbf{T}$, ficando esta consideração como sugestão para uma pesquisa futura.

A limitação de flecha é imposta pelo engenheiro de estruturas, devendo estar de acordo com as prescrições da Norma. As flechas das vigas apresentadas pelo programa são calculadas considerando a rigidez do pavimento, uma vez que isto é feito pela diferença relativa dos deslocamentos nodais.

\section{4 - Variáveis Específicas do Problema}

O projeto arquitetônico é fator decisivo na determinação das dimensões da estrutura. Em geral, as larguras das vigas são limitadas pelas espessuras das alvenarias de vedação e por isso não serão consideradas como uma variável a ser otimizada. Já as alturas máximas das vigas são limitadas por portas, janelas, descontinuidade das alvenarias de vedação, etc., sendo assim bastante flexíveis suas variações.

A escolha dos materiais utilizados na estrutura implica nas tensões admissíveis das seções de aço e de concreto, que têm influência em todas as variáveis do

problema bem como nas restrições em equilíbrio, compatibilidade e deformação excessiva.

Uma variável de grande importância são as inércias dos elementos, diretamente responsáveis pela distribuição de cargas nas vigas, e suas flechas. Esta influência nos módulos das flechas altera sensivelmente os resultados obtidos pela otimização. À esta variável será dedicado o capítulo 7 .

De acordo com a função objetivo, um conjunto de dados de extrema importância nos resultados finais são os relacionados aos custos dos materiais. Outros dados importantes, responsáveis pela precisão dos resultados, são os erros admissíveis, o número de divisões internas da malha e o número máximo de iterações. 


\section{5 - Solicitações}

O principal determinante da altura da viga é o esforço de flexão, já que para o dimensionamento da seção à flexão, é decisivo o valor do braço de alavanca para formar o binário resistente ao momento fletor. Já o dimensionamento ao esforço cortante depende da área da seção transversal, não existindo prioridade da altura sobre a largura para o dimensionamento. Em geral, a armadura resistente à torção é grande com relação às demais, e por isso é usual se conceber a estrutura de tal forma que o momento de torção não seja necessário ao equilíbrio, ou seja, deixa-se a estrutura trabalhar e verifica-se se os deslocamentos continuam admissíveis. Por isso, foi considerado apenas o momento fletor na formulação matemática para se determinar a altura ótima da seção transversal das vigas.

Devido à simplificação descrita no parágrafo acima, deve-se verificar se as seções transversais ótimas são coerentes com os esforços cortantes e momentos de torção considerados. 


\section{4 - FUNDAMENTOS DA OTIMIZAÇÃO MATEMÁTICA}

\section{1 - Preâmbulo}

O conceito de otimização matemática está bem fixado como um dos princípios básicos da análise de muitos problemas complexos. Ao utilizar a filosofia de otimização enfoca-se um problema de decisão, que inclui uma seleção de valores para certo número de variáveis interrelacionadas, centralizando a atenção em um só objetivo designado para quantificar o rendimento e medir a qualidade da decisão. Este único objetivo se maximiza ( ou minimiza, dependendo da formulação) segundo as restrições que podem limitar a seleção dos valores das variáveis de decisão.

A habilidade da otimização está relacionada à formulação do problema e à interpretação dos resultados, a qual aumenta com a experiência prática do usuário e com a compreensão de uma teoria adequada para o problema.

Dentre os vários tipos de problemas, podem ser citados os de programação linear e não-linear, com e sem restrições.

A programação linear é o mecanismo mais natural para formular uma grande quantidade de problemas com o mínimo esforço. Um problema de programação linear se caracteriza, como seu nome indica, por funções lineares das incógnitas; a função objetivo é linear nas incógnitas e as restrições são igualdades ou desigualdades lineares nas incógnitas. Pode-se citar o método SIMPLEX como um método importante para resolução deste tipo de problema.

Caso não exista linearidade na função objetivo e/ou nas restrições, tem-se a programação não-linear.

Em muitos problemas importantes é possível considerá-los sem restrições, e, às vezes é fácil converter problemas com restrição em problemas sem restrição. Muitos aspectos da teoria e dos algoritmos desenvolvem-se e verificam-se de forma mais natural para os casos sem restrições, antes de passar para os casos com restrições.

Na engenharia, como em todo problema físico, a maior parte dos problemas é com restrição, facilitando, muitas vezes, conhecer a solução do problema proposto. 


\section{2 - Justificativa do Método utilizado}

O objetivo principal do presente trabalho é minimizar o custo do vigamento de um pavimento de concreto armado. Com o intuito de se obter um resultado aplicável à prática, a idéia do procedimento de otimização parte do princípio de que a minimização do somatório das seções transversais das vigas de um pavimento é a soma do mínimo da seção transversal de cada viga interagido com as demais vigas. A interação entre as vigas do pavimento é feita através de iterações de cálculo do pavimento, até convergir a valores aceitáveis na prática. Vale ressaltar que o resultado obtido com uma formulação feita nestas condições provavelmente não será o mesmo se fosse feita a minimização da grelha como um único elemento estrutural, mas acredita-se que para resultados práticos é bem razoável o uso desse procedimento. Sendo assim, foi desenvolvida uma formulação matemática para minimizar uma seção transversal de cada viga. Desta forma, o resultado do somatório da minimização de cada viga isoladamente fornecerá um mínimo global (de ordem prática) para a grelha.

Devido à interação entre as vigas, após ser otimizada cada seção desejada, as inércias de cada viga equacionada mudarão e, consequentemente, os esforços nela aplicados, perdendo-se a optimalidade da grelha. Sendo assim, é necessário fazer um "loop" com a otimização das seções transversais e o processamento da estrutura, até não haver redistribuição significativa dos esforços, e consequentemente variação significativa das inércias.

Devido à necessidade de se otimizar cada seção transversal desejada, e de se fazer um "loop" com a otimização das seções transversais e o cálculo dos esforços, pensou-se em algum processo de otimização de fácil implementação no programa de resolução de pavimentos e que este necessitasse o menor tempo possível para a sua convergência. Os pacotes computacionais que tratam do assunto apresentam entradas de dados complexas, e em geral, quando a função objetivo ou as restrições são funções não-lineares, na grande maioria das vezes os "softwares" que encontram soluções para estas funções utilizam processos iterativos. Como pode existir um 
grande número de seções a serem otimizadas, isto tornaria o processo mais lento que outro não iterativo.

Devido as inconveniências oferecidas pelas rotinas de otimização encontradas na literatura, partiu-se para o desenvolvimento de um "software" particular para este trabalho. Neste "software", o equacionamento matemático é feito levando-se em consideração condições particulares do problema. A resolução deste equacionamento oferece resultados exatos, dentro das restrições previamente estabelecidas, encontrados através da aplicação do método dos multiplicadores de Lagrange para extremização de funções não-lineares sujeitas às condições de Kuhn - Tucker. O sistema de equações não-lineares é resolvido analiticamente, evitando-se assim o processo iterativo, e eliminando-se o problema oferecido pelas entradas e saídas de dados dos pacotes computacionais existentes no mercado.

\section{3 - Conceitos Matemáticos}

Antes de iniciar o estudo de conceitos matemáticos necessários a um bom entendimento do método de otimização utilizado neste trabalho, será introduzido um apelo geométrico, figura 4.1, que facilitará bastante a compreensão deste capítulo. A figura 4.1 mostra geometricamente como introduzir os multiplicadores de Lagrange, que é a base de todo o modelo utilizado.

Considere que $f(x)$ seja a função objetivo, e que $h(x)$ represente as restrições ativas, sendo cada restrição representada por $h_{i}(x)$. Considere também que $x$ seja um ponto solução, mas não ótimo, e que $x^{*}$ seja um ponto extremo (mínimo ou máximo, local ou global). Então, pode-se ter a representação geométrica dos gradientes da seguinte forma: 

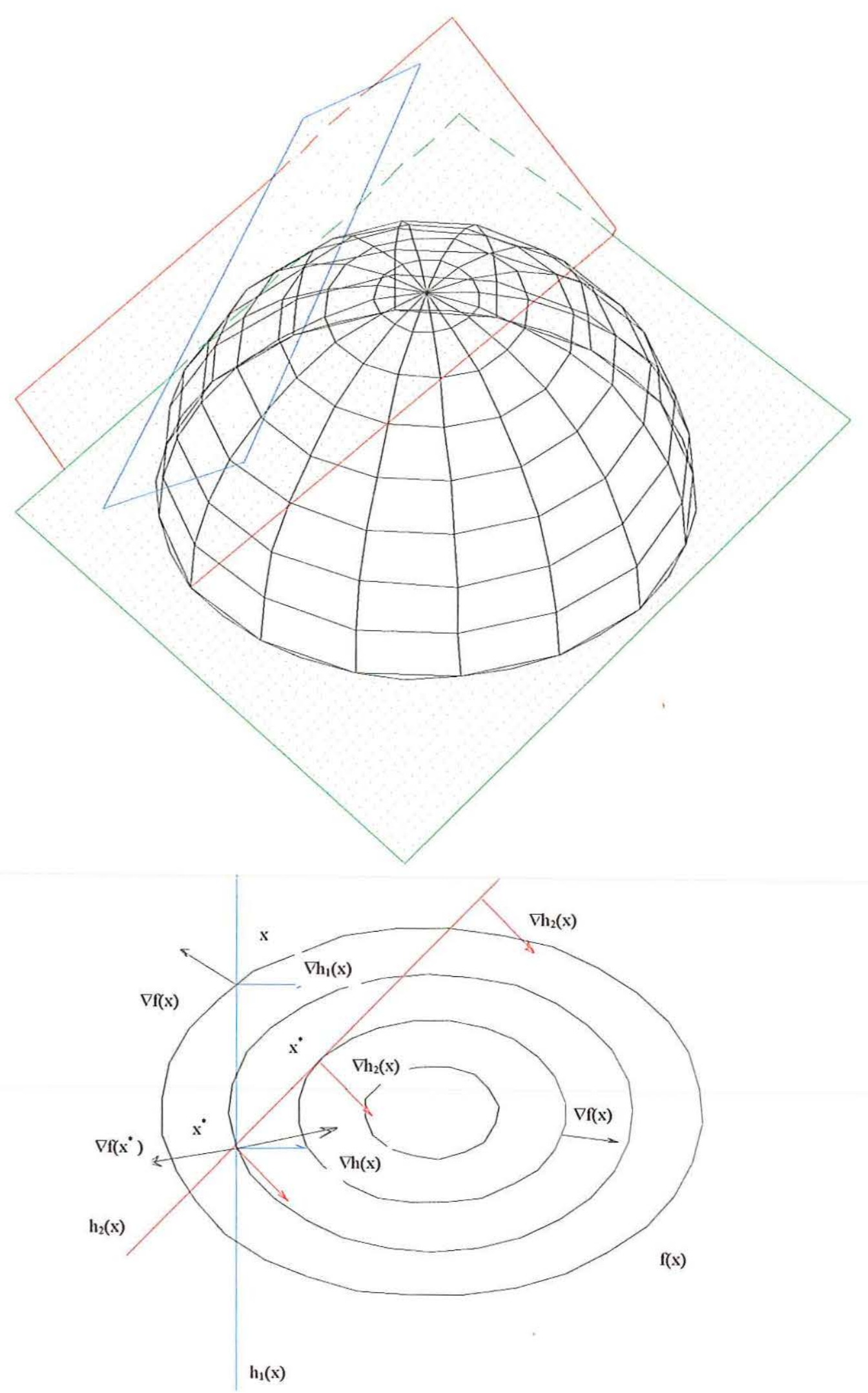

FIGURA 4.1 - Interpretação gráfica dos multiplicadores de Lagrange Representação geométrica dos gradientes. 
Através do apelo geométrico acima, verifica-se que para um ponto extremo $\mathrm{x}$, tem-se:

$$
\begin{aligned}
-\nabla \mathrm{f}_{(\mathrm{x})} & =\lambda_{\mathrm{l}} \cdot \nabla \mathrm{h}_{(\mathrm{x})_{1}}+\lambda_{2} \cdot \nabla \mathrm{h}_{(\mathrm{x})_{2}}+\lambda_{3} \cdot \nabla \mathrm{h}_{(\mathrm{x})_{3}}+\cdots+\lambda_{\mathrm{i}} \cdot \nabla \mathrm{h}_{(\mathrm{x})_{\mathrm{i}}} \\
\text { ou } \quad-\nabla \mathrm{f}_{(\mathrm{x})} & =\lambda \cdot \nabla \mathrm{h}_{(\mathrm{x})}
\end{aligned}
$$

Atribuindo às restrições ativas, resulta o seguinte sistema de equações:

$$
\begin{aligned}
& \nabla \mathrm{f}_{(\mathrm{x})}+\lambda \cdot \nabla \mathrm{h}_{(\mathrm{x})}=0 \\
& \mathrm{~h}_{(\mathrm{x})}=0
\end{aligned}
$$

Embora neste instante possa não parecer claro o que acaba de ser mostrado, no decorrer do capítulo será de extrema importância para um bom entendimento do mesmo.

A seguir, serão introduzidos conceitos, definições, teoremas e lemas referentes à extremização de funções sujeitas a restrições, os quais foram extraídos de LUENBERGER (1989).

Considere-se o problema da seguinte forma:

minimize $\quad f(x)$

$$
\begin{aligned}
& \begin{array}{lll}
\text { sujeito a } & \mathrm{h}_{1}(\mathrm{x})=0 & \mathrm{~g}_{1}(\mathrm{x}) \leq 0
\end{array} \\
& \mathrm{~h}_{2}(\mathrm{x})=0 \quad \mathrm{~g}_{2}(\mathrm{x}) \leq 0 \\
& \mathrm{~h}_{\mathrm{m}}(\mathrm{x})=0 \quad \mathrm{~g}_{\mathrm{p}}(\mathrm{x}) \leq 0 \\
& \mathrm{x} \in \Omega \subset \mathrm{E}^{\mathrm{n}} \text {, }
\end{aligned}
$$

onde $\Omega$ é uma região viável, região na qual pode existir solução, e $E^{\mathrm{n}} \mathrm{o}$ espaço que contém $\Omega$, sendo ainda $m \leq n$, e as funções $f, h_{i}, i=1,2, \ldots, m$ e $g_{j}, j=1,2, \ldots, p$ são contínuas. Considerando que $\mathrm{i} \in \mathrm{I}$ e $\mathrm{j} \in \mathrm{D}$, quando $\mathrm{I}=\phi$ e $\mathrm{D}=\phi$, ou seja, não existem as restrições $h_{i}(x)$ e $g_{j}(x)$ e ainda $\Omega \subset E^{n}$, diz-se tratar de um problema de otimização sem restrições. Quando $\mathrm{I} \neq \phi$ e/ou $\mathrm{D} \neq \phi$ diz-se tratar de um problema de otimização com restrições.

Uma medida evidente da complexidade de um problema de programação é seu tamanho, medido em função do número de variáveis incógnitas e o número de restrições. O tamanho dos problemas que podem ser resolvidos com eficácia tem 
aumentado com o avanço da tecnologia computacional e com o progresso da teoria. Segundo Luenberger, podem-se diferenciar três classes de problemas: problemas de pequena escala, que têm cinco ou menos incógnitas e restrições, problemas de escala intermediária que possuem entre cinco e cem variáveis e problemas de grande escala com mais de cem variáveis e restrições. Esta classificação não é completamente rígida, mas ela reflete, ao menos aproximadamente, tanto o tamanho como as diferenças básicas de enfoque correspondentes aos problemas de distintos tamanhos. Como regra geral, os problemas de pequena escala se podem resolver a mão, com uma simples calculadora. Os problemas de escala intermediária podem ser resolvidos com computadores com linguagem de programação matemática de uso geral. Os problemas de grande escala necessitam linguagens sofisticadas que têm uma estrutura especial e precisam de grandes computadores para serem executadas.

A maioria dos algoritmos feitos para resolver grandes problemas de otimização é de natureza iterativa. Como norma, ao buscar um vetor que resolve o problema de programação, elege-se um vetor inicial $\mathrm{X}_{0}$ e o algoritmo gera um vetor melhorado $\mathrm{X}_{1}$. O processo se repete e se encontra uma solução melhor $\mathrm{X}_{2}$. Continuando assim, se encontra uma sucessão de pontos cada vez mais apropriados $\mathrm{X}_{0}, \mathrm{X}_{1}, \ldots, \mathrm{X}_{k}, \ldots$, que tem um ponto solução $\mathrm{X}^{*}$. Nos problemas de programação linear, a sucessão gerada é de longitude finita, obtendo-se o ponto solução depois de um número finito de passos. Geralmente, nos problemas de programação não-linear, a sucessão não alcançará nunca o ponto solução. Do ponto de vista operativo, nos problemas não-lineares o processo termina a efeitos práticos quando se obtém um ponto suficientemente próximo ao ponto solução.

A teoria dos algoritmos iterativos pode se dividir em três aspectos: o primeiro se refere à criação dos algoritmos propriamente ditos, o segundo é a comprovação de que um algoritmo dado gerará uma sucessão convergente para uma solução (este aspecto se conhece como análise de convergência global), e o terceiro aspecto se refere à análise da convergência local, e trata da proporção em que a sucessão de pontos gerada converge para a solução. Um problema não pode ser considerado resolvido só porque se conhece um algoritmo que convergirá para a solução, pois talvez se precise de muito tempo para reduzir o erro para uma tolerância aceitável. Ao 
sugerir um algoritmo, é essencial dispor de alguma estimativa de tempo necessário para se chegar à solução. $\mathrm{O}$ que difere qualitativamente e quantitativamente um algoritmo do outro é a quantidade de iterações necessárias para chegar a um resultado aceitável, e sua precisão.

Visando à minimização no custo de estruturas, dar-se-á ênfase a funções não lineares com restrições lineares e/ou não-lineares, caso prático que acontece neste tipo de problema.

Serão estudadas, agora, as condições necessárias e suficientes que são satisfeitas num ponto solução. Estas condições, além de caracterizarem soluções, definem os multiplicadores de Lagrange e certa matriz hessiana que, considerados juntos, formam a base do desenvolvimento e análise dos algoritmos apresentados para resolver problemas não-lineares.

Os problemas tratados são os do tipo geral de programação não-linear da forma

$\begin{array}{ccc}\text { minimize } & \mathrm{f}(\mathrm{x}) & \\ \text { sujeito a } & \mathrm{h}_{1}(\mathrm{x})=0 & \mathrm{~g}_{1}(\mathrm{x}) \leq 0 \\ & \mathrm{~h}_{2}(\mathrm{x})=0 & \mathrm{~g}_{2}(\mathrm{x}) \leq 0 \\ & : & \\ & & \\ & \mathrm{h}_{\mathrm{m}}(\mathrm{x})=0 & \\ & & \\ & & \end{array}$

onde $m \leq n$, e as funções $f, h_{i}, i=1,2, \ldots, m$ e $g_{j}, j=1,2, \ldots, p$ são contínuas, e em geral, supõe-se que possuam segundas derivadas parciais contínuas. Por simplicidade notacional, introduzem-se as funções com valores vetoriais $h=\left(h_{1}, h_{2}, \ldots, h_{m}\right)$ e $g=\left(g_{1}, g_{2}, \ldots, g_{p}\right)$. E então pode-se escrever ( 4.1$)$ como

minimize $\mathrm{f}(\mathrm{x})$

sujeito à $\quad \mathrm{h}(\mathrm{x})=0 \quad \mathrm{~g}(\mathrm{x}) \leq 0$

$\mathrm{x} \in \Omega$ 
As restrições $h(x)=0$ e $g(x) \leq 0$ se denominam restrições funcionais e a restrição $\mathrm{x} \in \Omega$ é uma restrição de conjunto.

Supõe-se na maioria dos casos que $\Omega$ é todo o espaço $E^{n}$ e que a solução de (4.2) está no interior de $\Omega$. Um ponto $\mathrm{x} \in \Omega$ que cumpre todas as restrições funcionais se denomina factível. O conjunto de todos os pontos factíveis é denominado de região factível ou viável $\Gamma$. Exemplos de regiões viáveis podem ser vistos na figura 4.2 .

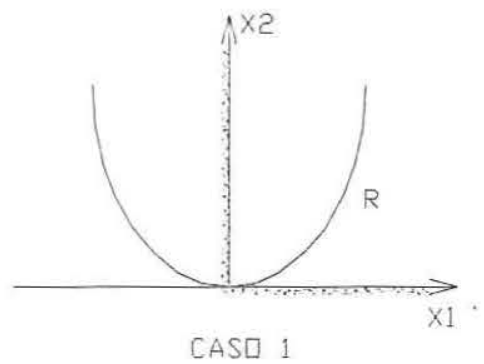

CASD 1

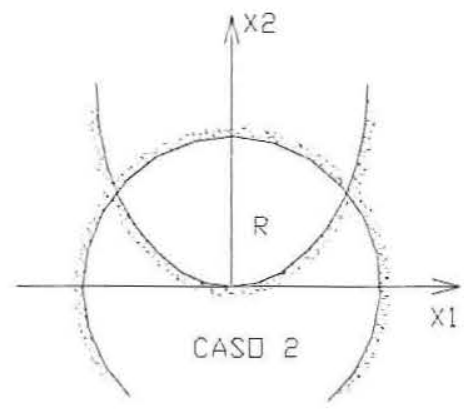

FIGURA 4.2 - Exemplos de regiões viáveis

Admitindo-se que a região factível $\Omega$ é limitada e fechada, então a solução do problema existirá. Se a região factível não for limitada, o problema pode ser ilimitado, ou seja, $\mathrm{f}(\mathrm{x}) \rightarrow \infty$. O problema também não terá solução se a região viável for vazia, ou seja, se não existir $x \in \Omega$ que satisfaça às restrições. Nesse caso, diz-se que as restrições são inconsistentes.

\section{Definição 4.1:}

Diz-se que um ponto $\mathrm{x}^{*} \in \Gamma$ é um ponto de mínimo local ou ponto de mínimo relativo de $f(x)$ se numa vizinhança aberta de $x^{*}, B_{a}\left(x^{*}, r\right), f(x) \geq f\left(x^{*}\right)$ para todo $x \in$ $\mathrm{B}_{\mathrm{a}}\left(\mathrm{x}^{*}, \mathrm{r}\right) \cap \Gamma$. Se $\mathrm{f}(\mathrm{x})>\mathrm{f}\left(\mathrm{x}^{*}\right)$ para todo $\mathrm{x} \in \mathrm{B}_{\mathrm{a}}\left(\mathrm{x}^{*}, \mathrm{r}\right) \cap \Gamma$ e $\mathrm{x} \neq \mathrm{x}^{*}$ diz-se que $\mathrm{x}^{*}$ é um ponto de mínimo local estrito de $\mathrm{f}(\mathrm{x})$.

\section{Definição 4.2:}

Diz-se que um ponto $x^{*} \in \Gamma$ é um ponto de mínimo global de $f(x)$ se $f(x) \geq$ $\mathrm{f}\left(\mathrm{x}^{*}\right)$ para todo $\mathrm{x} \in \Gamma$. Se $\mathrm{f}(\mathrm{x})>\mathrm{f}\left(\mathrm{x}^{*}\right)$ para todo $\mathrm{x} \in \Gamma, \mathrm{x} \neq \mathrm{x}^{*}$, diz-se que $\mathrm{x}^{*}$ é um ponto de mínimo global estrito de $\mathrm{f}(\mathrm{x})$. 
A figura. 4.3 ilustra, para uma função de uma variável, os pontos de mínimo local estrito ou não, e o ponto de mínimo global.

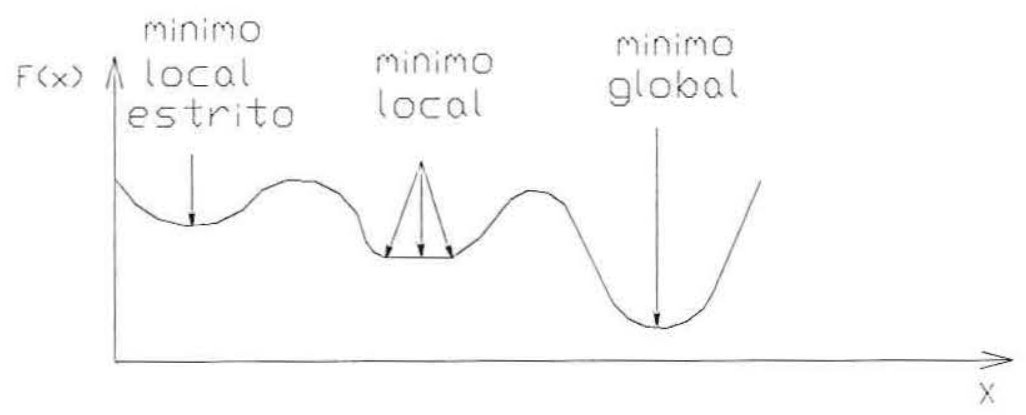

FIGURA 4.3 - Exemplos de pontos de mínimo

Um conceito fundamental que proporciona uma melhor compreensão, além de simplificar o desenvolvimento teórico necessário, é o de restrição ativa. Uma restrição de desigualdade $g_{i}(x) \leq 0$ se diz ativa em um ponto factível $x$ se $g_{i}(x)=0$, e é inativa em $x$ se $g_{i}(x)<0$. Adotar-se-á a convenção de considerar que qualquer restrição de igualdade $h_{i}(x)=0$ é ativa em qualquer ponto factível. As restrições ativas em um ponto factível $\mathrm{x}$ restringem $\mathrm{o}$ domínio de factibilidade nas proximidades de $\mathrm{x}$, enquanto as outras restrições, as inativas, não exercem influência nas proximidades de $\mathrm{x}$. Portanto, ao analisar as propriedades de um ponto mínimo local, é evidente que se pode centralizar a atenção nas restrições ativas.

Na figura. 4.4 são ilustrados exemplos de restrições ativas e inativas, onde a restrição $g_{1}\left(x^{*}\right)$ é ativa $e m x^{*}$ e as restrições $g_{2}\left(x^{*}\right)$ e $g_{3}\left(x^{*}\right)$ são inativas $e m x^{*}$.

Dado um ponto viável $\mathrm{x}$, as restrições ativas nesse ponto se comportam como restrições de igualdade. Além disso, as restrições inativas não influenciam nas restrições do problema. Por essa razão, pode-se considerar em cada ponto somente as restrições nele ativas, devendo, após encontrar o ponto ótimo, verificar se a solução encontrada satisfaz a todas as restrições. 


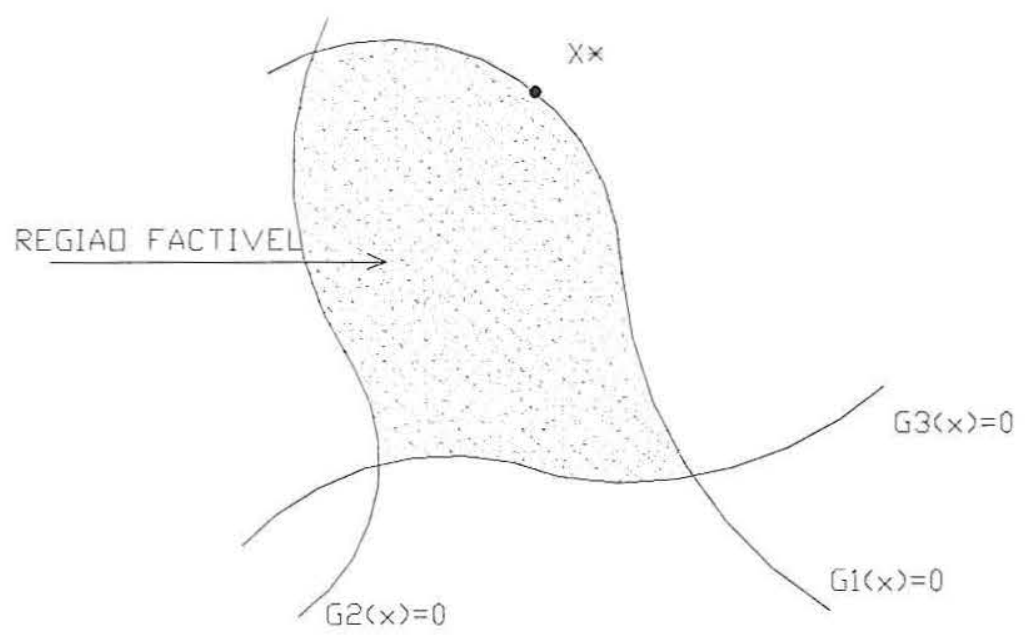

FIGURA 4.4 - Exemplos de restrições ativas e inativas

Então, com relação às restrições locais ( ou relativas ), pode-se considerar o problema como só tendo restrições de igualdade. Com isso, inicialmente vai-se desenvolver o raciocínio trabalhando com a igualdade ( soluções locais ) e depois expandindo para a desigualdade, chega-se a uma solução global.

Para um entendimento mais fácil da dedução das condições necessárias e suficientes para que um ponto seja um ponto de mínimo local sujeito às restrições de igualdade, será mostrada, a seguir, a representação do plano tangente.

Seja um conjunto de restrições de igualdade em $\mathrm{E}^{\mathrm{n}}$

$$
\begin{gathered}
h_{1}(x)=0 \\
h_{2}(x)=0 \\
: \\
h_{m}(x)=0
\end{gathered}
$$

Define-se, então, um subconjunto de $\mathrm{E}^{\mathrm{n}}$, que se considera mais apropriado ser tratado como uma hipersuperficie. Se as restrições são regulares em todas as partes, esta hipersuperficie tem dimensão (n-m). Se as funções $h_{i}, i=1,2, \ldots, m$ pertencem a $\mathrm{C}^{1}$, funções de $1^{0}$ ordem, a superficie definida por elas denomina-se uniforme. Associado a um ponto de uma superfície uniforme está o plano tangente neste ponto. Para formalizar a noção geral, começa-se definindo curvas em uma superficie. Uma 
curva em uma superfície $S$ é uma família de pontos $x(t) \in S$ continuamente parametrizados por t para $\mathrm{a} \leq \mathrm{t} \leq \mathrm{b}$. A curva é diferenciável se existe $(\mathrm{d} / \mathrm{dt}) \mathrm{x}(\mathrm{t})$, e é duas vezes diferenciável se existe $\left(\mathrm{d}^{2} / \mathrm{dt}^{2}\right) \mathrm{x}(\mathrm{t})$. Diz-se que uma curva $\mathrm{x}(\mathrm{t})$ passa por um ponto $x^{*}$ se $x^{*}=x(t *)$ para algum $t^{*}, a \leq t * \leq b$. A derivada da curva em $x^{*}$ está logicamente definida como $(\mathrm{d} / \mathrm{dt}) \mathrm{x}\left(\mathrm{t}^{*}\right)$, que é um vetor de $\mathrm{E}^{\mathrm{n}}$.

Consideram-se, agora, todas as curvas diferenciáveis em $\mathrm{S}$ que passam por um ponto $x^{*}$. O plano tangente em $x^{*}$ define-se como o conjunto de derivadas em $x^{*}$ de todas estas curvas diferenciáveis. O plano tangente é um sub-espaço de $\mathrm{E}^{\mathrm{n}}$.

Para as superfícies definidas por um conjunto de relações como (4.3), o problema de se obter uma relação explícita para o plano tangente é um problema fundamental. Idealmente, seria desejável expressar este plano tangente sob o ponto de vista das derivadas de funções $h_{i}$ que definem a superfície. Introduzindo o sub-espaço M, vem:

$$
\mathrm{M}=\left\{\mathrm{y}: \nabla \mathrm{h}\left(\mathrm{x}^{*}\right) \mathrm{y}=0\right\},
$$

e se verifica em que condições $\mathrm{M}$ é igual ao plano tangente em $\mathrm{x}$. O conceito chave para este propósito é o de ponto regular. Na fig. 4.5, mostram-se alguns exemplos para melhor claridade visual. Os planos tangentes ( que são sub-espaços ) se transladam ao ponto $\mathrm{x}$.

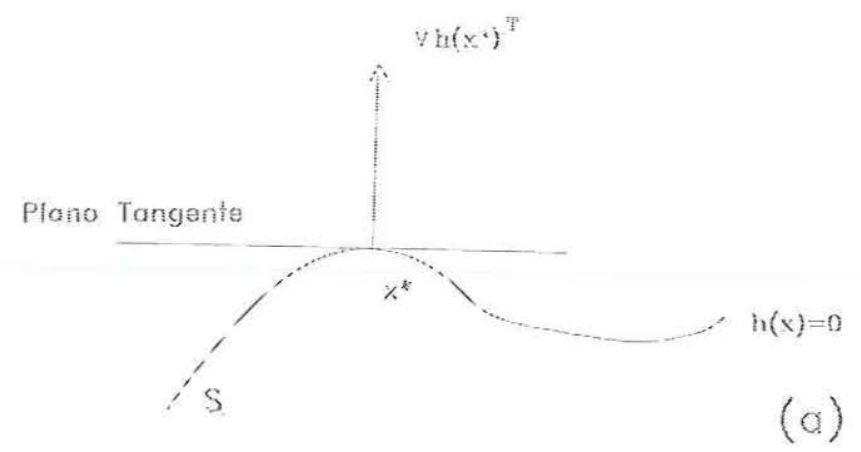



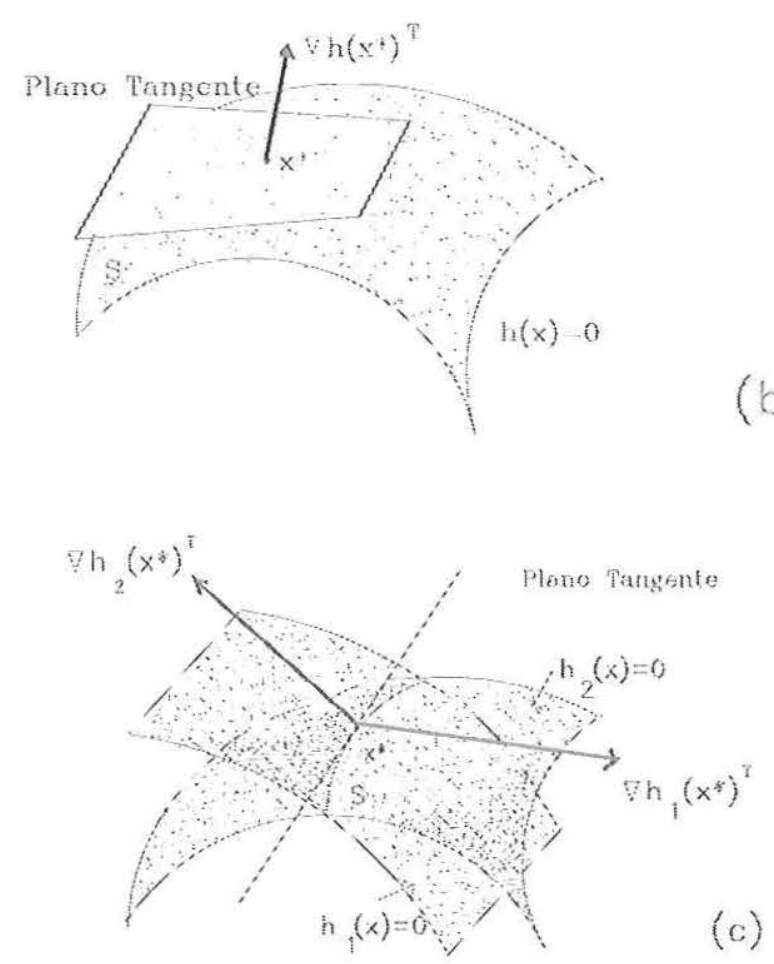

FIGURA 4.5 - Exemplos de planos tangente (transladados a $\mathrm{x}^{*}$ )

\section{Definição 4.3:}

Um ponto $\mathrm{x}^{*}$ que satisfaça à restrição $\mathrm{h}\left(\mathrm{x}^{*}\right)=0$ denomina-se ponto regular da restrição se os vetores gradientes $\nabla h_{1}\left(x^{*}\right), \nabla h_{2}\left(x^{*}\right), \ldots, \nabla h_{m}\left(x^{*}\right)$ são linearmente independentes.

Nos pontos regulares, pode-se caracterizar o plano tangente dependendo dos gradientes das funções de restrição.

\section{Teorema 4.1:}

Em um ponto regular $x^{*}$ da superfície $S$ definida por $h(x)=0$, o plano tangente é igual a :

$$
M=\left\{y: \nabla h\left(x^{*}\right) y=0\right\}
$$

A seguir, apresentam-se as condições necessárias de primeira ordem, ou seja, condições para extremar uma função. As condições indicadas abaixo são apenas para restrições de igualdade.

Considere-se $\mathrm{f}, \mathrm{h} \in \mathrm{C}^{1}$ 
A dedução de condições necessárias e suficientes para que um ponto seja um ponto de mínimo local, sujeito às restrições de igualdade, é bastante simples, agora que é conhecida a representação do plano tangente.

\section{Lema 4.1:}

Seja $x^{*}$ um ponto regular das restrições $h(x)=0$ e um ponto extremo local (mínimo ou máximo) de $\mathrm{f}$ sujeito às restrições. Então, todo $\mathrm{y} \in \mathrm{E}^{\mathrm{n}}$ que satisfaça

$$
\nabla h\left(x^{*}\right) y=0
$$

deve satisfazer também

$$
\nabla \mathrm{f}\left(\mathrm{x}^{*}\right) \mathrm{y}=0
$$

O lema anterior expressa que $\nabla \mathrm{f}\left(\mathrm{x}^{*}\right)$ é ortogonal ao plano tangente. Continuando, conclui-se que $\nabla f\left(x^{*}\right)$ é uma combinação linear dos gradientes de $\mathrm{h}$ em $\mathrm{x}^{*}$, uma relação que dá lugar à introdução dos multiplicadores de Lagrange.

\section{Teorema 4.4:}

Seja $x^{*}$ um ponto extremo local de $f$ sujeito às restrições $h(x)=0$. Suponha, ainda, que $\mathrm{x}^{*}$ é um ponto regular destas restrições. Então, existe um $\lambda \in \mathrm{E}^{\mathrm{m}}$ tal que

$$
\nabla \mathrm{f}\left(\mathrm{x}^{*}\right)+\lambda^{\mathrm{T}} \nabla \mathrm{h}\left(\mathrm{x}^{*}\right)=0
$$

Observa-se que as condições necessárias de primeira ordem

$$
\nabla \mathrm{f}\left(\mathrm{x}^{*}\right)+\lambda^{\mathrm{T}} \nabla \mathrm{h}\left(\mathrm{x}^{*}\right)=0
$$

junto com as restrições

$$
\mathrm{h}\left(\mathrm{x}^{*}\right)=0
$$

proporcionam um total de $(n+m)$ equações ( em geral, não-lineares ) nas $(n+m)$ variáveis que compreendem $x^{*}, \lambda$. Assim, as condições necessárias são um conjunto completo, pois, pelo menos localmente, determinam uma solução única.

Convém introduzir o lagrangeano associado ao problema com restrições, definido como

$$
l(\mathrm{x}, \lambda)=\mathrm{f}(\mathrm{x})+\lambda^{\mathrm{T}} \mathrm{h}(\mathrm{x})
$$

Então, as condições necessárias podem ser expressas da forma

$$
\begin{aligned}
& \nabla_{\mathrm{x}} l(\mathrm{x}, \lambda)=0 \\
& \nabla_{\lambda} l(\mathrm{x}, \lambda)=0
\end{aligned}
$$


A seguir, apresentam-se as condições necessárias de segunda ordem, ou seja, condições para determinar se o ponto extremo de uma função é um ponto de máximo, mínimo ou de inflexão.

Considere $\mathrm{f}, \mathrm{h} \in \mathrm{C}^{2}$

\section{Teorema 4.5:}

Suponha que $\mathrm{x}^{*}$ é um mínimo local de $\mathrm{f}$ sujeito a $\mathrm{h}(\mathrm{x})=0$ e que $\mathrm{x} *$ é um ponto regular das restrições. Então existe um $\lambda \in \mathrm{E}^{\mathrm{m}}$ tal que

$$
\nabla \mathrm{f}\left(\mathrm{x}^{*}\right)+\lambda^{\mathrm{T}} \nabla \mathrm{h}\left(\mathrm{x}^{*}\right)=0
$$

Se representar por $M$ o plano tangente $M=\left\{y: \nabla h\left(x^{*}\right) y=0\right\}$, então a matriz $\mathrm{L}\left(\mathrm{x}^{*}\right)=\mathrm{F}\left(\mathrm{x}^{*}\right)+\lambda^{\mathrm{T}} \mathrm{H}\left(\mathrm{x}^{*}\right)$ é semidefinida positiva em $M$, isto é, $\mathrm{y}^{\mathrm{T}} \mathrm{L}\left(\mathrm{x}^{*}\right)$ y $\geq 0$ para todo $\mathrm{y} \in \mathrm{M}$.

Dado qualquer $\lambda^{\mathrm{T}}=\left[\lambda_{1}, \lambda_{2}, \ldots, \lambda_{\mathrm{m}}\right] \in \mathrm{E}_{\mathrm{m}}$, se observa que a função com valor real $\lambda^{\mathrm{T}}$ f tem gradiente igual a $\lambda^{\mathrm{T}} \nabla \mathrm{f}_{(\mathrm{x})}$, e a Hessiana, denotada por $\lambda^{\mathrm{T}} \nabla^{2} \mathrm{f}_{(\mathrm{x})}$, igual a

$$
\lambda^{\mathrm{T}} \mathrm{F}_{(\mathrm{x})}=\sum_{\mathrm{i}=1}^{\mathrm{m}} \lambda_{\mathrm{i}} \mathrm{F}_{\mathrm{i}(\mathrm{x})} \text {, onde } \mathrm{F}_{(\mathrm{x})}=\nabla^{2} \mathrm{f}(\mathrm{x})
$$

O teorema anterior é o primeiro encontro com a matriz $\mathrm{L}=\mathrm{F}+\sum_{\mathrm{i}=1}^{\mathrm{m}} \lambda_{\mathrm{i}} \mathrm{H}_{\mathrm{i}}$, que é a Hessiana do Lagrangeano. Esta matriz é a base da teoria de algoritmos para problemas com restrições.

Suponha que haja um ponto $\mathrm{x}^{*}$ que satisfaça $\mathrm{h}\left(\mathrm{x}^{*}\right)=0$, e um $\lambda \in \mathrm{E}^{\mathrm{m}}$ tal que $\nabla \mathrm{f}\left(\mathrm{x}^{*}\right)+\lambda^{\mathrm{T}} \nabla \mathrm{h}\left(\mathrm{x}^{*}\right)=0$

Suponha também que a matriz $\mathrm{L}_{\left(\mathrm{x}^{*}\right)}=\mathrm{F}_{\left(\mathrm{x}^{*}\right)}+\sum_{\mathrm{i}=1}^{\mathrm{m}} \lambda_{\mathrm{i}} \mathrm{H}_{\mathrm{i}\left(\mathrm{x}^{*}\right)}$ é definida positiva em $M=\left\{y: \nabla h\left(x^{*}\right) y=0\right\}$, isto é, para $y \in M, y \neq 0$, se cumpre que $y^{T} L\left(x^{*}\right) y>0$. Então, $\mathrm{x}$ * é um mínimo local estrito de f sujeito a $\mathrm{h}(\mathrm{x})=0$.

Conclusão:

L não for positiva definida ; o ponto é um máximo local.

L for positiva definida ; o ponto é um mínimo local.

A matriz $\mathrm{L}$ restringida ao sub-espaço $\mathrm{M}$, que é tangente à superfície de restrição, tem uma função análoga, nas condições de segunda ordem, ao hessiano da 
função objetivo no caso sem restrições. Por isso, a estrutura de $\mathrm{L}$ restringida a $\mathrm{M}$ também determina as taxas de convergência dos algoritmos projetados para problemas com restrições, da mesma maneira que o faz a estrutura do hessiano da função objetivo para algoritmos sem restrições. Será visto que os valores próprios de $\mathrm{L}$ restringidos a $\mathrm{M}$ determinam as taxas naturais de convergência dos algoritmos projetados para problemas com restrições. Portanto, é importante compreender o que representam estes valores próprios restringidos. Primeiro, determina-se geometricamente o significado da restrição de $\mathrm{L}$ a $\mathrm{M}$, que se expressa mediante $\mathrm{Lm}$. Em seguida, definem-se os valores próprios do operador Lm. Por último, indica-se como se podem calcular as quantidades.

Dado qualquer vetor $\mathrm{y} \in \mathrm{M}$, o vetor Ly está em $\mathrm{E}^{\mathrm{n}}$, mas não necessariamente em M. Projeta-se, então, Ly ortogonalmente de volta a M, segundo mostra a fig. 4.6, e diz-se que o resultado é a restrição de L a M operando em y. Assim, obtém-se uma transformação linear de M a M. No entanto, a transformação se determina de maneira algo implícita, pois não se dispõe de uma representação matricial explícita.

Um vetor y $\in \mathrm{M}$ é um vetor próprio de $\mathrm{Lm}$, se existe um número real $\lambda$ tal que $\operatorname{Lm} y=\lambda y$;

onde o $\lambda$ correspondente é um valor próprio de $\mathrm{Lm}$, que coincide com a definição padrão. Em função de L, observa-se que y é um vetor próprio de Lm se Ly pode ser expresso como a soma de $\lambda$ y e um vetor ortogonal a $M$ (Ver figura. 4.7).

Para se obter uma representação matricial para Lm, é necessário introduzir uma base no sub-espaço M. É mais sensato introduzir uma base ortonormal, por exemplo $e_{1}, e_{2}, \ldots, e_{n-m}$. Define-se a matriz E como a matriz de $n \times(n-m)$, cujas colunas constam de vetores $\mathrm{e}_{\mathrm{i}}$. Então, qualquer vetor y em $\mathrm{M}$ pode ser expresso como $y=E z$ para algum $z \in E^{n-m} e$, por suposição, LEz representa a ação de $L$ sobre cada vetor. Para projetar o resultado de volta a $M$, e expressá-lo em função da base $e_{1}, e_{2}$ $, \ldots, \mathrm{e}_{\mathrm{n}-\mathrm{m}}$, basta multiplicar por $\mathrm{E}^{\mathrm{T}}$. Assim, $\mathrm{E}^{\mathrm{T}} \mathrm{LEz}$ é o vetor cujas componentes dão a representação em função da base; e a matriz de $(n-m) \times(n-m) \quad E^{T}$ LE é a representação matricial de $\mathrm{L}$ restringida a $\mathrm{M}$. 
Os valores próprios de $\mathrm{L}$ restringidos a $\mathrm{M}$ podem ser achados determinando os valores próprios de $\mathrm{E}^{\mathrm{T}} \mathrm{LE}$. Estes valores próprios são independentes da base ortonormal determinada $\mathrm{E}$.

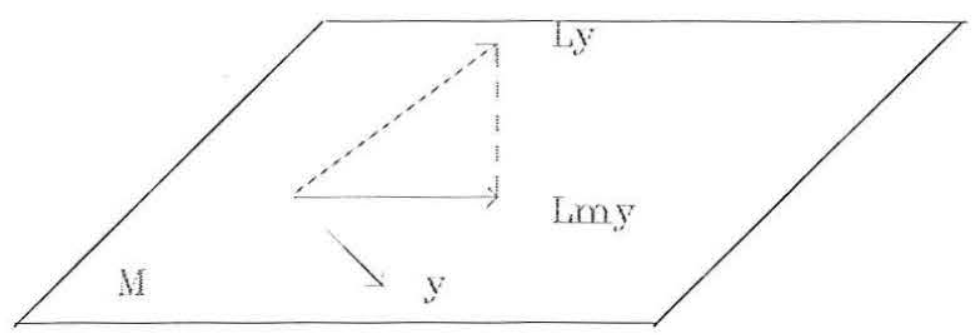

FIGURA 4.6 - Definição de $\mathrm{L}_{M}$

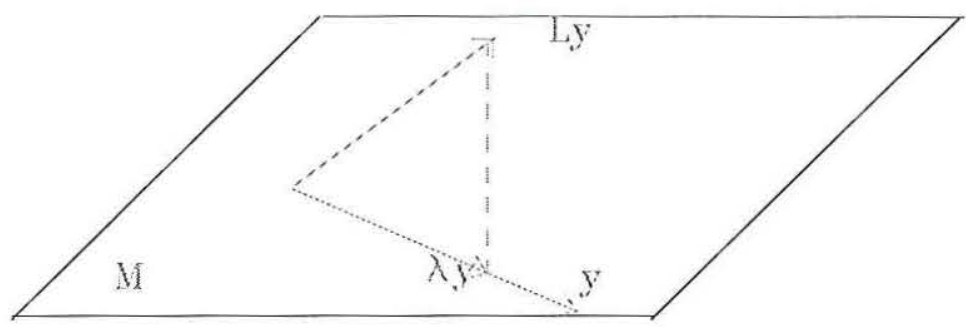

FIGURA 4.7 - Vetor próprio de $\mathrm{L}_{\mathrm{M}}$

Agora serão tratados problemas da forma

minimize $f(x)$

sujeito a $\quad \mathrm{h}(\mathrm{x})=0 \quad \mathrm{~g}(\mathrm{x}) \leq 0$

Admite-se que $\mathrm{f}$ e $\mathrm{h}$ são definidas como antes, e g é uma função p-dimensional. Inicialmente, supõe-se que $f, h$ e $g \in C^{l}$.

Há varias teorias distintas sobre este problema, baseadas em diversas condições de regularidade ou classificações de restrições, orientadas para obtenção de formulações gerais definitivas de condições necessárias e suficientes.

Condições necessárias de primeira ordem:

Com a seguinte generalização da definição anterior, pode-se estabelecer um paralelismo com o desenvolvimento das condições necessárias para as restrições de igualdade. 


\section{definição:}

Seja $x^{*}$ um ponto que satisfaça as restrições

$$
\mathrm{h}\left(\mathrm{x}^{*}\right)=0, \quad \mathrm{~g}\left(\mathrm{x}^{*}\right) \leq 0,
$$

e seja $\mathrm{J}$ o conjunto de índices j para o qual $\mathrm{g}_{\mathrm{j}}\left(\mathrm{x}^{*}\right)=0$. Então, diz-se que $\mathrm{x}^{*}$ é um ponto regular das restrições (4.11) se os vetores gradientes $\nabla h_{i}\left(x^{*}\right), \nabla g_{j}\left(x^{*}\right), 1 \leq i \leq$ $\mathrm{m}, \mathrm{j} \in \mathrm{J}$ são linearmente independentes.

Observa-se que, segundo a definição de restrições ativas comentada anteriormente, um ponto $x^{*}$ é um ponto regular se os gradientes das restrições ativas são linearmente independentes. Ou, de outra forma, $x^{*}$ é regular para as restrições se é regular no sentido da definição anterior para restrições de igualdade aplicadas às restrições ativas.

Se for definido que os multiplicadores de Lagrange são nulos para as restrições inativas, todos os resultados vistos até agora para problemas com restrições podem ser resumidos no teorema conhecido como Teorema de Kuhn-Tucker [LUENBERGER (1989)].

Condições de Kuhn-Tucker. Seja $x^{*}$ um ponto mínimo relativo para o problema

$$
\begin{aligned}
& \text { minimize } \quad f(x) \\
& \text { sujeito à } \quad \mathrm{h}(\mathrm{x})=0, \quad \mathrm{~g}(\mathrm{x}) \leq 0 \text {, }
\end{aligned}
$$

e suponha que $\mathrm{x}^{*}$ é um ponto regular para as restrições. Então existe um vetor $\lambda \in \mathrm{E}^{\mathrm{m}}$ e um vetor $\mu \in E^{p} \operatorname{com} \mu \geq 0$ tal que

$$
\begin{aligned}
\nabla \mathrm{f}\left(\mathrm{x}^{*}\right)+\lambda^{\mathrm{T}} \nabla \mathrm{h}\left(\mathrm{x}^{*}\right)+\mu^{\mathrm{T}} \nabla \mathrm{g}\left(\mathrm{x}^{*}\right) & =0 \\
\mu^{\mathrm{T}} \mathrm{g}\left(\mathrm{x}^{*}\right) & =0
\end{aligned}
$$

A condição $\mu^{\mathrm{T}} \mathrm{g}\left(\mathrm{x}^{*}\right)=0$ é chamada de condição de complementaridade. Esta condição estabelece que, quando a restrição de desigualdade for ativa, ou seja, $\mathrm{g}_{\mathrm{j}}\left(\mathrm{x}^{*}\right)$ $=0$, o multiplicador de Lagrange $\mu_{\mathrm{j}}$ pode ou não ser nulo, mas quando a restrição for inativa, ou seja, $\mathrm{g}_{\mathrm{j}}\left(\mathrm{x}^{*}\right)>0, \mu_{\mathrm{j}}$ será sempre nulo.

Condições de segunda ordem:

As condições de segunda ordem, necessárias e suficientes, para problemas com restrições de desigualdade, deduzem-se essencialmente tendo em conta só o problema com restrições de igualdade implicado pelas restrições ativas. O plano tangente apropriado para estes problemas é o plano tangente das restrições ativas. 
Condições necessárias de segunda ordem:

Suponha as funções $\mathrm{f}$, h e $\mathrm{g} \in \mathrm{C}^{2}$ e que $\mathrm{x}^{*}$ é um ponto regular das restrições (4.11). Se $x^{*}$ é um ponto mínimo relativo para o problema (4.10), então existe $\lambda \in \mathrm{E}^{\mathrm{m}}$ , $\mu \in E^{p}, \mu \geq 0$ tais que se cumpram (4.13) e (4.14) e tais que

$$
\mathrm{L}\left(\mathrm{x}^{*}\right)=\mathrm{F}\left(\mathrm{x}^{*}\right)+\lambda^{\mathrm{T}} \mathrm{H}\left(\mathrm{x}^{*}\right)+\mu^{\mathrm{T}} \mathrm{G}\left(\mathrm{x}^{*}\right)
$$

é semidefinida positiva no sub-espaço tangente das restrições ativas em $\mathrm{x}^{*}$.

Condições suficientes de segunda ordem:

Seja $f, h$ e $g \in C^{2}$. As condições suficientes para que um ponto $x^{*}$ que satisfaça (4.11) seja um ponto de mínimo relativo estrito do problema (4.10) são que existam $\lambda \in \mathrm{E}^{\mathrm{m}}, \mu \in \mathrm{E}^{\mathrm{p}}$, tal que

$$
\begin{aligned}
\mu & \geq 0 \\
\mu^{\mathrm{T}} \mathrm{g}\left(\mathrm{x}^{*}\right) & =0
\end{aligned}
$$

$$
\nabla \mathrm{f}\left(\mathrm{x}^{*}\right)+\lambda^{\mathrm{T}} \nabla \mathrm{h}\left(\mathrm{x}^{*}\right)+\mu^{\mathrm{T}} \nabla \mathrm{g}\left(\mathrm{x}^{*}\right)=0
$$

e a matriz hessiana

$$
\mathrm{L}\left(\mathrm{x}^{*}\right)=\mathrm{F}\left(\mathrm{x}^{*}\right)+\lambda^{\mathrm{T}} \mathrm{H}\left(\mathrm{x}^{*}\right)+\mu^{\mathrm{T}} \mathrm{G}\left(\mathrm{x}^{*}\right)
$$

seja definida positiva no sub-espaço

$$
M^{\prime}=\left\{y: \nabla h\left(x^{*}\right) y=0, \nabla g_{j}\left(x^{*}\right) y=0 \text { para todo } j \in J\right\},
$$

onde

$$
\mathrm{J}=\left\{\mathrm{j}: \mathrm{g}_{\mathrm{j}}\left(\mathrm{x}^{*}\right)=0, \mu_{\mathrm{j}}>0\right\} .
$$

Foram estabelecidas, até aqui, condições que devem ser satisfeitas para que a solução de um problema de programação matemática com restrições seja um ponto de mínimo local. Entretanto, se o problema possuir certas características de convexidade, a solução será não apenas um ponto de mínimo local mas também um mínimo global. Os conceitos de convexidade foram retirados da referência MEDRANO (1994).

Considere-se então o problema:

minimize $\quad f(x)$

sujeito à $\quad \mathrm{g}_{\mathrm{j}}(\mathrm{x}) \leq 0$,

$$
\mathrm{x} \in \Omega \subset \mathrm{E}^{\mathrm{n}}
$$


Adimite-se que as funções $g_{j}(x)$ são convexas no conjunto convexo $\Omega$. Demonstra-se em [3] que o conjunto delimitado por cada uma das restrições $g_{j}(x) \leq 0$ é um conjunto convexo, assim como a interseção de vários conjuntos convexos também é um conjunto convexo. Conclui-se então, que a região viável $\Gamma$ delimitada pelas restrições $g_{j}(x)$ é convexa. Se ainda, a função $f(x)$ for convexa em $\Omega$, diz-se que (4.19) é um problema de programação convexa.

Relativamente à programação convexa, valem os seguintes resultados:

\section{Teorema 4.6:}

Toda solução $x^{*}$ de um problema de programação convexa é uma solução global, e o conjunto das soluções globais $\mathrm{S}$ é um conjunto convexo.

\section{Colorário 4.1:}

Se no problema de programação convexa a função objetivo for estritamente convexa em $\Omega$, então toda solução global é única.

\section{Teorema 4.7:}

Se, num programa de programação convexa, as funções $\mathrm{f}(\mathrm{x})$ e $\mathrm{g}_{\mathrm{j}}(\mathrm{x})$, para $\mathrm{j}=1,2 \ldots, \mathrm{p}$, são contínuas com derivadas parciais contínuas até primeira ordem, e se as condições de Kuhn - Tucker estão satisfeitas em $x^{*}$, então o ponto $x^{*}$ é uma solução global do problema de programação convexa.

Ou seja, dado um problema de minimização sujeito a restrições de desigualdade, nas quais todas as funções são uniformes, uma condição necessária que se satisfaz em um ponto de mínimo é que o gradiente da função objetivo seja ortogonal ao plano tangente da superfície de restrição. Então, se o ponto é regular, o plano tangente tem uma representação que depende dos gradientes das funções de restrição, e a condição anterior pode ser expressa em função dos multiplicadores de Lagrange.

Se as funções têm segundas derivadas parciais contínuas e há multiplicadores de Lagrange, então, a matriz hessiana do lagrangeano restringido ao plano tangente desempenha um papel nas condições de segunda ordem análogo ao que desempenha o hessiano da função objetivo nos problemas sem restrições. Especificamente, o hessiano restringido deve ser semi-definido positivo em um ponto mínimo e/ou, se é 
definido positivo em um ponto que satisfaça as condições de primeira ordem, este ponto é um ponto de mínimo local estrito.

As desigualdades se tratam determinando-se as que são ativas em uma solução. Então, a desigualdade ativa atua como uma igualdade, exceto que seu multiplicador de Lagrange associado nunca pode ser negativo devido à interpretação de sensibilidade dos multiplicadores. 


\section{5 - FORMULAÇÃo MATEMÁTICA PARA MINIMIZAÇÃo DA SEÇÃo TRANSVERSAL DE UMA VIGA.}

\section{1 - Localização do Problema no Campo da Otimização}

Neste item, será desenvolvida a formulação matemática para minimizar o custo de uma seção transversal de concreto armado. Inicialmente, o problema particular será situado no campo da otimização matemática. Em seguida, será explicitada a formulação da função objetivo e das restrições, assim como a resolução do problema e verificação dos resultados obtidos.

A definição do problema estrutural particular será auxiliada pela tabela 2.3.

- Nível de incerteza: será um problema determinístico;

- Nível de otimização: a formulação matemática será feita para uma seção retangular sujeita a um esforço de flexão simples predeterminado;

- Carregamento: será considerado apenas carregamento estático;

- Materiais: concreto, aço e madeira;

- Estado limite: o equacionamento será feito para o estado limite último, quando a restrição for em tensão, e estado limite de utilização, quando a restrição for em deslocamento;

- Restrições: na formulação, estarão incluídas restrições de tensão, flecha, colapso global e restrições decorrentes da prática da execução da obra;

- Função objetivo: a função objetivo é única, e constitui-se em determinar o custo mínimo;

- Método computacional: será resolvido analiticamente o sistema de equações obtido através do Método dos Multiplicadores de Lagrange. Este método pode ser incluído na programação matemática. 


\section{2 - Formulação da Função Objetivo e Restrições}

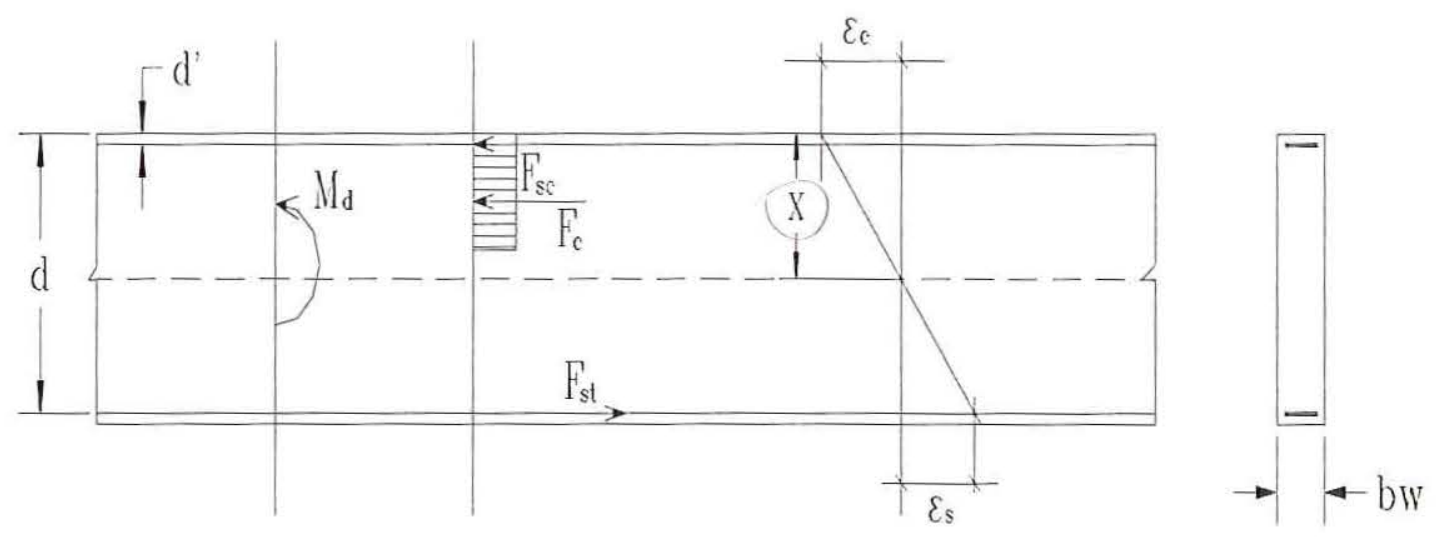

FIGURA. 5.1 - Seção sujeita a esforços de flexão, equilíbrio

Equações de equilíbrio e compatibilidade

$$
\begin{aligned}
& \mathrm{F}_{\mathrm{c}}=0,8 \cdot \mathrm{X} \cdot 0,85 \cdot \mathrm{f}_{\mathrm{cd}} \cdot \mathrm{b}_{\mathrm{w}} \\
& \mathrm{F}_{\mathrm{c}}+\mathrm{F}_{\mathrm{sc}}=\mathrm{F}_{\mathrm{st}} \\
& \mathrm{F}_{\mathrm{se}} \cdot\left(\mathrm{d}-\mathrm{d}^{\prime}\right)+\mathrm{F}_{\mathrm{c}} \cdot\left(\mathrm{d}-0,8 \cdot \frac{\mathrm{X}}{2}\right)=\mathrm{M}_{\mathrm{d}} \\
& \frac{\varepsilon_{\mathrm{c}}}{\mathrm{X}}=\frac{\varepsilon_{\mathrm{s}}}{(\mathrm{d}-\mathrm{X})}
\end{aligned}
$$

Desenvolvendo a equação (5.4), encontra-se:

$$
X=\frac{\varepsilon_{\mathrm{c}} \cdot \mathrm{d}}{\varepsilon_{\mathrm{s}}+\varepsilon_{\mathrm{c}}}
$$

Uma vez que a altura da viga é variável, para determina-la fixa-se a posição da linha neutra da seção transversal a ser otimizada. Esta posição é um dado de entrada do programa.

Em função de expressões constantes serem muito grandes, estas serão substituídas por $\mathrm{K}_{\mathbf{i}}$. E as expressões que dependem exclusivamente da variável altura da seção transversal serão substituídas por $\mathrm{F}_{\mathrm{i}}$.

Fazendo: $\mathrm{K}_{1}=0,8 \cdot \frac{\varepsilon_{\mathrm{c}}}{\varepsilon_{\mathrm{s}}+\varepsilon_{\mathrm{c}}} \cdot 0,85 \cdot \frac{\mathrm{f}_{\mathrm{ck}}}{1,4} \cdot \mathrm{b}_{\mathrm{w}}$.

$$
\mathrm{K}_{2}=1-0,4 \cdot \frac{\varepsilon_{\mathrm{c}}}{\varepsilon_{\mathrm{s}}+\varepsilon_{\mathrm{c}}}
$$


Substituindo as constantes nas equações de equilíbrio, tem-se:

$$
\begin{aligned}
& \mathrm{F}_{\mathrm{c}}=\mathrm{K}_{1} \cdot \mathrm{d} \\
& \mathrm{K}_{1} \cdot \mathrm{d}+\sigma_{\mathrm{s}}^{\prime} \cdot \mathrm{A}_{\mathrm{s}}{ }^{\prime}-\sigma_{\mathrm{s}} \cdot \mathrm{A}_{\mathrm{s}}=0 \\
& \sigma_{\mathrm{s}}^{\prime} \cdot \mathrm{A}_{\mathrm{S}}{ }^{\prime} \cdot\left(\mathrm{d}-\mathrm{d}^{\prime}\right)+K_{1} \cdot K_{2} \cdot \mathrm{d}^{2}-\mathrm{M}_{\mathrm{d}}=0
\end{aligned}
$$

Para maior facilidade de visualização matemática, as variáveis do problema serão denominadas de:

$\mathrm{d}=\mathrm{x}_{1}$

$\mathrm{A}_{\mathrm{s}}=\mathrm{x}_{2}$

$\mathrm{A}_{\mathrm{s}}{ }^{\prime}=\mathrm{x}_{3}$

\section{Função objetivo:}

$$
\mathrm{F}=\mathrm{b}_{\mathrm{w}} \cdot\left(\mathrm{d}+\mathrm{d}^{\prime}\right) \cdot \mathrm{C}_{\mathrm{c}}+\left(\mathrm{A}_{\mathrm{s}}+\mathrm{A}_{\mathrm{s}}^{\prime}\right) \cdot \rho_{\mathrm{s}} \cdot \mathrm{C}_{\mathrm{s}}+\left(\mathrm{b}_{\mathrm{w}}+2 \cdot d\right) \cdot \mathrm{C}_{\mathrm{F}}
$$

ou, escrevendo em função de x:

$$
\mathrm{F}_{(\mathrm{x})}=\mathrm{b}_{\mathrm{w}} \cdot\left(\mathrm{x}_{1}+\mathrm{d}^{\prime}\right) \cdot \mathrm{C}_{\mathrm{c}}+\left(\mathrm{x}_{2}+\mathrm{x}_{3}\right) \cdot \rho_{\mathrm{s}} \cdot \mathrm{C}_{\mathrm{s}}+\left(\mathrm{b}_{\mathrm{w}}+2 \cdot \mathrm{x}_{1}\right) \cdot \mathrm{C}_{\mathrm{F}}
$$

\section{Restrições:}

Restrições em equilíbrio e compatibilidade escritas em função de $\mathrm{x}$ :

$$
\begin{aligned}
& \mathrm{K}_{1} \cdot \mathrm{x}_{1}+\sigma_{\mathrm{s}}^{\prime} \cdot \mathrm{x}_{3}-\sigma_{\mathrm{s}} \cdot \mathrm{x}_{2}=0 \\
& \sigma_{\mathrm{s}}^{\prime} \cdot \mathrm{x}_{3} \cdot\left(\mathrm{x}_{1}-\mathrm{d}^{\prime}\right)+\mathrm{k}_{1} \cdot \mathrm{k}_{2} \cdot \mathrm{x}_{1}{ }^{2}-\mathrm{M}_{\mathrm{d}}=0
\end{aligned}
$$

Restrição que limita o excesso de armadura, a qual poderá causar fissuração exagerada no concreto:

$\mathrm{x}_{3}+\mathrm{x}_{2}-\mathrm{P}_{\mathrm{AC}} \cdot \mathrm{b}_{\mathrm{w}} \cdot \mathrm{x}_{1} \leq 0$

Restrição que limita a percentagem de armadura trabalhando à compressão em $50 \%$ da armadura de tração:

$\mathrm{x}_{3}-0,5 \cdot \mathrm{x}_{2} \leq 0$

Para imposição da restrição que limita o deslocamento máximo da viga, foram elaborados dois modelos neste trabalho. Eles diferenciam entre si basicamente pela concepção de cálculo da inércia. Em um modelo, a inércia é considerada constante e calculada no estádio I. Nesta situação, pode-se dizer que, para o cálculo do deslocamento da seção otimizada, foi estabelecida uma relação entre o quociente do deslocamento e a inércia da viga antes e depois de determinada a altura ótima da viga. Pode-se exprimir esta relação com o seguinte equacionamento: 


$$
\delta_{\mathrm{f}}=\delta_{\mathrm{i}} \cdot \frac{\mathrm{I}_{\mathrm{i}}}{\mathrm{I}_{\mathrm{f}}} \leq \delta_{\lim },
$$

onde:

$I_{i}=\frac{b_{w} \cdot h_{i}{ }^{3}}{12}$, inércia da seção antes de ser otimizada;

$I_{f}=\frac{b_{w} \cdot h_{f}{ }^{3}}{12}$, inércia da seção otimizada;

$\delta_{\mathrm{i}}=$ flecha fornecida pelo programa de cálculo de pavimento por elementos finitos;

$\delta_{\mathrm{f}}=$ flecha na viga com a seção otimizada.

No outro modelo desenvolvido, foi considerada uma inércia diferente para cada elemento finito. Para o cálculo desta inércia, foi considerada a área de concreto comprimida, as áreas de aço e a contribuição do concreto entre fissuras, sendo estas variáveis explicitadas pela fórmula empírica de BRANSON. O equacionamento utilizado para determinar a inércia dos elementos foi o seguinte:

$$
\begin{gathered}
X=\frac{-n \cdot\left(A_{s}+A_{s}^{\prime}\right)}{b_{w}}+\sqrt{\left[\frac{n \cdot\left(A_{s}+A_{s}^{\prime}\right)}{b_{w}}\right]^{2}+\frac{2 \cdot n}{b_{w}} \cdot\left(d \cdot A_{s}+d^{\prime} \cdot A_{s}^{\prime}\right)} \\
I_{2}=\frac{b_{w} \cdot X^{3}}{3}+n \cdot A_{s} \cdot(d-X)^{2}+n \cdot A_{s}^{\prime} \cdot\left(X-d^{\prime}\right)^{2} \\
n=\frac{E_{s}}{E_{c}} \quad ; I_{0}=\frac{b_{w} \cdot h^{3}}{12}
\end{gathered}
$$

Segundo BRANSON, tem-se a seguinte equação para determinar a inércia do elemento.

$$
I_{f}=\left(\frac{M_{R}}{M_{K}}\right)^{4} \cdot I_{0}+\left[1-\left(\frac{M_{R}}{M_{K}}\right)^{4}\right] \cdot I_{2} \quad<I_{0}
$$

Em ambos os modelos, foram considerados os esforços no estado em serviço. Vale salientar que as áreas de aço são calculadas com os esforços no estado limite último. 
Uma vez determinadas as inércias dos elementos das vigas, as flechas das mesmas foram calculadas de duas formas distintas: através dos deslocamentos relativos dos nós para as seções antes de passar por um tratamento de otimização, e por analogia de Mohr durante o processo de otimização, com o qual foi aplicada a restrição de deslocamento.

Quando a restrição de deslocamento foi imposta ao problema, explicitada na formulação matemática para determinar um mínimo, surgiu uma equação de ordem elevada, dificultando a solução analítica do problema. Ciente que não haverá mudança nos resultados, esta restrição foi imposta após encontrada a solução ótima. Determinada a altura ótima para cada viga, são verificadas suas respectivas flechas; caso estas ultrapassem o valor limite, através do método dos intervalos encaixantes seguido do método da bisseção, determina-se as alturas das vigas para que as flechas das mesmas sejam admissíveis satisfazendo um erro absoluto de 0,5\% prédeterminado internamente no programa.

\section{3 - Resolução do Problema}

Minimize: $\mathrm{F}_{(\mathrm{x})}=\mathrm{b}_{\mathrm{w}} \cdot\left(\mathrm{x}_{1}+\mathrm{d}^{\prime}\right) \cdot \mathrm{C}_{\mathrm{c}}+\left(\mathrm{x}_{2}+\mathrm{x}_{3}\right) \cdot \rho_{\mathrm{s}} \cdot \mathrm{C}_{\mathrm{s}}+\left(\mathrm{b}_{\mathrm{w}}+2 \cdot \mathrm{x}_{1}\right) \cdot \mathrm{C}_{\mathrm{F}}$ Sujeito a:

$$
\begin{aligned}
& \mathrm{K}_{1} \cdot \mathrm{x}_{1}+\sigma_{\mathrm{s}}^{\prime} \cdot \mathrm{x}_{3}-\sigma_{\mathrm{s}} \cdot \mathrm{x}_{2}=0 \\
& \sigma_{\mathrm{s}}^{\prime} \cdot \mathrm{x}_{3} \cdot\left(\mathrm{x}_{1}-\mathrm{d}^{\prime}\right)+\mathrm{k}_{1} \cdot \mathrm{k}_{2} \cdot \mathrm{x}_{1}{ }^{2}-\mathrm{M}_{\mathrm{d}}=0 \\
& \mathrm{x}_{3}+\mathrm{x}_{2}-\mathrm{P}_{\mathrm{AC}} \cdot \mathrm{b}_{\mathrm{w}} \cdot \mathrm{x}_{1} \leq 0 \\
& \mathrm{x}_{3}-0,5 \cdot \mathrm{x}_{2} \leq 0
\end{aligned}
$$

Para diminuir o número de restrições de igualdade, a variável $\mathbf{x}_{\mathbf{3}}$ será explicitada em função das demais.

$$
x_{3}=\frac{M_{d}-K_{1} \cdot K_{2} \cdot x_{1}{ }^{2}}{\sigma_{s}^{\prime} \cdot\left(x_{1}-d^{\prime}\right)}
$$

Aplicando o Lagrangeano e substituindo $\mathbf{x}_{3}$ pela expressão acima, tem-se: 


$$
\begin{aligned}
& \mathrm{F}_{(\mathrm{x}, \lambda, \mu)}=\mathrm{b}_{\mathrm{w}} \cdot\left(\mathrm{x}_{1}+\mathrm{d}^{\prime}\right) \cdot \mathrm{C}_{\mathrm{c}}+\left(\mathrm{x}_{2}+\frac{\mathrm{M}_{\mathrm{d}}-\mathrm{K}_{1} \cdot \mathrm{K}_{2} \cdot \mathrm{x}_{1}{ }^{2}}{\sigma_{\mathrm{s}}^{\prime} \cdot\left(\mathrm{x}_{1}-\mathrm{d}^{\prime}\right)}\right) \cdot \rho_{\mathrm{s}} \cdot \mathrm{C}_{\mathrm{s}}+\left(\mathrm{b}_{\mathrm{w}}+2 \cdot \mathrm{x}_{1}\right) \cdot \mathrm{C}_{\mathrm{F}} \\
& +\lambda_{1} \cdot\left[\mathrm{K}_{1} \cdot \mathrm{x}_{1}+\sigma_{\mathrm{s}}^{\prime} \cdot \frac{\mathrm{M}_{\mathrm{d}}-\mathrm{K}_{1} \cdot \mathrm{K}_{2} \cdot \mathrm{x}_{1}{ }^{2}}{\sigma_{\mathrm{s}}^{\prime} \cdot\left(\mathrm{x}_{1}-\mathrm{d}^{\prime}\right)}-\sigma_{\mathrm{s}} \cdot \mathrm{x}_{2}\right] \\
& +\mu_{1} \cdot\left[\frac{\mathrm{M}_{\mathrm{d}}-\mathrm{K}_{1} \cdot \mathrm{K}_{2} \cdot \mathrm{x}_{1}{ }^{2}}{\sigma_{\mathrm{s}}^{\prime} \cdot\left(\mathrm{x}_{1}-\mathrm{d}^{\prime}\right)}+\mathrm{x}_{2}-\mathrm{P}_{\mathrm{AC}} \cdot \mathrm{b}_{\mathrm{w}} \cdot \mathrm{x}_{1}\right] \\
& +\mu_{2} \cdot\left[\frac{\mathrm{M}_{\mathrm{d}}-\mathrm{K}_{1} \cdot \mathrm{K}_{2} \cdot \mathrm{x}_{1}{ }^{2}}{\sigma_{\mathrm{s}}^{\prime} \cdot\left(\mathrm{x}_{1}-\mathrm{d}^{\prime}\right)}-0,5 \cdot \mathrm{x}_{2}\right]
\end{aligned}
$$

Igualando o gradiente da função a zero, para determinar os pontos de mínimo locais:

$$
\begin{aligned}
& \frac{d}{d_{1}} F=b_{w} \cdot C_{c}+\left(-2 \cdot K_{1} \cdot K_{2} \cdot \frac{x_{1}}{\sigma_{s}^{\prime} \cdot\left(x_{1}-d^{\prime}\right)}-\frac{M_{d}-K_{1} \cdot K_{2} \cdot x_{1}{ }^{2}}{\sigma_{s}^{\prime} \cdot\left(x_{1}-d^{\prime}\right)^{2}}\right) \cdot \rho_{s} \cdot C_{s}+2 \cdot C_{F} \\
& +\lambda_{1} \cdot\left[K_{1}+\sigma_{s}^{\prime} \cdot\left(-2 \cdot K_{1} \cdot K_{2} \cdot \frac{x_{1}}{\sigma_{s}^{\prime} \cdot\left(x_{1}-d^{\prime}\right)}-\frac{M_{d}-K_{1} \cdot K_{2} \cdot x_{1}{ }^{2}}{\sigma_{s}^{\prime} \cdot\left(x_{1}-d^{\prime}\right)^{2}}\right)\right] \\
& +\mu_{1} \cdot\left[-2 \cdot K_{1} \cdot K_{2} \cdot \frac{x_{1}}{\sigma_{s}^{\prime} \cdot\left(x_{1}-d^{\prime}\right)}-\frac{M_{d}-K_{1} \cdot K_{2} \cdot x_{1}{ }^{2}}{\sigma_{s}^{\prime} \cdot\left(x_{1}-d^{\prime}\right)^{2}}-P_{A C} \cdot b_{w}\right] \\
& +\mu_{2} \cdot\left[-2 \cdot K_{1} \cdot K_{2} \cdot \frac{x_{1}}{\sigma_{s}^{\prime} \cdot\left(x_{1}-d^{\prime}\right)}-\frac{M_{d}-K_{1} \cdot K_{2} \cdot x_{1}{ }^{2}}{\sigma_{s}^{\prime} \cdot\left(x_{1}-d^{\prime}\right)^{2}}\right]=0 \\
& \frac{d}{d x_{2}} f=\rho_{s} \cdot C_{s}-\lambda_{1} \cdot \sigma_{s}+\mu_{1}-0,5 \cdot \mu_{2}=0 \\
& \frac{d}{d \lambda_{1}} f=K_{1} \cdot x_{1}+\sigma_{s}^{\prime} \cdot \frac{M_{d}-K_{1} \cdot K_{2} \cdot x_{1}{ }^{2}}{\sigma_{s}^{\prime} \cdot\left(x_{1}-d^{\prime}\right)}-\sigma_{s} \cdot x_{2}=0 \\
& \mu_{2} \cdot\left[\frac{M_{d}-K_{1} \cdot K_{2} \cdot x_{1}{ }^{2}}{\sigma_{s}^{\prime} \cdot\left(x_{1}-d^{\prime}\right)}-0,5 \cdot x_{2}\right]=0 \\
& \mu_{1} \cdot\left[\frac{M_{d}-K_{1} \cdot K_{2} \cdot x_{1}{ }^{2}}{\sigma_{s}^{\prime} \cdot\left(x_{1}-d^{\prime}\right)}+x_{2}-P_{A C} \cdot b_{w} \cdot x_{1}\right]=0
\end{aligned}
$$


Resolvendo o sistema de equações não lineares acima, e verificando se as soluções satisfazem às restrições inativas, encontram-se os pontos de mínimo local do problema.

\section{Soluções possíveis:}

Hipótese 01: $\quad \mu_{1}=0 ; \quad \mu_{2} \neq 0$

Hipótese 02: $\quad \mu_{1} \neq 0 \quad ; \quad \mu_{2}=0$

Hipótese 03: $\quad \mu_{1}=0 \quad ; \quad \mu_{2}=0$

Quando se iguala o coeficiente $\mu$ a zero, ou seja, torna-se a restrição inativa, é necessário verificar se os resultados satisfazem a esta restrição. Sendo assim, devem ser verdadeiras as seguintes relações:

Hipótese 01: $\left[\frac{\mathrm{M}_{\mathrm{d}}-\mathrm{K}_{1} \cdot \mathrm{K}_{2} \cdot \mathrm{x}_{1}{ }^{2}}{\sigma_{\mathrm{s}}^{\prime} \cdot\left(\mathrm{x}_{1}-\mathrm{d}^{\prime}\right)}+\mathrm{x}_{2}-\mathrm{P}_{\mathrm{AC}} \cdot \mathrm{b}_{\mathrm{w}} \cdot \mathrm{x}_{1}\right]<0 \quad ; \quad \mu_{2}>0$

Hipótese 02: $\left[\frac{\mathrm{M}_{\mathrm{d}}-\mathrm{K}_{1} \cdot \mathrm{K}_{2} \cdot \mathrm{x}_{1}{ }^{2}}{\sigma_{\mathrm{s}}^{\prime} \cdot\left(\mathrm{x}_{1}-\mathrm{d}^{\prime}\right)}-0,5 \cdot \mathrm{x}_{2}\right]<0 \quad ; \quad \mu_{1}>0$

Hipótese 03: $\left[\frac{\mathrm{M}_{\mathrm{d}}-\mathrm{K}_{1} \cdot \mathrm{K}_{2} \cdot \mathrm{x}_{1}{ }^{2}}{\sigma_{\mathrm{s}}^{\prime} \cdot\left(\mathrm{x}_{1}-\mathrm{d}^{\prime}\right)}+\mathrm{x}_{2}-\mathrm{P}_{\mathrm{AC}} \cdot \mathrm{b}_{\mathrm{w}} \cdot \mathrm{x}_{1}\right]<0$

$$
\left[\frac{\mathrm{M}_{\mathrm{d}}-\mathrm{K}_{1} \cdot \mathrm{K}_{2} \cdot \mathrm{x}_{1}{ }^{2}}{\sigma_{\mathrm{s}}^{\prime} \cdot\left(\mathrm{x}_{1}-\mathrm{d}^{\prime}\right)}-0,5 \cdot \mathrm{x}_{2}\right]<0
$$

Devido à dificuldade de resolução do sistema de equações, foram substituídas algumas expressões constantes por $K_{i}$ e expressões que variam em $\mathbf{X}_{1}$ por $F_{i}$.

$$
\begin{aligned}
& \mathrm{K}_{3}=-\mathrm{K}_{1} \cdot \mathrm{K}_{2}-\mathrm{K}_{1} \\
& \mathrm{~K}_{4}=\mathrm{K}_{1} \cdot \mathrm{d}^{\prime} \\
& \mathrm{K}_{5}=\mathrm{b}_{\mathrm{w}} \cdot \mathrm{C}_{\mathrm{c}}+2 \cdot \mathrm{C}_{\mathrm{F}} \\
& \mathrm{K}_{6}=\mathrm{K}_{1}-\mathrm{P}_{\mathrm{AC}} \cdot \mathrm{b}_{\mathrm{w}} \cdot \sigma_{\mathrm{s}}^{\prime} \\
& \mathrm{K}_{7}=\mathrm{K}_{6}-4 \cdot \mathrm{K}_{1} \cdot \mathrm{K}_{2} \\
& \mathrm{~K}_{8}=-\mathrm{K}_{6} \cdot \mathrm{d}^{\prime} \\
& \mathrm{K}_{9}=4 \cdot \mathrm{M}_{\mathrm{d}} \\
& \mathrm{K}_{10}=-\mathrm{K}_{5} \cdot \sigma_{\mathrm{s}}^{\prime} \cdot \mathrm{d}^{\prime}-\rho_{\mathrm{s}} \cdot \mathrm{C}_{\mathrm{s}} \cdot \mathrm{K}_{1} \cdot \mathrm{d}^{\prime}
\end{aligned}
$$




$$
\begin{aligned}
& \mathrm{K}_{11}=\mathrm{K}_{5} \cdot \sigma_{\mathrm{s}}-4 \cdot \rho_{\mathrm{s}} \cdot \mathrm{C}_{\mathrm{s}} \cdot \mathrm{K}_{1} \cdot \mathrm{K}_{2}+\rho_{\mathrm{s}} \cdot \mathrm{C}_{\mathrm{s}} \cdot \mathrm{K}_{1} \\
& \mathrm{~K}_{12}=-\mathrm{K}_{10} \cdot \mathrm{d}^{\prime}-2 \cdot \rho_{\mathrm{s}} \cdot \mathrm{C}_{\mathrm{s}} \cdot \mathrm{M}_{\mathrm{d}} \\
& \mathrm{K}_{13}=\mathrm{K}_{10}-\mathrm{K}_{11} \cdot \mathrm{d}^{\prime} \\
& \mathrm{K}_{14}=\mathrm{K}_{11}+2 \cdot \rho_{\mathrm{s}} \cdot \mathrm{C}_{\mathrm{s}} \cdot \mathrm{K}_{1} \cdot \mathrm{K}_{2} \\
& \mathrm{~F}_{1}=\frac{1}{\sigma_{\mathrm{s}}^{\prime} \cdot\left(\mathrm{x}_{1}-\mathrm{d}^{\prime}\right)} \\
& \mathrm{F}_{2}=\frac{1}{\sigma_{\mathrm{s}}^{\prime} \cdot\left(\mathrm{x}_{1}-\mathrm{d}^{\prime}\right)^{2}} \\
& \mathrm{~F}_{3}=\mathrm{M}_{\mathrm{d}}-\mathrm{K}_{1} \cdot \mathrm{K}_{2} \cdot \mathrm{x}_{1}^{2} \\
& \mathrm{~F}_{4}=-2 \cdot \mathrm{K}_{1} \cdot \mathrm{K}_{2} \cdot \mathrm{x}_{1} \cdot \mathrm{F}_{1}-\mathrm{F}_{3} \cdot \mathrm{F}_{2} \\
& \mathrm{~F}_{5}=\mathrm{K}_{1}+\sigma_{\mathrm{s}}^{\prime} \cdot \mathrm{F}_{4} \\
& \mathrm{~F}_{6}=\mathrm{F}_{4}-\mathrm{P}_{\mathrm{AC}} \cdot \mathrm{b}_{\mathrm{w}}
\end{aligned}
$$

\section{4 - Solução do Sistema de Equações}

As expressões abaixo descritas são soluções para cada hipótese considerada. Depois de encontrados valores numéricos para as variáveis, é necessário verificar a consistência dos resultados, verificando se estes satisfazem às restrições inativas.

Hipótese 01:

$$
\begin{aligned}
& \mathrm{x}_{1}=\frac{-\mathrm{K}_{4} \pm \sqrt{\mathrm{K}_{4}{ }^{2}-4 \cdot \mathrm{K}_{3} \cdot \mathrm{M}_{\mathrm{d}}}}{2 \cdot \mathrm{K}_{3}} \\
& \mathrm{x}_{2}=\frac{\mathrm{K}_{1} \cdot \mathrm{x}_{1}}{\sigma_{\mathrm{s}}}+\mathrm{F}_{3} \cdot \mathrm{F}_{1} \\
& \mathrm{x}_{3}=\mathrm{F}_{3} \cdot \mathrm{F}_{1} \\
& \lambda_{1}=\frac{-\mathrm{k}_{5}-3 \cdot \rho_{\mathrm{s}} \cdot \mathrm{C}_{\mathrm{s}} \cdot \mathrm{F}_{4}}{\mathrm{~F}_{5}-2 \cdot \sigma_{\mathrm{s}}^{\prime} \cdot \mathrm{F}_{4}} \\
& \mu_{1}=0 \\
& \mu_{2}=2 \cdot\left(\rho_{\mathrm{s}} \cdot \mathrm{C}_{\mathrm{s}}-\lambda_{1} \cdot \sigma_{\mathrm{s}}^{\prime}\right)>0
\end{aligned}
$$

Hipótese 02: 


$$
\begin{aligned}
& \mathrm{x}_{1}=\frac{-\mathrm{K}_{8} \pm \sqrt{\mathrm{K}_{8}{ }^{2}-4 \cdot \mathrm{K}_{7} \cdot \mathrm{K}_{9}}}{2 \cdot \mathrm{K}_{7}} \\
& \mathrm{x}_{2}=\frac{\mathrm{K}_{1} \cdot \mathrm{x}_{1}}{\sigma_{\mathrm{s}}}+\mathrm{F}_{3} \cdot \mathrm{F}_{1} \\
& \mathrm{x}_{3}=\mathrm{F}_{3} \cdot \mathrm{F}_{1} \\
& \lambda_{1}=\frac{-\mathrm{k}_{5}-\rho_{\mathrm{s}} \cdot \mathrm{C}_{\mathrm{s}} \cdot \mathrm{F}_{4}+\rho_{\mathrm{s}} \cdot \mathrm{C}_{\mathrm{s}} \cdot \mathrm{F}_{6}}{\mathrm{~F}_{5}+\sigma_{\mathrm{s}}^{\prime} \cdot \mathrm{F}_{6}} \\
& \mu_{1}=\lambda_{1} \cdot \sigma_{\mathrm{s}}^{\prime}-\rho_{\mathrm{s}} \cdot \mathrm{C}_{\mathrm{s}}>0 \\
& \mu_{2}=0
\end{aligned}
$$

Hipótese 03:

$$
\begin{aligned}
& \mathrm{x}_{1}=\frac{-\mathrm{K}_{13} \pm \sqrt{\mathrm{K}_{13}{ }^{2}-4 \cdot \mathrm{K}_{14} \cdot \mathrm{K}_{12}}}{2 \cdot \mathrm{K}_{14}} \\
& \mathrm{x}_{2}=\frac{\mathrm{K}_{1} \cdot \mathrm{x}_{1}}{\sigma_{\mathrm{s}}}+\mathrm{F}_{3} \cdot \mathrm{F}_{1} \\
& \mathrm{x}_{3}=\mathrm{F}_{3} \cdot \mathrm{F}_{1} \\
& \lambda_{1}=\frac{\rho_{\mathrm{s}} \cdot \mathrm{C}_{\mathrm{s}}}{\sigma_{\mathrm{s}}^{\prime}} \\
& \mu_{1}=0 \\
& \mu_{2}=0
\end{aligned}
$$

\section{5 - Verificação dos Resultados Obtidos}

Para exemplificar a rotina elaborada, considere-se a viga biapoiada da figura 5.2.

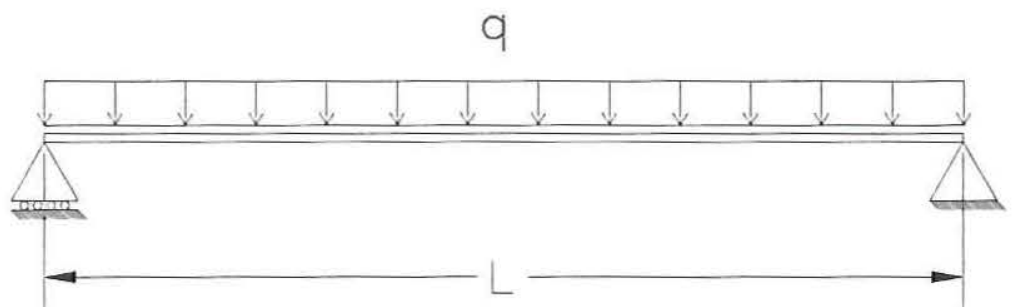

FIGURA 5.2 - Viga biapoiada 
Características geométricas:

$b_{w}=15 \mathrm{~cm} ; h_{i}=70 \mathrm{~cm} ; d^{\prime}=3 \mathrm{~cm} ; L=8,00 \mathrm{~m}$

Obs: - Os valores de $d_{i}$ e $L$ foram fornecidos para possibilitar a execução da restrição de deslocamento. A inércia da viga será calculada no estádio I, sendo esta constante para todo vão.

Para o cálculo da flecha inicial, neste problema, foi considerada apenas a flecha elástica e imediata, obtida da resistência dos materiais com a seguinte expressão:

$$
\delta_{i}=\frac{q \cdot x}{24 \cdot E_{c} \cdot I} \cdot\left(L^{3}-2 \cdot L \cdot x^{2}+x^{3}\right)
$$

No meio do vão, tem-se: $M=\frac{q \cdot L^{2}}{8} \quad ; \quad x=\frac{L}{2}$

Obtendo para flecha máxima a expressão abaixo:

$$
\delta_{i}=\frac{5 \cdot L^{2} \cdot M_{d}}{4 \cdot E_{c} \cdot b_{w} \cdot h^{3}}
$$

- A flecha máxima permitida por Norma deste problema é 2,667 cm.

Características das ações externas:

$\mathrm{M}_{\mathrm{i}}=1000,00 \mathrm{kN} . \mathrm{cm} ; \mathrm{M}_{\mathrm{f}}=70000,00 \mathrm{kN} . \mathrm{cm} ; \Delta \mathrm{M}=500,00 \mathrm{kN} . \mathrm{cm}$,

onde $\mathrm{M}_{\mathrm{i}}$ - momento fletor característico inicial,

$\mathrm{M}_{\mathrm{f}}$ - momento fletor característico final,

$\Delta \mathrm{M}$ - incremento do momento fletor.

Para uma melhor compreensão da relação de custo e de quantidades de materiais de seções ótimas, foi feita uma variação de momento (como citado acima) mantendo-se as características iniciais do problema, de forma a se obterem as seções ótimas para cada esforço pré-definido. Desta forma, tem-se idéia de como variam as dimensões ótimas das seções transversais, mantendo-se fixas determinadas características.

Características dos materiais:

Custo do concreto: $30 \%$ do custo total;

Custo do aço: $\quad 30 \%$ do custo total; 
Custo da forma: $\quad 40 \%$ do custo total;

Concreto tipo C20, aço tipo CA-50A;

$\mathrm{E}_{\mathrm{c}}=26.000 \mathrm{MPa}, \mathrm{E}_{\mathrm{s}}=210.000 \mathrm{MPa}$;

$\rho_{\mathrm{s}}=7,5 \times 10^{-5} \mathrm{kN} / \mathrm{cm}^{3}$;

$\varepsilon_{\mathrm{c}}=3,5 \%$;

\% máxima de aço em relação à área de concreto: $4 \%$.

$\mathrm{Na}$ tabela 5.1 podem-se observar alguns dos resultados obtidos neste exemplo.

\begin{tabular}{|c|c|c|c|c|c|c|c|}
\hline $\begin{array}{c}\text { Mk } \\
(\mathrm{kN} . \mathrm{cm})\end{array}$ & d $(\mathrm{cm})$ & As $\left(\mathrm{cm}^{2}\right)$ & As' $\left(\mathrm{cm}^{2}\right)$ & $\begin{array}{c}\text { Volume de } \\
\text { concreto } \\
\left(\mathrm{cm}^{3}\right)\end{array}$ & $\begin{array}{c}\text { Área de } \\
\text { aço }\left(\mathrm{cm}^{2}\right)\end{array}$ & $\begin{array}{c}\text { Flecha } \\
(\mathrm{cm})\end{array}$ & $\begin{array}{c}\text { Custo } \\
\text { relativo } \\
\left(\$ / \mathrm{cm}^{3}\right)\end{array}$ \\
\hline 1000,00 & 58,75 & 0,55 & 0,00 & 881,28 & 0,55 & 2,65 & 330,89 \\
\hline 2000,00 & 61,01 & 1,08 & 0,00 & 915,11 & 1,08 & 2,66 & 342,84 \\
\hline 3000,00 & 62,64 & 1,59 & 0,00 & 939,57 & 1,59 & 2,66 & 351,48 \\
\hline 4000,00 & 63,76 & 2,10 & 0,00 & 956,38 & 2,10 & 2,66 & 357,43 \\
\hline 5000,00 & 64,87 & 2,61 & 0,00 & 973,01 & 2,61 & 2,66 & 363,30 \\
\hline 6000,00 & 65,87 & 3,11 & 0,00 & 988,01 & 3,11 & 2,65 & 368,61 \\
\hline 8000,00 & 67,25 & 4,13 & 0,00 & 1008,75 & 4,13 & 2,66 & 375,93 \\
\hline 10000,00 & 68,27 & 5,19 & 0,00 & 1024,11 & 5,19 & 2,67 & 381,36 \\
\hline 15000,00 & 70,28 & 7,94 & 0,00 & 1054,20 & 7,94 & 2,66 & 392,00 \\
\hline 20000,00 & 71,48 & 11,05 & 0,00 & 1072,18 & 11,05 & 2,66 & 398,36 \\
\hline 30000,00 & 73,53 & 17,09 & 1,61 & 1102,92 & 18,71 & 2,67 & 409,24 \\
\hline 40000,00 & 77,24 & 20,94 & 4,68 & 1158,62 & 25,62 & 2,66 & 428,94 \\
\hline 50000,00 & 80,03 & 24,64 & 7,79 & 1200,48 & 32,44 & 2,66 & 443,74 \\
\hline 50500,00 & 80,43 & 24,77 & 7,83 & 1206,43 & 32,60 & 2,64 & 445,84 \\
\hline 60000,00 & 87,62 & 26,98 & 8,53 & 1314,24 & 35,51 & 2,42 & 483,94 \\
\hline 70000,00 & 94,59 & 29,13 & 9,21 & 1418,85 & 38,34 & 2,25 & 520,91 \\
\hline
\end{tabular}

TABELA 5.1 - Resultados obtidos no exemplo de viga em análise

Em seguida, serão apresentados alguns gráficos obtidos com valores encontrados quando o momento fletor variou entre 1000,00 e $70000,00 \mathrm{kN} . \mathrm{cm}$ com incremento de $500,00 \mathrm{kN} . \mathrm{cm}$.

Como pode ser observado no gráfico 5.1 , a inclinação da curva que representa a altura da seção transversal é mais acentuada a partir do valor relativo do momento fletor característico de aproximadamente $50000,00 \mathrm{kN} . \mathrm{cm}$, ponto a partir do qual a 
restrição de deslocamento deixa de ser principal, passando o problema a ser dominado pela restrição de equilíbrio dos esforços.

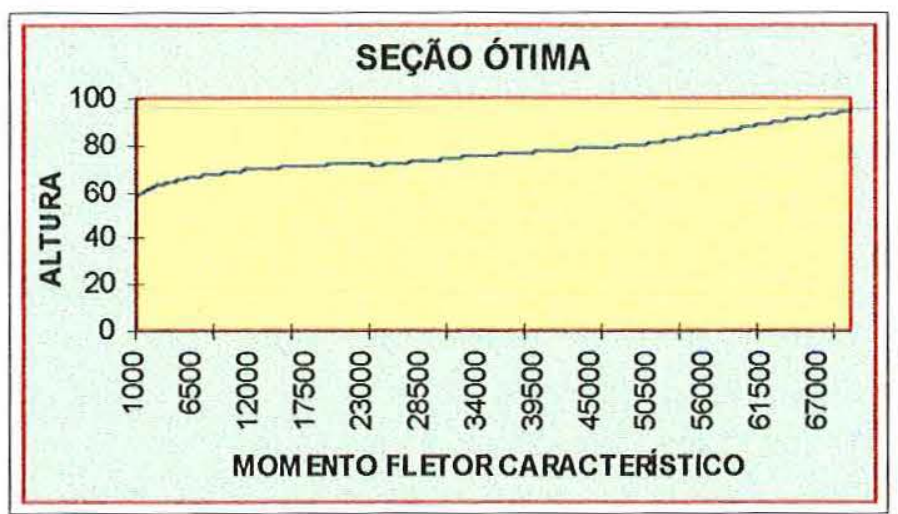

GRÁFICO 5.1 -Variação do momento fletor característico com respectiva altura da seção transversal otimizada

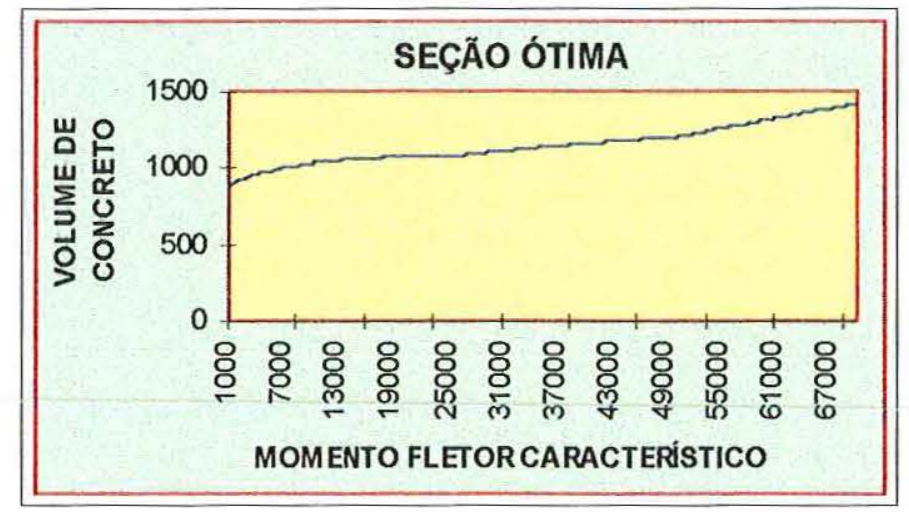

GRÁFICO 5.2 -Variação do momento fletor característico com respectivo volume de concreto da seção transversal otimizada

Como é de se esperar, o comportamento da curva de aumento da área de aço é inverso ao comportamento das curvas dos gráficos 5.1 e 5.2 , pois enquanto a restrição de deslocamento é predominante, a altura necessária para a viga é maior que a altura ótima exigida pelo equilíbrio dos esforços. Sendo assim, o aumento do esforço solicitante não causa grande variação na altura da seção transversal, e, para obedecer o equilíbrio, é necessário um maior aumento nas áreas de aço. 


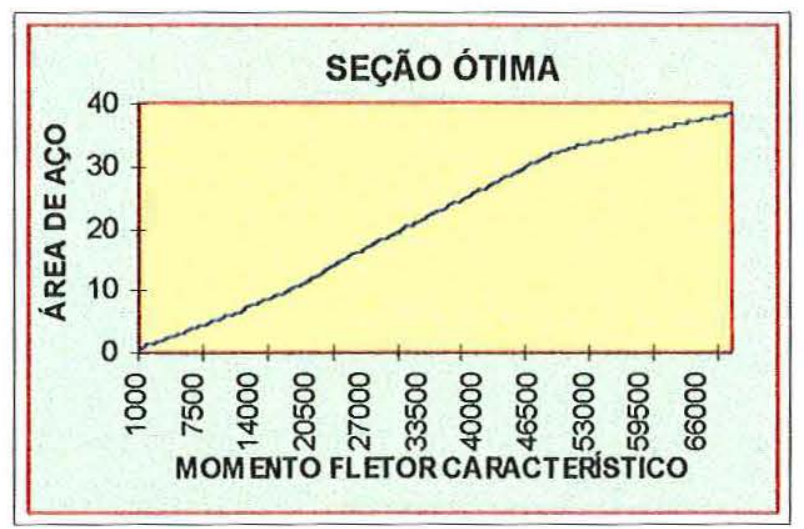

GRÁFICO 5.3 -Variação do momento fletor característico com respectiva área de aço da seção transversal otimizada

Como já mencionado anteriormente, o gráfico 5.4 mostra claramente o declínio da flecha, comprovando que esta deixa de ser restrição principal a partir de certo valor do esforço solicitante.

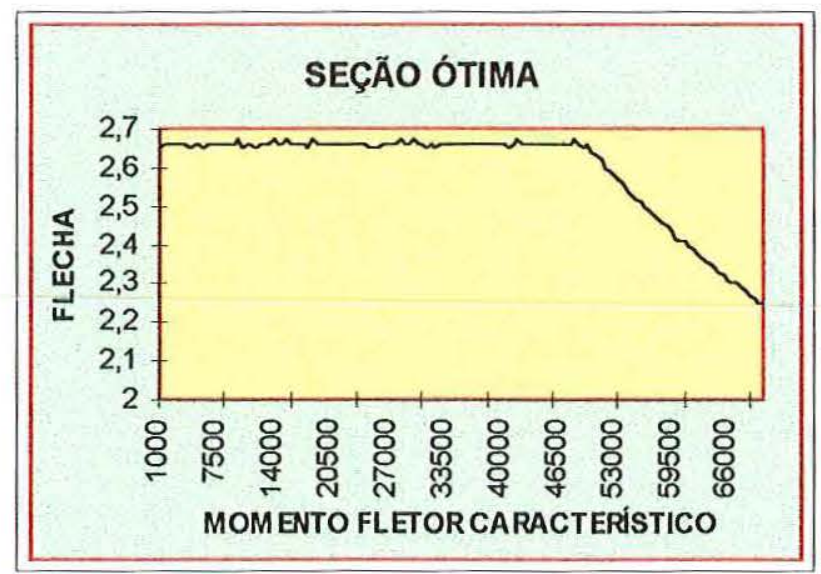

GRÁFICO 5.4 -Variação do momento fletor característico com respectiva flecha da seção transversal otimizada

O custo aumenta mais rapidamente quando a restrição de flecha deixa de ser dominante. Isto acontece porque nesta região a altura aumenta mais rápido que na região inicial, e consequentemente há um aumento maior da área de forma, sendo estes componentes juntos responsáveis pela maior parte do custo da estrutura. Como pode ser visto no gráfico 5.5, para encontrar uma solução ótima, deve-se usar mais aço e menos concreto, o que muitas vezes não é feito em estruturas convencionais. 


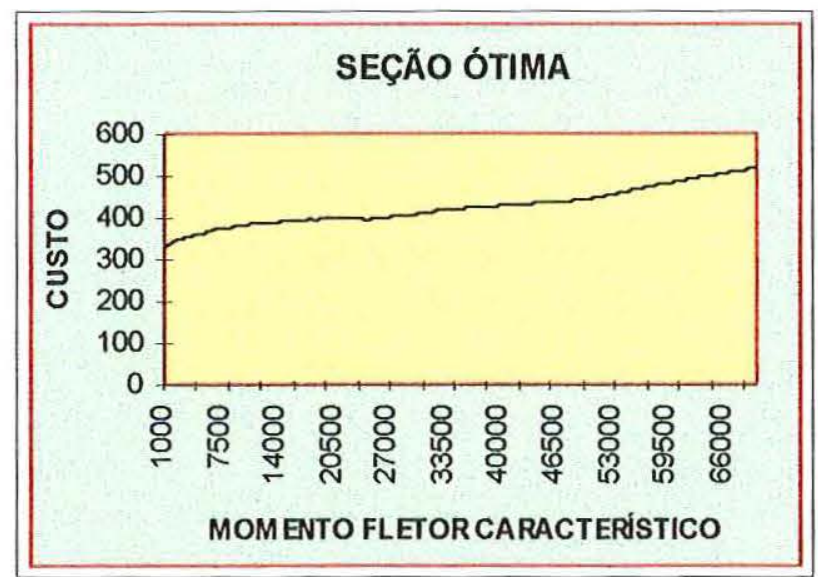

GRÁFICO 5.5 -Variação do momento fletor característico com respectivo custo da seção transversal otimizada

\section{6 - Verificação da Consistência dos Resultados}

Devido à extensão do equacionamento matemático que prova que os resultados obtidos são pontos de máximo ou de mínimo, optou-se pela verificação prática desta condição. O procedimento matemático utilizado foi de extremização de funções, ou seja, as soluções encontradas são obrigatoriamente pontos de máximo ou de mínimo. Desta forma, se para uma seção transversal qualquer, obedecendo às restrições impostas no problema, o custo for de maior valor que o custo para uma seção ótima, ter-se-á a solução obtida pelo equacionamento matemático como um ponto de mínimo.

Será provada a consistência através da verificação do custo de uma seção transversal com as mesmas características do exemplo acima, exceto a altura, e consequentemente áreas de aço. Considere a seção equivalente ao momento fletor característico de $60000,00 \mathrm{kN} . \mathrm{cm}$, e uma altura de $97,62 \mathrm{~cm}, 10 \mathrm{~cm}$ a mais que a seção ótima. As áreas de aço obtidas para esta seção não ótima são $A s=25,097 \mathrm{~cm}^{2} \mathrm{e}$ $A s^{\prime}=4,540 \mathrm{~cm}^{2}$. O custo para estes dados é $536,9527 \$ / \mathrm{cm}^{3}$, provando assim que a solução ótima é realmente um ponto de mínimo, uma vez que o custo para esta é $483,94 \$ / \mathrm{cm}^{3}$. 
A seguir é mostrado o gráfico que representa a função objetivo sujeita às restrições do problema em questão. Os valores numéricos explicitados no gráfico 5.6 foram obtidos considerando as características do exemplo utilizado acima, figura 5.2, para um momento fletor característico constante de valor $5000,00 \mathrm{kN}$.cm e a altura útil da viga variando entre $10 \mathrm{~cm}$ e $99 \mathrm{~cm}$, com incremento de $1 \mathrm{~cm}$.

No gráfico 5.6, a abscissa representa as alturas da viga, a ordenada representa a soma das áreas de aço, a compressão e a tração, e a cota representa a função objetivo e as restrições, exceto restrição de deslocamento. As restrições de equilíbrio e compatibilidade estão inclusas na função objetivo, uma vez que as áreas de aço devem estar coerentes com a altura útil da viga. Representa-se pela linha verde a restrição equivalente à limitação da área de aço de compressão em $50 \%$ da área de aço de tração, pela linha vermelha a limitação da taxa geométrica da armadura, e finalmente, pela linha rosa a função objetivo já restrita ao equilíbrio. A região viável se caracteriza sobre a curva custo a partir do ponto no qual os valores numéricos que representam as restrições são negativos. Como pode-se concluir, a função objetivo é sempre crescente, mostrando mais uma vez que os resultados encontrados na formulação representam um ponto de mínimo global.

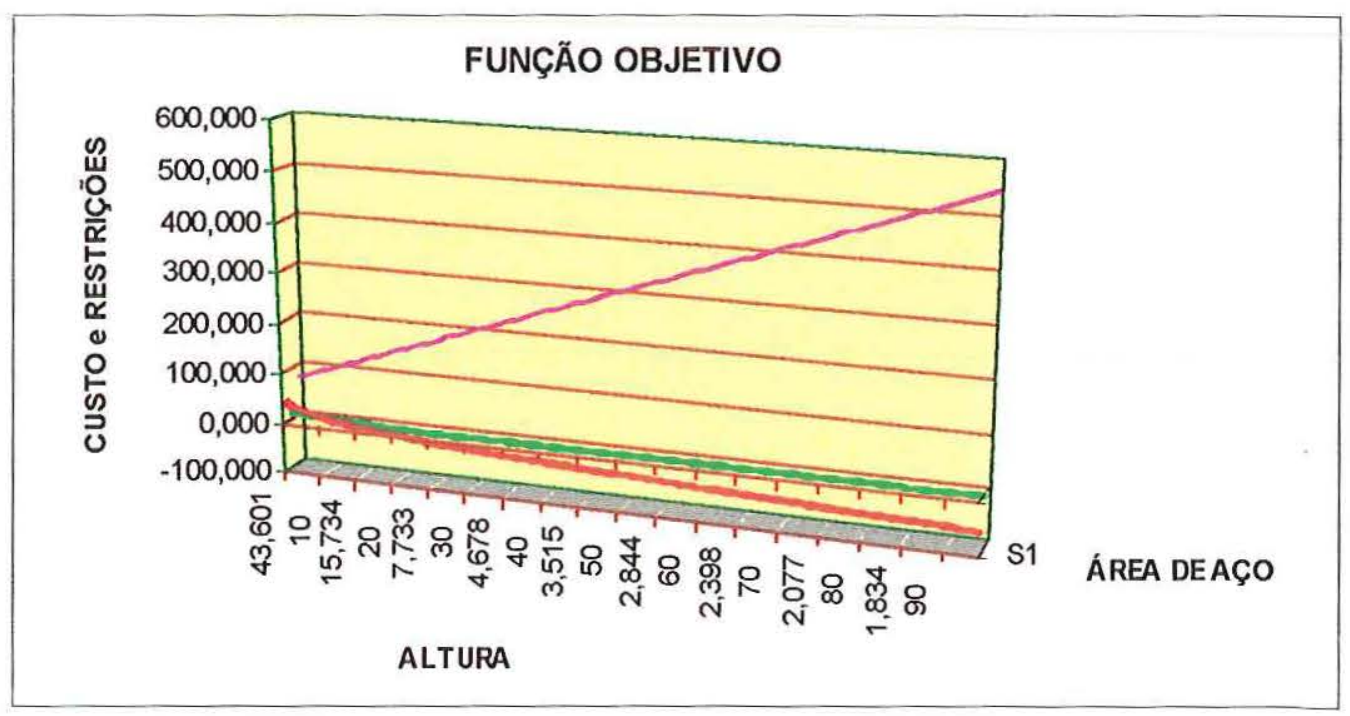

GRÁFICO 5.6 - Representação da função objetivo sujeita às restrições para uma seção transversal 


\section{6 - SOLUÇÃO ESTENDIDA ÀS SEÇÕES TRANSVERSAIS DE GRELHAS}

\section{1 - Introdução}

Sendo conhecida a formulação matemática para a otimização de uma seção transversal de concreto armado para uma determinada viga, pretende-se aplicar esta mesma formulação a seções transversais de grelhas. Como se sabe, uma grelha é um conjunto de vigas interligadas, e, de alguma forma, cada viga da grelha influencia nas características das demais. Esta interação entre as vigas de uma grelha é que diferencia o comportamento estrutural de uma grelha como elemento único de um conjunto de vigas. Ciente da diferença entre estes dois tipos estruturais (conjunto de vigas e grelha), pensou-se num modo de aplicar às grelhas técnicas matemáticas já conhecidas para as vigas. Sendo assim, se a estrutura for processada ' $n$ ' vezes, e em cada passo de processamento for determinada a altura ótima para as vigas, com os esforços devidamente corrigidos, quando não houver mais redistribuição significativa dos esforços, e consequentemente variação da geometria das seções transversais das vigas, será coerente utilizar o modelo para vigas em grelhas. É importante salientar que os resultados obtidos com esse modelo não são necessariamente os mesmos que se fosse feita a otimização da grelha como elemento único, mas espera-se que, para utilização prática, o modelo utilizado seja de precisão razoável. Acredita-se que não deve haver diferenças significativas entre a otimização da grelha como elemento único e como um somatório de vigas corrigidas iterativamente.

A redistribuição dos esforços de um pavimento está diretamente ligada à rigidez dos elementos estruturais; então, é de absoluta importância o uso de inércias coerentes para as vigas, pois isto é um fator decisivo no "caminho" das cargas, e consequentemente na precisão dos resultados obtidos. Devido à extrema importância na precisão da inércia do elemento de viga, ao estudo desta será dedicado o Capítulo 7.

\section{2 - Embasamento Matemático}


Segundo KIRSCH (1993), os vários métodos aproximados de otimização de estruturas topológicas podem ser divididos nas seguintes partes:

- Aproximações Globais - As aproximações são obtidas ao analisar a estrutura como um todo, ou seja, a função objetivo é formulada em todos os pontos de projeto, sendo assim válidos os seus resultados para todos os pontos espaciais. Entretanto, aproximações globais podem requerer muito esforço computacional nos problemas com um grande número de variáveis de projeto. Um exemplo deste tipo de aproximação, é formular a função objetivo na grelha, não numa seção transversal de uma viga.

- Aproximações Locais - Estas aproximações, baseadas em informações calculadas em pontos isolados do projeto, são na maioria das vezes eficientes, mas elas são efetivas somente nos casos de pequenas alterações nas variáveis de projeto. Para grandes alterações nas variáveis, a precisão das aproximações é deteriorada, e elas podem tornar-se sem sentido. Para melhorar a qualidade dos resultados, podem-se utilizar variáveis intermediárias. Um exemplo deste tipo de aproximação, é formular a função objetivo na seção transversal de uma viga.

- Aproximações Combinadas - Com este tipo de aproximação, pode-se obter resultados com qualidades globais através de aproximações locais. Este tipo de aproximação pode ser exemplificado com o presente trabalho.

No trabalho do KIRSCH (1993), uma aproximação para introduzir Aproximações Combinadas é definir a ordem da matriz de rigidez inicial, pois é possível que um elemento finito deixe de existir, reduzindo a ordem da matriz. No presente trabalho, a matriz de rigidez tem ordem constante, e o que é variável ao longo das iterações são seus componentes, como será visto adiante. A vantagem de usar um método de Aproximações Combinadas é que, semelhante às Aproximações Locais, a solução baseia-se em resultados de análises locais exatas; portanto, utilizamse de esforços matemáticos locais e obtêm-se resultados aproximados de qualidades globais. Este procedimento tem sido usado para vários tipos de variáveis de projeto e funções.

\subsection{1 - Formulação do Problema}


Assume-se a seguinte nomenclatura:

F - vetor de cargas ou das ações externas;

$\mathrm{K}$ - matriz de rigidez global;

Ke - matriz de rigidez global dos elementos de barra;

$\mathrm{Kp}$ - matriz de rigidez global dos elementos de placa;

U- vetor dos deslocamentos nodais em relação ao sistema de referência;

$\beta^{\mathrm{e}}$ - matriz de transformação de coordenadas globais para locais;

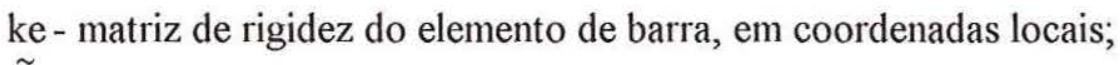

$\delta^{\mathrm{e}}$ - vetor de deslocamentos nas coordenadas locais;

$\mathrm{P}^{0}$ - vetor das ações de engastamento perfeito;

$p^{e}$ - esforços nas extremidades dos elementos de barra.

Para o $1^{0}$ passo de iteração, deve-se considerar o momento de inércia dos elementos no Estádio I.

Fazer $\mathrm{i}=0$, número máximo de iterações ou erro admissível.

1 - Dado um vetor de cargas, ou ações externas $\underset{\sim}{\mathrm{F}}$, a correspondente matriz de rigidez $\underset{\sim}{\mathrm{K}}$,e os deslocamentos $\underset{\sim}{\mathrm{U}}$ são computados pelas equações de equilíbrio.

$$
\begin{aligned}
& \underset{\sim \mathrm{i}}{\mathrm{Ke}}=\sum_{\mathrm{j}=1 \sim \mathrm{ke}_{\mathrm{j}}}^{\mathrm{n}} \\
& \underset{\sim \mathrm{i}}{\mathrm{K}}=\underset{\sim \mathrm{i}}{\mathrm{Ke}}+\underset{\sim}{\mathrm{Kp}} \quad \rightarrow \quad \underset{\sim}{\mathrm{F}}=[\underset{\sim}{\mathrm{Ke}}+\underset{\sim}{\mathrm{Kp}}] \cdot \underset{\sim}{\mathrm{U}_{\mathrm{i}}}
\end{aligned}
$$

Como os elementos de placa não são variáveis da otimização, assume-se que $\mathrm{Kp}=$ constante.

2 - Resolvendo o sistema de equações, obtém-se: 


$$
\begin{aligned}
& \underset{\sim}{\mathrm{U}_{\mathrm{i}}}=\underset{\sim \mathrm{i}}{\mathrm{K}^{-1} \cdot \underset{\sim}{\mathrm{F}}} \Rightarrow \quad \underbrace{\delta_{\mathrm{i}}^{\mathrm{F}}}_{\sim}=\underset{\sim}{\beta^{\mathrm{e}} \cdot \underset{\sim \mathrm{i}}{\mathrm{U}}} \\
& \underset{\sim \mathrm{i}}{\mathrm{p}^{\mathrm{e}}}=\underset{\sim}{\mathrm{P}^{0}+\underset{\sim \mathrm{i}}{\mathrm{ke}} \cdot \underset{\sim \mathrm{i}}{\delta^{\mathrm{e}}}}
\end{aligned}
$$

Assume-se que $\mathrm{p}^{\mathrm{e}}=$ constante.

3 - Aplica-se a rotina de otimização aos elementos finitos desejados; neste momento, todas as restrições do problema devem ser impostas. Uma vez definidas as dimensões dos elementos, calculam-se as inércias destes e segue o processo.

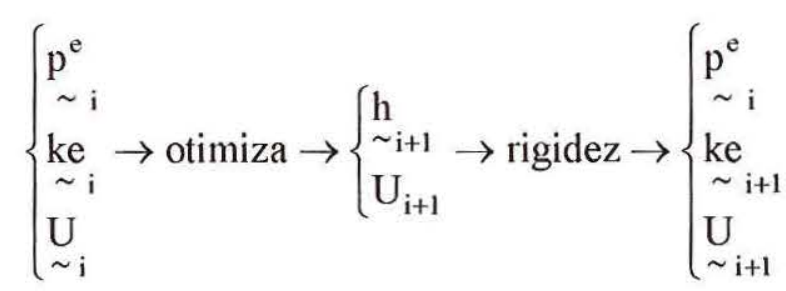

Se $\frac{\mathrm{h}_{\mathrm{i}+1}-\mathrm{h}_{\mathrm{i}}}{\sim} \underset{\mathrm{h}_{\mathrm{i}+1}}{\sim} \leq$ erro, interrompe o "loop" e vai para o passo 5 .

4 - Como a matriz de rigidez global é formada pela superposição da matriz de rigidez dos elementos, é necessário zerar seus termos.

$$
\mathrm{K}_{\mathrm{i}+1}=0
$$

Volta-se ao passo 1, com novos valores para a matriz de rigidez. Este "loop" deve terminar quando um erro preestabelecido pelo usuário for satisfeito, ou quando atingir um número de iterações pré-definido.

5 - Mostra-se ao usuário as alturas das vigas otimizadas; caso se deseje alterar algum desses valores, recomeça-se o processo de otimização, passo 1, e as vigas que estão livres continuam a serem otimizadas.

6 - Com as dimensões dos elementos já definidas, as inércias destes precisam ser corrigidas. Como elas dependem da área de concreto comprimida, do concreto entre fissuras e da área de aço, necessita-se de um processo iterativo para sua correção. Para isto, seguem-se os seguintes passos:

$$
\underset{\sim \mathrm{i}}{\mathrm{Ke}}=\sum_{\mathrm{j}=1 \sim}^{\mathrm{n}} \mathrm{ke}_{\mathrm{j}}
$$




$$
\begin{aligned}
& \underset{\sim \mathrm{i}}{\mathrm{K}}=\underset{\sim \mathrm{i}}{\mathrm{Ke}}+\underset{\sim}{\mathrm{Kp}} \quad \rightarrow \quad \underset{\sim}{\mathrm{K}}=[\underset{\sim \mathrm{i}}{\mathrm{Ke}}+\underset{\sim}{\mathrm{Kp}}] \cdot \underset{\sim}{\mathrm{U}_{\mathrm{i}}} \\
& \underset{\sim}{\mathrm{U}_{\mathrm{i}}}=\underset{\sim \mathrm{i}}{\mathrm{K}^{-1}} \cdot \underset{\sim}{\mathrm{F}} \Rightarrow \underset{\sim}{\delta_{\mathrm{i}}^{\mathrm{e}}}=\underset{\sim}{\beta^{\mathrm{e}}} \cdot \underset{\sim \mathrm{i}}{\mathrm{U}} \\
& \underset{\sim \mathrm{i}}{\mathrm{p}^{\mathrm{e}}}=\underset{\sim}{\mathrm{P}^{0}}+\underset{\sim \mathrm{i}}{\mathrm{ke}} \cdot \underset{\delta_{\mathrm{i}}}{\mathrm{e}}
\end{aligned}
$$

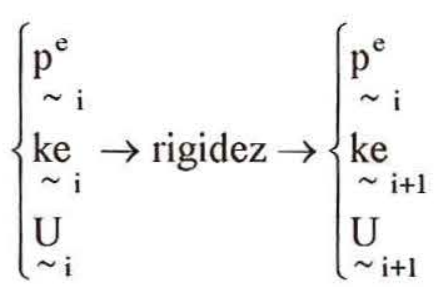

$\operatorname{Se} \frac{\|\underset{\mathrm{i}+1}{\sim}\|}{\|\underset{\mathrm{i}}{\sim}\|} \leq$ erro, finaliza o processamento do programa, com os elementos devidamente dimensionados.

Este loop deve terminar quando um erro preestabelecido pelo usuário for satisfeito, ou quando se atingir um número de iterações pré-definido.

Fim do processo.

\section{3 - Procedimentos Utilizados no "Software"}

\subsection{1 - Cálculo da Flecha}

A flecha é calculada de duas formas distintas; por deslocamentos relativos entre nós e por analogia de Mohr.

Para se determinar a flecha que será apresentada no arquivo de saída do programa ("*.SOL"), e a flecha imprimida ao longo das iterações no arquivo ("*.OTI") como flecha inicial, é feita a diferença relativa entre os deslocamentos verticais dos nós das extremidades do vão em análise, e o referente ao posicionamento da flecha. De acordo com as condições de contorno do vão, se é apoiado nas extremidades ou se está em balanço, foram elaboradas as seguintes expressões para se determinar o módulo da flecha. 


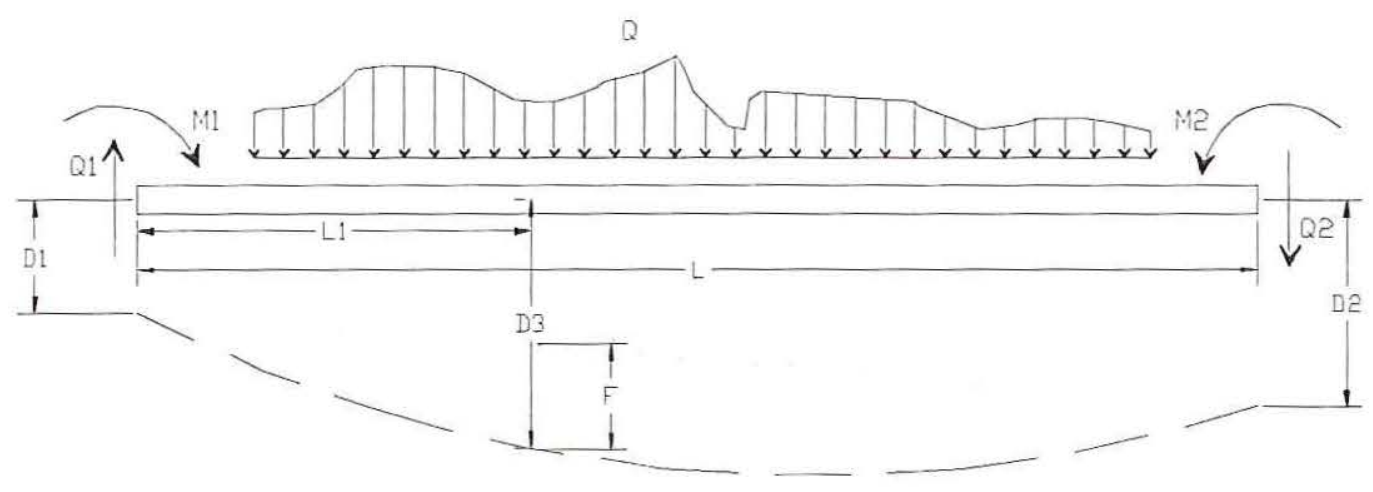

FIGURA. 6.1 - Vão da seção a ser otimizada

a) Vão apoiado nas extremidades:

$$
\mathrm{F}=-\frac{\mathrm{L}_{1}}{\mathrm{~L}} \cdot\left|\mathrm{d}_{2}-\mathrm{d}_{1}\right|+\mathrm{d}_{3}-\mathrm{d}_{1}
$$

b) Vão em balanço do lado esquerdo: $\quad F=d_{3}-d_{2}$

c) Vão em balanço do lado direito: $\quad F=d_{3}-d_{1}$

onde:

$\mathrm{L}=$ comprimento do vão da viga no qual se localiza a seção que deseja-se determinar a flecha;

$\mathrm{L}_{1}=$ distância da seção na qual pretende-se conhecer a flecha a extremidade esquerda do tramo;

$\mathrm{d}_{1}=$ deslocamento do nó da extremidade esquerda do vão;

$\mathrm{d}_{2}=$ deslocamento do nó da extremidade direita do vão;

$\mathrm{d}_{3}=$ deslocamento do nó da seção em que será determinada a flecha;

$\mathrm{F}$ = flecha da viga na seção desejada.

O outro método de obtenção das flechas foi utilizado na imposição da restrição de deslocamento na otimização das seções transversais das vigas, cujos resultados são apresentados no arquivo "*.OTI" como flecha final. O presente trabalho apresenta dois modelos para o cálculo das inércias dos elementos finitos, cabendo ao usuário definir se esta será calculada no Estádio I ou no Estádio II através da fórmula de BRANSON. Tanto para inércia constante (Estádio I), como para inércia variável (Estádio II), a flecha para imposição do deslocamento foi calculada como apresentado em seguida. 
Para o modelo que considera a inércia da viga constante e calculada no Estádio I, foi considerada a seguinte relação entre as flechas da viga antes e depois da otimização.

$$
F_{i} \cdot I_{i}=F_{f} \cdot I_{f} \Rightarrow F_{f}=\frac{F_{i} \cdot I_{i}}{I_{f}}
$$

onde:

$\mathrm{F}_{\mathrm{i}}=$ flecha obtida pelo programa de cálculo de pavimentos (calculada por deslocamento relativo entre os nós), antes da viga ser otimizada;

$\mathrm{F}_{\mathrm{f}}=$ flecha obtida pelo equacionamento acima, após a otimização da seção transversal; $\mathrm{I}_{\mathrm{i}}=$ Inércia da seção antes de ser otimizada; $\mathrm{I}_{\mathrm{f}}=$ Inércia da seção depois de ser otimizada.

Para o modelo que considera a inércia de cada elemento da viga diferente, Estádio II, variando com o esforço nele aplicado, a flecha foi calculada por analogia de Mohr, pois este procedimento é de fácil aplicação para vigas com inércia variável. De acordo com Mohr, tem-se a analogia apresentada no quadro 6.1.

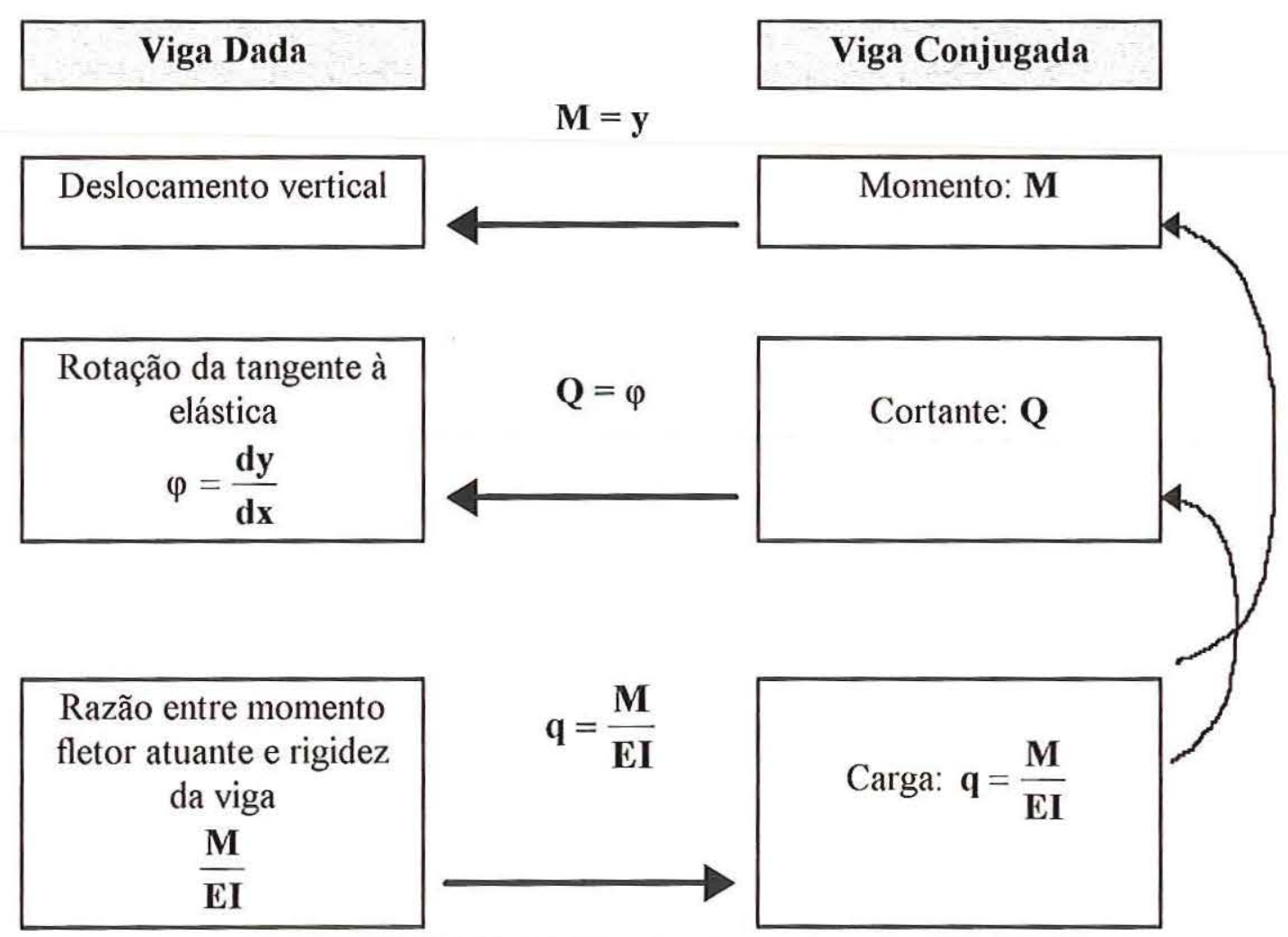

QUADRO 6.1 - Analogia de Mohr 
Como explicitado acima, para determinar a flecha do vão da seção que está sendo otimizada, basta calcular o momento fletor da viga conjugada. A carga aplicada na viga conjugada é variável, pois ela está em função do momento da viga dada que é variável, e em função da inércia da viga dada, que também é variável. Para o cálculo do momento fletor de uma viga sujeita a carga variável (viga conjugada) foi utilizado o Método dos Trapézios. Para garantir sucesso na sua utilização, é importante que a estrutura seja bem discretizada, e, para isso, foram feitas divisões internas dos elementos de viga, sendo este número de divisões um dado de entrada do programa, devendo ser coerente com o refinamento da malha.

\subsubsection{1 - Aplicação da Analogia de Mohr para Vãos Apoiados nas Extremidades}

No caso de vãos intermediários ou apoiados nas extremidades, foi utilizado o equacionamento explicitado a seguir para determinar a flecha na seção a ser otimizada.

Com relação ao tramo que representa a estrutura real, os esforços solicitantes foram obtidos pelo programa SSPO, sendo suas condições de contorno equivalentes às das vigas fictícias mostradas nas figuras abaixo.

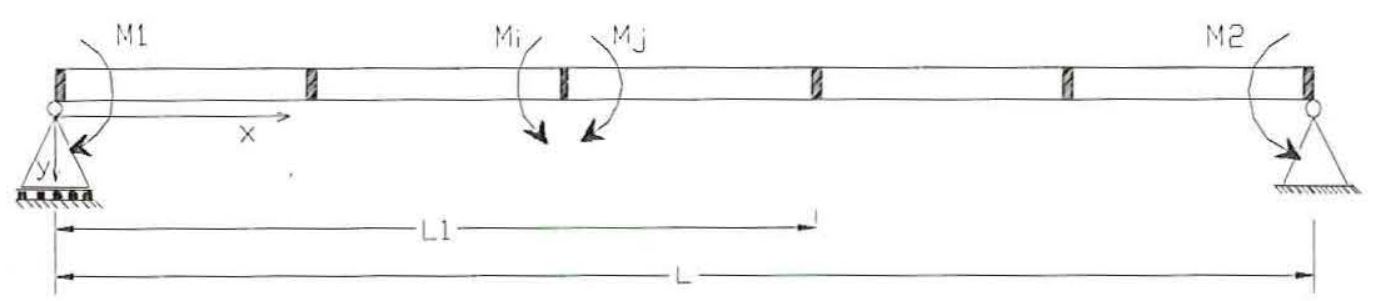

FIGURA 6.2 - Viga dada

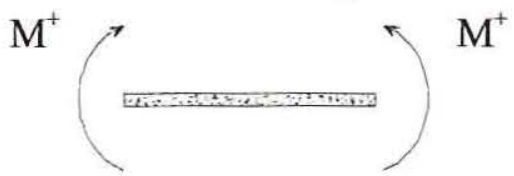

Sentido positivo do momento fletor da estrutura real 


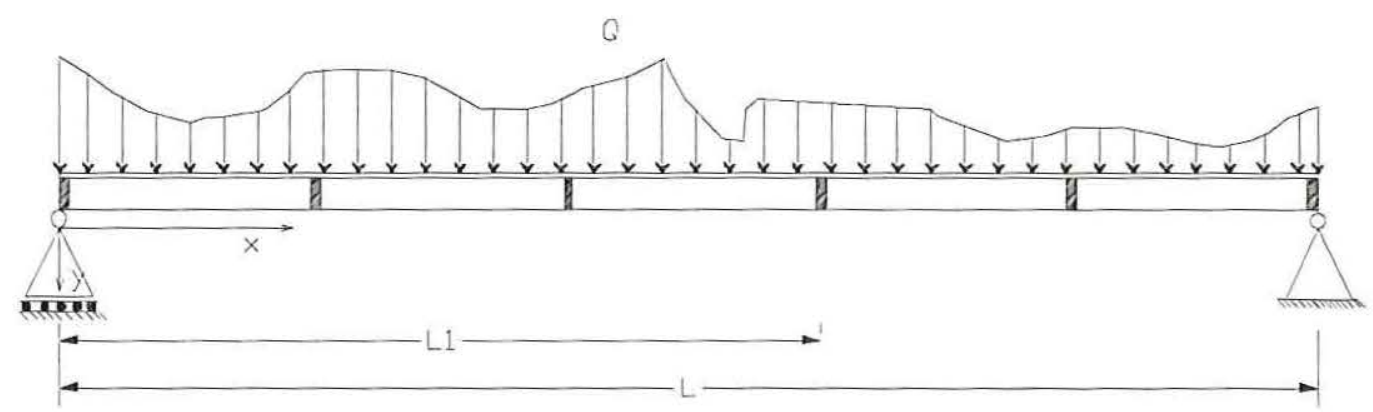

FIGURA 6.3 - Viga conjugada

Equacionamento para cálculo da flecha:

O esforço cortante à esquerda do vão na viga conjugada pode ser representado como:

$$
V_{e}=\int_{0}^{L} \frac{M_{(x)}}{E I_{(x)}} \cdot \frac{x}{L} \cdot d x
$$

A equação que representa a flecha da estrutura real é:

$$
\mathrm{F}=\mathrm{V}_{\mathrm{e}} \cdot \mathrm{L}_{1}-\int_{0}^{\mathrm{L}_{1}} \frac{\mathrm{M}_{(\mathrm{x})}}{\mathrm{EI}_{(\mathrm{x})}} \cdot\left(\mathrm{L}_{1}-\mathrm{x}\right) \cdot \mathrm{dx}
$$

\subsubsection{2 - Aplicação da Analogia de Mohr para Vãos em Balanço}

Os esforços solicitantes para estruturas com este tipo de condições de contorno são obtidos da mesma forma apresentada no item anterior.

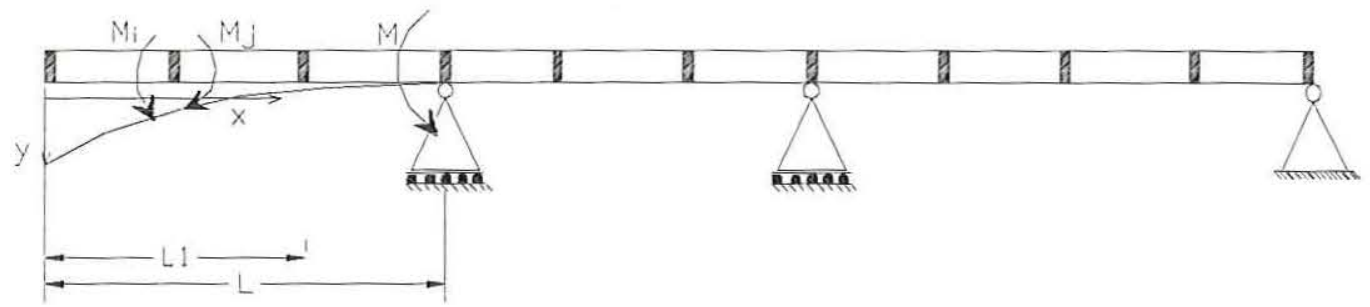

FIGURA 6.4 - Viga dada 


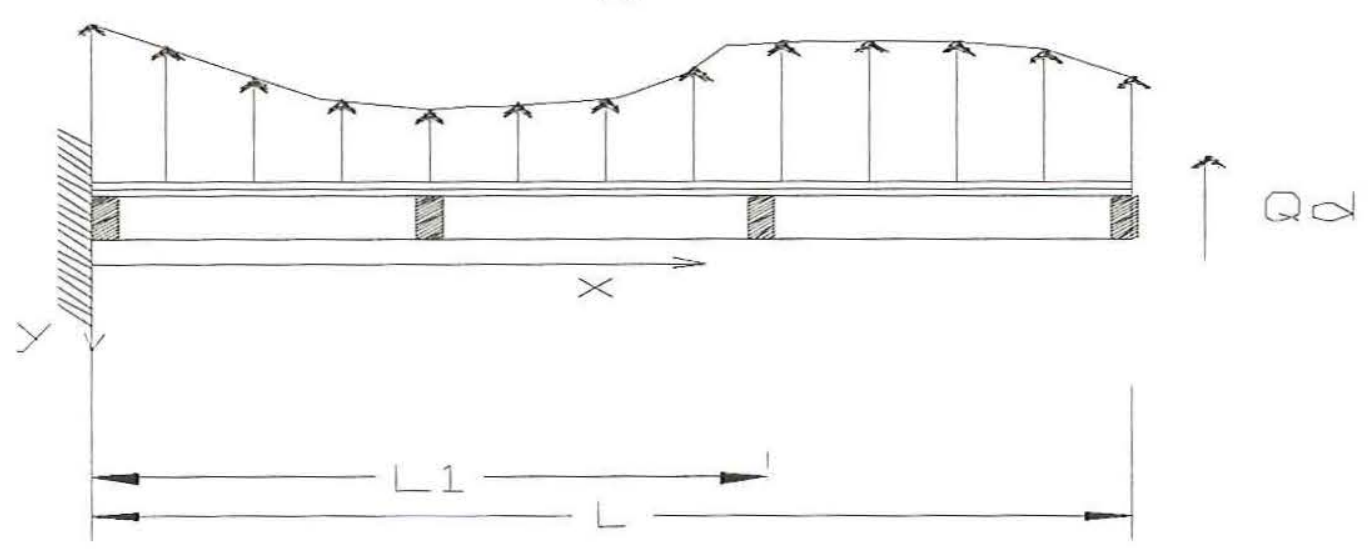

FIGURA 6.5 - Viga conjugada

Equacionamento para cálculo da flecha.

De acordo com a analogia de Mohr, o esforço cortante do tramo na viga conjugada equivale à rotação da estrutura real no mesmo local, a qual foi calculada pelo software SSPO. Assim sendo, a flecha no balanço é calculada pela seguinte equação:

$$
F=V_{d} \cdot\left(L-L_{1}\right)+\int_{L_{1}}^{L} \frac{M_{(x)}}{E I_{(x)}} \cdot\left(x-L_{1}\right) \cdot d x
$$

\subsection{2 - Fluência}

Foi considerado a seguinte aproximação para consideração da fluência:

$\beta=\frac{\frac{1}{r_{f}}}{\frac{1}{r_{i}}}=\frac{\frac{\varepsilon_{c}^{f}+\varepsilon_{s}^{f}}{d}}{\frac{\varepsilon_{c}^{i}+\varepsilon_{s}^{i}}{d}}=\frac{\varepsilon_{c}^{f}+\varepsilon_{s}^{f}}{\varepsilon_{c}^{i}+\varepsilon_{s}^{i}}$

$\left\{\varepsilon_{s}^{\mathrm{f}}=\varepsilon_{\mathrm{s}}^{\mathrm{i}}\right.$

$\left\{\varepsilon_{\mathrm{c}}^{\mathrm{f}}=\mathrm{m} \cdot \varepsilon_{\mathrm{c}}^{\mathrm{i}}\right.$

onde:

$\beta$ - coeficiente de fluência;

$\varepsilon_{\mathrm{s}}$ - deformação do aço; 
$\varepsilon_{\mathrm{c}}$ - deformação do concreto;

$\mathrm{m}$ - coeficiente de entrada do programa. Em geral considera-se igual à 2 quando a estrutura é carregada após o sexto mês de concretada e igual a 3 caso contrário.

\subsection{3 - Esforços Solicitantes}

É importante frisar que, em ambos os modelos, não foi considerado o esforço cortante nem o momento de torção para determinação da seção ótima. Cabe ao engenheiro de estruturas verificar estes esforços, e se os elementos estão devidamente dimensionados para absorvê-los. A respeito do momento de torção, no caso de torção de equilíbrio (resistência à torção necessária à manutenção do equilíbrio em relação às cargas e às ações externas), a grande queda de rigidez à torção significa uma grande rotação, que facilmente pode atingir um valor capaz de prejudicar a capacidade de utilização. Nestes casos, é necessária a verificação da rotação, pois esta pode ser determinante para o dimensionamento. No programa, foi introduzido um coeficiente redutor de rigidez à torção. A utilização deste coeficiente tem um efeito favorável, desde que os momentos de torção, que surgem por efeito de coação (torção de compatibilidade), frequentes em pisos de edificios, desapareçam rapidamente com o aumento da carga até a ruptura, e por conseguinte possam ser desprezados na verificação da capacidade resistente.

\section{4 - Obtenção da Seção Ótima}

Para se determinar qual seção da viga será otimizada, faz-se uma pesquisa sobre quais as seções que possuem maior momento fletor positivo, maior momento fletor negativo e maior deslocamento. Otimiza-se cada uma destas seções, e assumese para a viga a maior altura fornecida pelas três opções. Como se sabe, a maior altura satisfaz obrigatoriamente às três hipóteses, e o contrário não é verdade. Fazendo este procedimento para todas as vigas completa-se um passo de iteração. Em cada passo, é feita uma pesquisa em todos os nós da estrutura para determinarem-se as seções mais 
críticas de cada viga; desta forma, quando uma viga é otimizada, sua altura é suficiente para satisfazer às restrições impostas ao problema em todos os seus nós.

\section{5 - Precisão dos Resultados}

Neste item, serão discutidas algumas variáveis que possam causar imprecisão nos resultados obtidos com o programa SSPO. Como já comentado anteriormente, poder-se-á ter alguma diferença entre os valores ótimos para as alturas das vigas obtidas pelo modelo em questão, e a otimização da grelha como elemento único. A ordem de grandeza desta diferença é desconhecida, pois não foram encontrados, na literatura, programas que façam este tipo de estudo, mas, pelos resultados obtidos, mostrados no capítulo 9, acredita-se que não venha a ter diferença de ordem prática entre os modelos.

Como a maioria dos programas feitos com o método dos elementos finitos, é importante que a estrutura seja bem discretizada. Se for utilizada uma malha pobre, possivelmente os resultados não serão consistentes; entre outras variáveis, a rigidez dos elementos, e consequentemente da estrutura, será alterada, pois esta é determinada em função dos esforços nas extremidades dos elementos. Aconselha-se, para espaçamento da malha de estruturas padrão de pavimento, que estes tenham em torno de $50 \mathrm{~cm}$ ou que os vãos das vigas sejam divididos em 8 a 12 partes. Ressalta-se que a divisão interna da malha para obter melhor precisão no cálculo das inércias dos elementos finitos, utiliza-se de uma simplificação que é a linearização do momento fletor. Sendo assim, se a malha não for refinada o suficiente, mesmo se o número de divisões internas dos elementos for grande, não haverá precisão desejável nos resultados.

O programa dispõe de um processo iterativo, um método secante, para otimizar a estrutura, no qual uma das principais variáveis para a convergência do modelo é a rigidez dos elementos, a qual é função dos esforços neles aplicados. Então, necessariamente as inércias dos elementos são dependentes dos esforços calculados no passo de iteração anterior, o que não causa variação significativa nos resultados, uma vez que estes se confundem na iminência da convergência. Se no 
instante em que se pede ao usuário para fixar as alturas das vigas estas têm módulos muito diferentes dos expostos pela otimização, e o número máximo de iterações for pequeno, poderá haver pouca precisão nas inércias dos elementos finitos. Aconselhase para número máximo de iteração um valor igual ou superior a 20.

Existe uma pequena variação entre os resultados oferecidos pelos modelos de cálculo das flechas, como se pode ver no arquivo "*.OTI" explicitado por flecha inicial e final. Pela diferença em módulo das flechas inicial e final das vigas, pode-se analisar a coerência do refinamento da malha lançada sobre a estrutura e a convergência do modelo. É natural que os resultados não coincidam exatamente, pois eles são calculados por modelos distintos com precisões diferentes. Não foram analisadas as flechas dos elementos de placa, que com certeza seria de extrema importância para o presente trabalho.

Devido à imposição da restrição de flecha máxima ser um processo iterativo, necessitou-se estabelecer um erro. Para tal, foi considerado um erro absoluto de $0,5 \%$.

O módulo de elasticidade longitudinal do concreto é um dado de entrada do programa, o qual é considerado constante ao longo destè.

$\mathrm{Na}$ determinação do custo dos elementos estruturais não foi considerado o referente ao aço, pois este é função do detalhamento, que não é o objetivo do presente trabalho. Para determinar o custo total da estrutura, as lajes foram consideradas independentes das vigas, exceto as vigas com altura semelhante à maior espessura das lajes. Ou seja, exceto para as vigas cujas alturas se confundem com a maior espessura das lajes, não foi descontado o volume de concreto e a área de forma em comum às vigas e lajes. 


\section{7 - ANÁLISE DO MOMENTO DE INÉRCIA}

\section{1 - Introdução}

Tem-se observado na prática do concreto armado que devemos nos preocupar cada vez mais com o estado em serviço. Com o desenvolvimento tecnológico e um maior aproveitamento dos materiais trazendo como consequência estruturas mais arrojadas, não é suficiente que o engenheiro dimensione as estruturas considerando apenas a capacidade resistente do elemento estrutural. Pelo contrário, há necessidade tanto de garantir a capacidade resistente da peça quanto um perfeito comportamento no estado em serviço. Para garantir que a peça de concreto armado esteja coerentemente dimensionada para representar o estado limite de utilização, dois fatores são de importância fundamental; são eles: fissuras e flecha. Qualquer fissura que se torne visível causa ao leigo uma impressão de início de ruína ou de perigo, embora muitas vezes não representem nada disto. Para evitar a percepção das fissuras, a armadura deve ser dimensionada e disposta de tal forma que a abertura das fissuras fique imperceptível.

Tratando-se de materiais homogêneos, há muito tempo já é conhecido o cálculo de deformações (e consequentemente flechas) de estruturas, pois estes materiais apresentam leis constitutivas conhecidas. Já no caso de materiais heterogêneos, como o concreto armado, as leis de deformação são funções nãolineares, o que traz uma maior dificuldade de representação algébrica. Para tais materiais, muitas vezes na prática fazem-se aproximações no cálculo das deformações das estruturas por eles compostas, sendo estas aproximações feitas no equacionamento do problema ou por fórmulas empíricas. No caso do concreto armado, podem-se calcular de maneira análoga a materiais homogêneos, com suficiente precisão, as deformações no Estádio I, isto é, para o estado anterior ao surgimento da primeira fissura no concreto. Para as deformações entre o início do estádio II (início das fissuras) e imediatamente antes de atingir o Estádio II puro (região onde o concreto está completamente fissurado), na maioria dos casos, tem-se considerado as áreas de aço de tração e compressão e a seção transversal da peça 
excluindo-se as áreas tracionadas e levando-se em consideração a contribuição do concreto na zona tracionada através de um coeficiente empírico. No Estádio II puro a inércia do elemento é de fácil obtenção, através de um simples equacionamento.

Pela prática de projetos estruturais, vê-se que as deformações calculadas quando a peça está parcialmente fissurada, na maioria dos casos, têm valores exagerados, e, consequentemente, as vigas e lajes têm grandes alturas, pois estas estão diretamente relacionadas às inércias, que por sua vez relacionam-se às deformações. Através de ensaios sabe-se há muito tempo que a fissuração se estende por uma variação de carregamento considerável, e que, sob a ação de cargas permanentes ou frequentemente repetidas, a fissuração ocorre apenas parcialmente, de modo que as deformações são bem menores que aquelas nas quais o Estádio II tenha sido integralmente atingido. Pretende-se estudar neste capítulo uma formulação adequada para explicitar a inércia de um elemento finito de concreto armado nos Estádios I e II. Para esta inércia, serão consideradas as áreas de aço de tração e compressão, a área de concreto comprimida e também a contribuição do concreto entre fissuras.

\section{2 - Momento Crítico de fissuração}

O momento crítico de fissuração será definido segundo a proposta para revisão da NB-1, apresentada no III Simpósio EPUSP sobre Estruturas de Concreto. Para seções retangulares, propõe-se que o momento resistente tenha módulo igual a:

$$
M_{r}=\frac{b_{w} \cdot h^{2}}{3} \cdot f_{t},
$$

onde $f_{t}=0,53 \cdot f_{c t \text {,sup }}$, para seções submetidas a flexão simples. De acordo com a regulamentação atual, no item 7.4.5.3 do CEB-FIP tem-se a seguinte expressão para determinar a resistência do concreto à tração no instante em que a primeira fissura é esperada:

$$
\mathrm{f}_{\mathrm{ct}, \text { sup }}=0,39 \cdot \sqrt[3]{\mathrm{f}_{\mathrm{ck}}^{2}}
$$




\section{3 - Momento de Inércia à Flexão}

Assim como o momento crítico de fissuração, a inércia à flexão também será definida segundo a proposta para revisão da NB-1, apresentada no III Simpósio EPUSP sobre Estruturas de Concreto GRAZIANO (1993).

Para se determinar a inércia da viga dada, são consideradas duas situações: antes e depois de se atingir o momento de fissuração. Antes da peça atingir o momento de fissuração, é considerada a inércia no Estádio I, ou seja,

$$
\mathrm{I}_{0}=\frac{\mathrm{b}_{\mathrm{w}} \cdot \mathrm{h}^{3}}{12},
$$

e, após atingir o momento de fissuração, a inércia será calculada segundo a fórmula empírica de BRANSON, através de uma rigidez equivalente para o elemento finito de barra.

Segundo a proposta da Norma, quando o diagrama de momentos tiver um único sinal, a rigidez da viga será determinada na seção mais solicitada. No entanto, quando houver reversão de sinais no diagrama de momentos, dever-se-á analisar cada trecho de mesmo sinal no diagrama, determinando-se a rigidez representativa daquele trecho pela sua seção mais solicitada, tomando-se como inércia equivalente daquele vão a média ponderada da rigidez de cada trecho pelo seu respectivo comprimento.

Embora a forma de avaliação da flecha imediata em vigas através de uma rigidez equivalente para o tramo seja suficientemente aproximada, pretende-se refinar ainda mais os resultados utilizando uma rigidez equivalente para o elemento finito de viga. Uma das dificuldades de execução deste modelo (rigidez variável para cada elemento finito) é que não se encontra na literatura uma formulação para tal situação. Quando é explicitada uma fórmula ou uma equação que possa ser utilizada para cada seção da viga, esta é geralmente em função da curvatura, não da inércia. Este obstáculo propôs uma discussão interessante: qual coeficiente é mais adequado para a fórmula de BRANSON quando se deseja determinar a flecha imediata através do momento de inércia próprio de cada elemento finito? Para a curvatura, que é analisada em cada seção ou nó da malha da estrutura, sugere-se que este coeficiente (m) seja igual a 4. E para o cálculo da rigidez equivalente, constante para cada vão da viga, módulo igual a 3. Com o intuito de responder a esta questão, serão analisados alguns 
exemplos no decorrer do capítulo, através dos quais será decidido que coeficiente utilizar na determinação da inércia dos elementos.

\subsection{1 - Momento de Inércia Segundo BRANSON}

O cálculo da inércia equivalente proposto por BRANSON considera a área de concreto comprimida, as áreas de aço da seção transversal e o concreto entre as fissuras.

A determinação do momento de inércia da peça toda fissurada, pode ser explicitado pelo seguinte equacionamento:

$$
\begin{gathered}
X=\frac{-n \cdot\left(A_{s}+A_{s}^{\prime}\right)}{b_{w}}+\sqrt{\left[\frac{n \cdot\left(A_{s}+A_{s}^{\prime}\right)}{b_{w}}\right]^{2}+\frac{2 \cdot n}{b_{w}} \cdot\left(d \cdot A_{s}+d^{\prime} \cdot A_{s}^{\prime}\right)} \\
I_{2}=\frac{b_{w} \cdot X^{3}}{3}+n \cdot A_{s} \cdot(d-X)^{2}+n \cdot A_{s}^{\prime} \cdot\left(X-d^{\prime}\right)^{2} \\
n=\frac{E_{s}}{E_{c}}
\end{gathered}
$$

onde: $\mathrm{E}_{\mathrm{s}}=$ módulo de elasticidade do aço;

$\mathrm{E}_{\mathrm{c}}=$ módulo de elasticidade do concreto;

$\mathrm{b}_{\mathrm{w}}=$ base da seção transversal;

$\mathrm{d}=$ altura útil da seção transversal;

d' = distância do C.G. da armadura de compressão à face da seção mais comprimida;

$\mathrm{A}_{\mathrm{s}}=$ armadura longitudinal devido ao esforço de tração;

$\mathrm{A}_{\mathrm{s}}{ }^{\prime}=$ armadura longitudinal devido ao esforço de compressão;

$X=$ posição da linha neutra;

$\mathrm{I}_{2}=$ momento de inércia a flexão no Estádio II puro.

Para momentos de serviço superiores ao de fissuração, $M_{k}>M_{r}$, região na qual é válida a fórmula empírica de BRANSON, o momento de inércia equivalente $\mathrm{I}_{\mathrm{eq}}$, é definido mediante a expressão: 


$$
\begin{gathered}
(E \cdot I)_{e q}=\left\{\left(\frac{M_{r}}{M_{k}}\right)^{m} \cdot I_{0}+\left[1-\left(\frac{M_{r}}{M_{k}}\right)^{m}\right] \cdot I_{2}\right\} E_{c} \rightarrow M_{k}>M_{r} \\
I_{0}=\frac{b_{w} \cdot h^{3}}{12}
\end{gathered}
$$

onde:

$\mathrm{M}_{\mathrm{r}}=$ momento fletor de fissuração ou momento resistente;

$\mathrm{M}_{\mathrm{k}}=$ momento fletor de serviço;

$\mathrm{I}_{0}=$ momento de inércia da seção no Estádio I;

$\mathrm{I}_{2}=$ momento de inércia da seção totalmente fissurada;

$\mathrm{E}_{\mathrm{c}}=$ módulo secante de elasticidade do concreto;

$\mathrm{m}=$ coeficiente discutido no item 7.3, a ser definido no decorrer do capítulo. Para inércia constante no tramo, $\mathrm{m}=3$.

OBS.: neste trabalho será considerado constante o valor de E.

Para o cálculo das curvaturas das seções analisadas isoladamente, segundo BRANSON, tem-se:

$$
\left(\frac{1}{r}\right)_{e q}^{-1}=\left(\frac{M_{r}}{M_{k}}\right)^{m} \cdot\left(\frac{1}{r}\right)_{0}^{-1}+\left[1-\left(\frac{M_{r}}{M_{k}}\right)^{m}\right] \cdot\left(\frac{1}{r}\right)_{I I}^{-1} \rightarrow M_{k}>M_{r}
$$

onde:

$\mathrm{M}_{\mathrm{r}}=$ momento fletor de fissuração;

$\mathrm{M}_{\mathrm{k}}=$ momento fletor de serviço;

$\left(\frac{1}{\mathrm{r}}\right)_{0}=$ curvatura em Estádio I para a seção de concreto simples;

$\left(\frac{1}{r}\right)_{\text {II }}=$ curvatura em Estádio II.

$\mathrm{m}=$ coeficiente discutido no item 7.3, será definido no decorrer do capítulo. Para a utilização da fórmula de BRANSON em função da curvatura de cada seção, considera-se $\mathrm{m}=4$. 


\section{4 - Análise Numérica do coeficiente "m"}

Pretende-se neste item, através de conceitos e de exemplos práticos, definir o módulo de " $m$ " mais adequado para ser utilizado quando a inércia da viga varia para cada elemento finito. Como os valores 3 e 4 foram obtidos através de fórmulas empíricas, seria incoerente aplicar um tratamento matemático na busca da solução do problema. Por isso, este coeficiente será determinado optando pela segurança, ou seja, a escolha deste valor deverá satisfazer a ambos os modelos.

Devido à inércia do elemento de viga ser variável em função dos esforços nele aplicados, e estes diferem-se ao longo do elemento finito, foi considerada a seguinte simplificação para se determinar esta inércia: dividiu-se o elemento em um número de partes iguais definido pelo usuário, e para cada extremidade dessas partes foi calculado o momento fletor, através de uma linearização dos momentos das extremidades do elemento, que são determinados pelo SSPO. Após obtidos estes valores, foi feita uma média aritmética das inércias de cada divisão interna da malha, a qual resultou na inércia à flexão do elemento de barra. Esta linearização do momento é de aproximação razoável, pois a malha lançada na estrutura deve ter refinamento suficiente para fornecer bons resultados.

Para os exemplos analisados neste capítulo, considerem-se os seguintes dados:

As alturas das vigas serão determinadas pelo programa de otimização desenvolvido no presente trabalho, e as bases têm módulo igual a $15 \mathrm{~cm}$.

Características das ações externas: $q=20 \mathrm{kN} / \mathrm{m}$

Características dos materiais:

- custo do aço: $\mathrm{R} \$ 1,7885 / \mathrm{kg}$;

- custo do concreto das vigas: $\mathrm{R} \$ 131,3900 / \mathrm{m}^{3}$;

- custo da forma das vigas: $\mathrm{R} \$ 24,7666 / \mathrm{m}^{2}$;

- custo do concreto das lajes: $\mathrm{R} \$ 131,3900 / \mathrm{m}^{3}$;

- custo da forma das lajes: $\mathrm{R} \$ 24,7666 / \mathrm{m}^{2}$;

$\checkmark$ CA-50A; fck $\geq 20 \mathrm{MPa}$;

$\diamond$ deformação máxima do aço: $\varepsilon_{\mathrm{s}}=\frac{\text { fyd }}{\mathrm{E}}=\frac{4348}{2100000}=2,0705 \%$; 
$\checkmark$ deformação máxima do concreto: $3,5000 \%$;

$\diamond$ limite da flecha do vão apoiado nos extremos: L / 300;

$\diamond$ limite da flecha do vão em balanço: L / 150;

- taxa máxima de armadura: $4 \%$;

- distância do C.G. da armadura positiva à face da viga mais comprimida: $3 \mathrm{~cm}$;

- cobrimento das armaduras: $2 \mathrm{~cm}$;

- coeficiente de majoração das ações externas $\left(\gamma_{\mathrm{f}}\right): 1,4$;

- coeficiente de minoração da resistência característica do concreto $\left(\gamma_{c}\right): 1,4$;

- coeficiente de minoração da resistência característica do aço $\left(\gamma_{s}\right): 1,15$;

* número de iterações: 20;

* número de divisões internas do elemento: 10;

* espaçamento da malha de elementos finitos: $100 \mathrm{~cm}$.

OBS: As unidades utilizadas nos exemplos são $\mathrm{cm}$ e kN.

Para cada exemplo utilizado neste capítulo foram feitas duas análise distintas: Na primeira, considerou-se a altura da viga otimizada para cada modelo, ou seja, foi determinada a altura da seção transversal ótima considerando o coeficiente " $m$ " igual a 3 e a 4, e ainda para inércia constante calculada no Estádio I. Nesta situação, como é de se esperar, as vigas têm alturas diferentes para os modelos, o que será comentado posteriormente.

Na segunda análise, consideraram-se as alturas das vigas fixas, determinadas pelo modelo que considera $m=4$. Esta opção para o coeficiente " $m$ " foi devido ao elemento apresentar menor inércia quando considerada a mesma altura da viga para os três modelos. Por conseguinte, as restrições do problema serão satisfeitas por todos os modelos, fato que não seria verdade caso se optasse pela altura ótima fornecida quando se utiliza $\mathrm{m}=3$ ou a inércia no Estádio $\mathrm{I}$. 


\subsection{1 - Exemplo - Viga Biapoiada}

Considera-se a seguinte viga:

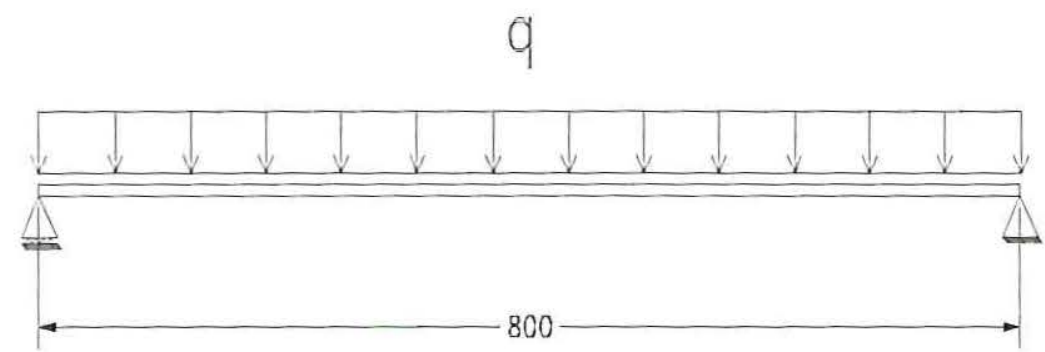

FIGURA 7.1 - Viga biapoiada

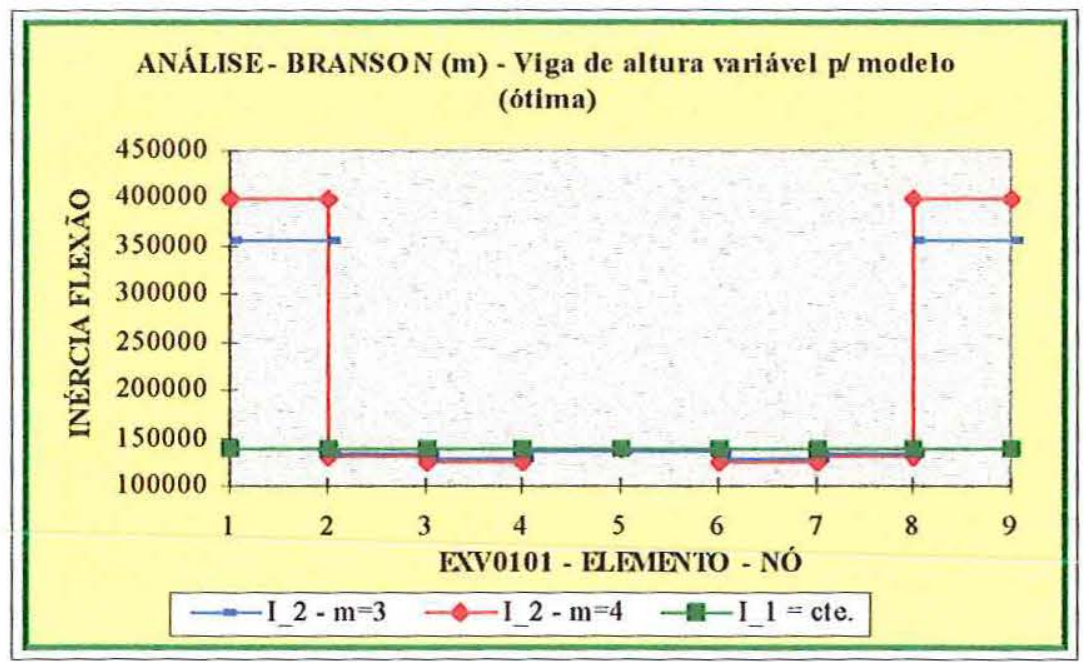

GRÁFICO 7.1 - Inércia relativa às alturas ótimas

Como pode ser visto no gráfico 7.1, as inércias dos elementos da viga, quando se considera o concreto fissurado, são praticamente constantes, sendo estas de módulo mais elevado nas seções mais armadas. Isto ocorre pelo fato que, neste tipo de estrutura, isostática, não há redistribuição dos esforços. Exceto perto dos apoios, onde o momento atuante é menor que o momento resistente, as inércias obtidas com o coeficiente $\mathrm{m}=3$ ou 4 e pelo Estádio I praticamente coincidem, embora esses modelos apresentem alturas ótimas diferentes. Este resultado é coerente, pois a ordem de grandeza da rigidez da estrutura deve ser a mesma para todos os modelos, uma vez que estes devem satisfazer à restrição de flecha máxima. 


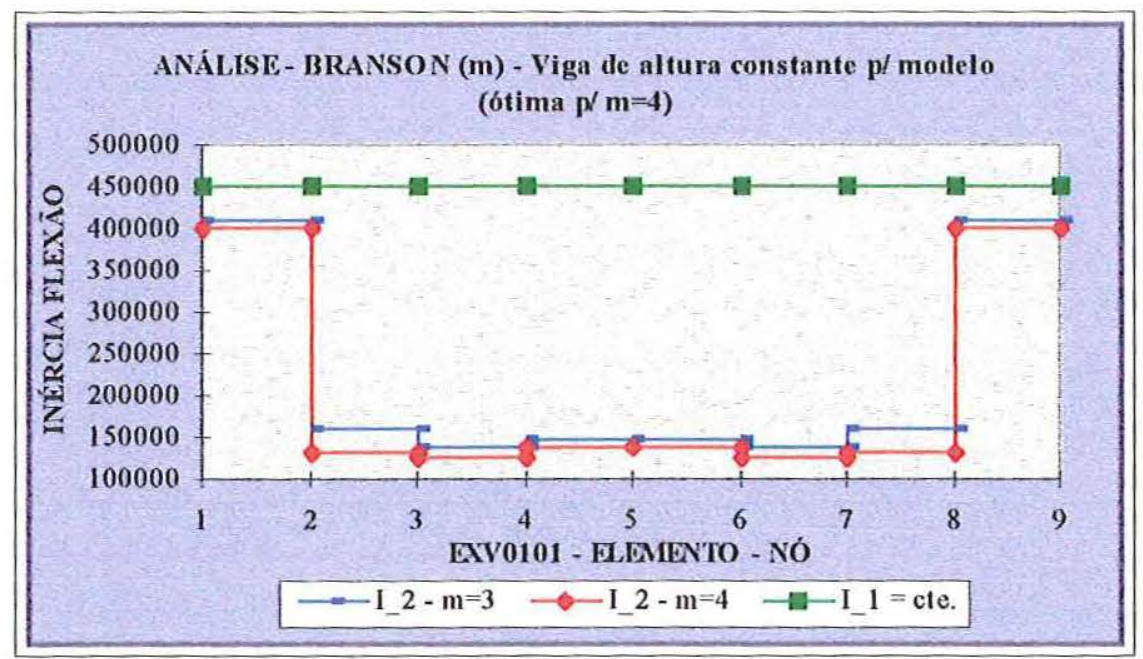

GRÁFICO 7.2 - Inércia relativa às alturas determinadas com $\mathrm{m}=4$

Observa-se que ao considerar-se a altura ótima obtida com $m=4$, a rigidez determinada pelos outros modelos é maior, garantindo assim que nesta situação os resultados estarão a favor da segurança. 


\subsection{2 - Exemplo - Viga com 2 Tramos}

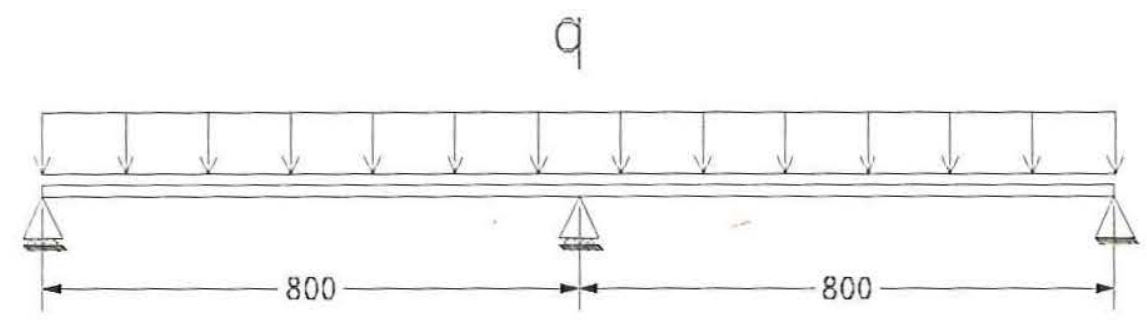

FIGURA 7.2 - Viga com dois tramos

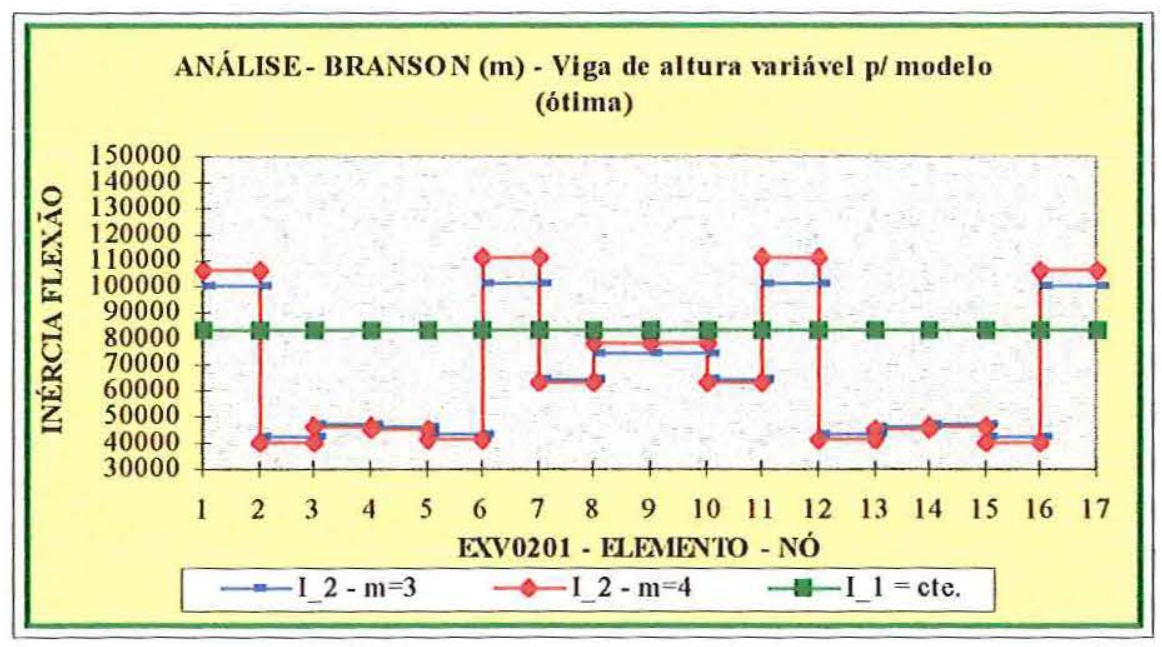

GRÁFICO 7.3 - Inércia relativa às alturas ótimas

No gráfico 7.3, as inércias dos elementos da viga, quando se considera o concreto fissurado, são bastante variáveis. Isto ocorre pelo fato de que neste tipo de estrutura, hiperestática, ocorre redistribuição dos esforços, o que fica claro ao se observar a variação das inércias dos elementos ao longo da viga . Os elementos que têm maior rigidez são aqueles onde o momento atuante é menor que o resistente, no local de transição entre momento fletor positivo e negativo e próximo aos apoios extremos quando não têm balanço. Ressalta-se que a altura da viga obtida com o modelo que considera a inércia no Estádio I não foi determinada pela restrição de flecha máxima, como os demais modelos, por isso, esta se apresenta um pouco maior que nos outros exemplos em condições semelhantes. Embora esses modelos apresentem alturas ótimas diferentes, as inércias obtidas com o coeficiente $m=3$ ou 4 
praticamente coincidem nas regiões onde a peça está fissurada, mostrando mais uma vez a coerência dos resultados.

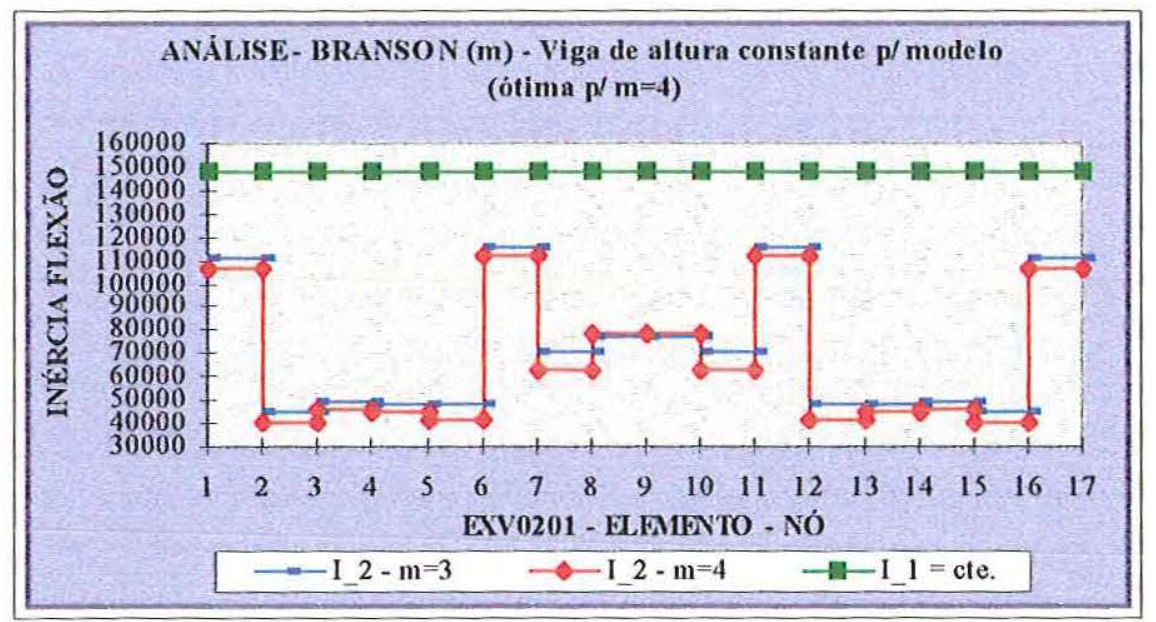

GRÁFICO 7.4 - Inércia relativa às alturas determinadas com $m=4$

Assim como na estrutura isostática, no gráfico 7.4 pode-se observar que o modelo com $\mathrm{m}=4$ determina inércia de menor valor para a estrutura, porém não muito distante do caso $\mathrm{m}=3$, obtendo com isto resultados a favor da segurança, e sem ir de encontro à economia. Já quando comparado à inércia constante, Estádio I, a rigidez desta é bem maior, mas como é mais distante ainda da representação do comportamento do material, quando utilizada é necessário majorar os resultados. 


\subsection{3 - Exemplo - Viga com 3 Tramos}

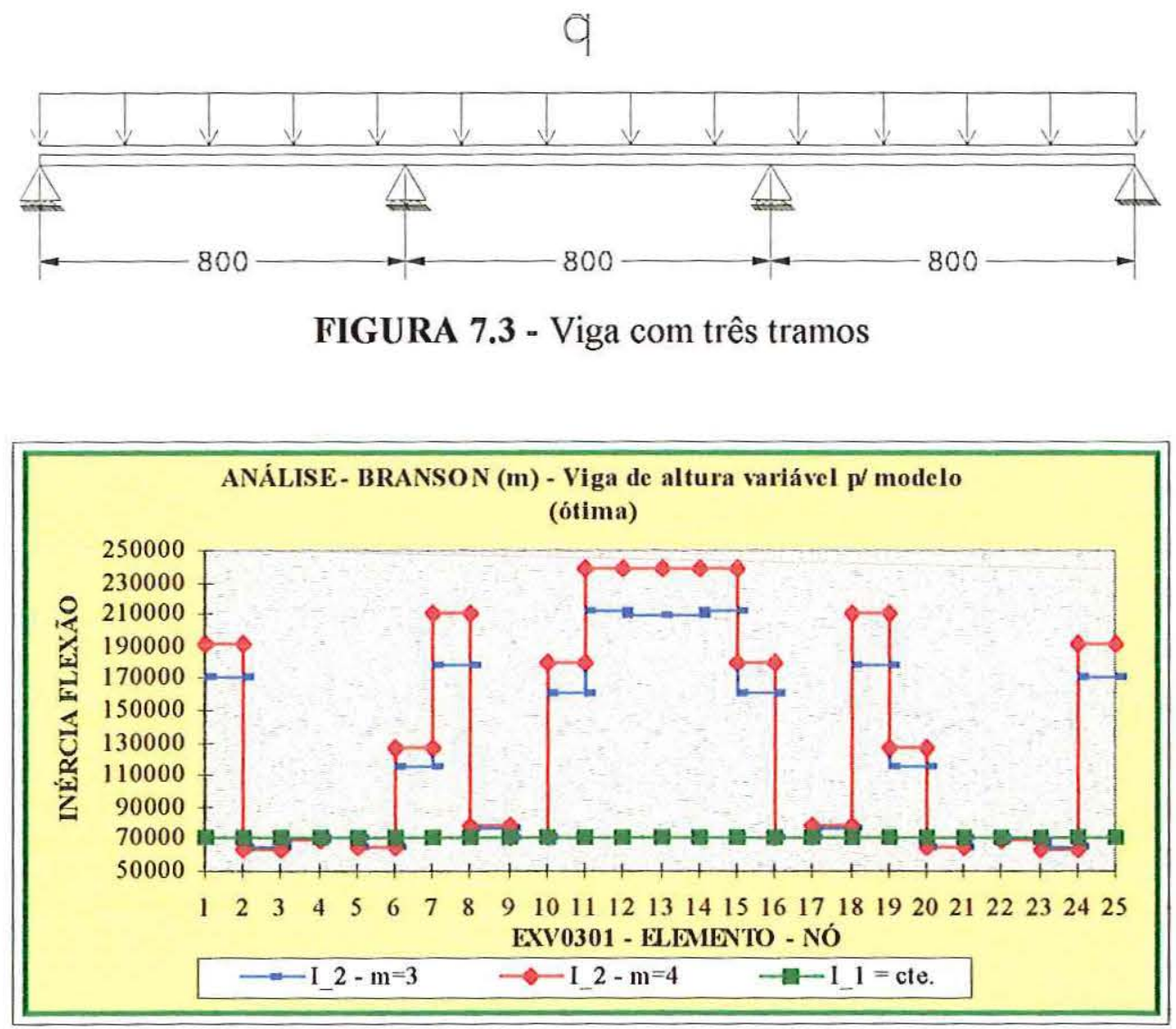

GRÁFICO 7.5 - Inércia relativa às alturas ótimas

Da mesma forma que na viga com dois tramos, observa-se no gráfico 7.5 , que as inércias dos elementos, quando se considera o concreto fissurado, são bastante variáveis. $\mathrm{O}$ tramo central apresenta maior rigidez, pois este é menos solicitado; com esta característica, ele absorve mais esforço, e consequentemente alivia os vãos adjacentes, obtendo-se um melhor comportamento estrutural. 


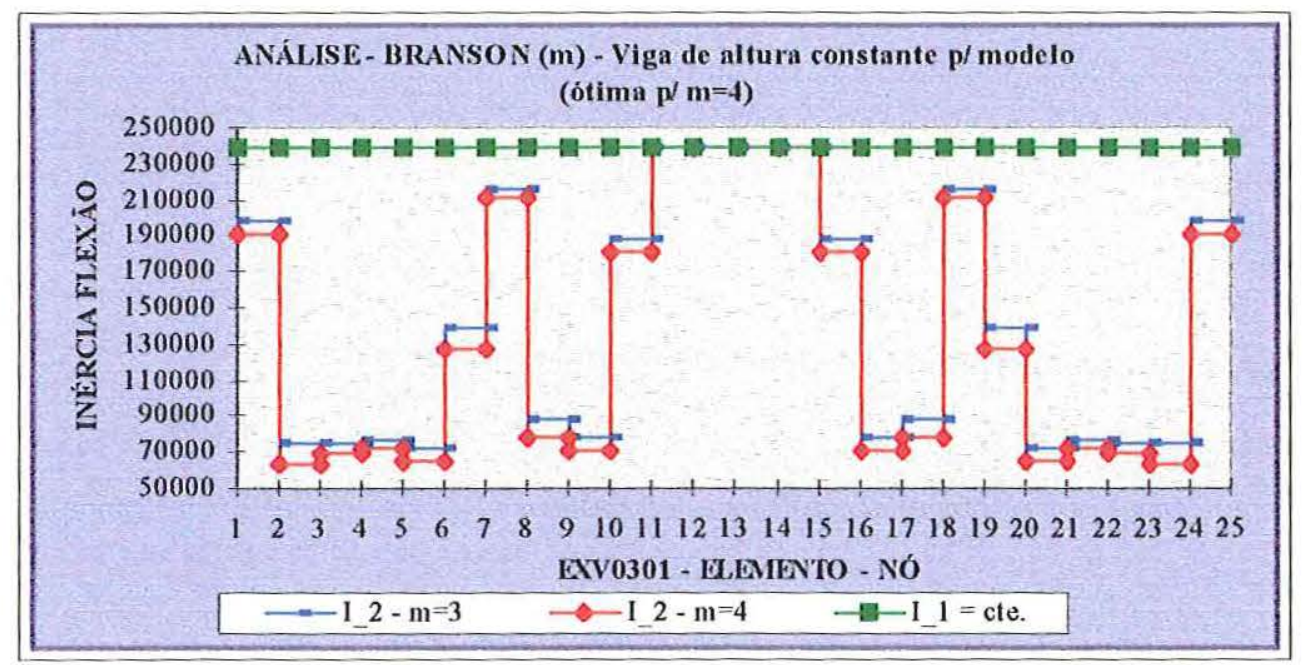

GRÁFICO 7.6 - Inércia relativa às alturas determinadas com $\mathrm{m}=4$

Observa-se que a diferença entre os módulos de rigidez apresentados pelos modelos com $\mathrm{m}=3$ e $\mathrm{m}=4$ é bem pequena, e praticamente constante ao longo da viga, tendo um decréscimo na região mais fissurada. Na região mais solicitada, também pode-se observar que há um aumento da inércia; isto ocorre devido ao aumento relativo da área de aço. Para os momentos negativos este fato é bastante importante, pois são nestas regiões que geralmente precisa-se de maior rigidez.

\subsection{4 - Exemplo - Viga em Balanço com 2 Tramos}

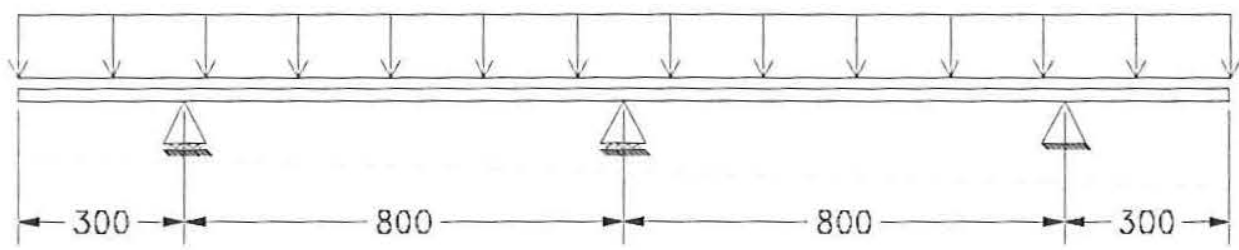

FIGURA 7.4 - Viga em balanço 


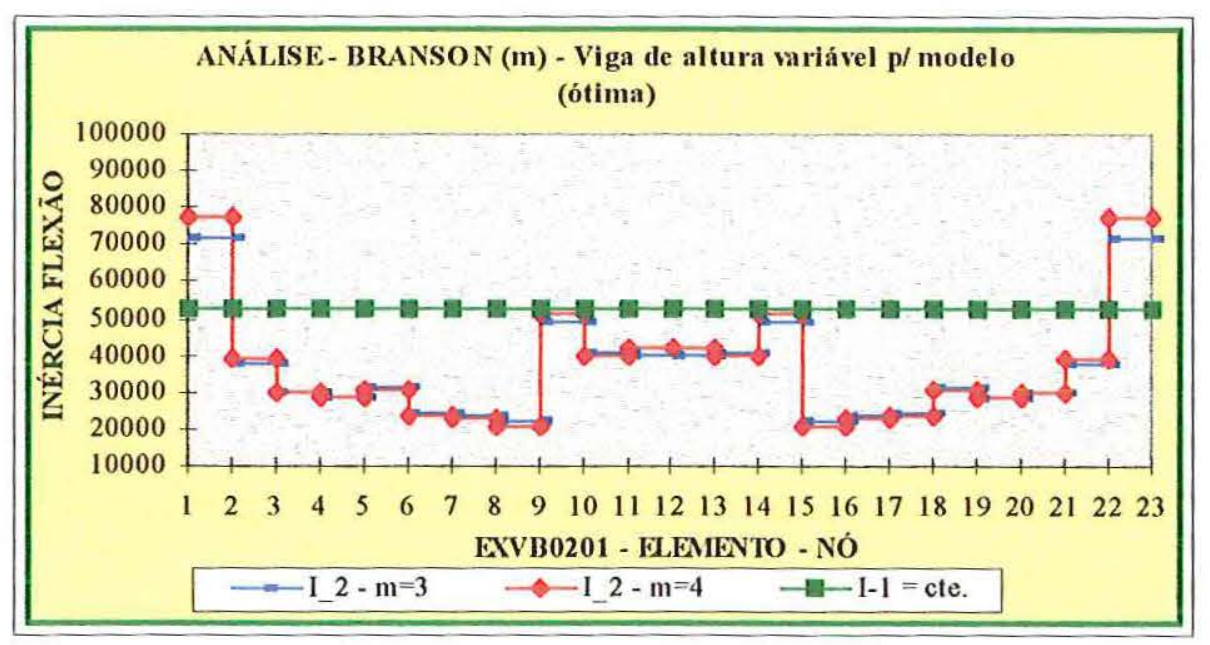

GRÁFICO 7.7 - Inércia relativa às alturas ótimas

A maior rigidez da viga localiza-se no balanço, posição que não contribui para melhorar o comportamento da estrutura. A contribuição positiva do balanço é que este alivia o apoio central, aumentando a rigidez dos elementos, e consequentemente a concentração dos esforços em torno destes.

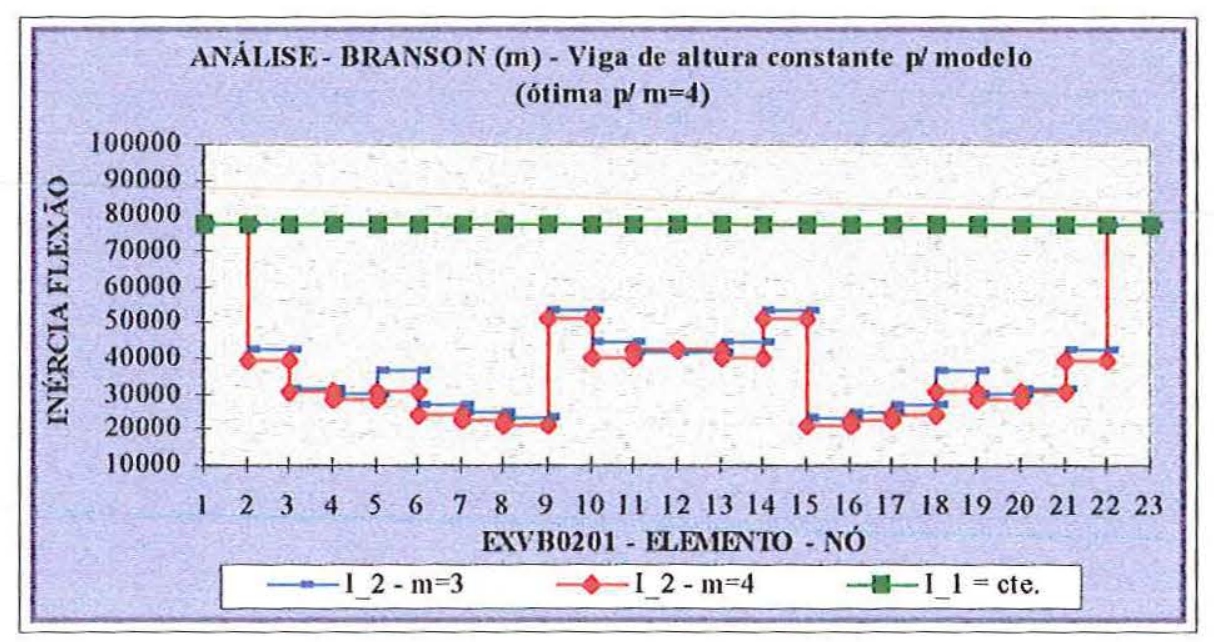

GRÁFICO 7.8 - Inércia relativa às alturas determinadas com $\mathrm{m}=4$

Como pode ser observado nos exemplos 1,2, 3 e 4, quando se utiliza a altura ótima para as vigas, obtidas com o coeficiente " $m$ " igual a 4 , a rigidez dos elementos nos demais modelos é superior ou equivalente ao mesmo. Através dos exemplos conclui-se que é mais adequado utilizar " $m$ " igual a 4, ficando-se assim sempre a favor da segurança. Percebeu-se também que com este valor de " $m$ ", não diferem muito os 
resultados dos obtidos com " $\mathrm{m}$ " igual a 3 , diferentemente do que ocorre quando a inércia é calculada no Estádio I.

Uma outra forma de se optar pelo valor de " $m$ ", esperando que os resultados estejam a favor da segurança, é analisando a própria fórmula de BRANSON. Como o momento atuante na seção é elevado a um expoente negativo, o expoente que tiver maior valor determinará a menor inércia, que por sua vez fornecerá a maior altura para a viga a fim de que a restrição de deslocamento seja satisfeita. Então, conclui-se que é mais adequado utilizar o coeficiente "m" com módulo igual a 4.

No gráfico 7.9 mostram-se as alturas ótimas das vigas dos exemplos deste capítulo para cada um dos modelos analisados.

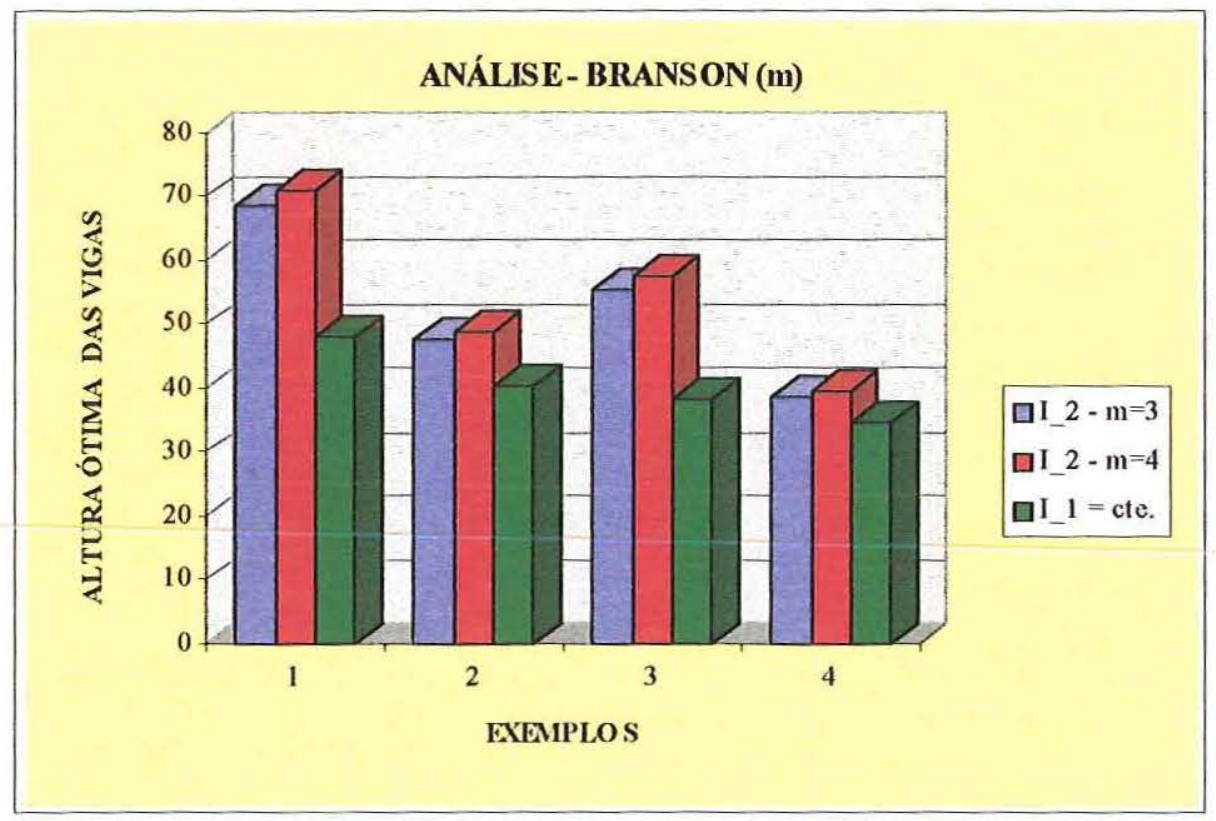

GRÁFICO 7.9 - Altura das vigas dos exemplos 1, 2, 3 e 4 obtidas pelos três modelos

Como se pode observar no gráfico 7.9, em todos os exemplos, a altura da viga obtida com "m" igual a 4 é maior que as demais, garantindo que as restrições do problema sempre serão satisfeitas em todos os modelos quando se considerar a altura ótima para "m" igual a 4. Percebe-se também que para estruturas hiperestáticas, a discrepância entre as alturas ótimas dos modelos é menor. Percebe-se ainda a variação das alturas ótimas das vigas com o grau de hiperestacidade. 


\section{5 - Cálculo do Momento de Inércia à Torção}

Para o cálculo da rigidez à torção foram consideradas apenas deformações elásticas. Devido à variação das alturas das vigas ao longo dos passos de iteração, foi formulada uma equação que determina o momento de inércia à torção em função das características geométricas da seção, possibilitando assim a variação da rigidez à torção à medida que a viga seja otimizada. Ver formulação abaixo.

$\mathrm{I}_{\mathrm{t}}=\eta \cdot \mathrm{b}_{\mathrm{w}}^{3} \cdot \mathrm{h} \quad ; \quad \mathrm{b}_{\mathrm{w}}<\mathrm{h}$

onde:

$I_{t}$ - Momento de inércia efetivo de torção;

$\mathrm{b}_{\mathrm{w}}$ - menor dos lados da seção transversal;

h - maior dos lados da seção transversal.

\begin{tabular}{|c|c|c|c|c|c|c|c|c|}
\hline $\mathrm{h} / \mathrm{b}_{\mathrm{w}}$ & 1 & 1,5 & 2 & 3 & 4 & 6 & 8 & 10 \\
\hline$\eta$ & 0,140 & 0,196 & 0,229 & 0,263 & 0,281 & 0,299 & 0,307 & 0,313 \\
\hline
\end{tabular}

TABELA 7.1 - Coeficiente $\eta$ fornecido pelo SUSSEKIND (1974)

Para peças de concreto armado, dependendo do grau de fissuração, a inércia à torção pode cair para $15 \%$ dos valores indicados nesta tabela.

Através de um programa que utiliza o método das diferenças finitas desenvolvido para problemas de torção em seções retangulares, obteve-se a tabela 7.2 . 


\begin{tabular}{|c|c|c|c|}
\hline $\mathrm{h} / \mathrm{b}_{\mathrm{w}}$ & $\eta$ & $\mathrm{h} / \mathrm{b}_{\mathrm{w}}$ & $\eta$ \\
\hline $\mathrm{l}$ & 0,140 & 3,5 & 0,27257 \\
\hline 1,2 & 0,165833 & 4,0 & 0,27975 \\
\hline 1,4 & 0,186429 & 4,5 & 0,285556 \\
\hline 1,5 & 0,195333 & 5,0 & 0,2902 \\
\hline 1,8 & 0,2166667 & 5,5 & 0,293818 \\
\hline 2,0 & 0,228 & 6,0 & 0,296833 \\
\hline 2,2 & 0,237273 & 8,0 & 0,305 \\
\hline 2,5 & 0,2488 & 9,0 & 0,30778 \\
\hline 2,8 & 0,2575 & 10,0 & 0,3099 \\
\hline 3,0 & 0,262667 & & \\
\hline
\end{tabular}

TABELA 7.2 - Coeficiente $\eta$ gerado via diferenças finitas

Utilizando-se os 19 pontos da tabela 7.2 , foi feita uma regressão numérica resultando numa função ALOMÉTRICA CURVILINEAR, obtendo um $r=0,9959$, sendo $\eta$ obtido em função de $b_{w}$ e $h$ cuja expressão é:

$$
\eta=0,1468297 \cdot\left[\left(\frac{h}{b_{w}}\right)^{\left(0,7271532-0,4155907 \cdot \log \left(\frac{h}{b_{w}}\right)\right)}\right]
$$

logo, o momento de inércia à torção em função de $b_{w} \mathrm{e} h$ é dado por:

$$
I_{t}=0,1468297 \cdot\left[\left(\frac{h}{b_{w}}\right)^{\left(0,7271532-0,4155907 \cdot \operatorname{LOG}\left(\frac{h}{b_{w}}\right)\right)}\right] \cdot b_{w}^{3} \cdot h
$$




\section{8 - EXPERIMENTAÇÃO NUMÉRICA}

Neste capítulo, através de exemplos práticos, tentar-se-á mostrar o desempenho do software desenvolvido. Para os exemplos mostrados no decorrer do texto, será verificada a convergência do programa, percebendo-se que, independente das alturas iniciais fornecidas às vigas, o custo da estrutura sempre converge a um valor mínimo, mostrando assim que os resultados obtidos dizem respeito a um mínimo global da função objetivo. As alturas das vigas tendem a convergir a um mesmo valor, em geral menor que o usado na prática.

No dia a dia do cálculo de projetos estruturais, para pavimentos convencionais, usa-se, para pré-dimensionamento e muitas vezes o próprio dimensionamento, altura para as vigas referentes a $8 \%$ do vão, em caso de vigas com mais de um tramo, e $10 \%$, quando a viga é biapoiada. Sempre que conveniente, os resultados obtidos serão comparados a estes valores, tomando-os como referência.

Em um dos exemplos, para se ter noção de comportamento estrutural, será verificada a variação das alturas das vigas em função das espessuras das lajes. Além disto, será analisado, também através de um dos exemplos, o refinamento da malha de elementos finitos lançada na estrutura.

Por fim, comparar-se-ão resultados de estruturas já executadas por alguns escritórios da região com os obtidos processando a mesma estrutura no programa SSPO. Acredita-se que, com essas análises, pelo menos fisicamente, se prova o objeto do presente trabalho.

\section{1 - Exemplos}

Exceto quando explicitado, as características citadas a seguir serão utilizadas nos exemplos mostrados no decorrer deste capítulo. São elas:

- custo do aço: $\mathrm{R} \$ 1,7885 / \mathrm{kg}$;

- custo do concreto das vigas: $\mathrm{R} \$ 131,3900 / \mathrm{m}^{3}$;

- custo da forma das vigas: $\mathrm{R} \$ 24,7666 / \mathrm{m}^{2}$;

- custo do concreto das lajes: $\mathrm{R} \$ 131,3900 / \mathrm{m}^{3}$; 
- custo da forma das lajes: $\mathrm{R} \$ 24,7666 / \mathrm{m}^{2}$;

$\diamond \mathrm{f}_{\text {ck }}=20 \mathrm{MPa}$. ; aço tipo CA-50A;

$\diamond \mathrm{E}_{\mathrm{c}}=0,9 \cdot 6600 \cdot \sqrt{\mathrm{f}_{\mathrm{ck}}+3,5} \quad \mathrm{f}_{\mathrm{ck}}(\mathrm{MPa})$

$\checkmark$ deformação mínima do aço: $\varepsilon_{\mathrm{s}}=\frac{\text { fyd }}{\mathrm{E}_{\mathrm{s}}}=\frac{4348}{2100000}=2,0705 \%$;

$\diamond$ deformação máxima do concreto: $3,5000 \%$;

$\diamond$ limite da flecha do vão apoiado nos extremos: L / 300;

$\diamond$ limite da flecha do vão em balanço: L / 150;

- taxa máxima de armadura: $4 \%$;

- distância do C.G. da armadura positiva à face mais comprimida: $3 \mathrm{~cm}$;

- cobrimento da armadura: $2 \mathrm{~cm}$;

- coeficiente de majoração das ações externas $\left(\gamma_{\mathrm{f}}\right): 1,4$;

- coeficiente de minoração da resistência característica do concreto $\left(\gamma_{\mathrm{c}}\right): 1,4$;

- coeficiente de minoração da resistência característica do aço $\left(\gamma_{\mathrm{s}}\right): 1,15$;

* número de iterações: 20 ;

* número de divisões internas do elemento: 10;

* o cálculo da inércia será feito com a fórmula empírica de BRANSON.

OBS: - As unidades utilizadas nos exemplos são cm e kN;

- Os custos dos materiais foram tirados da revista Construção $n^{\circ} 2523$ junho 17/96.

Quando as estruturas forem analisadas como pavimento, as ações externas aplicadas à elas serão distribuídas transversalmente e uniformemente ao longo das vigas (V1 à V9) e das lajes. Quando a estrutura for considerada como grelha, as ações provenientes das lajes serão distribuídas nas vigas adequadamente, de tal forma que o somatório das ações externas seja o mesmo para as estruturas de grelha e de pavimento (grelha + laje). Este somatório será constante para possibilitar a comparação de custo entre os dois modelos.

Toma-se como módulo das ações externas os seguintes valores: 
Considera-se um pé-direito de $3,00 \mathrm{~m}$.

Alvenaria: $2 \mathrm{kN} / \mathrm{m}^{2} \rightarrow 3,00 \times 2=6 \mathrm{kN} / \mathrm{m}$

Lajes:

$$
\begin{array}{ll}
\text { Sobrecarga: } & =2 \mathrm{kN} / \mathrm{m}^{2} \\
\text { Piso + Contra-piso + Peso próprio: } & =3 \mathrm{kN} / \mathrm{m}^{2} \\
\text { Total: } & 5 \mathrm{kN} / \mathrm{m}^{2}
\end{array}
$$

Nos exemplos abaixo, quando é verificada a convergência do modelo, foram feitas três situações para cada problema. As alturas iniciais das vigas na primeira situação têm valores exagerados de acordo com a prática. Na segunda, têm valores modestos, que com certeza não satisfazem nem as restrições impostas pelo problema. Finalmente, na terceira situação, foram fornecidas alturas iniciais para as vigas aleatoriamente. Pretende-se com isso mostrar a convergência do modelo, pois se em situações opostas e/ou aleatórias o custo converge para o mesmo valor, pressupõe-se que este seja o mínimo global.

\subsection{1 - Exemplo - Viga Biapoiada}

Este exemplo refere-se à viga biapoiada da figura 7.1. Após o primeiro passo de iteração o problema convergiu para resultados exatos, os quais são mostrados na tabela 8.1. Esta convergência imediata já era esperada, pois a função a ser otimizada foi elaborada para uma seção transversal de uma viga qualquer, e na viga isostática não há redistribuição dos esforços.

\begin{tabular}{|c|c|c|c|c|c|c|c|}
\cline { 2 - 7 } \multicolumn{1}{c|}{} & \multicolumn{2}{c|}{ Situação 01 } & \multicolumn{2}{c|}{ Situação 02 } & \multicolumn{2}{c|}{ Situação 03 } & \multicolumn{1}{c}{} \\
\hline & $\mathrm{h}_{\mathrm{i}}$ & $\mathrm{h}_{\mathrm{opt}}$ & $\mathrm{h}_{\mathrm{i}}$ & $\mathrm{h}_{\mathrm{opt}}$ & $\mathrm{h}_{\mathrm{i}}$ & $\mathrm{h}_{\mathrm{opt}}$ & $10 \%$ vão \\
\hline V1 & 60 & 71,15 & 20 & 71,15 & 100 & 71,15 & 80 \\
\hline Custo R\$ & & 415,90 & & 415,90 & & 415,90 & \\
\hline
\end{tabular}

TABELA 8.1 - Resultados numéricos das alturas ótimas da viga

No gráfico 8.1 cada cor representa uma altura inicial diferente para a viga, mostrando claramente a convergência do modelo. A linha verde com espessura mais grossa equivale a $10 \%$ do vão, valor comumente usado na prática. 


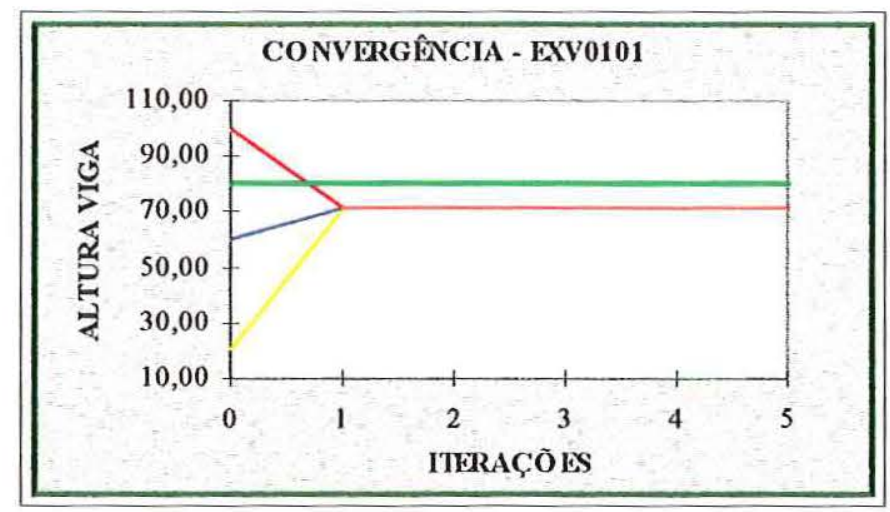

GRÁFICO 8.1 - Análise de convergência da altura da viga

\subsection{2 - Exemplo - Viga com 3 Tramos}

Devido à sua hiperesticidade e consequente capacidade de redistribuição dos esforços, a viga da figura 7.3 convergiu na quinta iteração, diferentemente do exemplo anterior. O resultado para cada situação do problema pode ser visto na tabela 8.2.

\begin{tabular}{|c|c|c|c|c|c|c|c|}
\cline { 2 - 7 } \multicolumn{1}{c|}{} & \multicolumn{2}{c|}{ Situação 01 } & \multicolumn{2}{c|}{ Situação 02 } & \multicolumn{2}{c|}{ Situação 03 } & \multicolumn{1}{c}{} \\
\hline & $\mathrm{h}_{\mathrm{i}}$ & $\mathrm{h}_{\mathrm{opt}}$ & $\mathrm{h}_{\mathrm{i}}$ & $\mathrm{h}_{\mathrm{opt}}$ & $\mathrm{h}_{\mathrm{i}}$ & $\mathrm{h}_{\text {opt }}$ & $8 \%$ vão \\
\hline V1 & 60 & 57,51 & 20 & 57,51 & 100 & 57,51 & 64 \\
\hline Custo R\$ & & 1021,13 & & 1021,13 & & 1021,13 & \\
\hline
\end{tabular}

TABELA 8.2 - Resultados numéricos das alturas ótimas da viga

A convergência para um número inteiro aconteceu após o primeiro passo de iteração, tornando-se exata apenas no quinto passo. Assim como na viga biapoiada, a altura ótima é menor que a na maioria das vezes utilizada pela boa técnica.

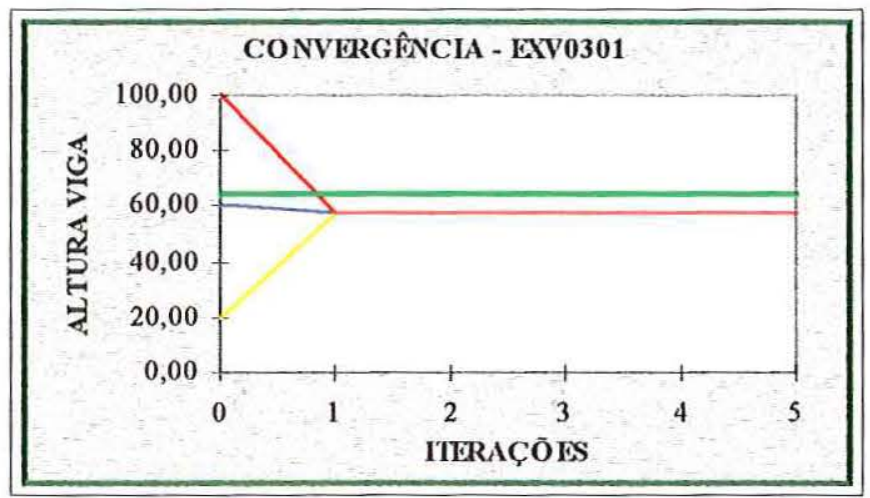

GRÁFICO 8.2 - Análise de convergência da altura da viga 


\subsection{3 - Exemplo - Grelha Composta por 9 Vigas}

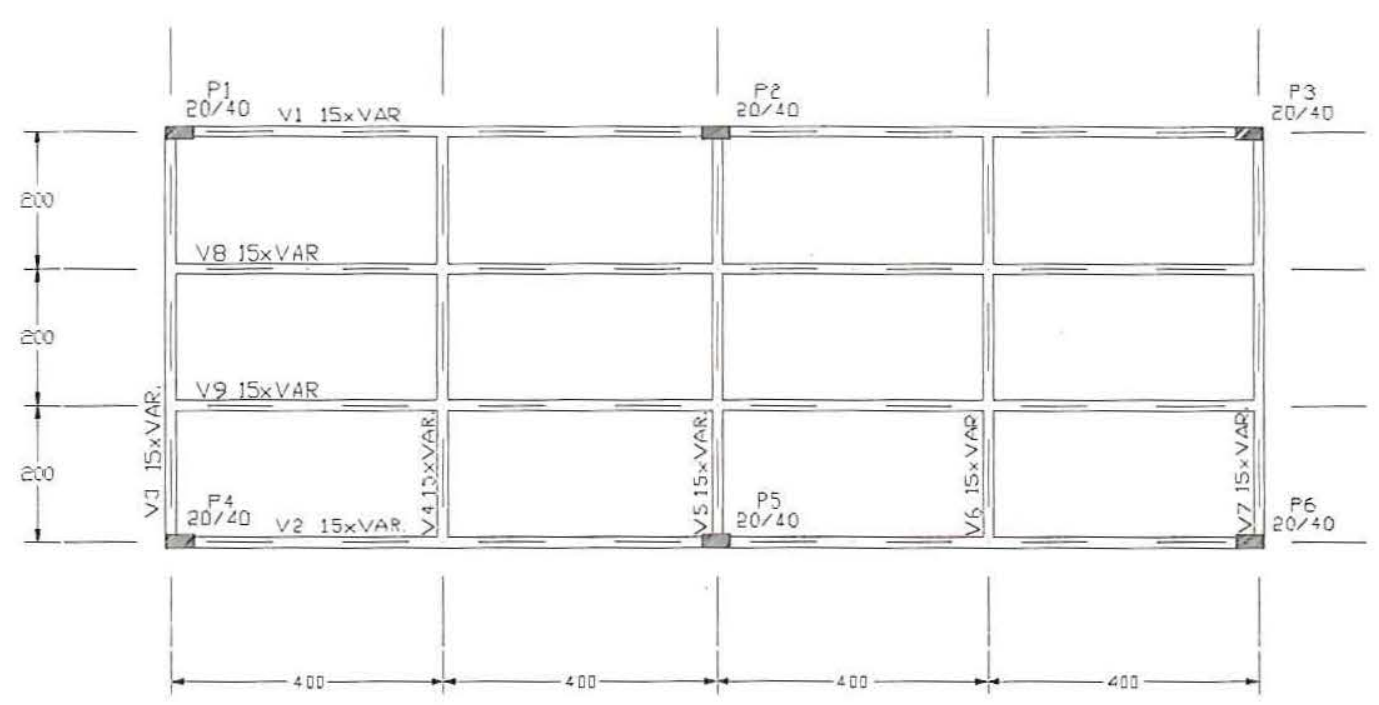

FIGURA 8.1 - Forma da grelha

Durante todos os passos iterativos, verifica-se que a restrição dominante do problema é a de deslocamento. Isto implica que uma má determinação dos vãos pode mascarar os resultados. Vale ressaltar que a definição dos vãos é necessária apenas para definir os módulos dos valores limites das flechas, por isso esta variável é de extrema importância na precisão dos resultados.

Após 20 iterações, obtiveram-se os resultados apresentados na tabela 8.3 para a grelha da figura 8.1 


\begin{tabular}{|c|c|c|c|c|c|c|c|}
\cline { 2 - 7 } \multicolumn{1}{c|}{} & \multicolumn{2}{c|}{ Situação 01 } & \multicolumn{2}{c|}{ Situação 02 } & \multicolumn{2}{c|}{ Situação 03 } & \multicolumn{1}{c}{} \\
\hline & $\mathrm{h}_{\mathrm{i}}$ & $\mathrm{h}_{\text {opt }}$ & $\mathrm{h}_{\mathrm{i}}$ & $\mathrm{h}_{\text {opt }}$ & $\mathrm{h}_{\mathrm{i}}$ & $\mathrm{h}_{\text {opt }}$ & 8 ou 10\% vão \\
\hline V1 & 100 & 47,75 & 20 & 47,72 & 60 & 47,55 & 64 \\
\hline V2 & 100 & 47,75 & 20 & 47,72 & 80 & 47,77 & 64 \\
\hline V3 & 100 & 56,44 & 20 & 56,45 & 40 & 56,42 & 60 \\
\hline V4 & 100 & 49,29 & 20 & 49,31 & 50 & 48,93 & 60 \\
\hline V5 & 100 & 64,68 & 20 & 64,71 & 80 & 64,72 & 60 \\
\hline V6 & 100 & 49,29 & 20 & 49,31 & 70 & 48,93 & 60 \\
\hline V7 & 100 & 56,44 & 20 & 56,45 & 70 & 56,42 & 60 \\
\hline V8 & 100 & 44,42 & 20 & 44,47 & 70 & 44,93 & 64 \\
\hline V9 & 100 & 44,42 & 20 & 44,47 & 40 & 44,32 & 64 \\
\hline Custo R\$ & & $3.445,65$ & & $3.446,16$ & & $3.445,03$ & \\
\hline
\end{tabular}

TABELA 8.3 - Resultados numéricos das alturas ótimas das vigas

Como se pode observar na tabela 8.3, independente das alturas iniciais fornecidas às vigas, há convergência a valores ótimos de ordem prática na engenharia, tanto para as alturas das vigas, como para o custo total da grelha (concreto + forma).

As alturas ótimas das vigas com mais de um tramo mais solicitadas são na ordem de $75 \%$ das alturas utilizadas pela boa técnica. Já para as vigas menos solicitadas, este percentual diminui para $69 \%$. Ou seja, o percentual do vão ideal, neste exemplo, para determinar as alturas das vigas com mais de um tramo é de $6 \%$. É um pouco difícil comparar este valor com o utilizado na prática (8\%), por não estar sendo considerada a deformação lenta no modelo. 


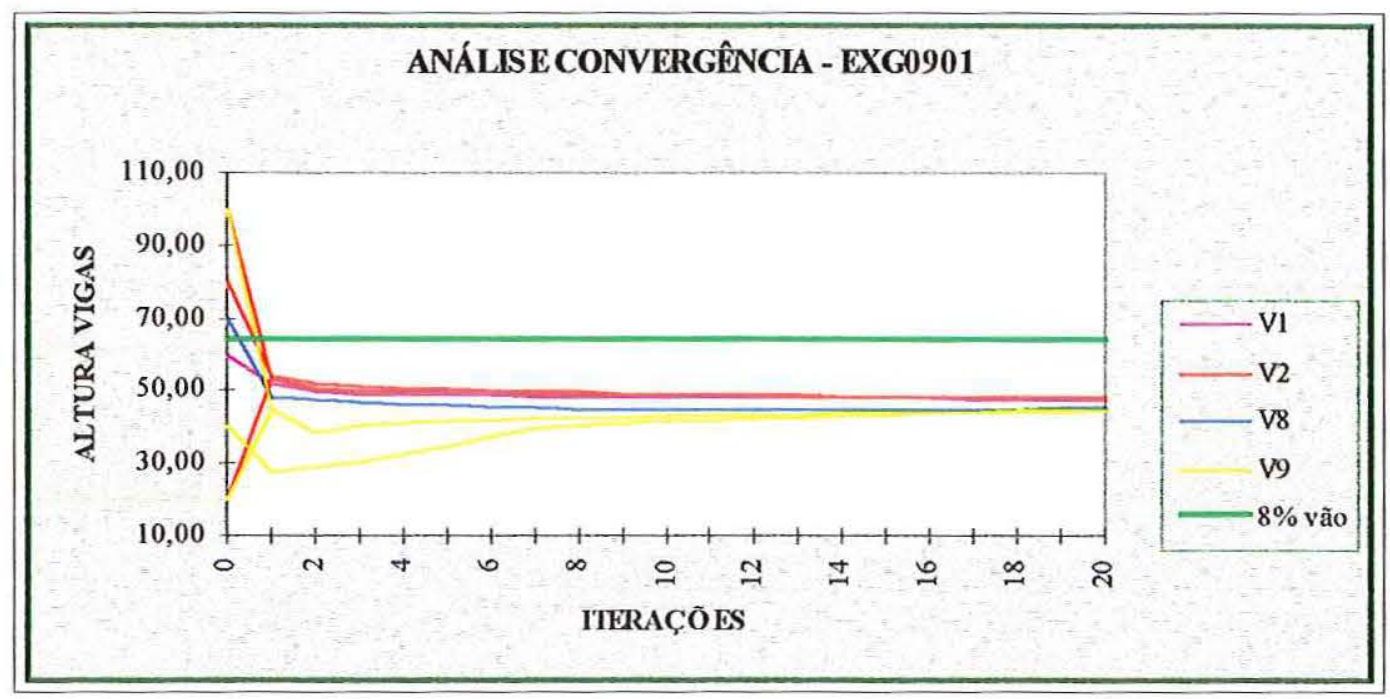

GRÁFICO 8.3 - Análise de convergência das vigas com mais de um tramo

Apenas a viga com um tramo mais solicitada, (gráfico 8.4) possui altura ótima superior à utilizada na prática. Para este tipo de viga, existe uma maior variação nos módulos das alturas ótimas que nas vigas com mais de um tramo, que, além disto, convergem mais rapidamente para uma solução final.

Percebe-se que a convergência de ordem prática das vigas com um tramo praticamente se define ao fim do primeiro passo de iteração, mas, para a estrutura como um todo, pode-se dizer que a convergência ocorre no décimo segundo passo.

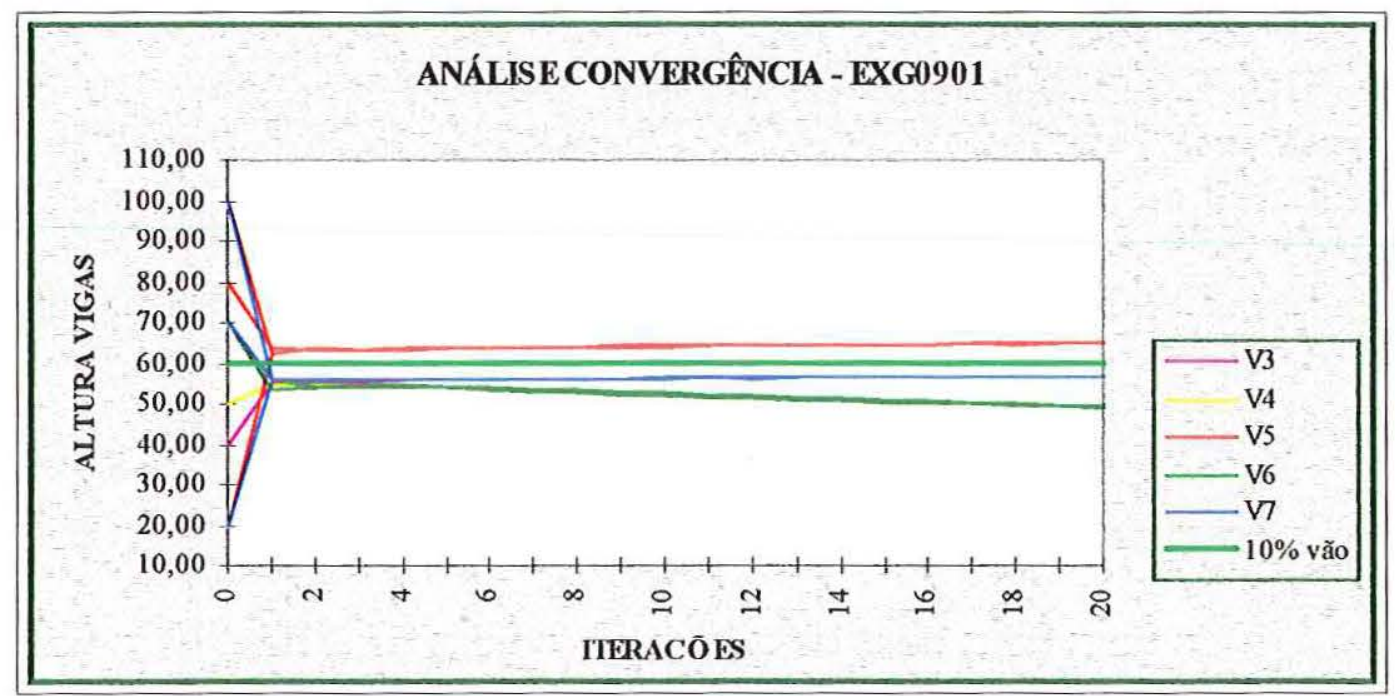

GRÁFICO 8.4 - Análise de convergência das vigas com um tramo 
Assim como nas vigas, percebe-se claramente no gráfico 8.5 a convergência para um custo mínimo da grelha. Na situação 2 , antes de se processar a estrutura, o custo é inferior ao mínimo, porque a geometria das vigas não satisfaz às condições de contorno do problema. Ou seja, as alturas iniciais fornecidas às vigas não são suficientes para suportar as ações a elas aplicadas.

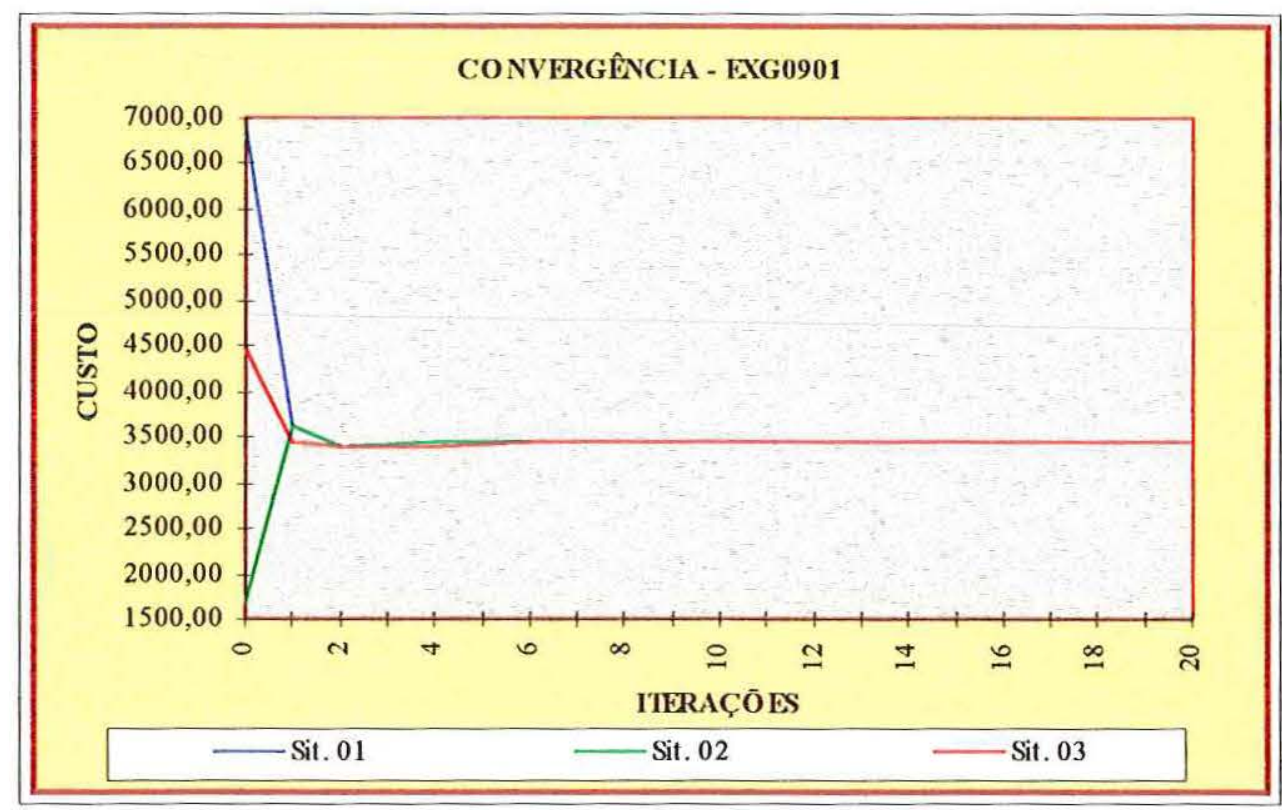

GRÁFICO 8.5 - Análise de convergência do custo

\subsection{4 - Exemplo - Pavimento Composto por 7 Vigas}

Nos próximos três exemplos, será considerado o mesmo pavimento, adicionando-se vigas a cada um deles.

A espessura das placas é de fundamental importância na análise estrutural dos pavimentos. Nos próximos exemplos, procurou-se adotar para as lajes espessuras uniformes em todos elementos, com módulo coerente com a prática em projetos estruturais. 


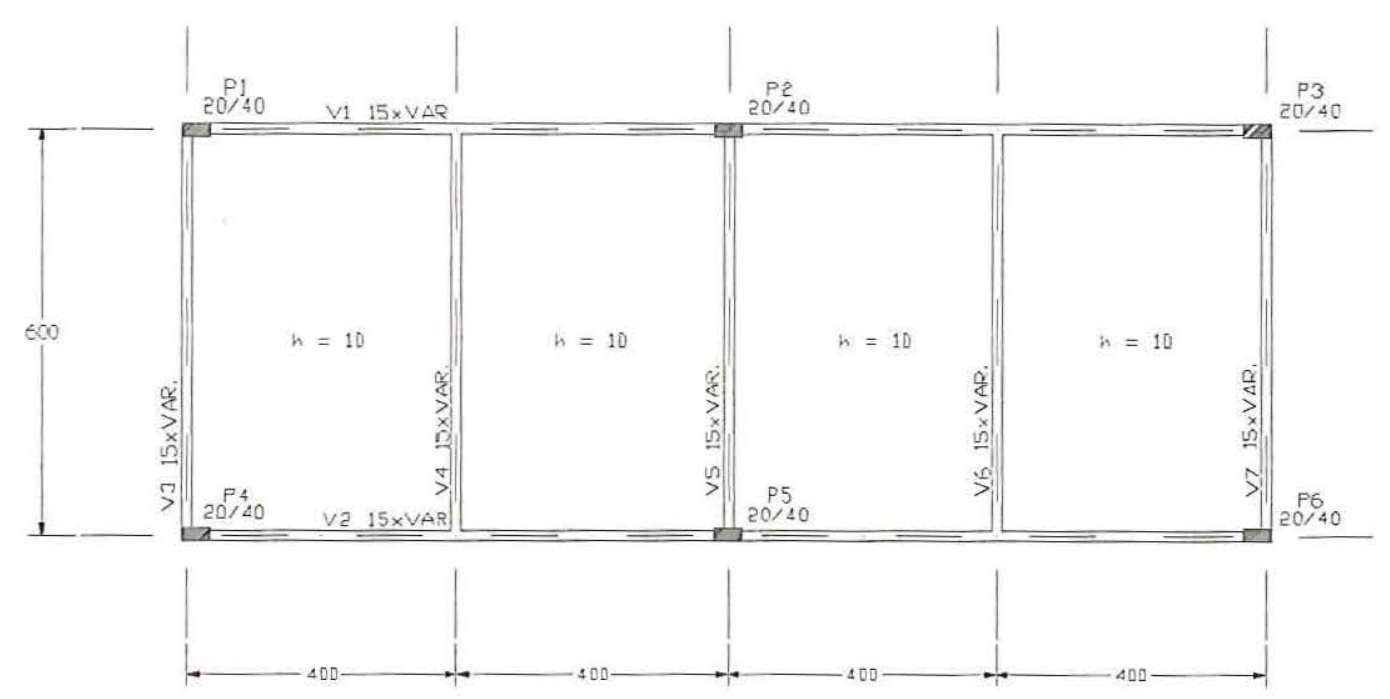

FIGURA 8.2 - Forma do pavimento

\begin{tabular}{|c|c|c|c|c|c|c|c|}
\cline { 2 - 7 } \multicolumn{1}{c|}{} & \multicolumn{2}{c|}{ Situação 01 } & \multicolumn{2}{c|}{ Situação 02 } & \multicolumn{2}{c|}{ Situação 03 } & \multicolumn{1}{c}{} \\
\hline & $\mathrm{h}_{\mathrm{i}}$ & $\mathrm{h}_{\text {opt }}$ & $\mathrm{h}_{\mathrm{i}}$ & $\mathrm{h}_{\text {opt }}$ & $\mathrm{h}_{\mathrm{i}}$ & $\mathrm{h}_{\text {opt }}$ & $\begin{array}{c}8 \text { ou 10\% } \\
\text { vão }\end{array}$ \\
\hline V1 & 100 & 49,87 & 20 & 49,86 & 20 & 49,88 & 64 \\
\hline V2 & 100 & 49,87 & 20 & 49,86 & 100 & 49,88 & 64 \\
\hline V3 & 100 & 51,21 & 20 & 51,21 & 20 & 51,19 & 60 \\
\hline V4 & 100 & 39,72 & 20 & 39,62 & 50 & 39,74 & 60 \\
\hline V5 & 100 & 61,18 & 20 & 61,23 & 30 & 61,17 & 60 \\
\hline V6 & 100 & 39,72 & 20 & 39,62 & 70 & 39,76 & 60 \\
\hline V7 & 100 & 51,21 & 20 & 51,21 & 200 & 51,19 & 60 \\
\hline Custo R $\$$ & & $2.283,72$ & & $2.282,67$ & & $2.283,79$ & \\
\hline
\end{tabular}

TABELA 8.4 - Resultados numéricos das alturas ótimas das vigas

Percebe-se que, independente dos valores iniciais fornecidos para as alturas das vigas, ocorre convergência, de ordem prática, para as mesmas alturas das vigas.

As alturas ótimas das vigas com mais de um tramo equivalem a $6,2 \%$ do vão, valor bem inferior ao utilizado na prática. Já para as vigas com um tramo, há uma grande variação neste percentual.

No gráfico 8.6 , pode-se observar a rápida convergência das vigas com mais de um tramo, em torno da sexta iteração, e a diferença entre a altura devido à boa técnica e a altura obtida no programa. Quando se considera o elemento de placa na análise, 
não existe prioridade de convergência entre as vigas hiperestáticas e isostáticas, pois ocorre redistribuição de esforços através dos elementos de placa. Isto é mais uma razão para se ter uma melhor precisão dos resultados quando se consideram as lajes no modelo.

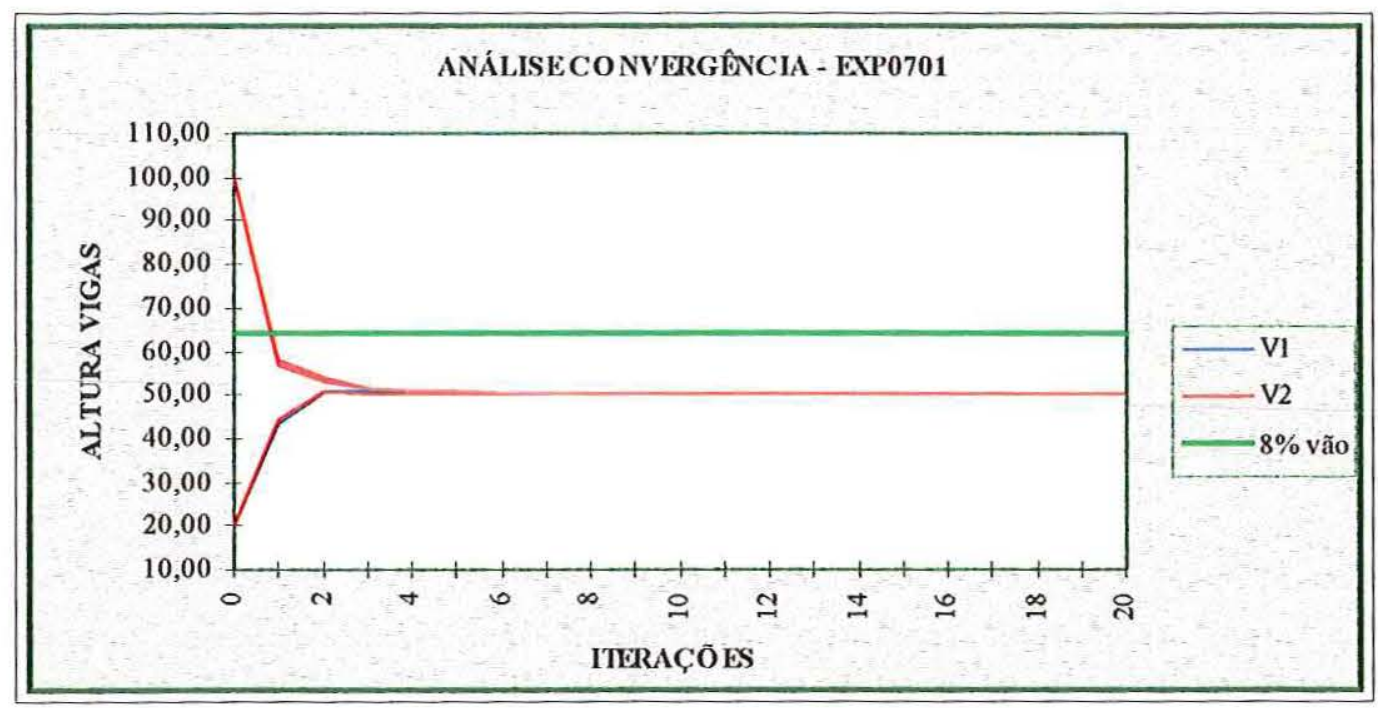

GRÁFICO 8.6 - Análise de convergência das vigas com mais de um tramo

Observa-se no gráfico 8.7 a convergência das vigas com um tramo. Pode-se dizer que a convergência de todas as vigas ocorre no décimo passo iterativo.

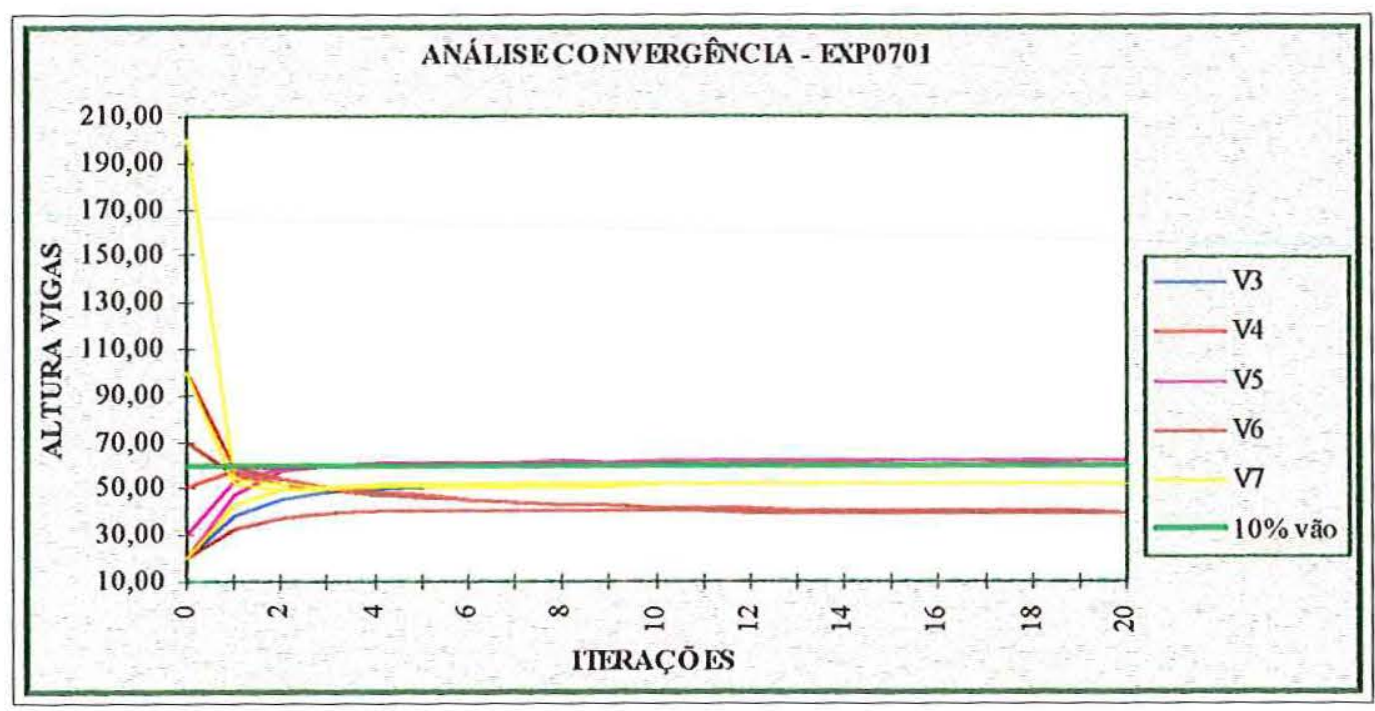

GRÁFICO 8.7 - Análise de convergência das vigas isostáticas 
- gráfico 8.8 mostra a convergência do custo da grelha a um valor único e mínimo.

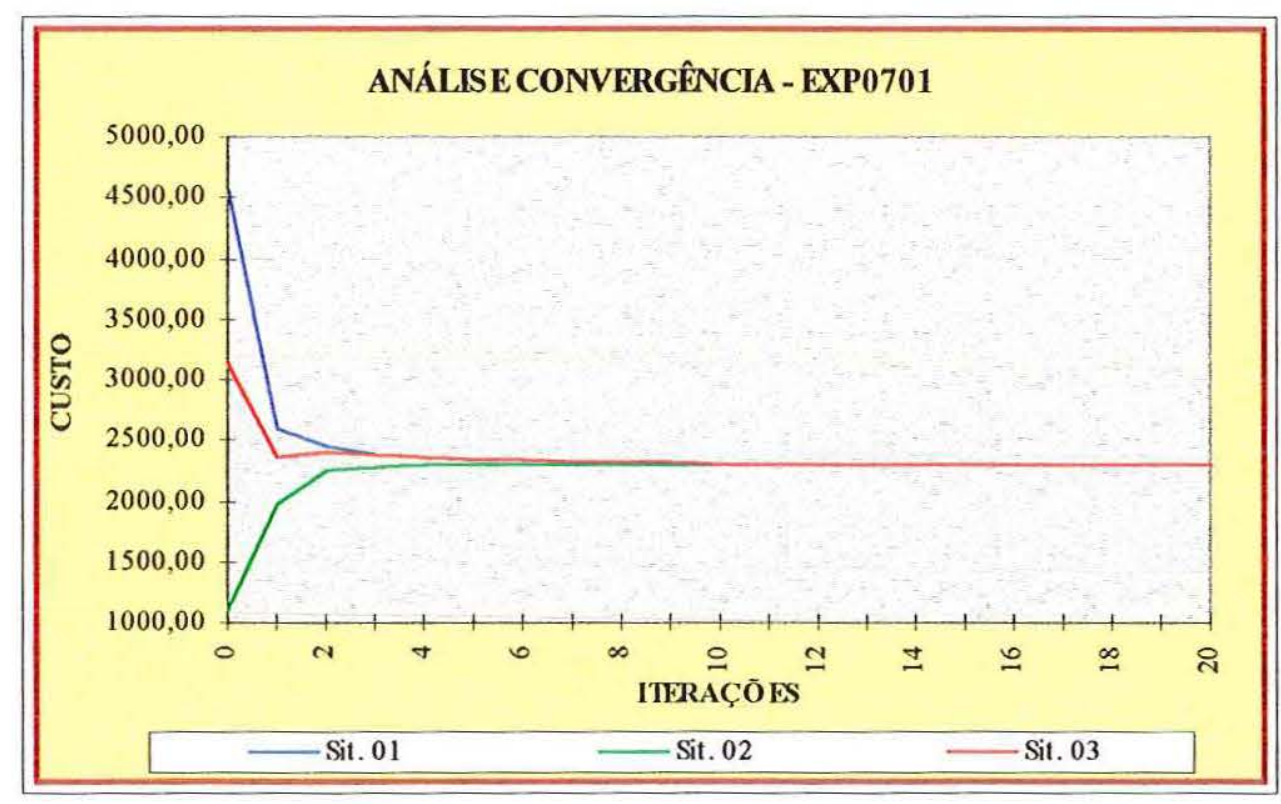

GRÁFICO 8.8 - Análise de convergência do custo

\subsection{5 - Exemplo - Pavimento Composto por 9 Vigas}

Este exemplo é semelhante ao 8.1.3 (EXG0901), diferenciando-se apenas porque neste são considerados os elementos de placa, e no outro a estrutura foi analisada apenas como grelha. O objetivo desta semelhança é a comparação entre os custos finais fornecidos pelos dois modelos. 


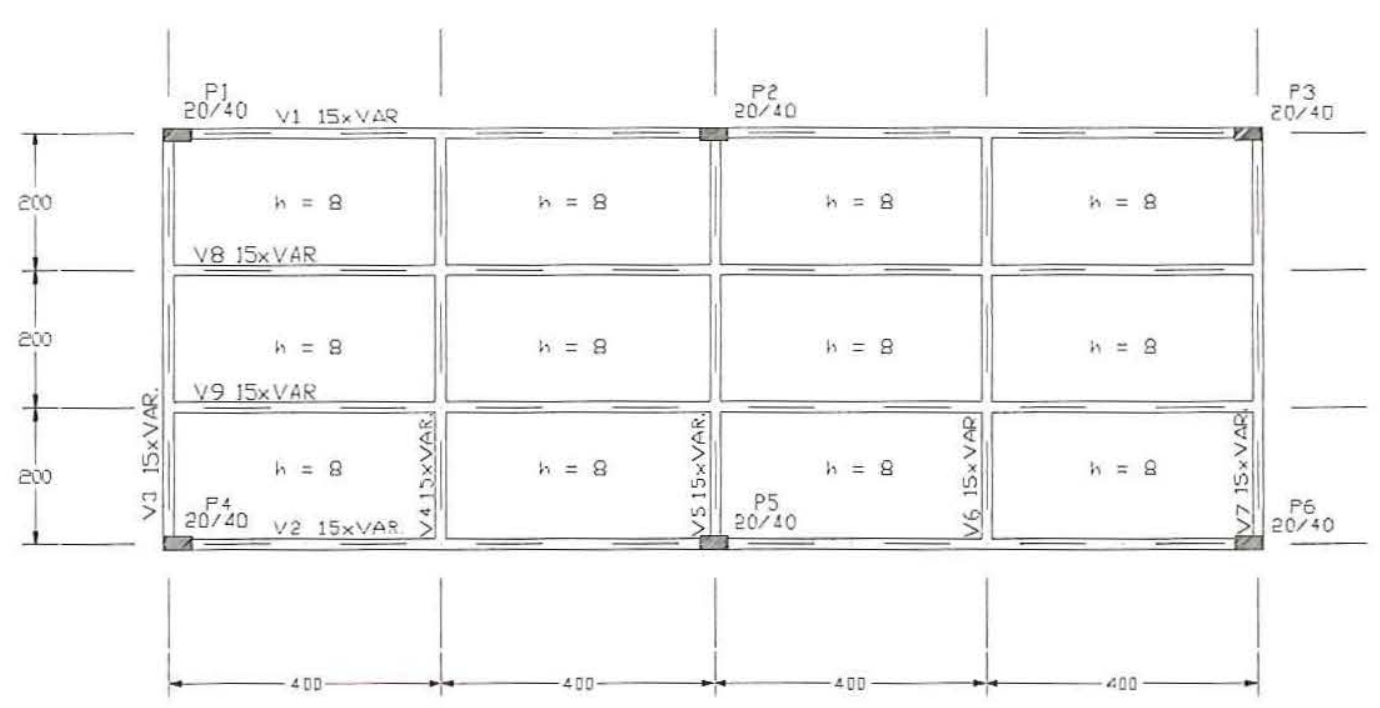

FIGURA 8.3 - Forma do pavimento

\begin{tabular}{|c|c|c|c|c|c|c|c|}
\cline { 2 - 7 } \multicolumn{1}{c|}{} & \multicolumn{2}{c|}{ Situação 01 } & \multicolumn{2}{c|}{ Situação 02 } & \multicolumn{2}{c|}{ Situação 03 } & \multicolumn{1}{c}{} \\
\hline & $\mathrm{h}_{\mathrm{i}}$ & $\mathrm{h}_{\mathrm{opt}}$ & $\mathrm{h}_{\mathrm{i}}$ & $\mathrm{h}_{\mathrm{opt}}$ & $\mathrm{h}_{\mathrm{i}}$ & $\mathrm{h}_{\text {opt }}$ & 8 ou 10\% vão \\
\hline V1 & 100 & 48,56 & 20 & 48,28 & 20 & 46,79 & 64 \\
\hline V2 & 100 & 48,56 & 20 & 48,28 & 100 & 46,85 & 64 \\
\hline V3 & 100 & 54,89 & 20 & 55,06 & 20 & 55,72 & 60 \\
\hline V4 & 100 & 44,92 & 20 & 43,52 & 50 & 33,67 & 60 \\
\hline V5 & 100 & 62,78 & 20 & 62,93 & 30 & 64,12 & 60 \\
\hline V6 & 100 & 44,92 & 20 & 43,52 & 70 & 33,71 & 60 \\
\hline V7 & 100 & 54,89 & 20 & 55,06 & 200 & 55,72 & 60 \\
\hline V8 & 100 & 37,56 & 20 & 38,26 & 25 & 42,48 & 64 \\
\hline V9 & 100 & 37,56 & 20 & 38,35 & 150 & 42,45 & 64 \\
\hline Custo R\$ & & $3.253,95$ & & $3.254,78$ & & $3.243,80$ & \\
\hline
\end{tabular}

TABELA 8.5 - Resultados numéricos das alturas ótimas das vigas

Percebe-se que quando as alturas iniciais das vigas são iguais, sejam exageradas ou inferiores à necessária, há a convergência tanto para as alturas ótimas como para o custo da grelha. Quando se inicia o processamento com alturas aleatórias e razoavelmente discrepantes, pode-se dizer que o custo converge para mesmo valor que as situações anteriores, com alturas iniciais das vigas iguais. Entretanto, há uma diferença significativa nas alturas de algumas vigas. Isto ocorre porque, se inicialmente há uma grande diferença de rigidez dos elementos de barra, 
consequentemente estes elementos bem mais rígidos absorverão muito mais cargas, iniciando o problema com uma distribuição de esforços bem perturbada. Quando a diferença das alturas iniciais das vigas não é grande, ver exemplo 8.1.3, o programa supera essa perturbação inicial sem maiores problemas, apenas a convergência fica mais lenta.

Vale salientar que essa variação inicial nas alturas das vigas não invalida o modelo, pois há uma equivalência entre as alturas das vigas, convergindo sempre a um custo mínimo para a estrutura.

Como era de se esperar, o custo desta estrutura analisada como pavimento é inferior ao da mesma analisada como grelha, sendo esta diferença da ordem de 5,9\%.

A convergência do modelo quando processado como pavimento é um pouco mais lenta que quando processado como grelha. Isto é natural porque, além dos elementos de barra, os elementos de placa também se responsabilizam pela redistribuição dos esforços. A diferença no número de iterações necessárias à convergência entre os modelos não é significativa, comparando-se com o melhor resultado que se pode obter quando se analisa a estrutura como pavimento (grelha + placas).

Observa-se no gráfico 8.9 que as vigas com mais de um tramo têm alturas sempre menores que a utilizada pela boa técnica. $\mathrm{O}$ valor percentual do vão da viga mais solicitada é da ordem de $6,0 \%$. 


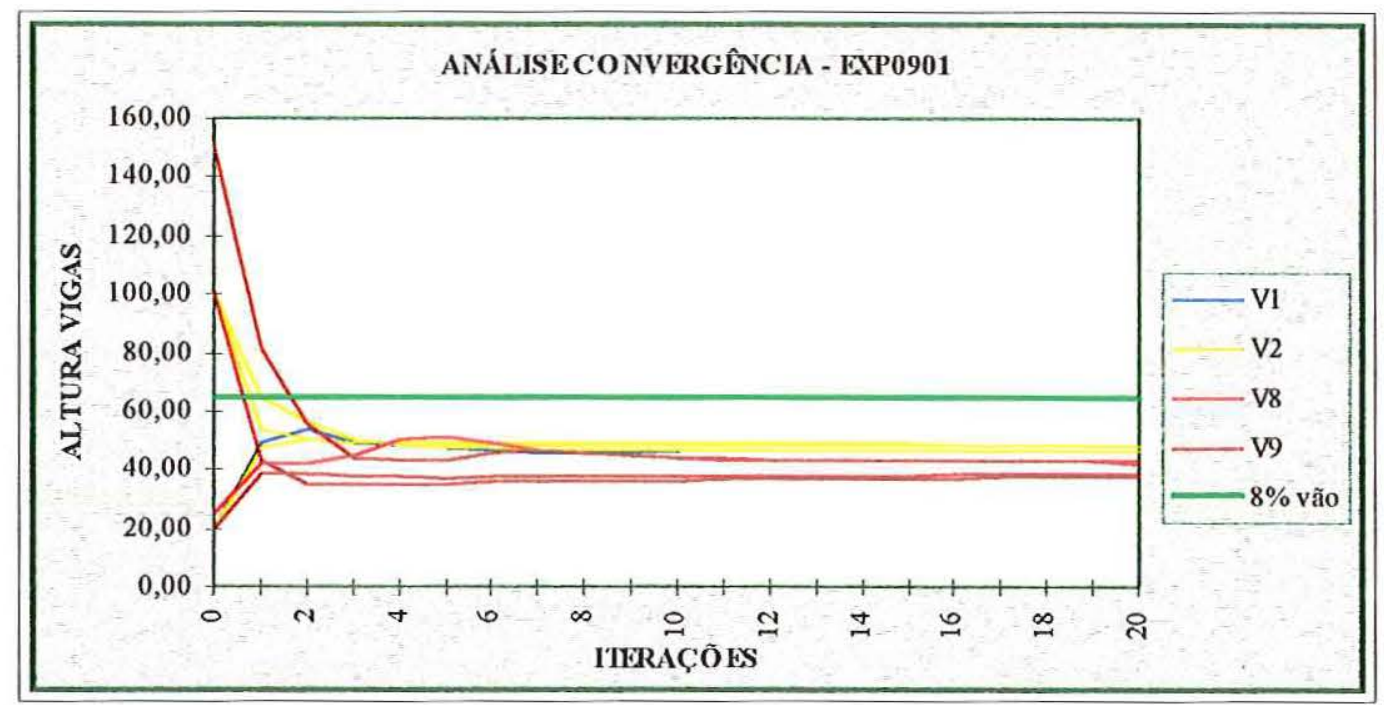

GRÁFICO 8.9 - Análise de convergência das vigas com mais de um tramo

A convergência dos valores das alturas das vigas com um tramo é verificada no gráfico 8.10. Contudo, é significante a variação percentual dos vãos.

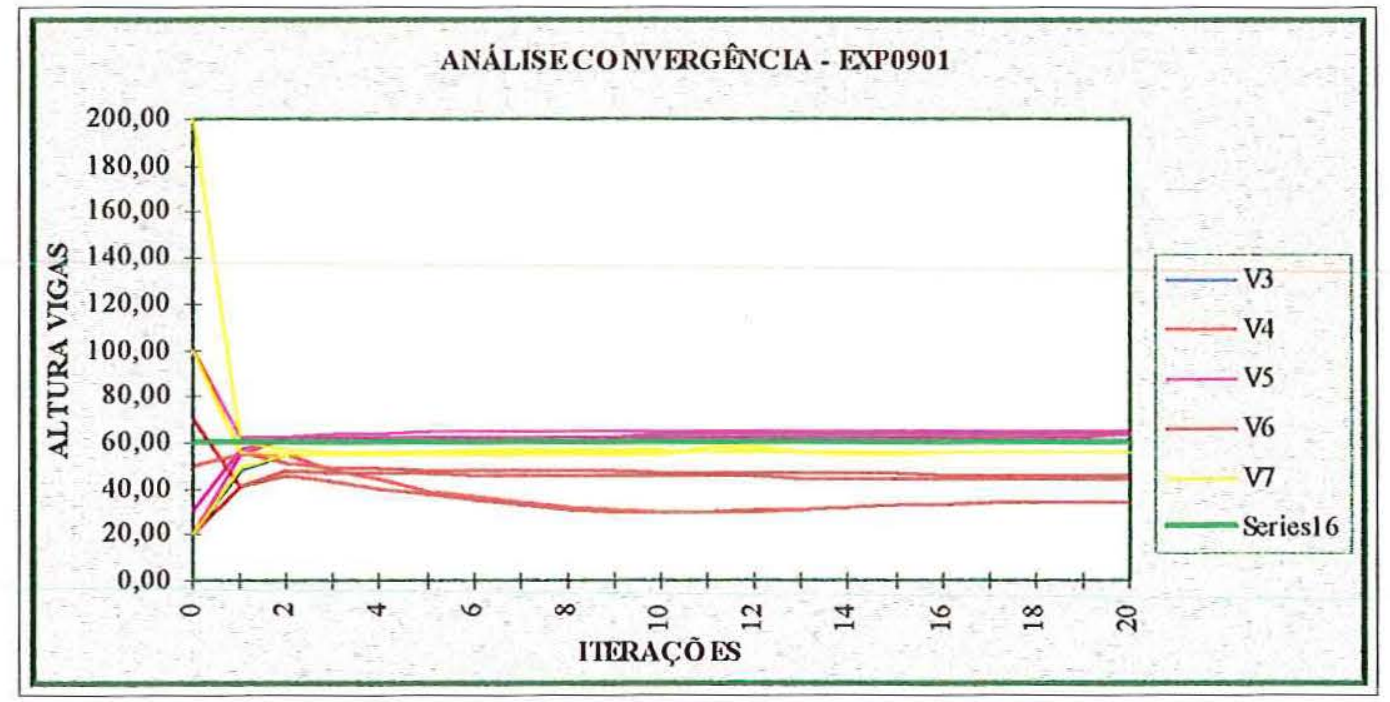

GRÁFICO 8.10 - Análise de convergência das vigas com um tramo

Analisando-se o gráfico 8.11 , percebe-se que a convergência acontece na décima sexta iteração. 


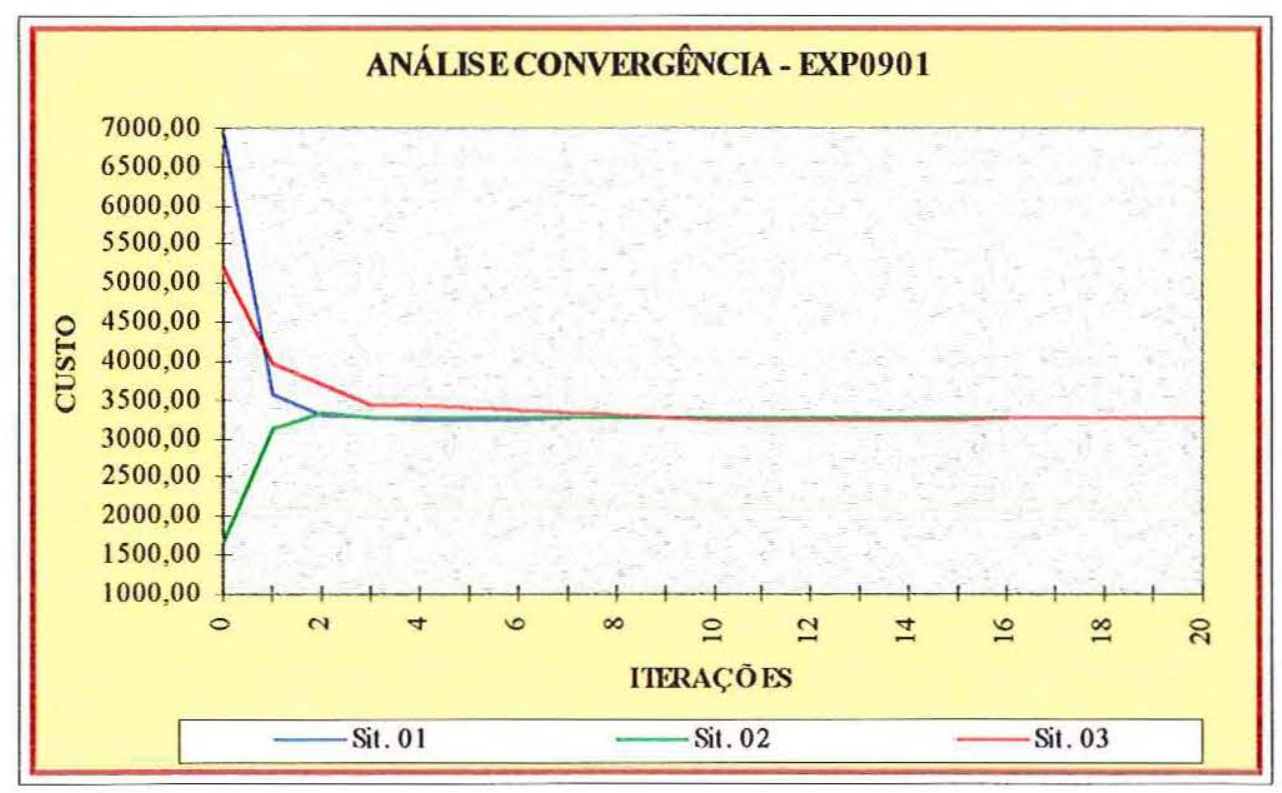

GRÁFICO 8.11 - Análise de convergência do custo 


\subsection{6 - Exemplo - Pavimento Composto por 13 Vigas}

O pavimento seguinte equivale ao do exemplo anterior com a adição de quatro vigas.

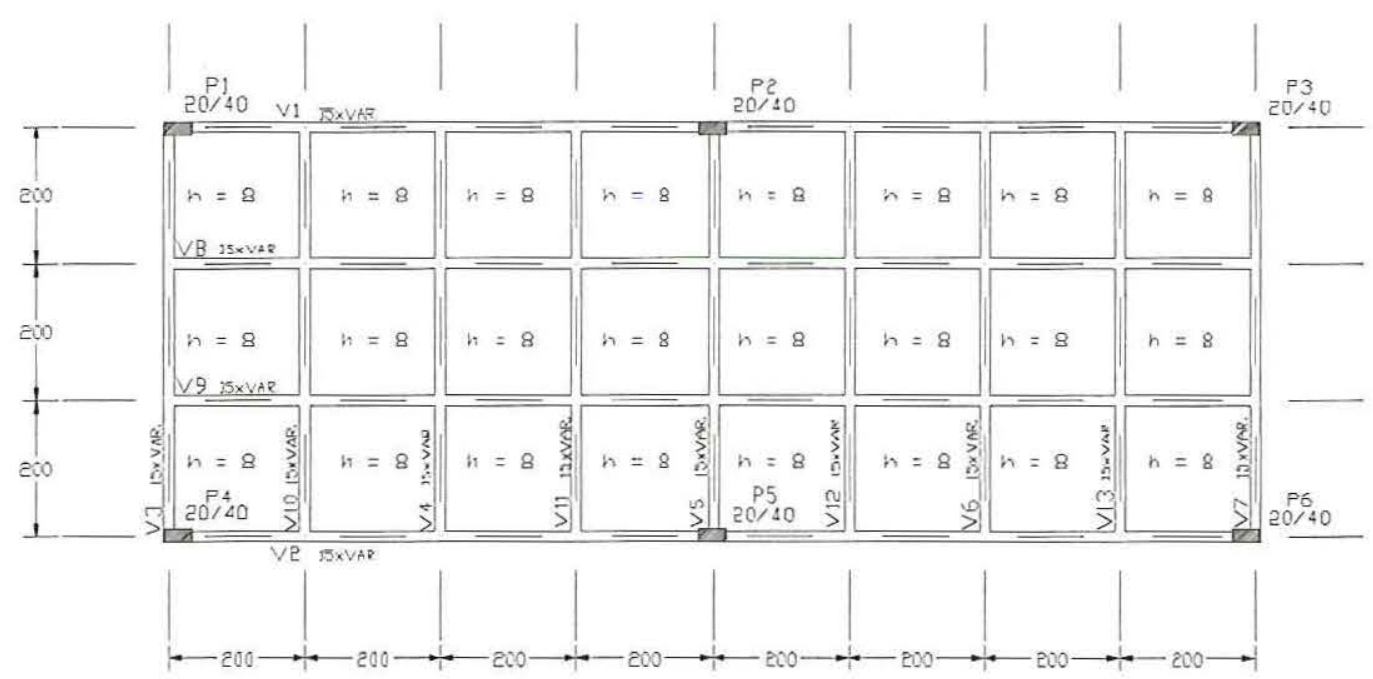

FIGURA 8.4 - Forma do pavimento

\begin{tabular}{|c|c|c|c|c|c|c|c|}
\cline { 2 - 7 } \multicolumn{1}{c|}{} & \multicolumn{2}{c|}{ Situação 01 } & \multicolumn{2}{c|}{ Situação 02 } & \multicolumn{2}{c|}{ Situação 03 } & \multicolumn{1}{c}{} \\
\hline & $\mathrm{h}_{\mathrm{i}}$ & $\mathrm{h}_{\text {opt }}$ & $\mathrm{h}_{\mathrm{i}}$ & $\mathrm{h}_{\text {opt }}$ & $\mathrm{h}_{\mathrm{i}}$ & $\mathrm{h}_{\text {opt }}$ & 8 ou 10\% vão \\
\hline V1 & 100 & 48,79 & 20 & 48,64 & 40 & 48,74 & 64 \\
\hline V2 & 100 & 48,79 & 20 & 48,64 & 100 & 48,78 & 64 \\
\hline V3 & 100 & 53,73 & 20 & 53,75 & 40 & 53,46 & 60 \\
\hline V4 & 100 & 28,70 & 20 & 28,29 & 50 & 36,10 & 60 \\
\hline V5 & 100 & 60,86 & 20 & 60,76 & 50 & 61,41 & 60 \\
\hline V6 & 100 & 28,70 & 20 & 28,24 & 70 & 36,12 & 60 \\
\hline V7 & 100 & 53,73 & 20 & 53,75 & 100 & 53,39 & 60 \\
\hline V8 & 100 & 35,77 & 20 & 36,09 & 40 & 36,54 & 64 \\
\hline V9 & 100 & 35,77 & 20 & 36,09 & 100 & 36,66 & 64 \\
\hline V10 & 100 & 34,20 & 20 & 34,05 & 40 & 35,71 & 60 \\
\hline V11 & 100 & 49,40 & 20 & 49,43 & 50 & 44,47 & 60 \\
\hline V12 & 100 & 49,40 & 20 & 49,43 & 60 & 44,42 & 60 \\
\hline V13 & 100 & 34,20 & 20 & 34,05 & 70 & 35,70 & 60 \\
\hline Custo R\$ & & $3,828,30$ & & $3.827,40$ & & $3.877,84$ & \\
\hline
\end{tabular}

TABELA 8.6 - Resultados numéricos das alturas ótimas das vigas 
Assim como no exemplo anterior, houve convergência no custo para as três situações, e em todas as vigas quando iniciadas com alturas iguais.

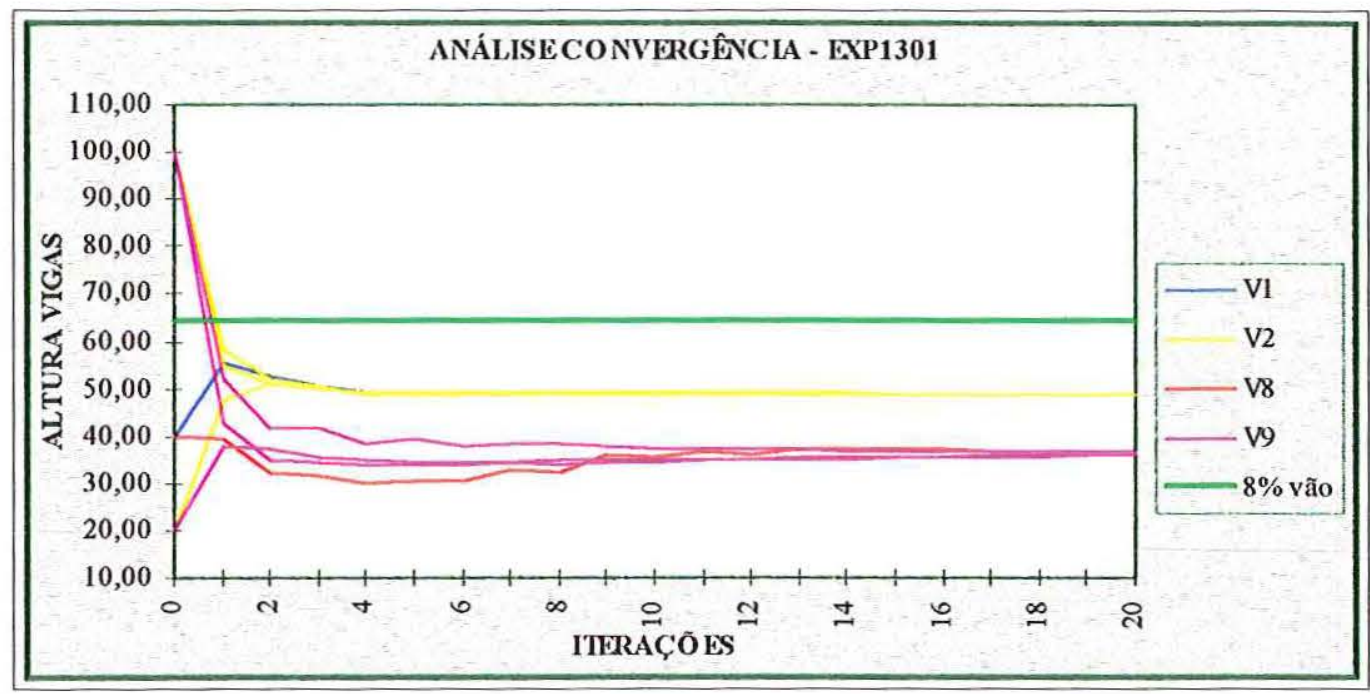

GRÁFICO 8.12 - Análise de convergência das vigas com mais de um tramo

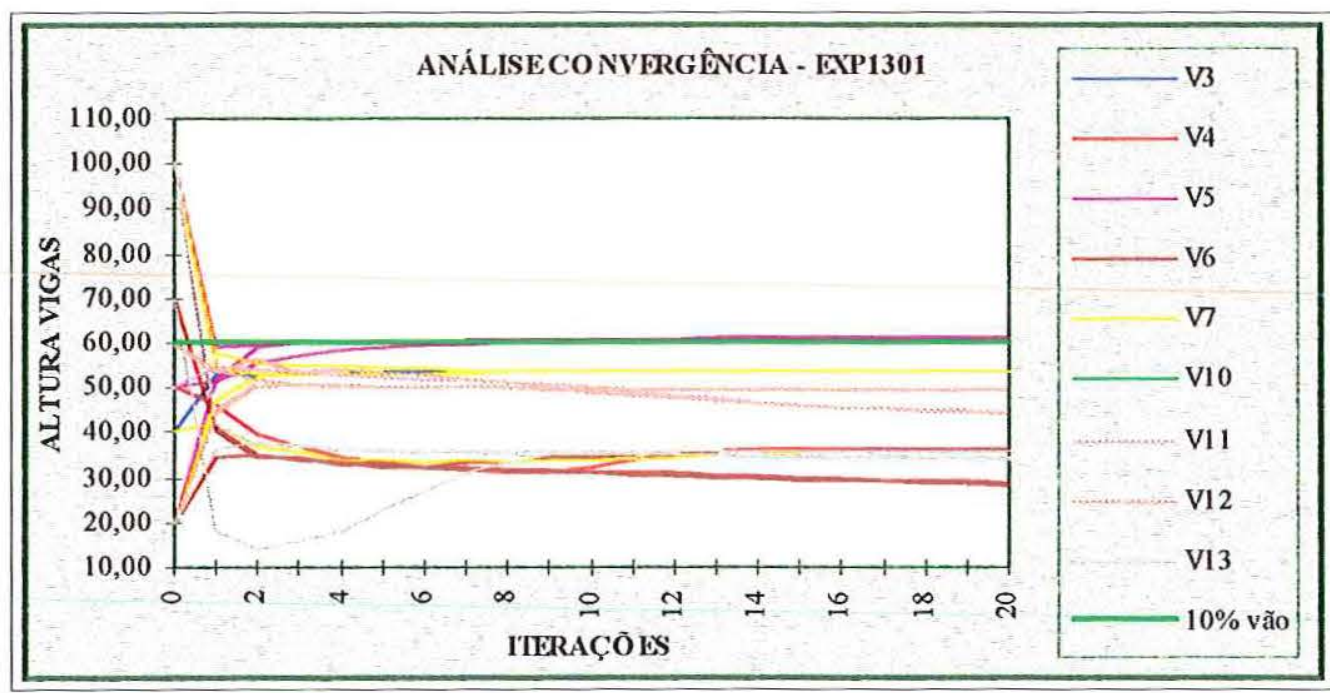

GRÁFICO 8.13 - Análise de convergência das vigas com um tramo

O gráfico 8.14 refere-se a um "zoom" do gráfico 8.13 . 


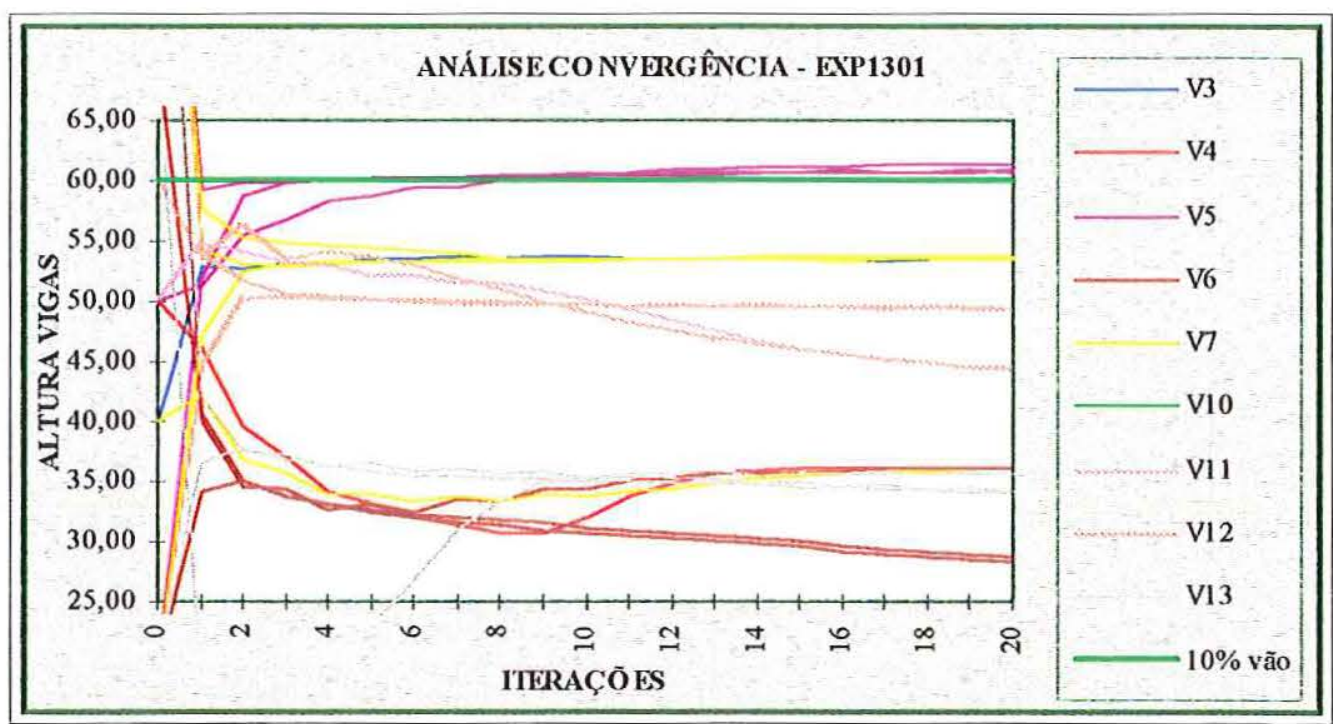

GRÁFICO 8.14 - Análise de convergência das vigas com um tramo - "zoom"

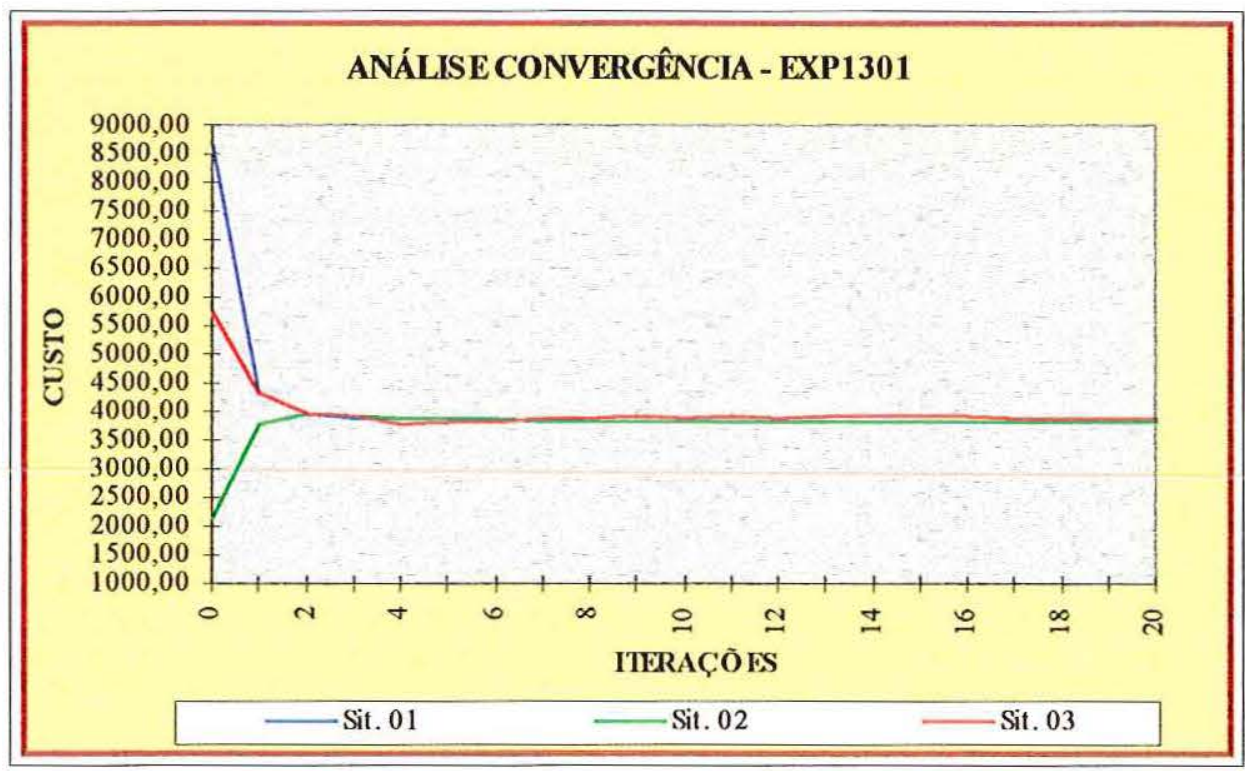

GRÁFICO 8.15 - Análise de convergência do custo

O gráfico 8.16 refere-se a um "zoom" do gráfico 8.15 . 


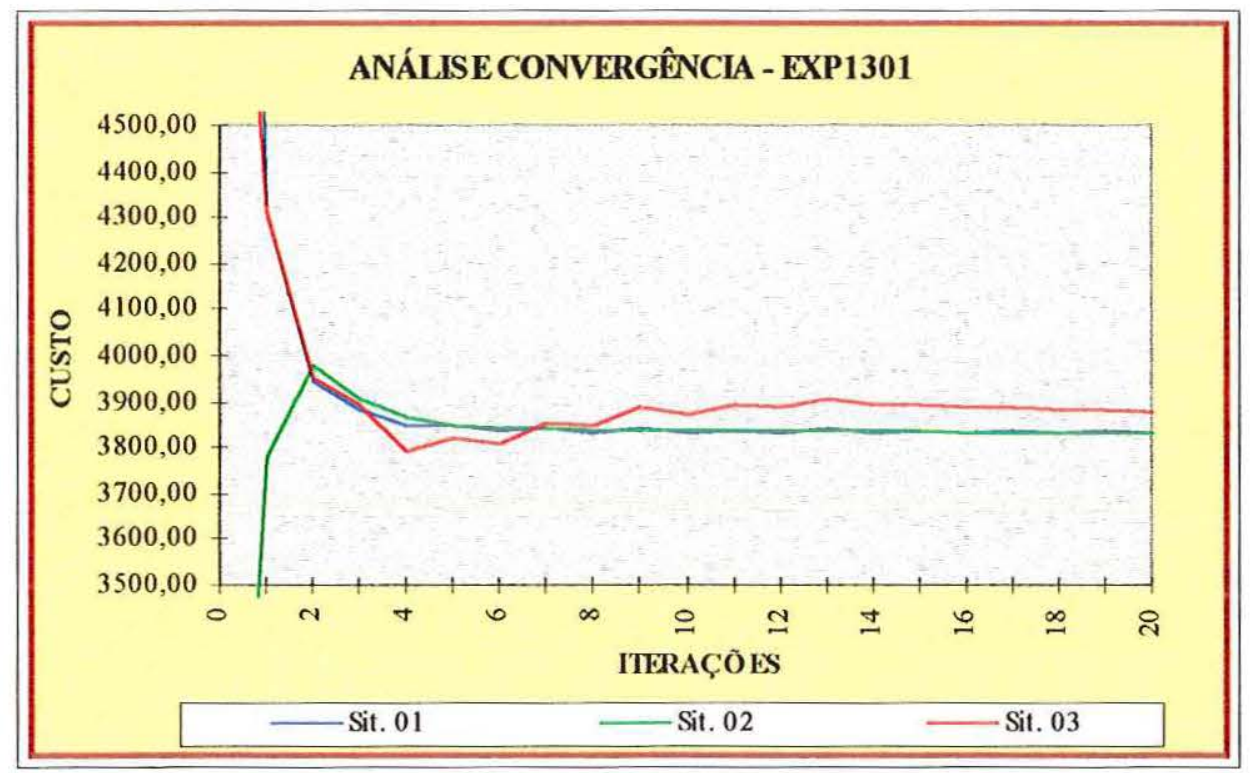

GRÁFICO 8.16 - Análise de convergência do custo - "zoom"

Quando as alturas iniciais das vigas são muito discrepantes, pode-se perturbar ou deteriorar o resultado ótimo. Para evitar que isto ocorra, aconselha-se que sejam fornecidas alturas iniciais de igual módulo para as vigas, garantindo assim a perfeita convergência do método.

Salienta-se a importância da definição dos vãos pois, como comentado anteriormente, estes têm influência direta nas alturas ótimas das vigas.

Percebe-se que o custo aumentou junto com o número de vigas do pavimento, então surge a pergunta: Por que estas vigas adicionadas não sumiram no processo de otimização, uma vez que com sua ausência a estrutura seria mais econômica? A resposta a esta pergunta é que no presente trabalho não são analisadas as flechas das lajes, e a partir do momento em que passam a existir vigas em determinados locais, passam-se a ser verificados os deslocamentos daqueles nós que estão sob as vigas, o que antes não ocorria. Por isso, é importante que as espessuras das lajes sejam coerentes com a estrutura, uma vez que estas não são consideradas variáveis a serem otimizadas. Aproveitando o comentário, fica como sugestão para uma próxima pesquisa a implementação da verificação das flechas das lajes no programa SSPO. Sabe-se que, em pavimentos convencionais de edificios residenciais, a principal determinante nas espessuras das lajes é a flecha. Se isto é verificado, facilmente alcança-se a otimização do pavimento, não apenas da grelha. 
No gráfico 8.17 é feita uma análise das alturas ótimas das vigas quando se varia a espessura das placas do pavimento, sendo os valores numéricos desta análise apresentados na tabela 8.7. Como era de se esperar, observa-se que à medida que se aumenta a rigidez das lajes, as vigas vão sendo menos necessárias à rigidez global do pavimento. No instante em que as vigas deixam de ser importantes para a estrutura, elas têm o mesmo comportamento, perdendo bruscamente o significado de sua existência. Isto faz com que quando uma viga intermediária desaparece, algumas vezes haja perturbação nas vigas vizinhas. Coerentemente com o estimado pela análise estrutural, as vigas mais solicitadas são as últimas a desaparecerem no processo de otimização.

\begin{tabular}{|c|c|c|c|c|c|c|c|}
\hline $\begin{array}{l}\text { espessura } \\
\text { da laje } \\
(\mathrm{cm})\end{array}$ & $\begin{array}{c}\mathrm{h}_{\text {opt }} \\
(\mathrm{cm}) \\
\mathrm{V} 1= \\
\mathrm{V} 2\end{array}$ & $\begin{array}{c}\mathrm{h}_{\text {opt }} \\
(\mathrm{cm}) \\
\mathrm{V} 3= \\
\mathrm{V} 7\end{array}$ & $\begin{array}{c}\mathrm{h}_{\mathrm{opt}} \\
(\mathrm{cm}) \\
\mathrm{V} 4= \\
\mathrm{V} 6\end{array}$ & $\begin{array}{c}\mathrm{h}_{\mathrm{opt}} \\
(\mathrm{cm}) \\
\mathrm{V} 5\end{array}$ & $\begin{array}{c}\mathrm{h}_{\mathrm{opt}} \\
(\mathrm{cm}) \\
\mathrm{V} 8= \\
\mathrm{V} 9\end{array}$ & $\begin{array}{c}\mathrm{h}_{\mathrm{opt}}(\mathrm{cm}) \\
\mathrm{V} 10=\mathrm{V} 13\end{array}$ & $\begin{array}{c}\mathrm{h}_{\mathrm{opt}}(\mathrm{cm}) \\
\mathrm{V} 11=\mathrm{V} 12\end{array}$ \\
\hline 8,00 & 48,79 & 53,73 & 28,70 & 60,86 & 35,77 & 34,20 & 49,40 \\
\hline 9,00 & 48,17 & 53,54 & 27,08 & 61,01 & 34,04 & 28,34 & 46,58 \\
\hline 10,00 & 47,50 & 52,91 & 26,28 & 61,44 & 31,60 & 25,09 & 40,14 \\
\hline 11,00 & 46,06 & 52,26 & 21,00 & 61,79 & 31,20 & 22,22 & 32,45 \\
\hline 12,00 & 44,43 & 50,80 & 12,00 & 61,72 & 29,92 & 21,13 & 25,43 \\
\hline 13,00 & 42,57 & 48,51 & 13,00 & 61,01 & 28,38 & 13,00 & 24,73 \\
\hline 14,00 & 41,82 & 43,49 & 14,00 & 58,73 & 14,00 & 14,00 & 29,96 \\
\hline 15,00 & 38,32 & 37,10 & 15,00 & 56,62 & 15,00 & 15,00 & 28,93 \\
\hline 16,00 & 32,52 & 28,04 & 16,00 & 51,26 & 16,00 & 16,00 & 28,00 \\
\hline 17,00 & 32,40 & 30,11 & 17,00 & 34,06 & 17,00 & 17,00 & 24,50 \\
\hline 18,00 & 18,00 & 29,37 & 18,00 & 34,47 & 18,00 & 18,00 & 18,00 \\
\hline 19,00 & 19,00 & 19,00 & 19,00 & 31,98 & 19,00 & 19,00 & 19,00 \\
\hline 20,00 & 20,00 & 20,00 & 20,00 & 20,00 & 20,00 & 20,00 & 20,00 \\
\hline 21,00 & 21,00 & 21,00 & 21,00 & 21,00 & 21,00 & 21,00 & 21,00 \\
\hline
\end{tabular}

\section{TABELA 8.7 - Análise da espessura das placas}

A limitação inferior das alturas das vigas na tabela 8.7 é devido à espessura das lajes. 


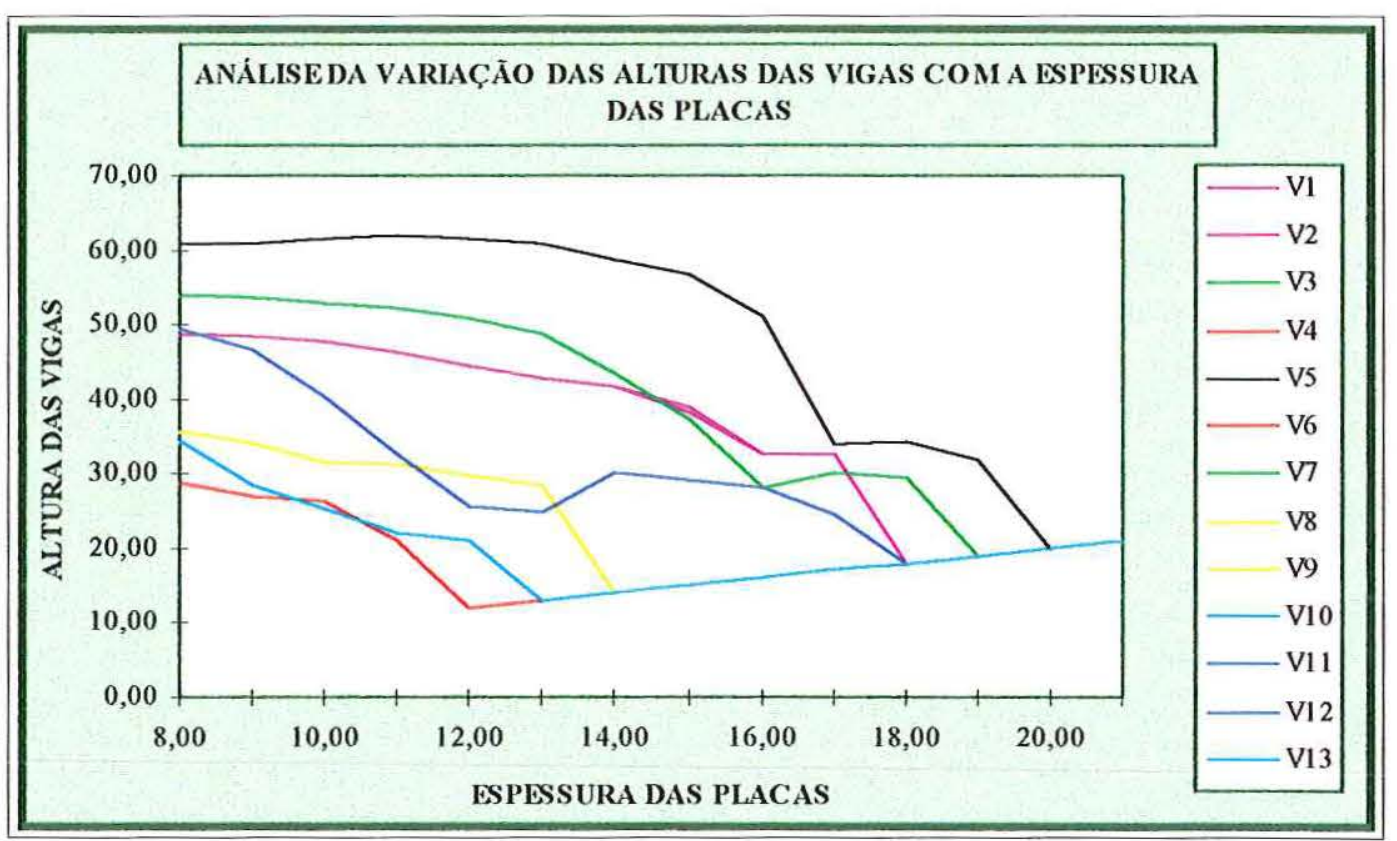

GRÁFICO 8.17 - Variação da espessura das placas

A respeito do necessário refinamento da malha, como já comentado anteriormente, o elemento de barra foi dividido em um número de partes definido pelo usuário. Mesmo assim, como se sabe, o programa utiliza um método discreto para resolver a estrutura, e isto implica que esta deve estar bem discretizada para a solução ter fundamento. Neste exemplo, com o intuito de avaliar o quanto o refinamento da malha pode influenciar nas alturas finais das vigas, foram discutidos os resultados com os vãos divididos em 6 e 8 partes (espaçamento de $100 \mathrm{~cm}$ ), e os vãos divididos em 12 e 16 partes (espaçamento de $50 \mathrm{~cm}$ ).

Na tabela 8.8, apresentam-se os resultados numéricos nestas condições. 


\begin{tabular}{|c|c|c|c|c|}
\cline { 2 - 5 } \multicolumn{1}{c|}{} & \multicolumn{2}{c|}{$\begin{array}{c}\text { espaçamento } \\
100 \mathrm{~cm}\end{array}$} & \multicolumn{2}{c|}{ espaçamento } \\
\hline & $\mathrm{h}_{\mathrm{i}}$ & $\mathrm{h}_{\text {opt }}$ & $\mathrm{h}_{\mathrm{i}}$ & $\mathrm{h}_{\text {opt }}$ \\
\hline V1 & 100 & 48,79 & 100 & 50,71 \\
\hline V2 & 100 & 48,79 & 100 & 50,72 \\
\hline V3 & 100 & 53,73 & 100 & 53,39 \\
\hline V4 & 100 & 28,70 & 100 & 33,54 \\
\hline V5 & 100 & 60,86 & 100 & 59,69 \\
\hline V6 & 100 & 28,70 & 100 & 33,54 \\
\hline V7 & 100 & 53,73 & 100 & 53,39 \\
\hline V8 & 100 & 35,77 & 100 & 33,20 \\
\hline V9 & 100 & 35,77 & 100 & 33,20 \\
\hline V10 & 100 & 34,20 & 100 & 34,04 \\
\hline V11 & 100 & 49,40 & 100 & 50,49 \\
\hline V12 & 100 & 49,40 & 100 & 50,49 \\
\hline V13 & 100 & 34,20 & 100 & 34,04 \\
\hline Custo R\$ & & $3.828,30$ & & $3.854,63$ \\
\hline
\end{tabular}

TABELA 8.8 - Análise numérica do refinamento da malha

Como se pode observar na tabela 8.8 , houve uma pequena variação nas alturas das vigas e no custo final da estrutura. A rigidez dos elementos é função do esforço de flexão neles aplicados, que por sua vez têm uma certa variação com a malha utilizada para discretizar a estrutura. Vale salientar que embora a estrutura quando é mais discretizada apresenta maior custo, nesta situação tem-se uma maior proximidade do comportamento real da mesma.

Como se pode observar nos gráficos 8.18 e 8.19 , o refinamento da malha praticamente não tem influência sobre a velocidade de convergência do modelo. 


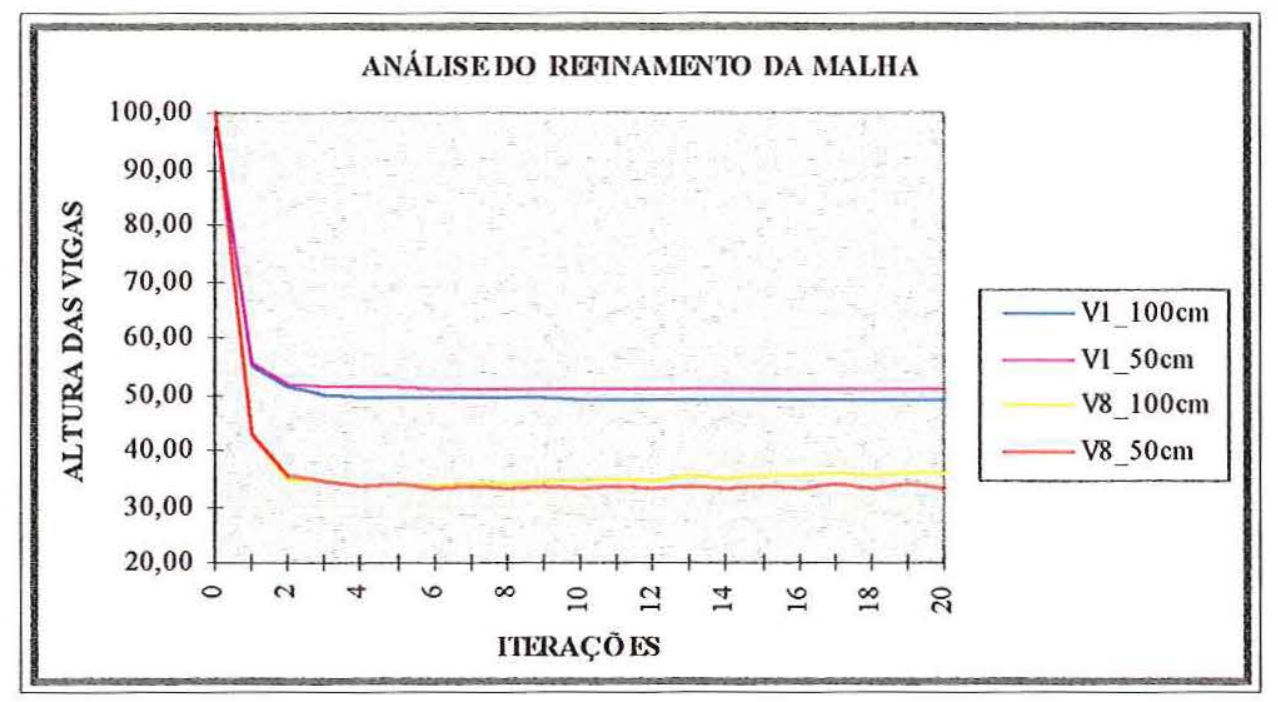

GRÁFICO 8.18 - Análise do refinamento da malha - vigas com mais de um tramo

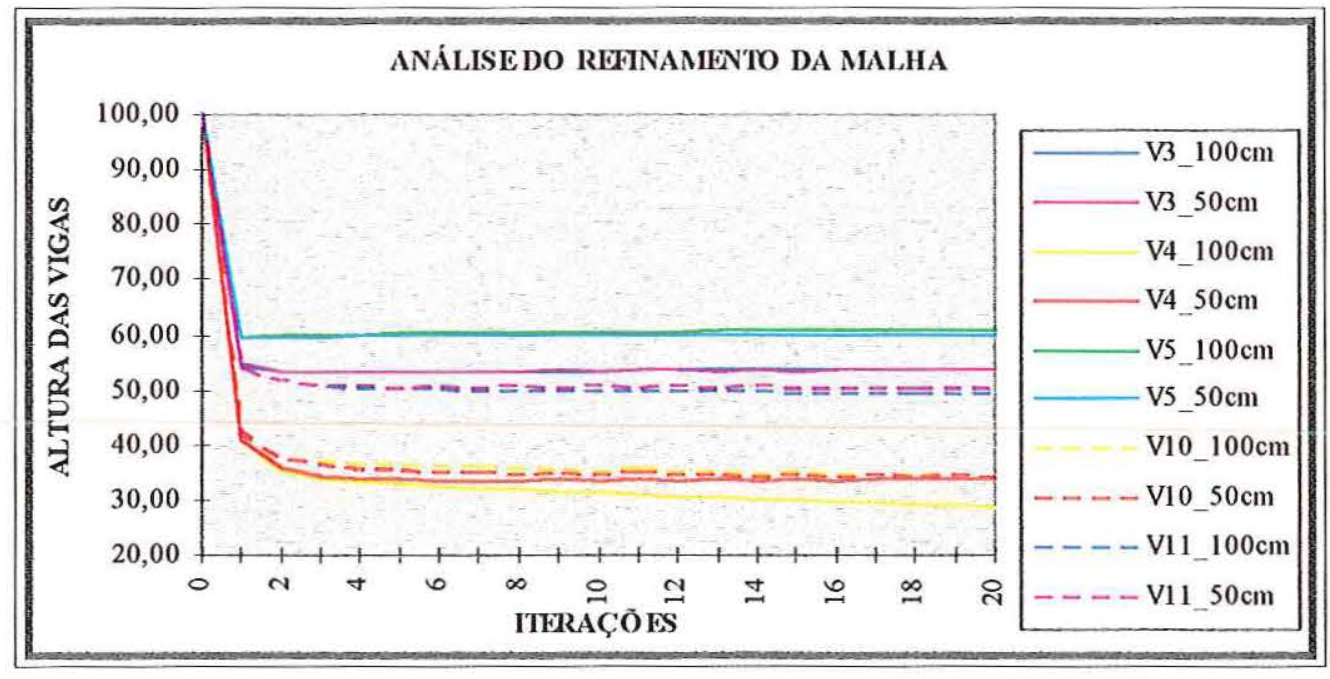

GRÁFICO 8.19 - Análise do refinamento da malha - vigas com um tramo 


\section{2 - Comparação com Estruturas Existentes}

Os exemplos 8.2.1 e 8.2.2 foram dimensionados e calculados pela TECSOF Engenharia de Estruturas, a qual gentilmente os cederam para o devido uso. Fica claro que os comentários feitos no decorrer dos exemplos são de caráter acadêmico, pretendendo-se avaliar apenas os resultados do programa SSPO. Como se sabe, na prática existem muitas outras variáveis envolvidas que não foram consideradas neste trabalho, e a TECSOF, reconhecida pela eficiência e competência de seus trabalhos, com certeza as considerou.

Para a EPLAN - Engenharia de Projetos S/C Ltda., que gentilmente cedeu o exemplo 8.2.3, valem os mesmos comentários feitos à TECSOF.

Nos exemplos a seguir, foram feitas oito análises para cada um deles. A diferença entre os modelos foi em dois conjuntos de variáveis: a restrição de otimização da taxa geométrica da armadura máxima, $\mathrm{P}_{\mathrm{ac}}$, variando em $4 \%, 3 \%$, e $2 \%$; e a inércia dos elementos, que foi considerada ou em Serviço ou no Estádio I. Para cada percentual de taxa geométrica de armadura, serão analisados os resultados obtidos considerando as inércias dos elementos em Serviço e no Estádio I. As últimas duas análises serão feitas considerando-se as alturas das vigas fixas, utilizadas no projeto original, porém não ótimas, variando a concepção de cálculo das inércias. Estes modelos serão feitos para se analisar as flechas máximas das vigas das estruturas.

Pensou-se em variar a taxa geométrica para verificar, como já comentado em capítulo anterior, a variação do custo com a densidade de armadura utilizada na estrutura. Um outro motivo, é que esta variável é muito particular de cada projetista, e os resultados mostrados em seguida tentam abranger todo o campo comumente utilizado na prática.

Muitos projetistas consideram as inércias dos elementos no Estádio I, por isso serão mostrados e comentados resultados obtidos considerando tais características.

\subsection{1 - Exemplo - Edifício LIBERAL OFFICE}


Este exemplo consta do $1^{\circ}$ pavimento do Edificio LIBERAL OFFICE, o qual é utilizado como transição para o restante dos pavimentos. Neste nível, foi utilizado um sistema de lajes maciças e vigas de concreto armado. Tanto o carregamento, quanto a geometria e as características dos materiais, foram considerados idênticos ao projeto original.

A estrutura foi analisada como pavimento constituído de elementos de placa e de barra, os quais foram discretizados com uma malha com espaçamento em torno de $55 \mathrm{~cm}$. A discretização da estrutura foi feita por 1214 nós, 1124 elementos de placa e 366 elementos de barra, podendo sua forma ser vista na figura 8.5.

O tempo utilizado pela otimização é mínimo, quando comparado ao usado com o restante do programa, representando cerca de $8 \%$ do tempo total de processamento. Apresentam-se na tabela 8.9 , as alturas ótimas das vigas obtidas com as três análises efetuadas neste exemplo.

A segunda coluna da tabela 8.9 refere-se às alturas originais das vigas utilizadas no projeto, sendo representado o custo total do volume de concreto + área de forma na última linha. Da $3^{0}$ à $5^{0}$ coluna, as alturas das vigas foram obtidas considerando o momento de inércia em Serviço, próprio para cada elemento finito, calculados conforme apresentado no capítulo 7. Nas colunas 6, 7 e 8, para determinar as alturas das vigas, foi considerado momento de inércia constante ao longo de todo seu comprimento, sendo este calculado no Estádio I.

A taxa geométrica da armadura é utilizada como restrição de máxima armadura, aplicada diretamente à função objetivo de minimização do custo. Por isso, há influência desta variável na determinação da $\mathrm{h}_{\mathrm{opt}}$ independentemente da concepção do momento de inércia a ser considerado.

Como a maior espessura das lajes é de $10 \mathrm{~cm}$, fica como limite mínimo para as alturas das vigas este valor. 


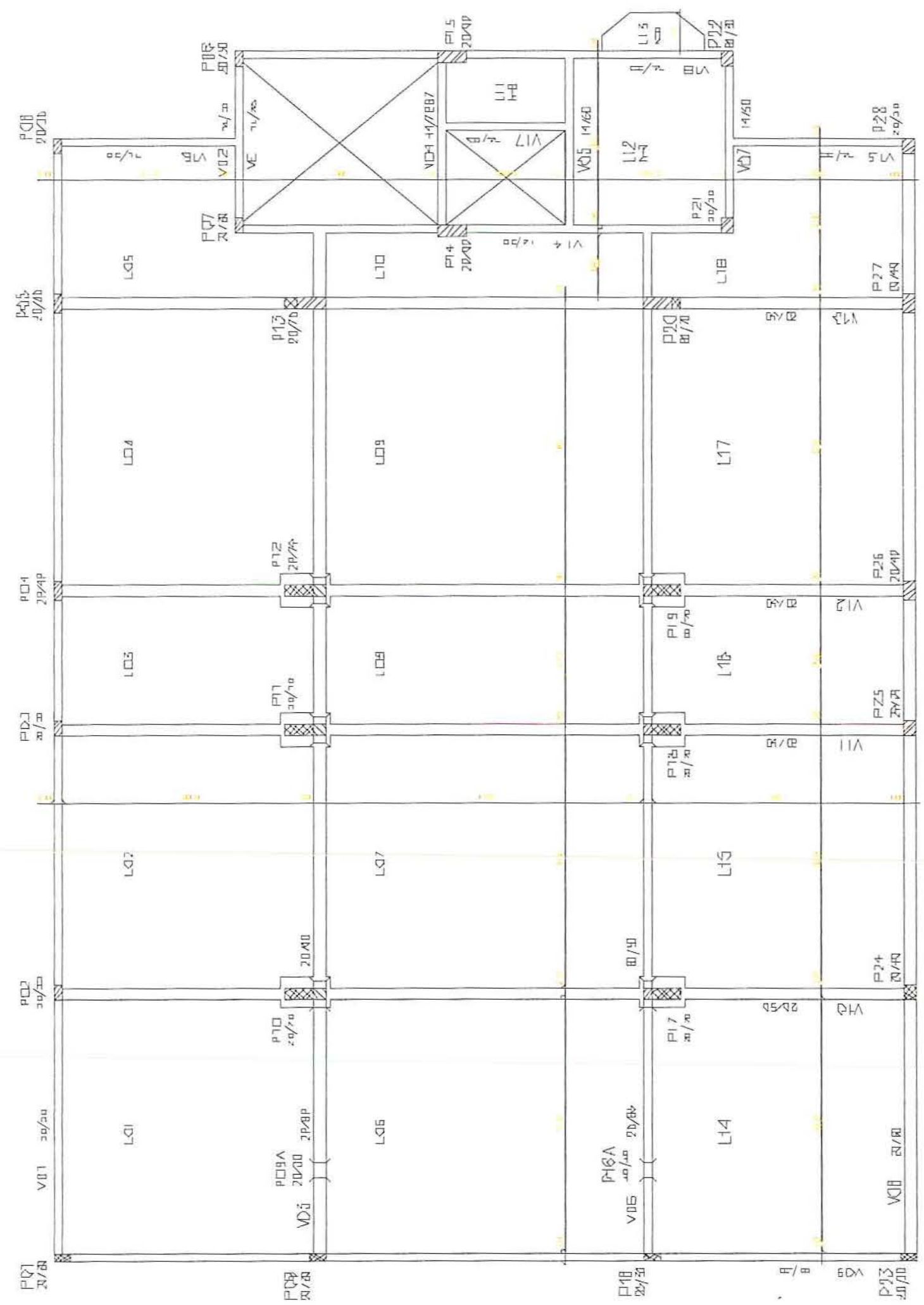

FIGURA 8.5 - Forma do $1^{0}$ pavimento do edifício LIBERAL OFFICE 


\begin{tabular}{|c|c|c|c|c|c|c|c|}
\hline \multirow[t]{2}{*}{ Vigas } & & $P_{a c}=4 \%$ & $\mathrm{P}_{\mathrm{ac}}=3 \%$ & $P_{a c}=2 \%$ & $P_{a c}=4 \%$ & $\mathrm{P}_{\mathrm{ac}}=3 \%$ & $\mathrm{P}_{\mathrm{ac}}=2 \%$ \\
\hline & & \multicolumn{3}{|c|}{$I_{\text {Serviço }}$} & \multicolumn{3}{|c|}{$\mathrm{I}_{0}$} \\
\hline & $\mathrm{h}_{\mathrm{i}}(\mathrm{cm})$ & $\mathrm{h}_{\mathrm{opt}}(\mathrm{cm})$ & $\mathrm{h}_{\text {opt }}(\mathrm{cm})$ & $\mathrm{h}_{\text {opt }}(\mathrm{cm})$ & $\mathrm{h}_{\text {opt }}(\mathrm{cm})$ & $\mathrm{h}_{\text {opt }}(\mathrm{cm})$ & $\mathrm{h}_{\text {opt }}(\mathrm{cm})$ \\
\hline 1 & 50 & 30.3 & 30.3 & 30.3 & 17.1 & 19.3 & 22.3 \\
\hline 2 & 50 & 10.0 & 10.0 & 10.0 & 12.2 & 13.0 & 14.6 \\
\hline 3 & 80 & 66.8 & 72.2 & 79.3 & 65.6 & 71.2 & 78.3 \\
\hline 4 & 72.67 & 19.7 & 21.2 & 23.1 & 19.1 & 20.6 & 22.6 \\
\hline 5 & 50 & 10.0 & 10.0 & 10.0 & 10.0 & 10.0 & 10.0 \\
\hline 6 & 80 & 67.0 & 72.4 & 79.5 & 65.6 & 71.2 & 78.3 \\
\hline 7 & 50 & 10.0 & 10.0 & 10.0 & 10.0 & 10.0 & 10.0 \\
\hline 8 & 50 & 31.8 & 31.8 & 31.8 & 19.0 & 18.7 & 19.7 \\
\hline 9 & 50 & 10.0 & 10.0 & 10.0 & 10.0 & 10.0 & 10.0 \\
\hline 10 & 50 & 10.0 & 10.0 & 10.0 & 10.0 & 10.0 & 10.0 \\
\hline 11 & 50 & 10.0 & 25.3 & 34.1 & 10.0 & 10.0 & 10.0 \\
\hline 12 & 50 & 10.0 & 10.0 & 10.0 & 20.6 & 26.8 & 32.7 \\
\hline 13 & 50 & 10.0 & 10.0 & 10.0 & 10.0 & 10.0 & 10.0 \\
\hline 14 & 50 & 10.0 & 10.0 & 10.0 & 10.0 & 10.0 & 10.0 \\
\hline 15 & 50 & 17.7 & 17.7 & 17.7 & 10.0 & 10.0 & 10.0 \\
\hline 16 & 50 & 10.0 & 10.0 & 10.0 & 10.0 & 10.0 & 10.0 \\
\hline 17 & 50 & 10.0 & 10.0 & 10.0 & 10.0 & 10.0 & 10.0 \\
\hline 18 & 50 & 36.3 & 36.3 & 36.5 & 25.1 & 25.1 & 26.4 \\
\hline Custo R\$ & $9.107,79$ & $3.726,18$ & $4.245,05$ & $4.554,08$ & $3.488,84$ & $3.758,28$ & $4.114,84$ \\
\hline $\begin{array}{c}\text { Núm. } \\
\text { iterações }\end{array}$ & & 58 & 32 & 23 & 11 & 10 & 22 \\
\hline
\end{tabular}

TABELA 8.9 - Análise das alturas das vigas do Ed. LIBERAL OFFICE

Observa-se na tabela 8.9 que há um aumento do custo à medida em que $\mathrm{P}_{\mathrm{ac}}$ é reduzido, concluindo-se que a estrutura é mais econômica quando é mais fortemente armada. Quando as alturas ótimas das vigas são determinadas considerando as inércias dessas no Estádio I, pode-se dizer que as flechas destas calculadas no Estádio II são maiores que as admissíveis previamente determinadas pelo engenheiro. Pois, se a 
estrutura for calculada com estas alturas e consideradas as inércias dos elementos em serviço, as restrições do problema não serão satisfeitas. Nas vigas menos solicitadas esta diferença entre as alturas das vigas para os diferentes modelos é mais perceptível. Isto ocorre porque a rigidez dos elementos também é função da armadura à flexão, e nestes casos a taxa geométrica da armadura é pequena.

Como se sabe, as flechas de uma determinada estrutura são parâmetros de análise fundamental. Quando se otimiza uma estrutura, ou se busca um melhor aproveitamento da mesma, trabalha-se quase sempre na sua capacidade limite, sendo essencial e decisiva a análise das flechas máximas das vigas. A preocupação com esta variável levou à necessidade de se confeccionar a tabela 8.10 , onde se mostra os valores parciais $\mathrm{e}$ definitivos, oriundos de passos iterativos intermediários e finais respectivamente, das flechas máximas das vigas. Para cada modelo, foram impressos valores obtidos no último passo de iteração da otimização das seções transversais ótimas. Estes valores foram calculados pelo método dos elementos finitos $\left(\mathrm{MEF}_{\mathrm{i}}\right)$ antes das seções serem otimizadas; por analogia de Mohr (MOHR) após ser realizada a otimização; e pelo método dos elementos finitos $\left(\mathrm{MEF}_{\mathrm{f}}\right)$ para as alturas das seções transversais ótimas com respectivas rigidez já corrigidas, resultados finais. Salienta-se que estas seções onde obtêm-se as flechas finais podem não coincidir com as seções ótimas, deteriorando os resultados apresentados na tabela 8.10 .

Nas tabelas $8.10,8.12$ e 8.14 , quando for indicado para a flecha valor zero, significa que a restrição predominante não é a flecha máxima. Quando for indicado (--), significa que a altura da viga tem módulo igual à espessura da laje, sendo eliminada do processo de otimização. 


\begin{tabular}{|c|c|c|c|c|c|c|c|c|c|c|c|}
\hline \multirow[t]{4}{*}{$\begin{array}{c}\text { Viga } \\
\mathrm{s}\end{array}$} & \multicolumn{3}{|c|}{$\begin{array}{l}\mathrm{h}_{\text {opt }} \\
(\mathrm{cm})\end{array}$} & \multicolumn{3}{|c|}{$\begin{array}{l}\mathrm{h}_{\mathrm{opt}} \\
(\mathrm{cm})\end{array}$} & \multicolumn{3}{|c|}{$\begin{array}{l}\mathrm{h}_{\text {fixo }} \\
(\mathrm{cm})\end{array}$} & $\begin{array}{l}\mathrm{h}_{\text {fixo }} \\
(\mathrm{cm})\end{array}$ & \\
\hline & \multicolumn{3}{|c|}{$\mathrm{I}_{\text {Serviço }}$} & \multicolumn{3}{|c|}{$\overline{\mathrm{I}_{0}}$} & \multicolumn{3}{|c|}{$\mathrm{I}_{\text {Servico }}$} & $\mathrm{I}_{0}$ & \\
\hline & $\mathrm{MEF}_{\mathrm{i}}$ & $\mathrm{MOHR}$ & $\mathrm{MEF}_{\mathrm{f}}$ & $\mathrm{MEF}_{\mathrm{i}}$ & $\mathrm{MEF}_{\mathrm{opt}}$ & $\mathrm{MEF}_{\mathrm{f}}$ & $\mathrm{MEF}_{\mathrm{i}}$ & MOHR & $\mathrm{MEF}_{\mathrm{f}}$ & $\mathrm{MEF}_{\mathrm{f}}$ & \\
\hline & $\begin{array}{l}\text { flecha } \\
(\mathrm{cm})\end{array}$ & $\begin{array}{l}\text { flecha } \\
\text { (cm) }\end{array}$ & $\begin{array}{c}\text { flech } \\
\text { a } \\
(\mathrm{cm})\end{array}$ & $\begin{array}{l}\text { flecha } \\
\text { (cm) }\end{array}$ & $\begin{array}{l}\text { flecha } \\
(\mathrm{cm})\end{array}$ & $\begin{array}{l}\text { flecha } \\
(\mathrm{cm})\end{array}$ & $\begin{array}{l}\text { flecha } \\
(\mathrm{cm})\end{array}$ & $\begin{array}{l}\text { flecha } \\
(\mathrm{cm})\end{array}$ & $\begin{array}{l}\text { flecha } \\
(\mathrm{cm})\end{array}$ & $\begin{array}{l}\text { flecha } \\
(\mathrm{cm})\end{array}$ & $\begin{array}{c}\text { flecha }_{\text {bim }} \\
(\mathrm{cm})\end{array}$ \\
\hline 1 & 2.00 & 1.81 & 1.99 & 0.00 & 0.00 & 1.50 & 1.15 & 1.06 & 1.11 & 0.16 & 1.82 \\
\hline 2 & -- & $\cdots$ & 2.08 & 0.00 & 0.00 & 1.00 & 0.44 & 0.38 & 0.43 & 0.07 & 1.09 \\
\hline 3 & 0.79 & 0.00 & 0.89 & 0.56 & 0.00 & 0.61 & 0.69 & 0.65 & 0.77 & 0.38 & 1.82 \\
\hline 4 & 0.00 & 0.00 & 0.91 & 0.00 & 0.00 & 0.34 & 0.23 & 0.19 & 0.23 & 0.02 & 1.09 \\
\hline 5 & --- & $\cdots$ & 0.81 & $\cdots$ & -- & 0.53 & 0.34 & 0.25 & 0.34 & 0.05 & 1.09 \\
\hline 6 & 0.79 & 0.00 & 0.89 & 0.56 & 0.00 & 0.61 & 0.69 & 0.66 & 0.77 & 0.38 & 1.82 \\
\hline 7 & $\cdots$ & $\cdots$ & 0.98 & --- & -- & 0.83 & 0.48 & 0.42 & 0.47 & 0.09 & 1.09 \\
\hline 8 & 1.96 & 1.82 & 1.96 & 1.81 & 1.81 & 1.81 & 1.19 & 1.12 & 1.15 & 0.19 & 1.82 \\
\hline 9 & --- & -- & 2.01 & $\cdots$ & $\cdots$ & 1.69 & 0.88 & 0.82 & 0.85 & 0.11 & 1.90 \\
\hline 10 & -.. & -.- & 1.33 & --- & -.- & 1.21 & 0.67 & 0.61 & 0.81 & 0.20 & 1.90 \\
\hline 11 & 1.39 & -1.90 & 1.36 & $\cdots$ & --- & 1.14 & 0.67 & 0.61 & 0.80 & 0.13 & 1.90 \\
\hline 12 & --. & --. & 1.77 & 0.00 & 0.00 & 0.90 & 0.74 & 0.69 & 0.79 & 0.21 & 1.90 \\
\hline 13 & --. & $\cdots$ & 1.35 & --. & $\cdots$ & 1.07 & 0.86 & 0.51 & 0.90 & 0.22 & 1.90 \\
\hline 14 & $\cdots$ & $\cdots$ & 1.01 & $\cdots$ & -- & 0.86 & 0.50 & 0.39 & 0.48 & 0.06 & 1.67 \\
\hline 15 & 0.41 & -1.04 & 0.49 & $\cdots$ & --- & 0.44 & 0.40 & 0.32 & 0.39 & 0.04 & 1.04 \\
\hline 16 & --- & -- & 0.58 & $--\cdot$ & --. & 0.53 & 0.44 & 0.40 & 0.43 & 0.04 & 1.04 \\
\hline 17 & -- & -- & 0.62 & --- & --- & 0.49 & 0.18 & 0.16 & 0.23 & 0.01 & 0.74 \\
\hline 18 & 1.77 & 1.67 & 1.75 & 1.67 & 1.67 & 1.67 & 1.18 & 1.12 & 1.14 & 0.29 & 1.67 \\
\hline
\end{tabular}

TABELA 8.10 - Análise das flechas máximas das vigas do Ed. LIBERAL OFFICE processando a estrutura por diferentes modelos, adotado $P_{a c}=3 \%$.

Devido aos baixos valores dos esforços solicitantes, boa parte das vigas foram eliminadas do processo de otimização. As vigas V2 e V15 apresentam resultados de flechas parciais inconsistentes, pois há uma influência muito forte da geometria da estrutura no cálculo das mesmas. Quando a viga isolada apresenta um comportamento 
muito diferente de quando se encontra na estrutura, pode haver inconsistência nos resultados apresentados pelos diferentes modelos, uma vez que MEF considera a estrutura globalmente e Mohr, no presente trabalho, considera apenas o vão em análise. Nas demais vigas que são "bem comportadas", não há diferença significativa nos resultados, confirmando coerência do programa e consequentemente adicionando confiança ao mesmo.

Na figura 8.6 podem serem vistas as curvas de isodeslocamentos das placas da estrutura. As alturas das vigas que deram origem aos resultados apresentados na figura 8.6 foram obtidas no modelo que considera a inércia em serviço e com uma máxima taxa geométrica de armadura de $3 \%$. De posse dos dados, estes foram processados pelo GL5, programa da TECSOF, o qual utiliza o método dos elementos finitos. Os resultados numéricos apresentados não são exatamente os mesmos, pois foram obtidos por dois programas diferentes (diferente tipo de elemento finito), com malhas diferentes, possíveis diferenças nas vinculações, etc.. Entre as diferenças apresentadas pelos programas, salienta-se a concepção do momento de inércia; que no SSPO é considerada em Serviço pela fórmula de BRANSON e no GL5 é considerada no Estádio I reduzida de $30 \%$. O processamento desta forma foi proposital, com o intuito de avaliar a ordem de grandeza dos resultados do SSPO, obtendo com isso confiança no programa.

Como a compatibilidade entre as placas e os elementos de barra é feita através da igualdade de deslocamento dos nós em comum para ambos os elementos (placa e barra), através da figura 8.6, também é possível analisar os deslocamentos das vigas.

Analisando a figura 8.6, conclui-se que os deslocamentos da estrutura estão de acordo com os máximos preestabelecidos por Norma, mostrando a coerência dos resultados. 


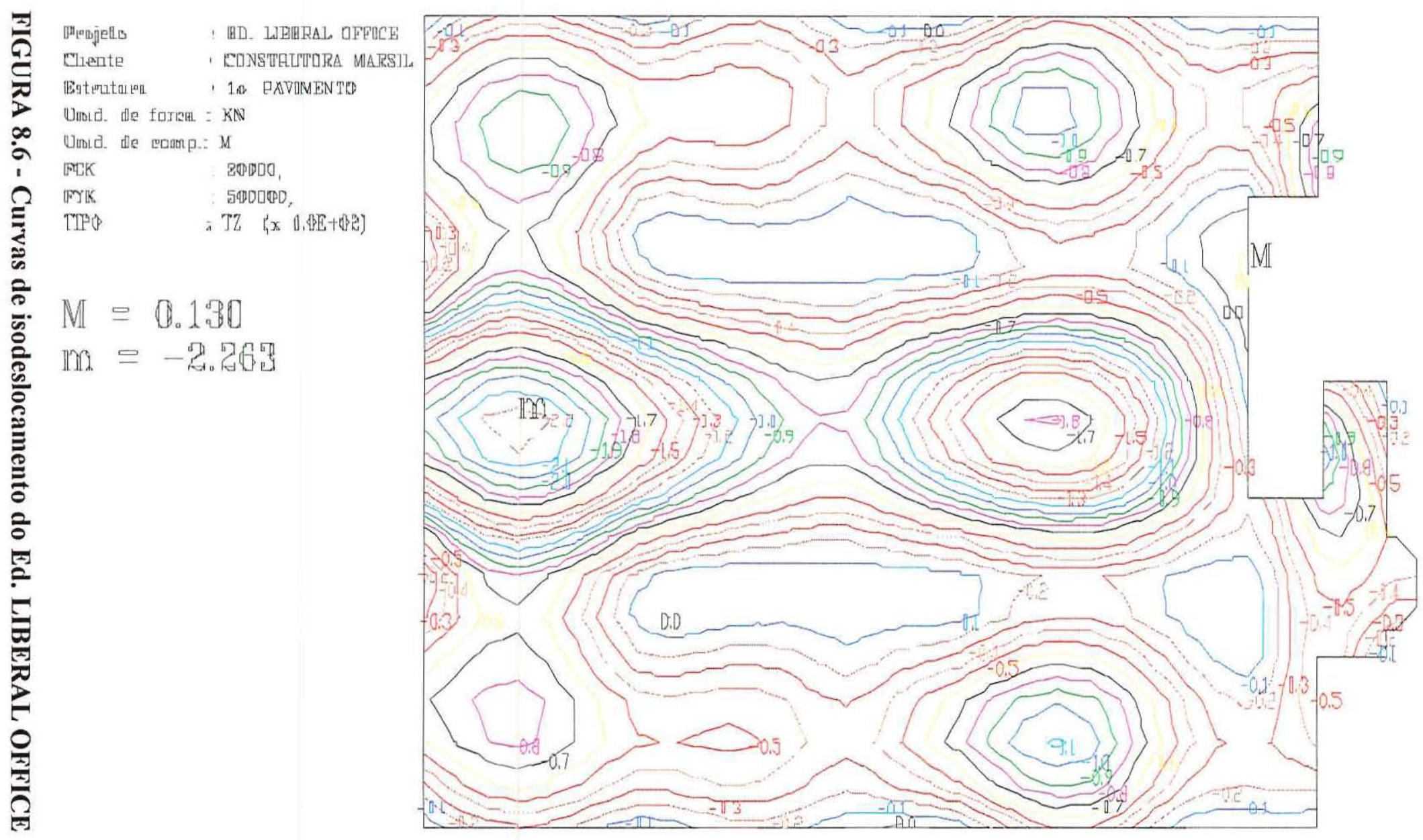


As flechas máximas das vigas obtidas pelo GL5 e pelo SSPO para as mesmas considerações utilizadas para obtenção das curvas de isodeslocamentos apresentadas na figura 8.6 apresentam-se na tabela 8.11.

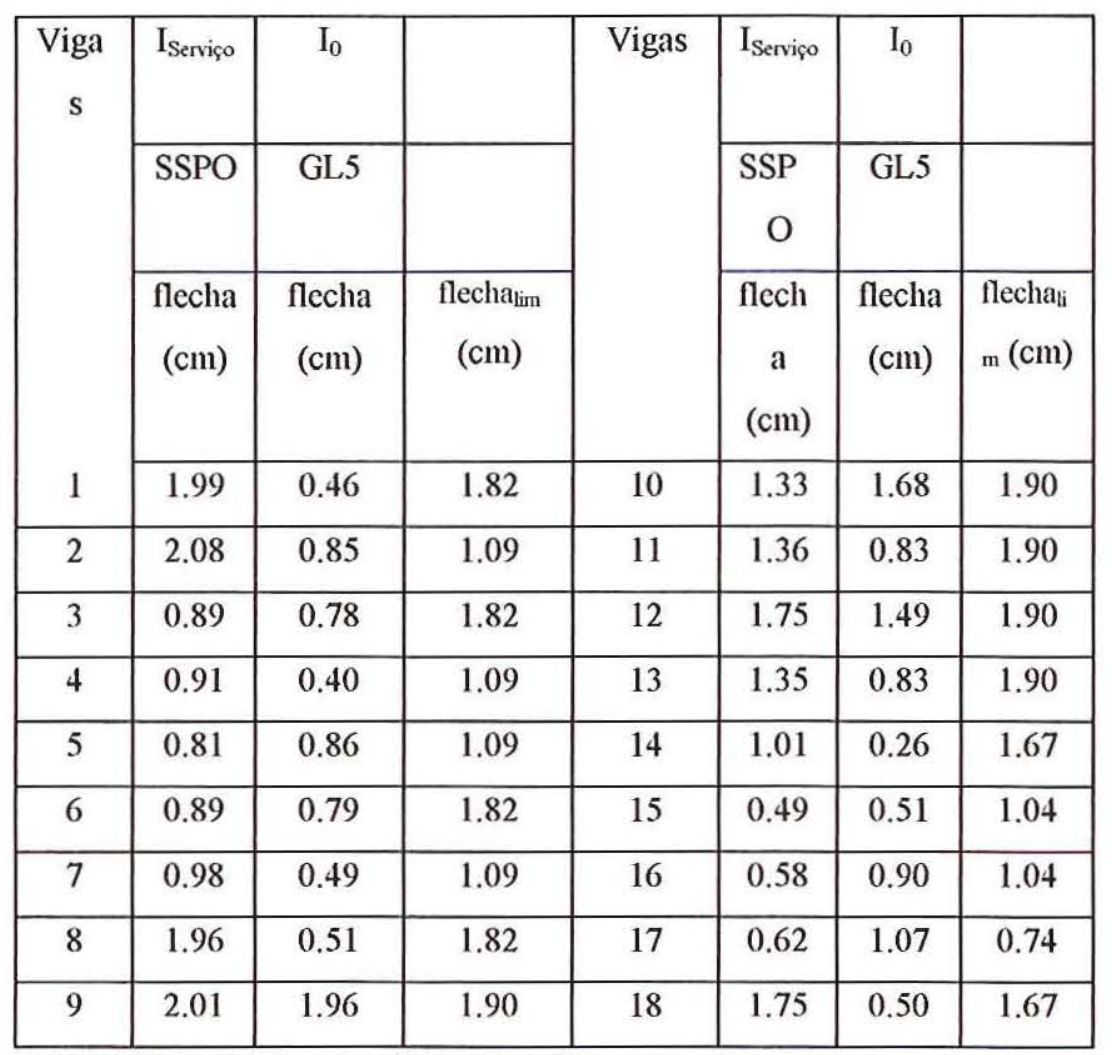

TABELA 8.11 - Análise das flechas máximas das vigas do Ed. LIBERAL OFFICE processando a estrutura pelo SSPO e pelo GL5, adotado $P_{a c}=3 \%$.

Na tabela 8.11, pode-se observar que, na maioria dos casos, as flechas das vigas quando calculadas pelo SSPO têm módulos mais elevados, isto é devido a concepção do momento de inércia. É importante perceber que as flechas máximas satisfazem o limite preestabelecido por Norma, com um erro menor que $10 \%$ quando considerado a inércia fissurada e dentro dos limites quando considerado o momento de inércia no Estádio I.

Os esforços e consequente dimensionamento apresentados por ambos os modelos foram analisados e verificada a consistência destes com valores coerentes com Normas. 


\subsection{2 - Exemplo - Edifício LAGO AZUL}

Será analisado agora o pilotis do Edificio LAGO AZUL, o qual é utilizado como suporte para um prédio em alvenaria estrutural composto por 6 pavimentos. Diante disto, verifica-se que as ações verticais nele aplicadas são de módulos bastante elevados. Neste nível, foi utilizado um sistema de lajes maciças e vigas de concreto armado. Tanto o carregamento, quanto a geometria e as características dos materiais, foram considerados idênticos ao projeto original.

A estrutura foi processada como pavimento com uma malha de espaçamento em torno de $70 \mathrm{~cm}$, sendo sua forma vista na figura 8.6. Na discretização da estrutura, foram utilizados 1036 nós, 960 elementos de placa e 468 elementos de barra.

Pode-se dizer que o custo das vigas convergiu em torno da $11^{\circ}$ iteração. Apresenta-se na tabela 8.11 a variação das alturas ótimas com o modelo em análise.

Como a maior espessura das lajes é de $10 \mathrm{~cm}$, fica como limite mínimo para as alturas das vigas este valor. 


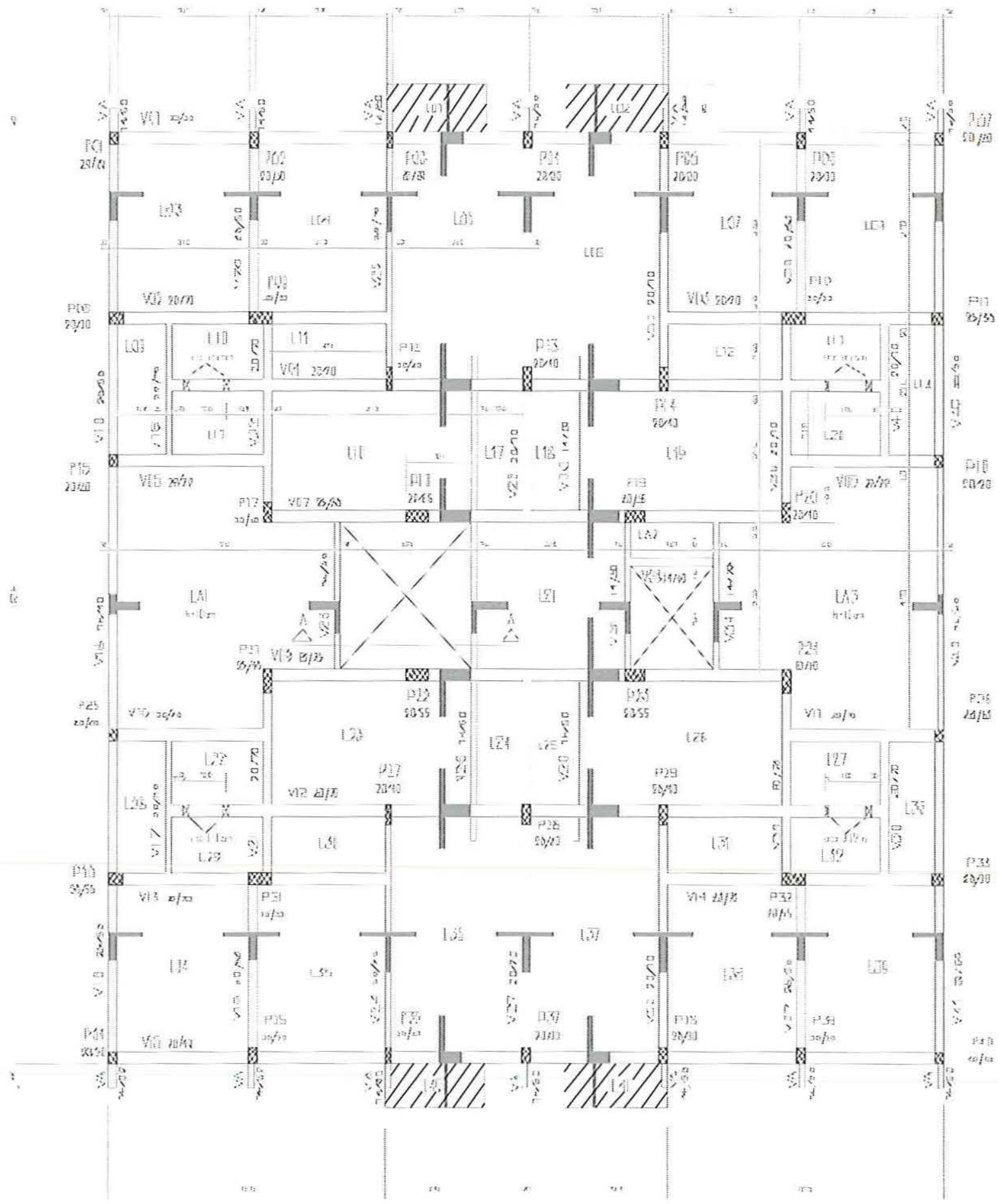

FIGURA 8.6 - Forma do Pilotis 


\begin{tabular}{|c|c|c|c|c|c|c|c|}
\hline \multirow[t]{3}{*}{ Vigas } & & $P_{a c}=4 \%$ & $\mathrm{P}_{\mathrm{ac}}=3 \%$ & $P_{a c}=2 \%$ & $P_{a c}=4 \%$ & $\mathrm{P}_{\mathrm{ac}}=3 \%$ & $\mathrm{P}_{\mathrm{ac}}=2 \%$ \\
\hline & & \multicolumn{3}{|c|}{$\mathrm{I}_{\text {Serviço }}$} & \multicolumn{3}{|c|}{$\mathrm{I}_{0}$} \\
\hline & $h_{i}(\mathrm{~cm})$ & $\mathrm{h}_{\mathrm{opt}}(\mathrm{cm})$ & $\mathrm{h}_{\mathrm{opt}}(\mathrm{cm})$ & $\mathrm{h}_{\text {opt }}(\mathrm{cm})$ & $\mathrm{h}_{\mathrm{opt}}(\mathrm{cm})$ & $\mathrm{h}_{\mathrm{opt}}(\mathrm{cm})$ & $\mathrm{h}_{\text {opt }}(\mathrm{cm})$ \\
\hline 1 & 50 & 29.4 & 31.7 & 34.2 & 28.6 & 30.7 & 33.5 \\
\hline 2 & 70 & 53.5 & 57.4 & 62.0 & 50.0 & 53.3 & 57.5 \\
\hline 3 & 70 & 51.1 & 54.8 & 59.2 & 48.2 & 51.1 & 55.4 \\
\hline 4 & 70 & 41.4 & 44.3 & 48.0 & 39.9 & 43.0 & 47.1 \\
\hline 5 & 70 & 44.8 & 48.8 & 53.9 & 44.8 & 49.5 & 55.6 \\
\hline 6 & 70 & 43.5 & 47.6 & 52.9 & 44.5 & 49.2 & 55.4 \\
\hline 7 & 70 & 55.1 & 59.6 & 65.3 & 50.4 & 54.7 & 60.1 \\
\hline 8 & 50 & 10.0 & 10.0 & 10.0 & 10.0 & 10.0 & 10.0 \\
\hline 9 & 70 & 51.0 & 55.0 & 60.2 & 49.7 & 53.9 & 59.2 \\
\hline 10 & 70 & 44.3 & 48.2 & 53.3 & 44.4 & 49.0 & 55.0 \\
\hline 11 & 70 & 40.9 & 44.8 & 49.7 & 42.2 & 46.7 & 52.2 \\
\hline 12 & 70 & 42.1 & 45.1 & 49.1 & 40.1 & 43.0 & 47.2 \\
\hline 13 & 70 & 53.2 & 57.1 & 61.6 & 49.8 & 53.0 & 57.2 \\
\hline 14 & 70 & 44.9 & 47.7 & 51.5 & 42.5 & 45.0 & 48.2 \\
\hline 15 & 50 & 29.6 & 31.7 & 34.3 & 28.6 & 30.7 & 33.6 \\
\hline 16 & 50 & 30.2 & 32.7 & 35.8 & 29.3 & 31.4 & 34.0 \\
\hline 17 & 70 & 10.0 & 10.0 & 10.0 & 10.0 & 16.2 & 24.7 \\
\hline 18 & 70 & 10.0 & 10.0 & 10.0 & 10.0 & 16.5 & 25.4 \\
\hline 19 & 50 & 20.9 & 22.0 & 27.9 & 23.7 & 28.6 & 34.0 \\
\hline 20 & 50 & 20.9 & 22.0 & 27.9 & 23.7 & 28.6 & 34.0 \\
\hline 21 & 70 & 53.4 & 58.1 & 64.6 & 54.1 & 59.4 & 65.7 \\
\hline 22 & 70 & 55.0 & 59.9 & 66.4 & 55.7 & 61.0 & 67.3 \\
\hline 23 & 50 & 15.3 & 16.4 & 17.7 & 15.3 & 16.0 & 17.0 \\
\hline 24 & 70 & 51.0 & 55.5 & 61.0 & 51.2 & 56.1 & 62.1 \\
\hline 25 & 70 & 50.7 & 55.2 & 60.7 & 50.9 & 55.8 & 61.8 \\
\hline 26 & 50 & 17.7 & 19.5 & 22.0 & 23.4 & 25.9 & 28.9 \\
\hline
\end{tabular}




\begin{tabular}{|c|c|c|c|c|c|c|c|}
\hline Vigas & \multirow{2}{*}{} & $\mathrm{P}_{\mathrm{ac}}=4 \%$ & $\mathrm{P}_{\mathrm{ac}}=3 \%$ & $\mathrm{P}_{\mathrm{ac}}=2 \%$ & $\mathrm{P}_{\mathrm{ac}}=4 \%$ & $\mathrm{P}_{\mathrm{ac}}=3 \%$ & $\mathrm{P}_{\mathrm{ac}}=2 \%$ \\
\cline { 3 - 8 } & & \multicolumn{3}{|c|}{$\mathrm{I}_{\text {Servico }}$} & \multicolumn{3}{|c|}{$\mathrm{I}_{0}$} \\
\hline & $\mathrm{h}_{\mathrm{i}}(\mathrm{cm})$ & $\mathrm{h}_{\text {opt }}(\mathrm{cm})$ & $\mathrm{h}_{\text {opt }}(\mathrm{cm})$ & $\mathrm{h}_{\text {opt }}(\mathrm{cm})$ & $\mathrm{h}_{\text {opt }}(\mathrm{cm})$ & $\mathrm{h}_{\text {opt }}(\mathrm{cm})$ & $\mathrm{h}_{\text {opt }}(\mathrm{cm})$ \\
\hline 27 & 70 & 52.4 & 56.4 & 61.6 & 48.8 & 52.3 & 56.8 \\
\hline 28 & 70 & 54.7 & 58.9 & 64.1 & 50.2 & 53.7 & 58.3 \\
\hline 30 & 50 & 16.1 & 16.1 & 16.1 & 17.5 & 19.7 & 22.3 \\
\hline 31 & 50 & 18.7 & 20.9 & 24.0 & 25.8 & 28.2 & 31.2 \\
\hline 32 & 70 & 10.0 & 10.0 & 10.0 & 10.0 & 10.0 & 10.0 \\
\hline 33 & 70 & 50.8 & 55.2 & 60.7 & 50.6 & 55.5 & 61.5 \\
\hline 34 & 70 & 26.8 & 31.0 & 35.7 & 30.8 & 35.3 & 40.4 \\
\hline 35 & 70 & 62.2 & 68.0 & 75.3 & 62.9 & 69.3 & 77.4 \\
\hline 36 & 70 & 53.4 & 58.3 & 64.9 & 53.9 & 60.1 & 66.0 \\
\hline 37 & 50 & 22.2 & 26.7 & 31.3 & 25.8 & 30.3 & 35.3 \\
\hline 38 & 50 & 20.9 & 22.2 & 28.0 & 23.7 & 28.6 & 34.0 \\
\hline 39 & 70 & 10.0 & 14.7 & 10.0 & 10.0 & 10.0 & 10.0 \\
\hline 40 & 70 & 10.0 & 10.0 & 12.7 & 10.0 & 10.0 & 24.1 \\
\hline 41 & 50 & 30.6 & 33.0 & 36.1 & 29.4 & 31.7 & 34.4 \\
\hline Custo R\$ & $14.029,08$ & $8.929,74$ & $9.581,17$ & $10.384,66$ & $8.759,32$ & $9.494,32$ & $10.435,81$ \\
\hline Núm. & & 27 & 19 & 19 & 25 & 53 & 37 \\
\hline iterações & & & & & & & \\
\hline
\end{tabular}

TABELA 8.11 - Análise das alturas das vigas do Ed. LAGO AZUL

$\mathrm{Na}$ tabela 8.11, observa-se que poucas vigas foram eliminadas no processo de otimização; isto ocorre pelo fato da estrutura estar bastante solicitada. Percebe-se também, que pelo fato das vigas estarem fortemente armadas, não há grande diferença no módulo da altura na maioria destas, quando é considerado o momento de inércia no Estádio I ou em Serviço. Isto acontece pela contribuição do aço na rigidez das vigas no cálculo do momento de inércia em Serviço, fato que compensa uma fração do concreto não-fissurado no Estádio I. 
Assim como no exemplo anterior, é clara a percepção do aumento do custo com a diminuição da taxa geométrica da armadura.

Mostra-se na tabela 8.12 resultados parciais das flechas máximas de cada viga.

\begin{tabular}{|c|c|c|c|c|c|c|c|c|c|c|c|}
\hline \multirow[t]{4}{*}{$\begin{array}{c}\text { Viga } \\
\text { s }\end{array}$} & \multicolumn{3}{|c|}{$\begin{array}{l}\mathrm{h}_{\text {opt }} \\
(\mathrm{cm})\end{array}$} & \multicolumn{3}{|c|}{$\begin{array}{l}\mathrm{h}_{\mathrm{opt}} \\
(\mathrm{cm})\end{array}$} & \multicolumn{3}{|c|}{$\begin{array}{l}\mathrm{h}_{\mathrm{fixo}} \\
(\mathrm{cm})\end{array}$} & $\begin{array}{l}\mathrm{h}_{\text {fixo }} \\
(\mathrm{cm})\end{array}$ & \\
\hline & \multicolumn{3}{|c|}{$\mathrm{I}_{\text {Servico }}$} & \multicolumn{3}{|c|}{$\mathrm{I}_{0}$} & \multicolumn{3}{|c|}{$\mathrm{I}_{\text {Servico }}$} & $\mathrm{I}_{0}$ & \\
\hline & $\mathrm{MEF}_{\mathrm{i}}$ & MOHR & $\mathrm{MEF}_{\mathrm{f}}$ & $\mathrm{MEF}_{\mathrm{i}}$ & $\mathrm{MEF}_{\text {opt }}$ & $\mathrm{MEF}_{\mathrm{f}}$ & $\mathrm{MEF}_{\mathrm{i}}$ & MOHR & $\mathrm{MEF}_{\mathrm{f}}$ & $\mathrm{MEF}_{\mathrm{f}}$ & \\
\hline & $\begin{array}{l}\text { flecha } \\
(\mathrm{cm})\end{array}$ & $\begin{array}{l}\text { fleda } \\
(\mathrm{cm})\end{array}$ & $\begin{array}{l}\text { flecha } \\
(\mathrm{cm})\end{array}$ & $\begin{array}{l}\text { flecha } \\
(\mathrm{cm})\end{array}$ & $\begin{array}{l}\text { flecha } \\
(\mathrm{cm})\end{array}$ & $\begin{array}{l}\text { fledha } \\
(\mathrm{cm})\end{array}$ & $\begin{array}{l}\text { flecha } \\
(\mathrm{cm})\end{array}$ & $\begin{array}{l}\text { flecha } \\
(\mathrm{cm})\end{array}$ & $\begin{array}{l}\text { flecha } \\
(\mathrm{cm})\end{array}$ & $\begin{array}{l}\text { flecha } \\
(\mathrm{cm})\end{array}$ & $\begin{array}{c}\text { flecha }_{\text {lim }} \\
\text { (cm) }\end{array}$ \\
\hline 1 & 0.00 & 0.00 & 0.90 & 0.00 & 0.00 & 0.57 & 0.51 & 0.43 & 0.49 & 0.15 & 1.12 \\
\hline 2 & 0.00 & 0.00 & 0.40 & 0.00 & 0.00 & 0.16 & 0.32 & 0.26 & 0.31 & 0.06 & 1.12 \\
\hline 3 & 0.00 & 0.00 & 0.42 & 0.00 & 0.00 & 0.16 & 0.31 & 0.25 & 0.30 & 0.05 & 1.12 \\
\hline 4 & 0.00 & 0.00 & 0.37 & 0.00 & 0.00 & 0.23 & 0.19 & 0.16 & 0.26 & 0.04 & 1.79 \\
\hline 5 & 0.82 & 0.00 & 0.87 & 0.61 & 0.00 & 0.64 & 0.53 & 0.48 & 0.54 & 0.26 & 1.23 \\
\hline 6 & 0.84 & 0.00 & 0.89 & 0.61 & 0.00 & 0.64 & 0.53 & 0.48 & 0.55 & 0.26 & 1.23 \\
\hline 7 & 0.00 & 0.00 & 0.51 & 0.00 & 0.00 & 0.29 & 0.40 & 0.36 & 0.40 & 0.14 & 1.27 \\
\hline 8 & 0.00 & 0.00 & 0.18 & 0.00 & 0.00 & 0.13 & 0.00 & 0.00 & 0.11 & 0.00 & 0.72 \\
\hline 9 & 0.00 & 0.00 & 0.64 & 0.00 & 0.00 & 0.42 & 0.49 & 0.44 & 0.48 & 0.21 & 1.27 \\
\hline 10 & 0.83 & 0.00 & 0.88 & 0.62 & 0.00 & 0.65 & 0.53 & 0.48 & 0.55 & 0.26 & 1.23 \\
\hline 11 & 0.89 & 0.00 & 0.93 & 0.63 & 0.00 & 0.65 & 0.53 & 0.47 & 0.54 & 0.24 & 1.23 \\
\hline 12 & 0.00 & 0.00 & 0.42 & 0.00 & 0.00 & 0.25 & 0.24 & 0.21 & 0.30 & 0.05 & 1.79 \\
\hline 13 & 0.00 & 0.00 & 0.41 & 0.00 & 0.00 & 0.16 & 0.32 & 0.26 & 0.31 & 0.06 & 1.12 \\
\hline 14 & 0.00 & 0.00 & 0.52 & 0.00 & 0.00 & 0.12 & 0.24 & 0.20 & 0.24 & 0.04 & 1.12 \\
\hline 15 & 0.00 & 0.00 & 0.89 & 0.00 & 0.00 & 0.57 & 0.51 & 0.42 & 0.49 & 0.15 & 1.12 \\
\hline 16 & 0.00 & 0.00 & 0.75 & 0.00 & 0.00 & 0.50 & 0.47 & 0.41 & 0.46 & 0.14 & 1.59 \\
\hline 17 & $\cdots$ & --- & 0.87 & 0.63 & 0.00 & 0.60 & 0.23 & 0.20 & 0.22 & 0.05 & 0.84 \\
\hline 18 & -.. & --- & 0.89 & 0.64 & 0.00 & 0.61 & 0.23 & 0.20 & 0.23 & 0.05 & 0.84 \\
\hline
\end{tabular}




\begin{tabular}{|c|c|c|c|c|c|c|c|c|c|c|c|}
\hline \multirow[t]{4}{*}{$\begin{array}{c}\text { Viga } \\
\mathrm{s}\end{array}$} & \multicolumn{3}{|c|}{$\begin{array}{l}\mathrm{h}_{\mathrm{opt}} \\
(\mathrm{cm})\end{array}$} & \multicolumn{3}{|c|}{$\begin{array}{l}\mathrm{h}_{\mathrm{opt}} \\
(\mathrm{cm})\end{array}$} & \multicolumn{3}{|c|}{$\begin{array}{l}\mathrm{h}_{\text {fixo }} \\
(\mathrm{cm})\end{array}$} & $\begin{array}{l}\mathrm{h}_{\text {fixo }} \\
(\mathrm{cm})\end{array}$ & \\
\hline & \multicolumn{3}{|c|}{$\mathrm{I}_{\text {Servico }}$} & \multicolumn{3}{|c|}{$\mathrm{I}_{0}$} & \multicolumn{3}{|c|}{$\mathrm{I}_{\text {Servico }}$} & $\mathrm{I}_{0}$ & \\
\hline & $\mathrm{MEF}_{\mathrm{i}}$ & MOHR & $\mathrm{MEF}_{\mathrm{f}}$ & $\mathrm{MEF}_{\mathrm{i}}$ & $\mathrm{MEF}_{\mathrm{opt}}$ & $\mathrm{MEF}_{\mathrm{f}}$ & $\mathrm{MEF}_{\mathrm{i}}$ & MOHR & $\mathrm{MEF}_{\mathrm{f}}$ & $\mathrm{MEF}_{\mathrm{f}}$ & \\
\hline & $\begin{array}{l}\text { flecha } \\
(\mathrm{cm})\end{array}$ & $\begin{array}{l}\text { flecha } \\
(\mathrm{cm})\end{array}$ & $\begin{array}{l}\text { flecha } \\
(\mathrm{cm})\end{array}$ & $\begin{array}{l}\text { flecha } \\
(\mathrm{cm})\end{array}$ & $\begin{array}{l}\text { flecha } \\
(\mathrm{cm})\end{array}$ & $\begin{array}{l}\text { flecha } \\
\text { (cm) }\end{array}$ & $\begin{array}{l}\text { fledha } \\
(\mathrm{cm})\end{array}$ & $\begin{array}{l}\text { flecha } \\
(\mathrm{cm})\end{array}$ & $\begin{array}{l}\text { flecha } \\
(\mathrm{cm})\end{array}$ & $\begin{array}{l}\text { flecha } \\
(\mathrm{cm})\end{array}$ & $\begin{array}{l}\text { flecha } a_{\text {lim }} \\
(\mathrm{cm})\end{array}$ \\
\hline 19 & 1.21 & 0.00 & 1.23 & 0.73 & 0.00 & 0.73 & 0.51 & 0.46 & 0.49 & 0.23 & 1.04 \\
\hline 20 & 1.21 & 0.00 & 1.23 & 0.73 & 0.00 & 0.73 & 0.51 & 0.46 & 0.49 & 0.23 & 1.04 \\
\hline 21 & 0.65 & 0.00 & 0.65 & 0.55 & 0.00 & 0.54 & 0.51 & 0.48 & 0.50 & 0.29 & 1.17 \\
\hline 22 & 0.63 & 0.00 & 0.63 & 0.53 & 0.00 & 0.53 & 0.52 & 0.48 & 0.50 & 0.31 & 1.17 \\
\hline 23 & 0.00 & 0.00 & 1.02 & 0.00 & 0.00 & 0.76 & 0.00 & 0.00 & -0.40 & 0.00 & 0.92 \\
\hline 24 & 1.01 & 0.00 & 1.02 & 0.84 & 0.00 & 0.84 & 0.75 & 0.71 & 0.74 & 0.44 & 1.44 \\
\hline 25 & 1.01 & 0.00 & 1.02 & 0.84 & 0.00 & 0.85 & 0.75 & 0.71 & 0.74 & 0.44 & 1.44 \\
\hline 26 & 0.00 & 0.00 & 0.33 & 0.00 & 0.00 & 0.13 & 0.14 & 0.09 & 0.19 & 0.03 & 0.92 \\
\hline 27 & 0.00 & 0.00 & 0.78 & 0.00 & 0.00 & 0.60 & 0.61 & 0.55 & 0.59 & 0.26 & 1.44 \\
\hline 28 & 0.00 & 0.00 & 0.73 & 0.00 & 0.00 & 0.54 & 0.59 & 0.53 & 0.58 & 0.25 & 1.44 \\
\hline 29 & 0.32 & -0.77 & 0.32 & 0.00 & 0.00 & 0.22 & 0.15 & 0.10 & 0.19 & 0.05 & 0.77 \\
\hline 30 & 0.00 & 0.00 & 0.50 & 0.00 & 0.00 & 0.22 & 0.17 & 0.13 & 0.23 & 0.07 & 0.77 \\
\hline 31 & -- & --. & 0.12 & --- & --. & 0.15 & 0.15 & 0.14 & 0.17 & 0.02 & 0.92 \\
\hline 32 & 1.10 & 0.00 & 1.10 & 0.90 & 0.00 & 0.90 & 0.74 & 0.70 & 0.72 & 0.37 & 1.44 \\
\hline 33 & 1.02 & 0.00 & 1.02 & 0.85 & 0.00 & 0.85 & 0.75 & 0.71 & 0.74 & 0.43 & 1.44 \\
\hline 34 & 0.75 & 0.00 & 0.75 & 0.49 & 0.00 & 0.49 & 0.44 & 0.38 & 0.42 & 0.20 & 0.92 \\
\hline 35 & 0.55 & 0.00 & 0.55 & 0.44 & 0.00 & 0.44 & 0.52 & 0.49 & 0.51 & 0.36 & 1.17 \\
\hline 36 & 0.64 & 0.00 & 0.64 & 0.54 & 0.00 & 0.54 & 0.51 & 0.48 & 0.50 & 0.30 & 1.17 \\
\hline 37 & 1.04 & 0.00 & 1.05 & 0.70 & 0.00 & 0.70 & 0.51 & 0.46 & 0.50 & 0.24 & 1.04 \\
\hline 38 & 1.20 & 0.00 & 1.23 & 0.73 & 0.00 & 0.73 & 0.51 & 0.46 & 0.49 & 0.23 & 1.04 \\
\hline 39 & 0.77 & -0.84 & 0.78 & --- & --- & 0.68 & 0.23 & 0.20 & 0.22 & 0.05 & 0.84 \\
\hline 40 & --. & -- & 0.87 & --- & $\cdots$ & 0.63 & 0.23 & 0.20 & 0.23 & 0.05 & 0.84 \\
\hline 41 & 0.00 & 0.00 & 0.74 & 0.00 & 0.00 & 0.48 & 0.48 & 0.41 & 0.46 & 0.14 & 1.59 \\
\hline
\end{tabular}

TABELA 8.12 - Análise das flechas máximas das vigas do Ed. LAGO AZUL processando a estrutura por diferentes modelos, adotar $P_{a c}=3 \%$. 
Percebe-se através da tabela 8.12 que a maior parte das vigas tem a restrição de otimização dominante no momento fletor negativo, não na flecha máxima. Este resultado também é devido ao alto grau de solicitação das vigas. As vigas V23 e V30 fazem parte desse conjunto porque apresentam momento fletor negativo devido aos resultados obtidos quando a estrutura foi modelada como pavimento. As vigas V29 e V39 apresentam flechas negativas quando estas são calculadas por analogia de Mohr. Isto acontece porque estas vigas têm alturas bem próximas da mínima, ou da espessura das lajes adjacentes, quase se confundindo com a espessura das placas, e, nesta situação, os resultados apresentados por Mohr são deteriorados.

Não há praticamente diferença entre os resultados das flechas obtidas com os diferentes modelos. Isto ocorre pelo fato do "bom comportamento" estrutural do pavimento em análise.

Mantendo-se as características da estrutura, será feita uma análise dos seguintes modelos:

1. Não se considera a fluência e as inércias dos elementos são calculadas no Estádio II.

2. Considera-se a fluência e as inércias dos elementos são calculadas no Estádio II.

3. Não se considera a fluência e as inércias dos elementos são calculadas no Estádio I.

4. Considera-se a fluência e as inércias dos elementos são calculadas no Estádio I.

Apresenta-se na tabela 8.13 o tempo de processamento para convergência dos diferentes modelos. Ainda nesta tabela, pode-se observar a variação do custo antes e depois do processo de otimização, assim como a sua taxa de redução ou economia em relação aos valores iniciais. 


\begin{tabular}{|c|c|c|c|c|c|c|}
\hline Modelo & $\begin{array}{c}\text { Tempo } \\
\text { total (s) }\end{array}$ & $\begin{array}{c}\mathrm{n}^{\circ} \mathrm{de} \\
\text { iterações }\end{array}$ & $\begin{array}{c}\text { Tempo por } \\
\text { iteração (s) }\end{array}$ & $\begin{array}{c}\text { Custo } \\
\text { inicial } \\
\mathrm{R} \$\end{array}$ & $\begin{array}{c}\text { Custo } \\
\text { final R\$ }\end{array}$ & $\begin{array}{c}\text { Custo final / } \\
\text { Custo inicial } \\
(\%)\end{array}$ \\
\hline 1 & 748 & 19 & 39,36842 & 13925 & 9581 & 68,8043 \\
\hline 2 & 1221 & 31 & 39,3871 & 13925 & 9576 & 68,7684 \\
\hline 3 & 1811 & 53 & 34,16981 & 13925 & 9526 & 68,4093 \\
\hline 4 & 1013 & 31 & 32,67742 & 13925 & 9569 & 68,7181 \\
\hline
\end{tabular}

TABELA 8.13 - Análise do tempo e do custo apresentados pelos diferentes modelos de análise do LAGO AZUL.

Como pode ser observado no gráfico 8.20 , a convergência do custo dos diferentes modelos é rápida, chegando próximo ao resultado final já na segunda iteração. Como esta estrutura está fortemente carregada, a restrição de flecha não é predominante na maioria das vigas, acarretando valores próximos para os custos finais dos diferentes modelos.

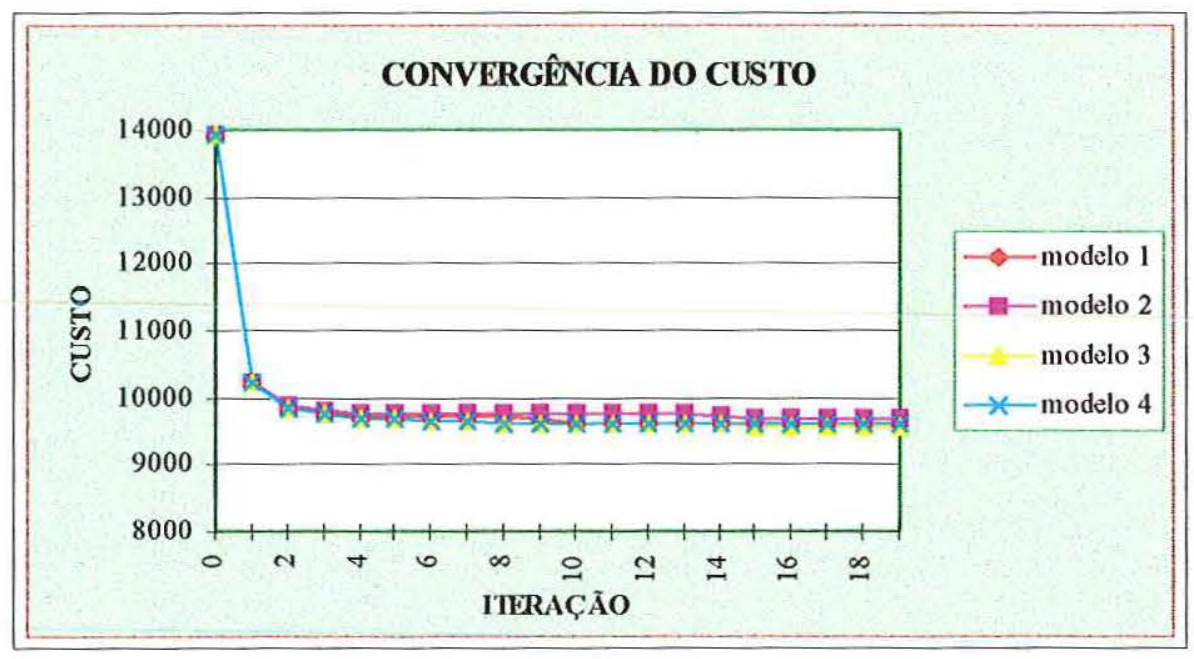

GRÁFICO 8.20 - Análise da convergência do custo do LAGO AZUL.

O gráfico 8.21 mostra que houve uma redução razoável nas alturas das vigas. Caso se deseja utilizar valores práticos, como no caso do projeto original, que foram utilizados apenas dois valores para as alturas das vigas, estes poderiam ser: $60 \mathrm{~cm}$ para as vigas com alturas originais de $70 \mathrm{~cm}$ e $30 \mathrm{~cm}$ para as vigas com alturas originais de $50 \mathrm{~cm}$. 
A aplicação prática do programa SSPO para pre-dimensionamento das alturas das vigas é claramente observada quando analisado o gráfico 8.21.

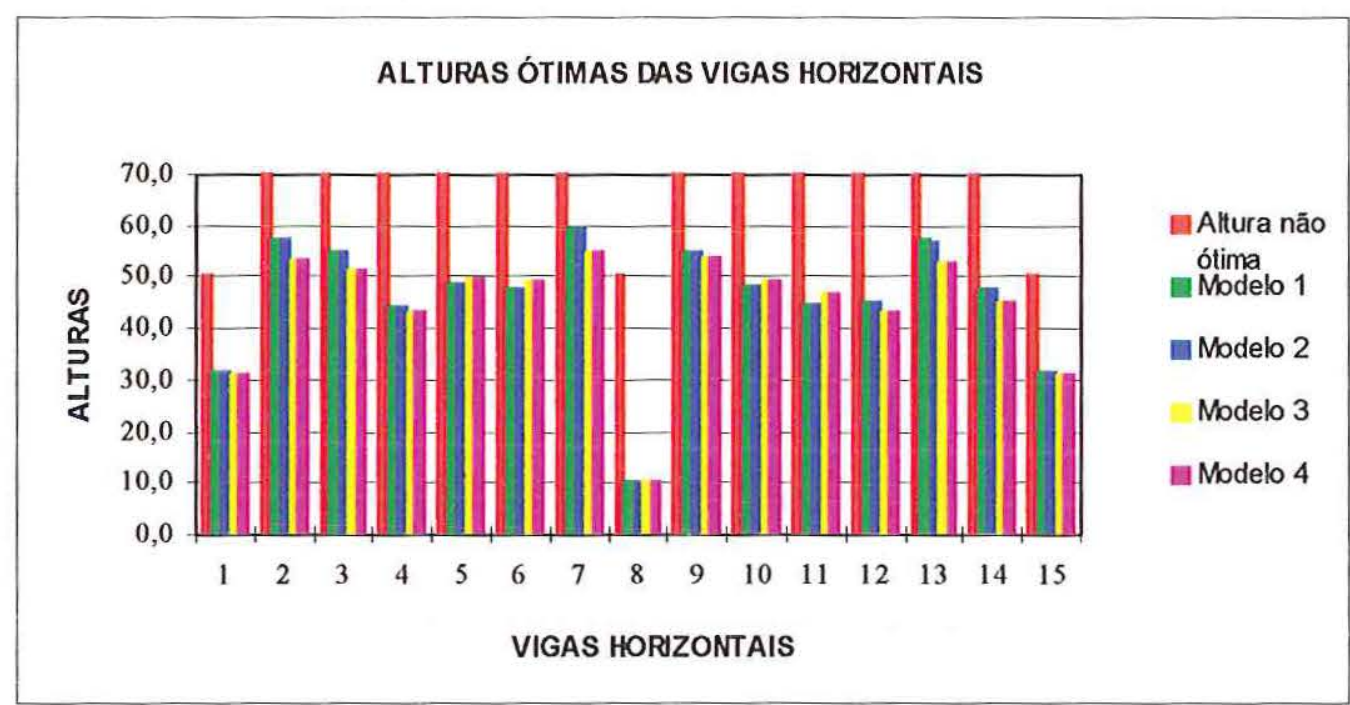

GRÁFICO 8.21 - Análise da variação das alturas das vigas horizontais do LAGO AZUL. 


\subsection{3 - Exemplo - Edifício Residencial}

Neste item, será analisado o pilotis de um Edificio residencial, o qual é utilizado como suporte para um prédio composto por 4 pavimentos, que será feito também em alvenaria estrutural. Diante disto, verifica-se que as ações verticais nele aplicadas são de módulos bastante elevados. Neste nível, foram utilizadas lajes pré-moldadas e vigas de concreto armado, caracterizando a principal diferença do exemplo 8.2.2, que é o tratamento da estrutura como uma grelha, não mais como um pavimento. Tanto o carregamento, quanto a geometria, as características dos materiais e as vinculações, foram considerados semelhantes ao projeto original.

A malha utilizada tem espaçamento variável, girando entre $30 \mathrm{~cm}$ e $60 \mathrm{~cm}$. Para a discretização da estrutura foram utilizados 385 nós, 390 elementos de barra e 28 elementos de placa. As placas foram utilizadas para a modelagem das lajes em balanço, ver planta de forma, figura 8.7 . 


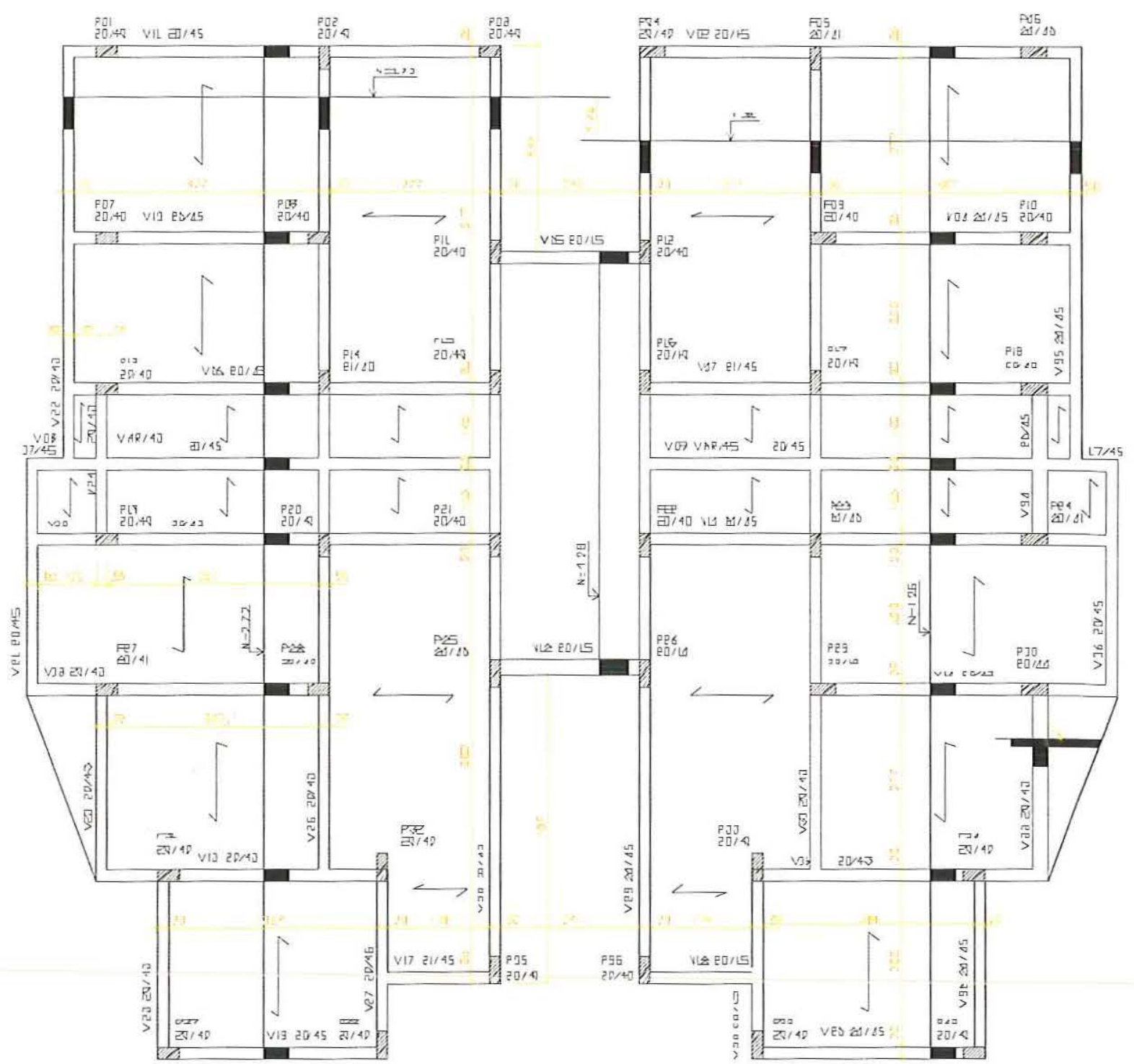

FIGURA 8.7 - Forma do pilotis do edifício RESIDENCIAL

A convergência do custo ocorreu em torno da $6^{0}$ iteração. Apresentam-se na tabela 8.11 alguns dos resultados obtidos neste exemplo. 


\begin{tabular}{|c|c|c|c|c|c|c|c|}
\hline \multirow[t]{3}{*}{ Vigas } & & $\mathrm{P}_{\mathrm{ac}}=4 \%$ & $\mathrm{P}_{\mathrm{ac}}=3 \%$ & $\mathrm{P}_{\mathrm{ac}}=2 \%$ & $\mathrm{P}_{\mathrm{ac}}=4 \%$ & $\mathrm{P}_{\mathrm{ac}}=3 \%$ & $P_{a c}=2 \%$ \\
\hline & & \multicolumn{3}{|c|}{$I_{\text {Serviço }}$} & \multicolumn{3}{|c|}{$\mathrm{I}_{0}$} \\
\hline & $\mathrm{h}_{\mathrm{i}}(\mathrm{cm})$ & $\mathrm{h}_{\mathrm{opt}}(\mathrm{cm})$ & $\mathrm{h}_{\mathrm{opt}}(\mathrm{cm})$ & $\mathrm{h}_{\mathrm{opt}}(\mathrm{cm})$ & $\mathrm{h}_{\mathrm{opt}}(\mathrm{cm})$ & $\mathrm{h}_{\mathrm{opt}}(\mathrm{cm})$ & $\mathrm{h}_{\mathrm{opt}}(\mathrm{cm})$ \\
\hline 1 & 45 & 25.7 & 26.6 & 29.1 & 24.3 & 26.0 & 28.3 \\
\hline 2 & 45 & 25.7 & 26.6 & 29.1 & 24.3 & 26.0 & 28.3 \\
\hline 3 & 45 & 32.9 & 35.4 & 38.6 & 32.8 & 35.2 & 38.4 \\
\hline 4 & 45 & 32.9 & 35.4 & 38.6 & 32.8 & 35.2 & 38.4 \\
\hline 5 & 45 & 21.5 & 21.4 & 21.4 & 18.1 & 18.6 & 20.2 \\
\hline 6 & 45 & 23.1 & 23.0 & 22.8 & 16.2 & 16.1 & 17.1 \\
\hline 7 & 45 & 23.1 & 23.0 & 22.8 & 16.2 & 16.1 & 17.1 \\
\hline 8 & 45 & 33.9 & 36.7 & 40.7 & 33.9 & 37.6 & 37.7 \\
\hline 9 & 45 & 33.9 & 36.7 & 40.7 & 33.9 & 37.6 & 37.7 \\
\hline 10 & 45 & 23.4 & 23.3 & 22.8 & 21.4 & 19.8 & 32.4 \\
\hline 11 & 45 & 23.4 & 23.3 & 22.8 & 21.4 & 19.8 & 32.4 \\
\hline 12 & 45 & 21.5 & 21.4 & 21.4 & 18.1 & 18.6 & 20.2 \\
\hline 13 & 45 & 33.9 & 36.5 & 39.8 & 34.1 & 36.6 & 40.7 \\
\hline 14 & 45 & 33.9 & 36.5 & 39.8 & 34.1 & 36.6 & 40.7 \\
\hline 15 & 45 & 37.2 & 40.1 & 43.8 & 37.1 & 39.9 & 43.6 \\
\hline 16 & 45 & 37.2 & 40.1 & 43.8 & 37.1 & 39.9 & 43.6 \\
\hline 17 & 45 & 16.1 & 16.1 & 16.1 & 12.0 & 12.4 & 13.3 \\
\hline 18 & 45 & 16.1 & 16.1 & 16.1 & 12.0 & 12.4 & 13.3 \\
\hline 19 & 45 & 33.3 & 33.2 & 35.4 & 30.9 & 32.5 & 35.5 \\
\hline 20 & 45 & 33.3 & 33.2 & 35.4 & 30.9 & 32.5 & 35.5 \\
\hline 21 & 45 & 16.3 & 17.7 & 19.8 & 15.9 & 18.6 & 16.0 \\
\hline 22 & 45 & 19.6 & 21.2 & 23.1 & 19.1 & 20.6 & 22.3 \\
\hline 23 & 45 & 24.1 & 24.1 & 24.1 & 20.6 & 21.2 & 23.7 \\
\hline 24 & 45 & 42.5 & 46.0 & 50.6 & 43.0 & 47.0 & 49.8 \\
\hline 25 & 45 & 23.4 & 23.4 & 23.5 & 18.4 & 18.4 & 19.8 \\
\hline 26 & 45 & 32.3 & 34.7 & 37.9 & 30.0 & 32.0 & 35.7 \\
\hline 27 & 45 & 25.1 & 25.7 & 28.0 & 24.0 & 25.8 & 28.1 \\
\hline 28 & 45 & 37.7 & 40.1 & 43.7 & 38.2 & 41.1 & 45.0 \\
\hline 29 & 45 & 37.7 & 40.1 & 43.7 & 38.2 & 41.1 & 45.0 \\
\hline
\end{tabular}




\begin{tabular}{|c|c|c|c|c|c|c|c|}
\hline \multirow{2}{*}{ Vigas } & \multirow{2}{*}{} & $\mathrm{P}_{\mathrm{ac}}=4 \%$ & $\mathrm{P}_{\mathrm{ac}}=3 \%$ & $\mathrm{P}_{\mathrm{ac}}=2 \%$ & $\mathrm{P}_{\mathrm{ac}}=4 \%$ & $\mathrm{P}_{\mathrm{ac}}=3 \%$ & $\mathrm{P}_{\mathrm{ac}}=2 \%$ \\
\cline { 3 - 8 } & $\mathrm{h}_{\mathrm{i}}(\mathrm{cm})$ & $\mathrm{h}_{\mathrm{opt}}(\mathrm{cm})$ & $\mathrm{h}_{\text {opt }}(\mathrm{cm})$ & $\mathrm{h}_{\text {opt }}(\mathrm{cm})$ & $\mathrm{h}_{\text {opt }}(\mathrm{cm})$ & $\mathrm{h}_{\text {opt }}(\mathrm{cm})$ & $\mathrm{h}_{\text {opt }}(\mathrm{cm})$ \\
\hline 30 & 45 & 25.1 & 25.7 & 28.0 & 24.0 & 25.8 & 28.1 \\
\hline 31 & 45 & 32.3 & 34.7 & 37.9 & 30.0 & 32.0 & 35.7 \\
\hline 32 & 45 & 23.4 & 23.5 & 23.5 & 18.4 & 18.4 & 19.8 \\
\hline 33 & 45 & 24.1 & 24.1 & 24.1 & 20.6 & 21.3 & 23.8 \\
\hline 34 & 45 & 42.5 & 46.0 & 50.6 & 43.0 & 47.0 & 49.8 \\
\hline 35 & 45 & 19.6 & 21.2 & 23.0 & 19.1 & 20.6 & 22.3 \\
\hline 36 & 45 & 16.3 & 17.7 & 19.8 & 15.9 & 18.8 & 16.0 \\
\hline Custo R\$ & $8.137,96$ & $5.605,34$ & $5.846,86$ & $6.204,84$ & $5.366,95$ & $5.641,39$ & $6.145,01$ \\
\hline Núm. & & 5 & 4 & 6 & 6 & 6 & 9 \\
iterações & & & & & & & \\
\hline
\end{tabular}

TABELA 8.14 - Análise das alturas das vigas de um Ed. RESIDENCIAL.

Nenhuma viga sumiu no processo de otimização, isto se explica pelo fato da "não" existência de elemento de placa. Ou seja, neste tipo de modelo as vigas nunca somem no processo de otimização. 


\begin{tabular}{|c|c|c|c|c|c|c|c|c|c|c|c|}
\hline \multirow[t]{4}{*}{$\begin{array}{c}\text { Viga } \\
\mathrm{s}\end{array}$} & \multicolumn{3}{|c|}{$\begin{array}{l}\mathrm{h}_{\text {opt }} \\
(\mathrm{cm})\end{array}$} & \multicolumn{3}{|c|}{$\begin{array}{l}\mathrm{h}_{\mathrm{opt}} \\
(\mathrm{cm})\end{array}$} & \multicolumn{3}{|c|}{$\begin{array}{l}\mathrm{h}_{\text {fixo }} \\
(\mathrm{cm})\end{array}$} & $\begin{array}{l}\mathrm{h}_{\text {fixo }} \\
(\mathrm{cm})\end{array}$ & \\
\hline & \multicolumn{3}{|c|}{$\mathrm{I}_{\text {Servico }}$} & \multicolumn{3}{|c|}{$\mathrm{I}_{0}$} & \multicolumn{3}{|c|}{$\mathrm{I}_{\text {Serriço }}$} & $\mathrm{I}_{0}$ & \\
\hline & $\mathrm{MEF}_{\mathrm{i}}$ & MOHR & $\mathrm{MEF}_{\mathrm{f}}$ & $\mathrm{MEF}_{\mathrm{i}}$ & $\mathrm{MEF}_{\text {opt }}$ & $\mathrm{MEF}_{\mathrm{f}}$ & $\mathrm{MEF}_{\mathrm{i}}$ & MOHR & $\mathrm{MEF}_{\mathrm{f}}$ & $\mathrm{MEF}_{\mathrm{f}}$ & \\
\hline & $\begin{array}{l}\text { flecha } \\
(\mathrm{cm})\end{array}$ & $\begin{array}{c}\text { fledia } \\
(\mathrm{cm})\end{array}$ & $\begin{array}{l}\text { flecha } \\
(\mathrm{cm})\end{array}$ & $\begin{array}{l}\text { flecha } \\
(\mathrm{cm})\end{array}$ & $\begin{array}{l}\text { flecha } \\
(\mathrm{cm})\end{array}$ & $\begin{array}{l}\text { flecha } \\
(\mathrm{cm})\end{array}$ & $\begin{array}{l}\text { flecha } \\
(\mathrm{cm})\end{array}$ & $\begin{array}{l}\text { flecha } \\
(\mathrm{cm})\end{array}$ & $\begin{array}{l}\text { flecha } \\
(\mathrm{cm})\end{array}$ & $\begin{array}{l}\text { flecha } \\
(\mathrm{cm})\end{array}$ & $\begin{array}{l}\text { flecha } a_{\text {lim }} \\
(\mathrm{cm})\end{array}$ \\
\hline 1 & 0.00 & 0.00 & 1.42 & 0.00 & 0.00 & 0.87 & 0.75 & 0.63 & 0.72 & 0.17 & 1.29 \\
\hline 2 & 0.00 & 0.00 & 1.42 & 0.00 & 0.00 & 0.87 & 0.75 & 0.63 & 0.72 & 0.17 & 1.29 \\
\hline 3 & 1.24 & 0.00 & 1.24 & 0.91 & 0.00 & 0.91 & 0.90 & 0.77 & 0.87 & 0.45 & 1.29 \\
\hline 4 & 1.24 & 0.00 & 1.24 & 0.91 & 0.00 & 0.91 & 0.90 & 0.77 & 0.87 & 0.45 & 1.29 \\
\hline 5 & 1.00 & 0.87 & 1.00 & 0.80 & 0.00 & 0.80 & 0.41 & 0.35 & 0.39 & 0.06 & 0.87 \\
\hline 6 & 1.10 & 0.99 & 1.10 & 0.99 & 0.99 & 0.99 & 0.49 & 0.43 & 0.47 & 0.06 & 1.29 \\
\hline 7 & 1.10 & 0.99 & 1.10 & 0.99 & 0.99 & 0.99 & 0.49 & 0.43 & 0.47 & 0.06 & 1.29 \\
\hline 8 & 0.00 & 0.00 & 0.77 & 0.00 & 0.00 & 0.39 & 0.60 & 0.46 & 0.57 & 0.19 & 1.29 \\
\hline 9 & 0.00 & 0.00 & 0.77 & 0.00 & 0.00 & 0.39 & 0.60 & 0.46 & 0.57 & 0.19 & 1.29 \\
\hline 10 & 1.09 & 0.99 & 1.11 & 1.52 & 0.93 & 1.52 & 0.48 & 0.42 & 1.10 & 0.06 & 0.93 \\
\hline 11 & 1.09 & 0.99 & 1.11 & 1.52 & 0.93 & 1.52 & 0.48 & 0.42 & 1.10 & 0.06 & 0.93 \\
\hline 12 & 1.00 & 0.87 & 1.00 & 0.80 & 0.00 & 0.80 & 0.41 & 0.35 & 0.39 & 0.06 & 0.87 \\
\hline 13 & 1.17 & 0.00 & 1.21 & 0.86 & 0.00 & 0.87 & 0.90 & 0.77 & 0.89 & 0.48 & 1.29 \\
\hline 14 & 1.17 & 0.00 & 1.21 & 0.86 & 0.00 & 0.87 & 0.90 & 0.77 & 0.89 & 0.48 & 1.29 \\
\hline 15 & 1.12 & 0.00 & 1.11 & 0.85 & 0.00 & 0.85 & 0.94 & 0.84 & 0.90 & 0.57 & 1.28 \\
\hline 16 & 0.88 & 0.00 & 0.87 & 0.67 & 0.00 & 0.67 & 0.74 & 0.66 & 0.71 & 0.45 & 1.28 \\
\hline 17 & 0.75 & 0.65 & 0.74 & 0.59 & 0.00 & 0.59 & 0.21 & 0.18 & 0.20 & 0.01 & 0.65 \\
\hline 18 & 0.75 & 0.65 & 0.74 & 0.59 & 0.00 & 0.59 & 0.21 & 0.18 & 0.20 & 0.01 & 0.65 \\
\hline 19 & 1.45 & 1.28 & 1.45 & 1.10 & 0.00 & 1.10 & 0.99 & 0.87 & 0.95 & 0.42 & 1.28 \\
\hline 20 & 1.45 & 1.28 & 1.45 & 1.10 & 0.00 & 1.10 & 0.99 & 0.87 & 0.95 & 0.42 & 1.28 \\
\hline 21 & 0.71 & 0.00 & 0.96 & 0.45 & 0.00 & 0.62 & 0.22 & 0.20 & 0.31 & 0.05 & 0.80 \\
\hline 22 & 0.00 & 0.00 & 0.94 & 0.00 & 0.00 & 0.30 & 0.35 & 0.27 & 0.34 & 0.02 & 0.99 \\
\hline 23 & 1.14 & 0.99 & 1.17 & 0.92 & 0.00 & 0.92 & 0.55 & 0.46 & 0.53 & 0.12 & 0.99 \\
\hline 24 & 0.41 & 0.00 & 0.41 & 0.25 & 0.00 & 0.25 & 0.42 & 0.36 & 0.41 & 0.25 & 0.80 \\
\hline 25 & 1.10 & 0.95 & 1.10 & 0.95 & 0.95 & 0.95 & 0.49 & 0.42 & 0.47 & 0.07 & 0.95 \\
\hline
\end{tabular}




\begin{tabular}{|c|c|c|c|c|c|c|c|c|c|c|}
\hline \multirow{2}{*}{$\begin{array}{c}\text { Viga } \\
\text { s }\end{array}$} & \multicolumn{3}{|c|}{$\begin{array}{c}\mathrm{h}_{\text {opt }} \\
(\mathrm{cm})\end{array}$} & \multicolumn{3}{c|}{$\begin{array}{c}\mathrm{h}_{\text {opt }} \\
(\mathrm{cm})\end{array}$} & \multicolumn{3}{c|}{$\mathrm{h}_{\text {fixo }}$} \\
$(\mathrm{cm})$
\end{tabular}

TABELA 8.15 - Análise das flechas máximas das vigas do Ed. RESIDENCIAL processando a estrutura por diferentes modelos, adotar $P_{a c}=3 \%$.

Em boa parte das vigas não há grande diferença em suas alturas para os diferentes tipos de modelagem. Mas para as flechas das mesmas existem diferenças razoáveis. Isto ocorre pelo fato que provavelmente para estas vigas a restrição de minimização dominante não é a de flecha máxima.

A diferença entre as flechas admissíveis e as flechas calculadas nas estruturas ocorre devido à diferença entre o modelo de cálculo utilizado na otimização e o utilizado para determinar as flechas das vigas.

Obtiveram-se as alturas das vigas pelo programa SSPO, e, mantendo-se as mesmas condições de carregamento, vinculação e constitutiva, com exceção da concepção das inércias dos elementos, a estrutura foi processada pelo TQS e obtidos os resultados apresentados em seguida. 
A respeito da inércia, o SSPO considerou a seção fissurada, segundo formulação apresentada no capítulo 7. O TQS considera a deformação elástico-linear, com inércia no Estádio I.

Os diagramas mostrados nas figuras 8.8 e 8.9 apresentam assimetria, embora a estrutura seja simétrica. Isto acontece pela assimetria na discretização da malha utilizada pelo TQS. Se a estrutura é simétrica, é desnecessário conhecer informações de ambos os lados, uma vez que estas informações têm um custo computacional.

Os resultados mais representativos de deslocamentos e de momentos fletores são explicitados numericamente nos diagramas 8.8 e 8.9. Na realidade, cada elemento apresenta estes resultados, mas devido à escala do desenho não é possível enxergá-los.

Como se pode observar, assim como os deslocamentos, os momentos fletores estão de acordo com o modelo de cálculo. 


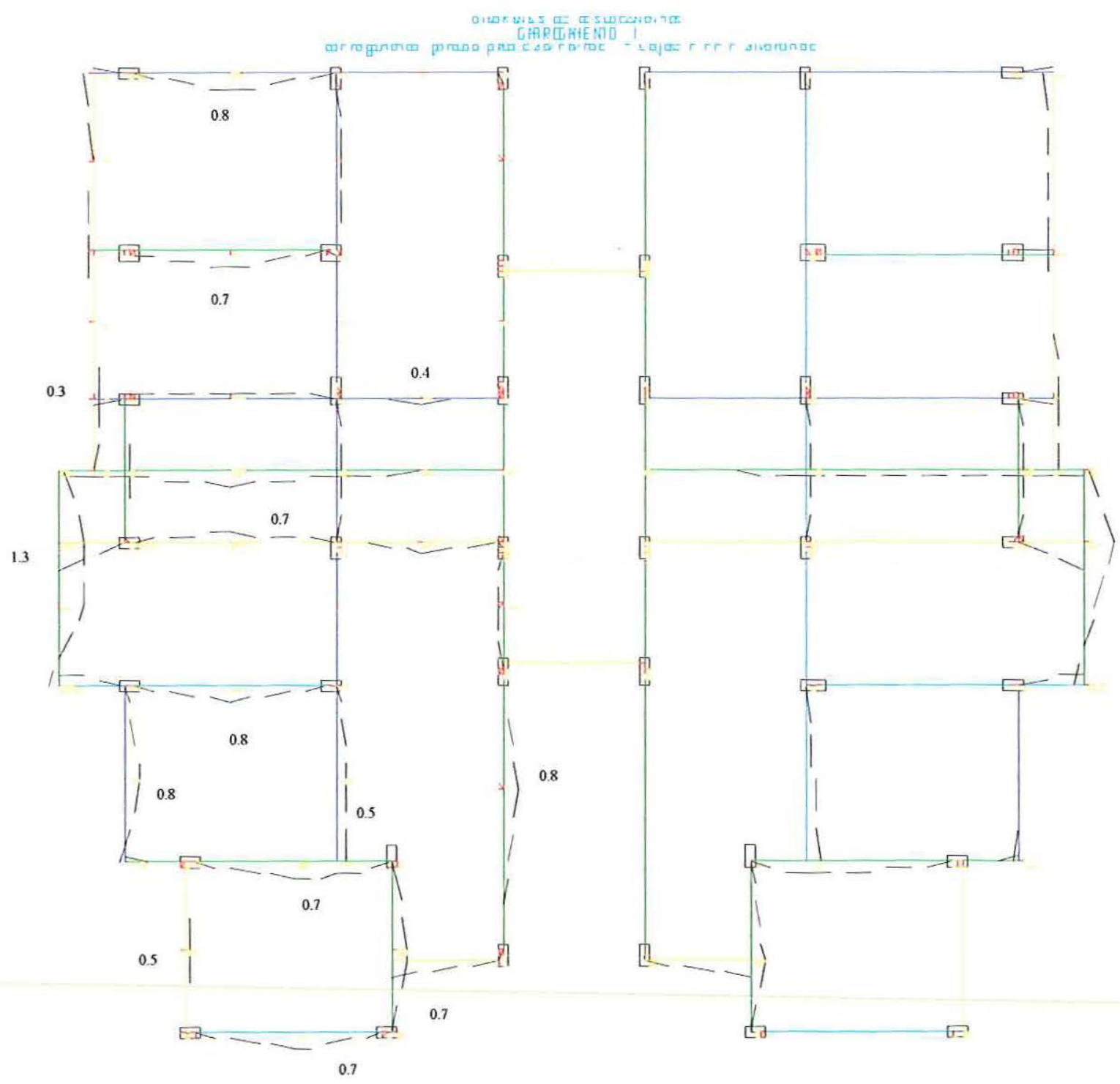

FIGURA 8.8 - Diagrama de deslocamentos da grelha 


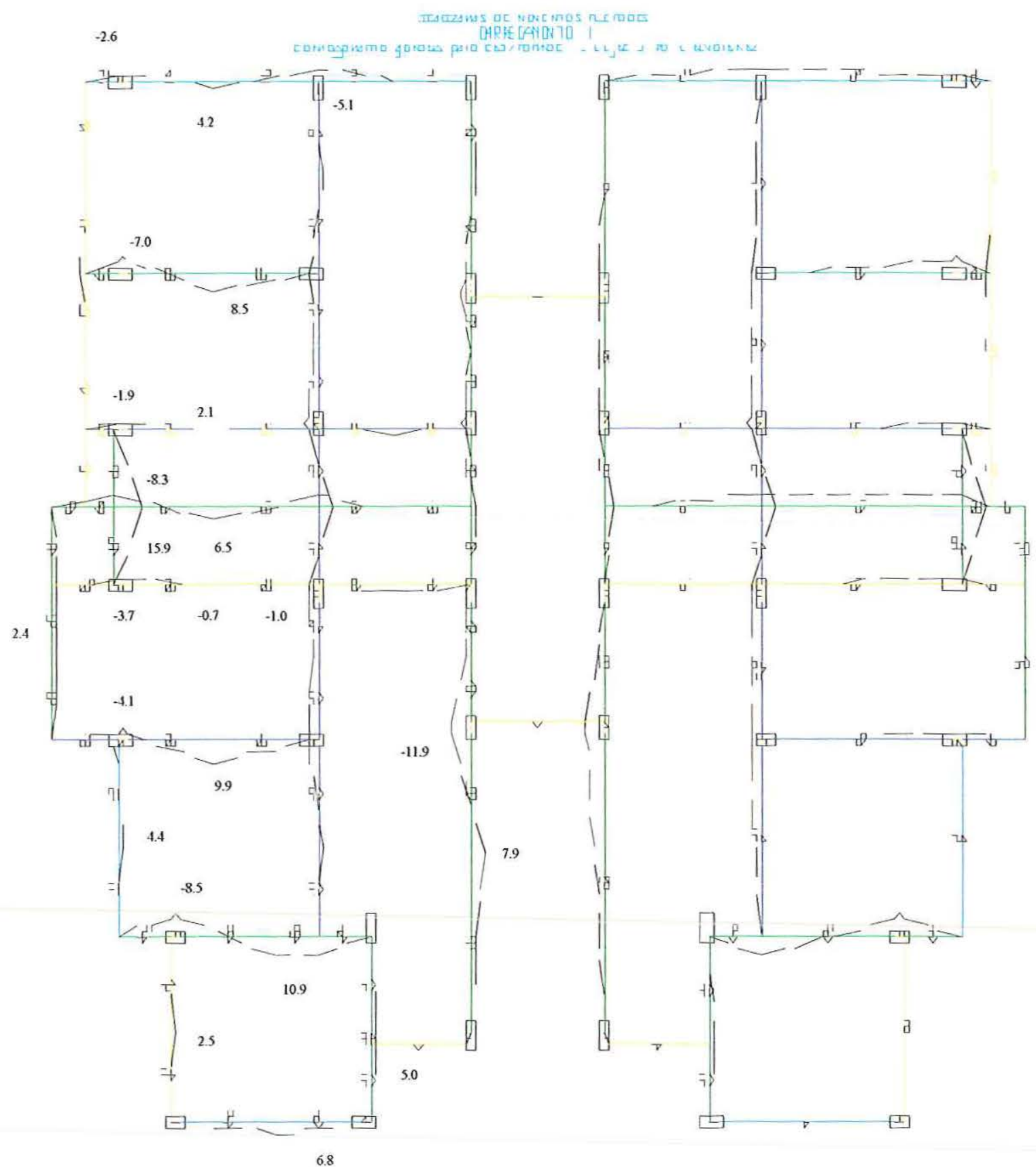

FIGURA 8.9 - Diagrama de momentos fletores da grelha

O resumo do dimensionamento, com os quadros de aço, da estrutura original e otimizada, referentes as mesmas condições utilizadas para obter os diagramas 8.8 e 8.9 , pode ser observado na tabela 8.16. 


\begin{tabular}{|c|c|c|}
\cline { 2 - 3 } \multicolumn{1}{c|}{} & Estrutura original & Estrutura ótima \\
\hline Bitola $(\mathrm{mm})$ & Peso $(\mathrm{kg})$ & Peso $(\mathrm{kg})$ \\
\hline$\phi 5.0$ & 220 & 62 \\
\hline$\phi 6.3$ & 88 & 209 \\
\hline$\phi 8.0$ & 212 & 333 \\
\hline$\phi 10.0$ & 305 & 320 \\
\hline$\phi 12^{5}$ & 354 & 358 \\
\hline$\phi 16$ & 558 & 1257 \\
\hline$\phi 20$ & 678 & 654 \\
\hline$\phi 22$ & --- & 20 \\
\hline$\phi 25$ & --- & 38 \\
\hline$\Sigma$ & 2415 & 3251 \\
\hline
\end{tabular}

TABELA 8.16 - Consumo de aço do Ed. RESIDENCIAL.

Houve um acréscimo de $35 \%$ no consumo de aço da estrutura, após esta ser otimizada. Em contra partida, há uma redução significativa no volume de concreto, como pode ser visto na tabela 8.17 .

\begin{tabular}{|l|c|c|c|c|}
\cline { 2 - 5 } \multicolumn{1}{c|}{} & \multicolumn{2}{c|}{ Estrutura original } & \multicolumn{2}{c|}{ Estrutura ótima } \\
\cline { 2 - 5 } \multicolumn{1}{c|}{} & eixo & face & eixo & face \\
\hline Volume $\left(\mathrm{m}^{3}\right)$ & 18.6 & 16.7 & 12.7 & 11.3 \\
\hline Taxa $\left(\mathrm{kg} / \mathrm{m}^{3}\right)$ & 129.8 & 144.6 & 256.0 & 287.7 \\
\hline
\end{tabular}

TABELA 8.17 - Consumo de concreto do Ed. RESIDENCIAL.

Na prática, para pavimentos de edificios usuais, a taxa é em torno de 100 à $120 \mathrm{~kg} / \mathrm{m}^{3}$. Mas este pavimento recebe toda a carga do prédio que foi construído sobre ele, trazendo como consequência uma taxa de armadura mais elevada.

Para determinar a área de forma apresentada na tabela 8.18 , foi considerado que todas as vigas (originais e otimizadas) tenham dimensões iguais a $20 \mathrm{~cm}$ de base e $45 \mathrm{~cm}$ de altura. Com essas dimensões e o volume de concreto das vigas já conhecido, obteve-se uma área aproximada para as formas. 


\begin{tabular}{|l|c|c|c|}
\cline { 2 - 4 } \multicolumn{1}{c|}{} & Unitário & Estrutura original & Estrutura ótima \\
\hline Aço $(\mathrm{R} \$ / \mathrm{kg})$ & 1,7885 & 4319,23 & 5814,41 \\
\hline Concreto $\left(\mathrm{R} \$ / \mathrm{m}^{3}\right)$ & 131,3900 & 2453,34 & 1668,65 \\
\hline Forma $\left(\mathrm{R} \$ / \mathrm{m}^{2}\right)$ & 24,7666 & 5630,27 & 3844,33 \\
\hline Total $\mathrm{R} \$$ & & 12402,84 & 11327,39 \\
\hline
\end{tabular}

TABELA 8.18 - Custo dos materiais do Ed. RESIDENCIAL.

Como pode ser visto na tabela 8.18 , o preço final da estrutura representa cerca de 91\% do preço inicial. É importante observar que este exemplo apresentou menor diferença entre os resultados originais e após o processo de otimização. 


\section{9 - CONCLUSÃo}

\section{1 - Conclusões do trabalho}

A otimização pode se tornar muito mais atraente e de fácil implementação quando se utilizam técnicas matemáticas associadas a conceitos físicos das variáveis envolvidas. Problemas práticos da engenharia podem limitar as variáveis, obtendo assim uma convergência mais rápida aos extremos das funções objetivo. Para a busca da otimalidade em estruturas é necessário que se conheça bem as variáveis envolvidas e quais são os objetivos práticos da otimização estrutural. Definido o problema fisicamente, busca-se um algoritmo matemático para extremar a função. Dentre as soluções possíveis apresentadas, volta-se a analisar fisicamente os resultados, e verifica-se o mais adequado para o problema. Embora para os engenheiros seja bem mais difícil, a busca da solução global do problema também pode ser feita exclusivamente pela análise matemática.

Para minimizar o custo das seções transversais das vigas de um pavimento de concreto armado, parte-se do princípio que o somatório dos mínimos locais interagidos representa o mínimo global da estrutura. Devido ao princípio de otimização escolhido, os valores ótimos para as alturas das vigas obtidos pelo método em questão podem não ser necessariamente os mesmos se a grelha for otimizada como uma função objetivo única. Não é conhecida a ordem de grandeza da diferença entre os resultados possíveis obtidos com os diferentes princípios, pois não foi encontrado na literatura programa que minimize as seções transversais de uma grelha de concreto armado. Através de exemplos, entre eles alguns apresentados nesta monografia, acredita-se que não haja diferença significativa entre os resultados dos diferentes modelos quando são analisadas estruturas-padrão.

O resultado obtido com o processo de otimização utilizado é independente dos valores iniciais adotados para as alturas das vigas. Entretanto, pode haver alguma perturbação nos resultados finais quando as alturas iniciais das vigas são muito discrepantes entre si. Para evitar esta possível perturbação, aconselha-se utilizar para 
as alturas iniciais das vigas valores de igual módulo, garantindo assim a convergência do modelo para um resultado único.

Para casos particulares, como o exemplo do edifício Liberal Office apresentado no capítulo 8, de geometria e solicitações, pode haver uma troca alternada na restrição dominante do problema a cada passo de iteração. Ou seja, suponha que para um passo i da iteração a restrição dominante seja a flecha, resultando assim numa altura grande da viga para o esforço solicitante. No passo i + 1, devido a altura da viga ser grande e consequentemente ter maior rigidez e por conseguinte os esforços solicitantes terem módulos mais elevados, a restrição predominante deixa de ser a flecha e passa a ser a tensão. Nesta situação, as alturas ótimas são reduzidas sensivelmente, e no próximo passo da iteração a restrição predominante volta a ser a flecha. Esta alternância da restrição dominante da otimização pode tornar a convergência do processo muito lenta. Mesmo lenta, a convergência ocorre na restrição de deslocamento, que satisfaz obrigatoriamente o restante das restrições.

A alternância das restrições descrita no parágrafo anterior, ocorre mais frequentemente em estruturas pouco carregadas e quando o módulo de elasticidade longitudinal do concreto é mais alto, ou seja, a estrutura é menos deformável.

A convergência do processo é mais lenta para estruturas com menor grau de solicitação, pois nesta situação, em geral a restrição predominante é a flecha, a qual exige maior esforço computacional para se chegar à solução A restrição de flecha é imposta por um processo iterativo, enquanto as outras são impostas diretamente. Pelo mesmo fato, quando se considera a fluência, a convergência também é mais lenta. Todas as vezes que a restrição de deslocamento é predominante, a convergência é mais lenta.

Em geral, o tempo de convergência necessário para a otimização de uma grelha é pequeno. O tempo gasto pela otimização das seções transversais representa cerca de $8 \%$ do tempo total utilizado pelo programa. A convergência dos modelos ocorre muito mais rapidamente no custo da estrutura, sendo um pouco mais lenta, em termos relativos, nas alturas das vigas. 
Para a implementação do processo iterativo foi utilizado um método secante. Tentou-se utilizar um método tangente, o de Newton-Raphson Puro, mas não houve convergência. O método de Newton Raphson Puro modifica a matriz de rigidez através de um vetor residual de cargas. Como as alturas das vigas são função dos esforços nelas aplicados, estas aumentam com o vetor residual de carga, deteriorando a convergência do método. Um outro motivo que pode explicar a não convergência do método de Newton-Raphison é que com a otimização há uma mudança brusca na matriz de rigidez.

Como todo programa que utiliza o método dos elementos finitos, é necessário que a malha esteja bem discretizada. A discretização da malha implica diretamente na rigidez dos elementos de barra, que por sua vez é uma variável de extrema importância para os resultados finais.

A concepção da rigidez dos elementos é de extrema importância para a solução do problema. Se se optar pelo cálculo dos momentos de inércia dos elementos no estádio I, os resultados são desfavoráveis à segurança. Pois nesta situação, as alturas ótimas das vigas são, em geral, menores que as alturas encontradas quando considera-se as inércias dos elementos no Estádio II. Sendo assim, quando se calculam as flechas das vigas da estrutura para inércia no estádio I e com alturas ótimas obtidas considerando as inércias dos elementos no estádio II, os resultados são coerentes, mas a recíproca não é verdade.

Quando se considera a inércia dos elementos no estádio II, estas são função da área de concreto comprimido, do concreto entre fissuras e das áreas de aço de tração e de compressão. Os métodos aproximados para concepção da inércia, CEB e ACI, propõem uma inércia constante para cada vão das vigas do pavimento, sendo esta inércia determinada para a seção mais solicitada. Através de uma análise feita em um trabalho paralelo, do programa de aperfeiçoamento ao ensino, PAE, verificou-se que nem sempre a inércia da seção mais solicitada é a menor do vão em análise, podendo ser assim, desfavorável à segurança a adoção de um valor constante baseado nesta seção. Se se observar que o valor da inércia é proporcional à área de concreto comprimida, estaria coerente adotar a inércia da seção mais solicitada. Mas é importante lembrar que esta variável aumenta com a área de aço, que é maior na 
seção mais solicitada. Para uma melhor representação do momento de inércia dos elementos, evitando que este seja desfavorável à segurança ou conservador em excesso, indica-se que este seja variável em um mesmo vão, constante para cada elemento finito.

Pode haver uma pequena variação entre as flechas limites das vigas e as flechas calculadas pelo programa SSPO. Esta variação é porque na imposição da restrição de deslocamento foi necessário um modelo para cálculo de flecha que dependesse de dados locais. Além disso, ainda na imposição da restrição da flecha na otimização, os esforços são considerados constantes no passo de iteração e as alturas das vigas mudam. Como há uma variação na flecha com as dimensões e esforços dos elementos, pode haver alguma interferência nos resultados. Os resultados finais apresentados pelo programa são obtidos por outro modelo, MEF, sendo estes os que melhor representam os valores reais das flechas.

Devido à possibilidade de incompatibilidade dos modelos, é necessária a verificação das alturas finais das vigas, precisando modificá-las manualmente se for o caso.

Quando se esta analisando um pavimento composto por elementos de placa e de barra, algumas vigas podem sumir no processo de otimização. À medida que estas vigas vão sumindo, os esforços solicitantes destas vão se redistribuindo pelas vigas e lajes adjacentes, verificando-se uma maior economia com a eliminação de algumas vigas.

Embora eventualmente o método apresente alguma incoerência, na grande maioria dos exemplos encontraram-se soluções adequadas para a prática da engenharia estrutural. Os resultados mostraram uma rápida convergência para uma solução única, reduzindo bastante o custo das estruturas.

Verificou-se que as estruturas mais econômicas têm uma maior taxa geométrica de armadura.

Na prática, as alturas das vigas são em geral padronizadas, o que a princípio faria com que as soluções expostas pelo SSPO fossem apenas teóricas. Mas, à medida que o programa apresenta as alturas ótimas, o engenheiro as padroniza o quanto mais 
perto do ótimo ele queira. Além do mais, possibilita a verificação da necessidade da existência de determinadas vigas.

Para a otimização das vigas, não foram considerados os esforços cortantes, momentos de torção, esforços normais às barras e esforços devido ao vento. Estas solicitações poderiam alterar os resultados.

Quando se otimiza uma estrutura, busca-se um melhor aproveitamento do material mantendo as condições de equilíbrio e compatibilidade de deformações e permanecendo dentro das especificações feitas por Normas. Este procedimento, em geral, trabalha com as estruturas no limite, seja de utilização ou de ruína. Devido a estas características, quando é feita a otimização de um elemento ou uma parte dos elementos de uma estrutura, é necessário analisar os resultados considerando a estrutura como elemento único. No caso das grelhas, com a otimização muitas vezes desaparecem vigas ou estas ficam com alturas pequenas, e é preciso pensar na rigidez horizontal da estrutura. As vigas são responsáveis pela formação de pórticos, e se estas não existem, podem deixar a edificação muito flexível a esforços horizontais.

\section{2 - Propostas para pesquisas futuras}

$\diamond$ Implementar os esforços cortantes, momentos de torção, forças normais às barras e esforços devido ao vento.

$\diamond$ A verificação das flechas nas lajes é de extrema importância neste tipo de análise. Nas estruturas-padrão, a restrição predominante nas lajes é a flecha, se estas são verificadas e suas espessuras alteradas em função dos limites preestabelecidos por Normas, os resultados apresentados seriam praticamente os equivalentes a um pavimento ótimo.

$\diamond$ A implementação de critérios de plastificação nos elementos de placa levaria a uma redistribuição diferente dos esforços, trazendo como consequência alturas diferentes para as vigas.

$\diamond$ Pode-se melhorar o modelo de fluência.

$\diamond$ Quando uma viga desaparece no processo de otimização, a sua parcela na matriz de rigidez não foi eliminada, foi apenas considerada uma rigidez muito pequena 
para seus elementos de barra. O correto seria quando a viga sumir, eliminá-la da matriz de rigidez.

$\diamond$ Otimizar a grelha como uma função objetivo única, não mais como um somatório de funções objetivo localizadas e interagidas. 


\section{BIBLIOGRAFIA}

AMIR, H.M.; HASEGAWA, T. (1989). Nonlinear mixed-discrete structural optimization. Journal of Structural Engineering, ASCE, v.115, n.3, p.626-646, Mar.

ASHLEY, H. (1982). On making things the best - Aeronautical uses of optimization. Aircraft, v.19, n.1, p.5-28.

BAZARAA, S.M.; SHETTY, C.M. (1979). Nonlinear programming: theory and Algorithms. New York, John Wiley.

BORKOWSKI, A.; JENDO, S. (1990). Structural optimization. Mathematical programming, v.2, Plenum, New York, N.Y.

CARVALHO, R.C. (1994). Análise não-linear de pavimentos de edifícios de concreto através da analogia de grelha. Tese (doutorado) - Escola de Engenharia de São Carlos, Universidade de São Paulo.

CHAKRABARTY, B.K. (1992). A model for optimal design of reinforced concrete beam. Journal of Structural Engineering, ASCE, v.118, n.11, p.3238-3242, Nov.

CHAN, C.M.; GRIERSON, D.E.; SHERBOURNE, A.N. (1995). Automatic optimal design of tall steel building frameworks. Journal of Structural Engineering, ASCE, v.121, n.5, p.838-847, May.

COHN, M.Z. (1993). Theory and practice of structural optimization. Proc. NATO-ASI Optimization of Large-Scale Structural Systems, G.I.N. Rozvany, ed., Kluwer Academic Publishers, Dordrecht, The Netherlands, v.2, p.843-862.

COHN, M.Z., FELLOW ; DINOVITZER, A.S. (1994). Aplication of structural optimization. Journal of Structural Engineering, ASCE, v.120, n.2, p.617-650, Feb.

COOK, R.D. (1995). Finite element modeling for stress analysis. Madison, John Wiley \& Sons, Inc.

COSTA, J.B. (1990). Automação do dimensionamento do vigamento de pavimentos tipo de edifícios de concreto armado. Dissertação (mestrado) - Escola de Engenharia de São Carlos, Universidade de São Paulo.

FRANGOPOL, D.M.; KLISINSKI, M. (1989). Material behavior and optimum design of structural systems. Journal of Structural Engineering, ASCE, v.115, n.5, p.10541075, May. 
GELLATLY, R.A.; DUPRÉE, D.M. (1976). Examples of computer-aided optimal design of structures. Introductory Report, 10th IABSE Congress, International Association for Bridge and Structural Engineering, Zürich, Switzerland, p.77-105.

GOLDBERG, D.E. (1989). Genetic algorithms in search, optimization, and machine learning. U.S.A., Addison-Wesley Publishing Company, Inc.

GRAZIANO, F.P.; FRANÇA, R.L.S. (1993). Solicitações Normais. Alguns tópicos. III Simpósio EPUSP sobre Estruturas de Concreto. São Paulo - SP. p. 197 - 207.

HAQUE, M.I. (1996). Optimal frame design with discrete members using the complex method. Computer \& Structures, v.59, n.5, p.847-858.

HASEGAWA, A.; SAKAMOTO, T.; SATO, N. (1992). Elastic and plastic designs for maximum load. Journal of Structural Engineering, ASCE, v.115, n.6, p.1342-1356, Jun.

HERSKOVITS, J. , comp (1993). Structural Optimization 93: The World Congress on Optimal Design of Structural Systems. Rio de Janeiro, COPPE-UFRJ. 2v.

HÖRNLEIN, H. (1987). Take-off in optimum structural design. Computer-Aided optimal Design, C.A. Mota Soares, ed., Springer-Verlag, Berlin, Germany, p.901-927.

HOROWITZ, B. (1993). Strength of slender concrete columns subjected to biaxial bending. In the World Congress on Optimal Design of Structural Systems, Rio de Janeiro, 1993. Anais. Rio de Janeiro COPPE/Federal University of Rio de Janeiro. v.1, p. 395-402.

JENKINS, W.M. (1992). Plane frame optimum design environment based on genetic algorithm. Journal of Structural Engineering, ASCE, v.118, n.11, p.3103-3112, Nov.

KIRSCH, U. (1993). Effective approximations for topological optimization. The World Congress on Optimal Design of Structural Systems, Rio de Janeiro, 1993. Anais. Rio de Janeiro COPPE/Federal University of Rio de Janeiro. v.1, p. 3-10.

KIRSCH, U.; TOPPING, B.H.V. (1992). Minimum weight design of strutural topologies. Journal of Structural Engineering, ASCE, v.118, n.7, p.1770-1785, Jul.

KRISHNAMOORTHY, C.S. (1986). Nonlinear analysis and optimal design of concrete framed structures. IN NARAYANAN, R. Concrete framed structures: stability and strength. London, Elsevier Applied Science. p. 71-110.

LASSEN, T. (1993). Optimum design of three-dimensional framework structures. Journal of Structural Engineering, ASCE, v.119, n.3, p.713-727, Mar. 
LEV, O.; ed. (1981). Structural optimization. ASCE, New York, N.Y.

LUENBERGER, D.L. (1989). Programación lineal y no lineal. Wilmington, Delaware, E.U.A., Addison-Wesley Iberoamericana.

MACHADO, C.P. (1989). Tensões, deformações e deslocamentos em estruturas de concreto armado e protendido. 3v. Dissertação (mestrado) - Escola Politécnica, Universidade de São Paulo.

MEDRANO, M.S. (1994). Aplicações de programação matemática em análise estrutural. Dissertação (mestrado) - Escola Politécnica, Universidade de São Paulo.

MENDES, P.T.C. (1983). A influência da fissuração no comportamento das vigas de concreto armado. Dissertação (mestrado) - Escola de Engenharia de São Carlos, Universidade de São Paulo.

MOHARRAMI, H.; GRIERSON, D.E. (1993). An optimality criteria method for the design of reinforced concrete frameworks. In the world congress on optimal design of structural systems, Rio de Janeiro, 1993. Anais. Rio de Janeiro COPPE/Federal University of Rio de Janeiro. v.1, p.403-413.

MOHARRAMI, H.; GRIERSON, D.E. (1993). Computer-automated design of reinforced concrete frameworks. Journal of Structural Engineering, ASCE, v.119, n.7, p.20362058, July.

PEZESHK, S.; HJELMSTAD, K.D. (1991). Optimal design of planar frames on stability criterion. Journal of Structural Engineering, ASCE, v.117, n.3, p.896-913, Mar.

PRESS, W.H. et alli (1994). Numerical recipes: the art of scientific computing. $\quad 2$. ed. New York, Cambridge University Press.

RAMOS, A.L.T.; STANGE, P.; ING (1993). A system for optimal design of reinforced concrete structures. IN THE WORLD CONGRESS ON OPTIMAL DESIGN OF STRUCTURAL SYSTEMS, Rio de Janeiro, 1993. Anais. Rio de Janeiro COPPE/Federal University of Rio de Janeiro. v.1, p. 415-421.

SALGADO, N.K. (1987). Técnicas de otimização matemática no projeto de pórticos planos retangulares. Dissertação (mestrado) - Escola de Engenharia de São Carlos, Universidade de São Paulo.

SALLOUM, A.; SIDDIQI, G.H. (1994). Cost-optimum design of reinforced concrete beams. ACI, Structural Journal, v.91, n.6, p.647-655, Nov-Dec.

SAVE, M.; PRAGER, W. (1985). Structural optimization. Optimality Criteria, v.1, Plenum, New York, N.Y. 
SOBIESKI, J. et alii (1987). Panel discussion: Trends in computer-aided optimal design. Computer-Aided optimal Design, C.A. Mota Soares, ed., Springer-Verlag, Berlin, Germany, p.1018-1029.

SOUSA, J.BM..; VAZ, L.E. (1993). Otimização do dimensionamento de pilar padrão de concreto armado com seção retangular. III Simpósio EPUSP sobre Estruturas de Concreto. São Paulo - SP. p. 393 - 405.

SÜSSEKIND, J.C. (1974). Curso de análise estrutural - deformações em estruturas, método das forças. São Paulo, Brasil. Globo.

THANEDAR, P.B.; VANDERPLAATS, G.N. (1995). Enhancing branch-and-bound method for structural optimization. Journal of Structural Engineering, ASCE, v.121, n.2, p.301-306, Feb.

TSENG, C.H.; WANG, L.W.; LING, S.F. (1995). Enhancing branch-and-bound method for structural optimization. Journal of Structural Engineering, ASCE, v.121, n.5, p.831-837, May.

VANDERPLAATS, G.N. (1984). Numerical optimization tecniques for engineering design. New York, Mc.Graw - Hill.

VANDERPLAATS, G.N.; MOSES, F. (1972). Automated design of trusses for optimum geometry. Journal of Structural Division, ASCE, v.98, n.6, p.671-690.

WEI, Z; YE, S. (1990). Optimal sectional design of frame structures using geometric programming. Journal of Structural Engineering, ASCE, v.116, n.8, p.2292-2298, Aug. 
APÊNDICE I

\section{I - FLUXOGRAMA PORMENORIZADO - PROGRAMA PRINCIPAL}

Será introduzido neste capítulo o fluxograma detalhado do programa SSPO, no qual tentar-se-á explicar todo o algoritmo desenvolvido para a obtenção de seções transversais "ótimas" de grelhas de concreto armado. Devido a um grande número de informações e a necessidade de posterior mudanças ou correções aconselha-se que a entrada de dados seja feita via arquivo.

\section{I.1 - Dados da Estrutura}

\section{I.1.1 - Dados gerais}

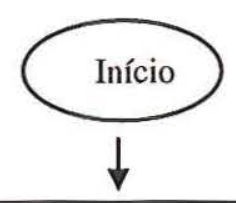

Arquivo de instalação

- Número máximo de iterações (NI)?

- Número de divisões internas da malha (ND)?

- Erro admissível para sair do processo iterativo de otimização?

- Erro admissível para sair do processo iterativo de correção das inércias?

- Custo dos materiais?

- Limites de deformação dos materiais?

- Limite mínimo para as alturas das vigas $\left(\mathrm{H}_{\min }\right)$ ?

- Limites de flecha?

- Máxima taxa geométrica de armadura?

- Cobrimento das armaduras?

- Coeficiente de majoração das ações externas?

- Coeficientes de minoração da resistência dos materiais?

- Considerar o cálculo da inércia no estádio I ou no estádio II quando o esforço ultrapassar o momento de fissuração?

Arquivo próprio do projeto

- Nome do arquivo de entrada?

- Nome do pavimento?

- Número de nós $(\mathrm{N})$ ?

- Número de elementos de barra (B)?

- Número de elementos de placa (P)?

- Número de vigas (V)?

- Número de pilares (PIL)?

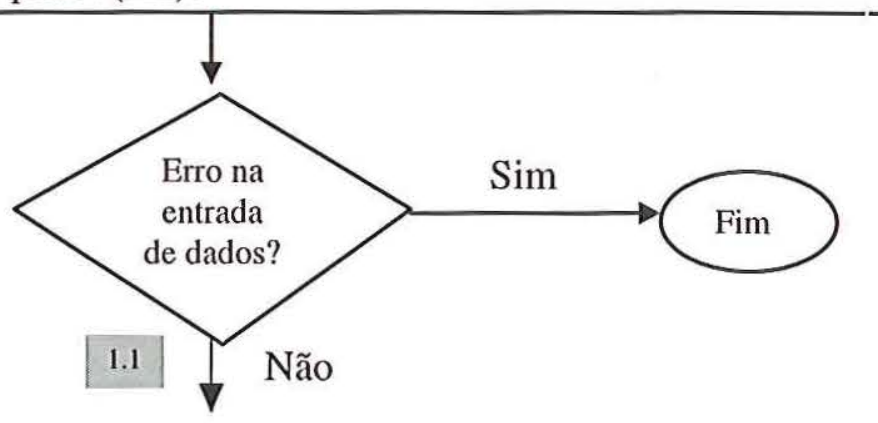


I.1.2 - Alocação das variáveis

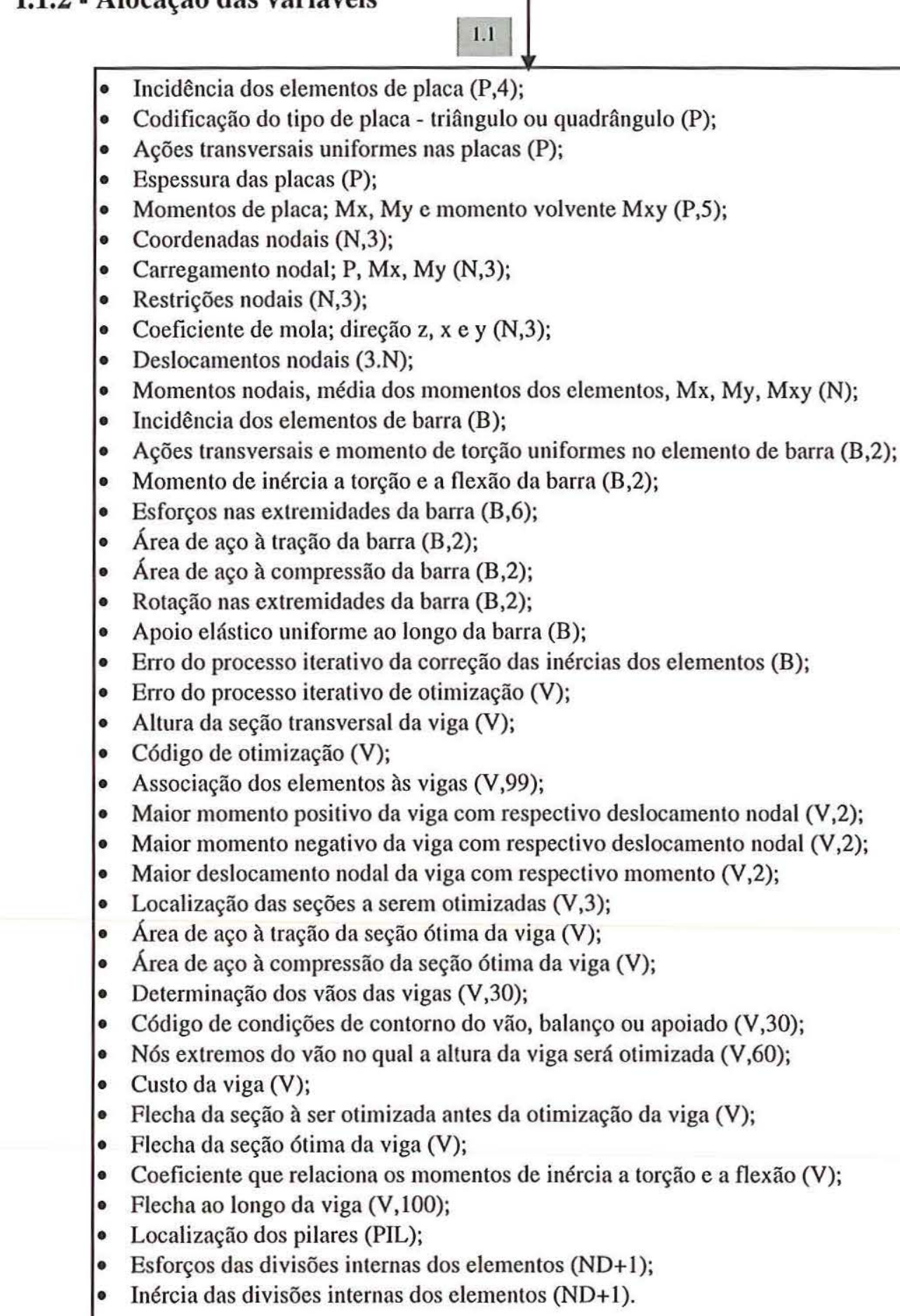

\section{I.1.3 - Coordenadas nodais}




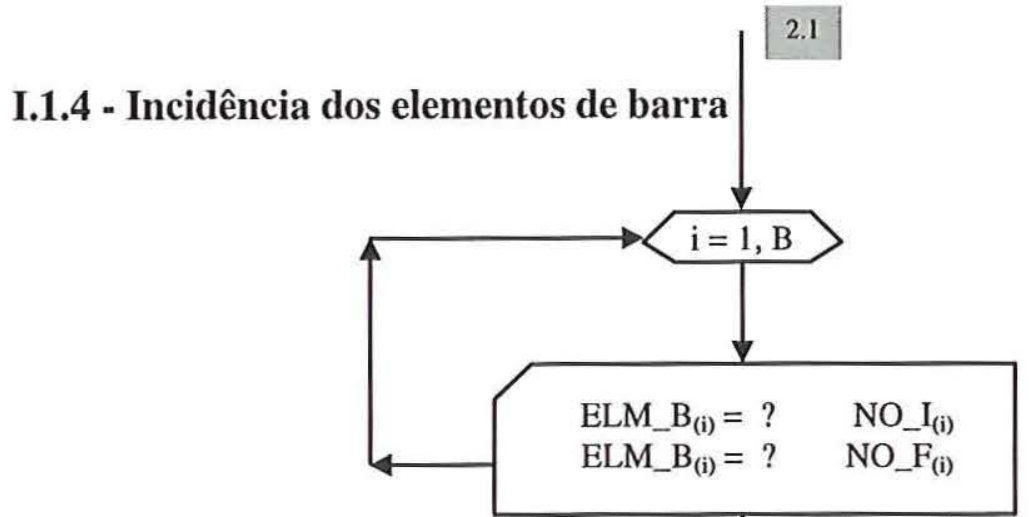

I.1.5 - Incidência dos elementos de placa

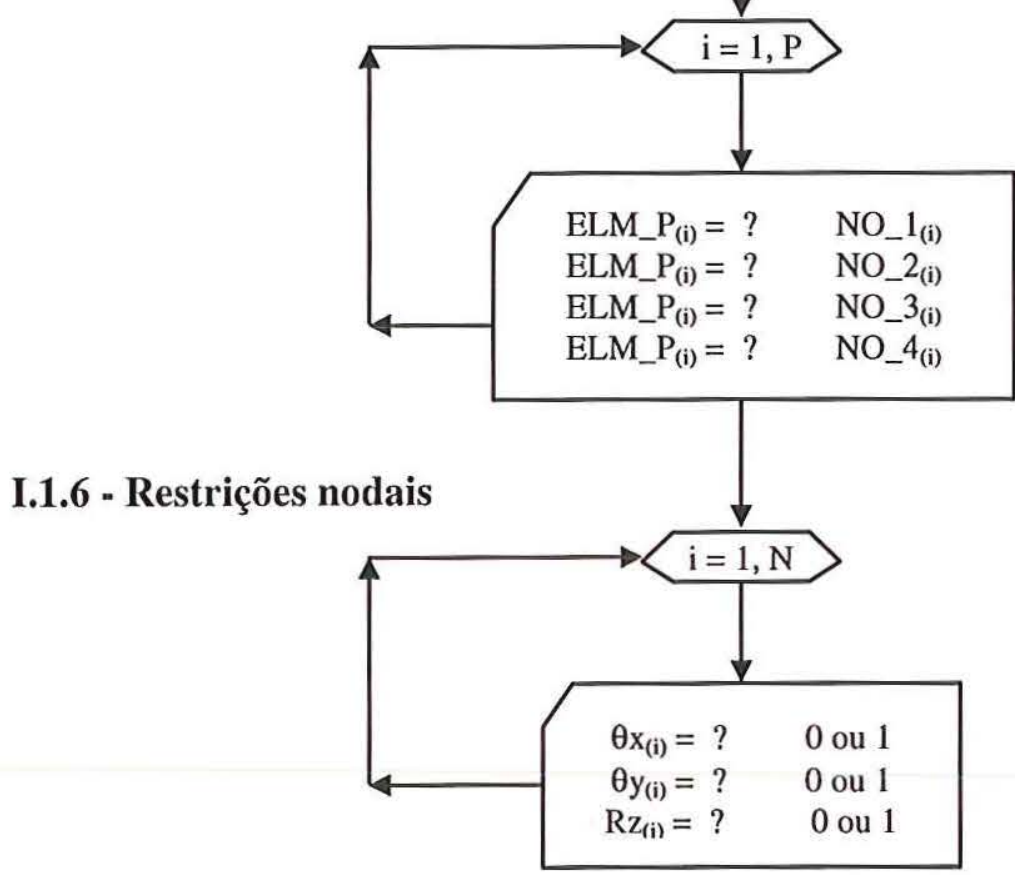

I.1.7 - Características geométricas das vigas

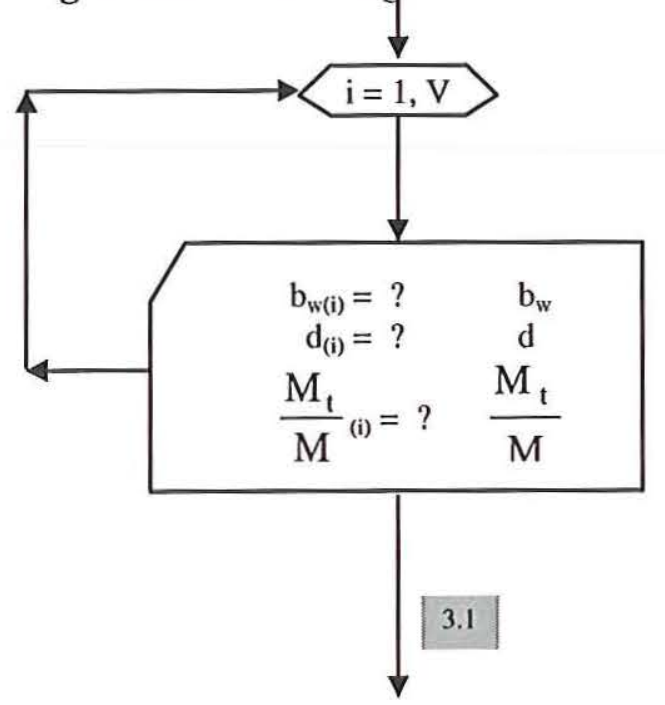


I.1.8 - Características geométricas dos elementos de placa

I.1.9 - Ações externas aplicadas nos elementos de barra
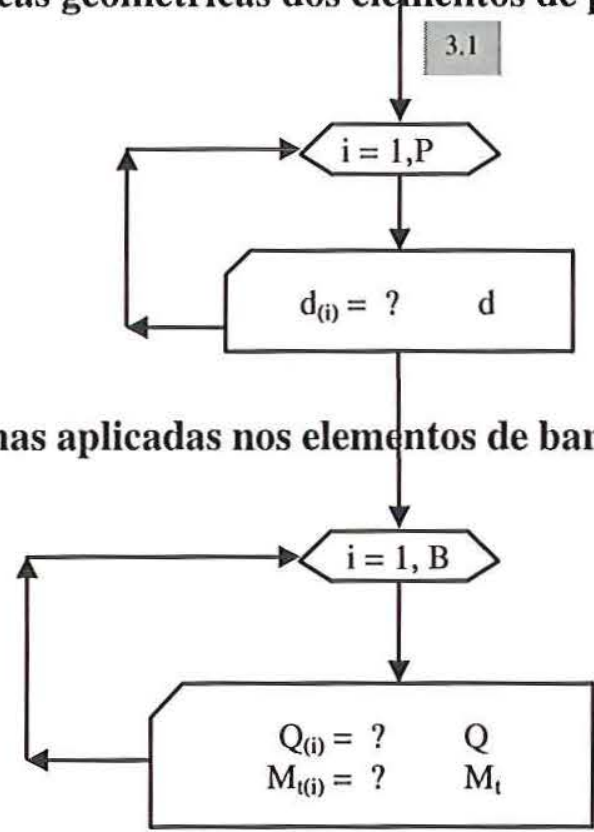

I.1.10 - Ações externas aplicadas nos elem entos de placa

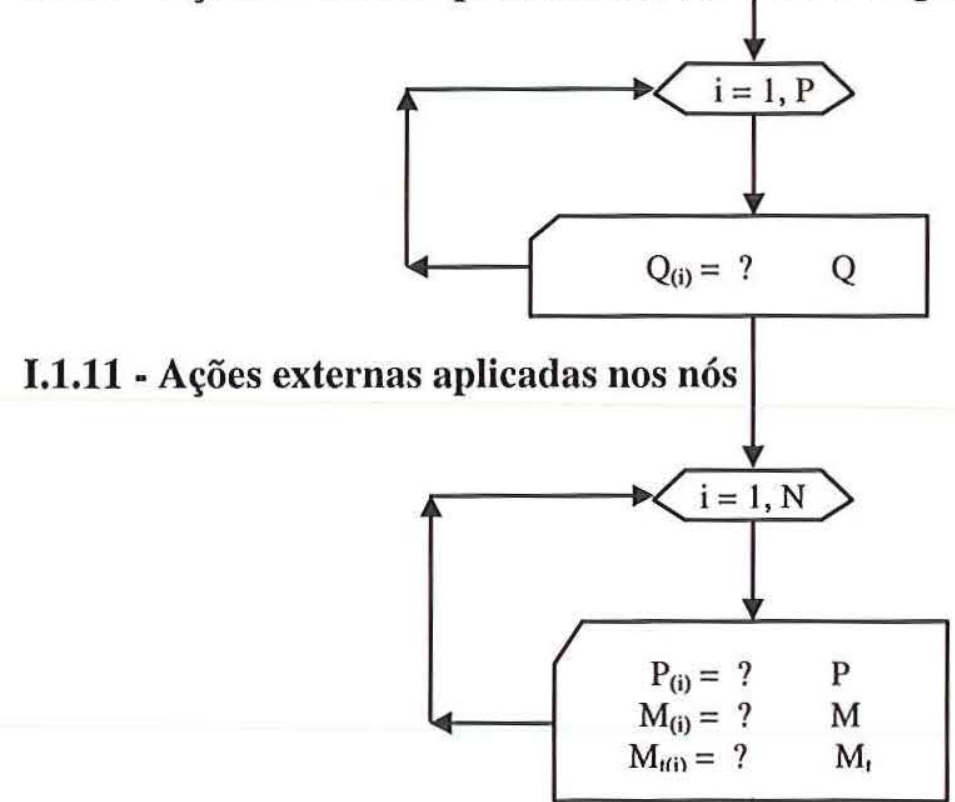

I.1.12 - Rigidez adicional dos pilares

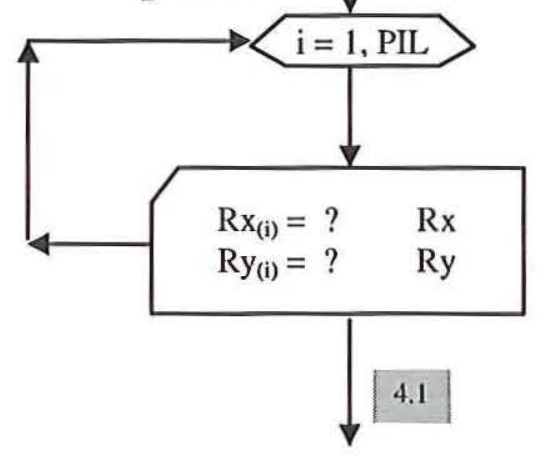




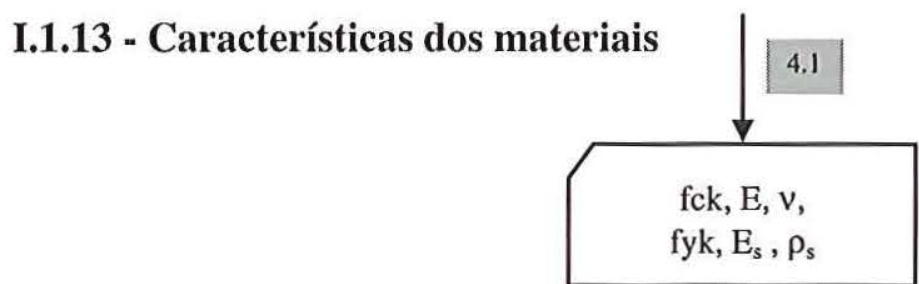

I.1.14 - Atribuição às vigas dos elementos $\mid$ que a elas pertencem

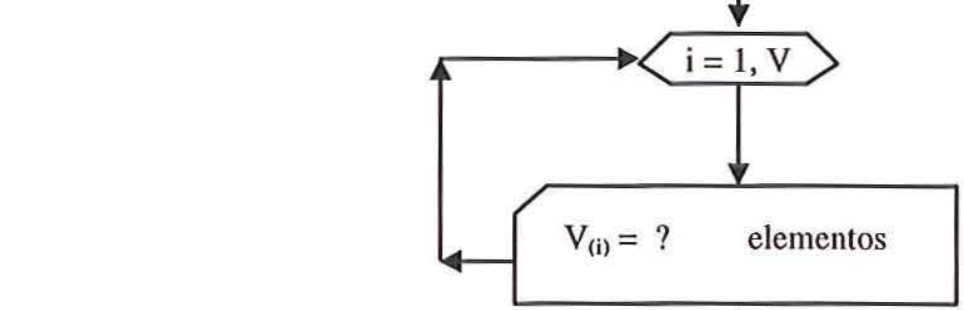

I.1.15 - Localização dos pilares na estrutu ra

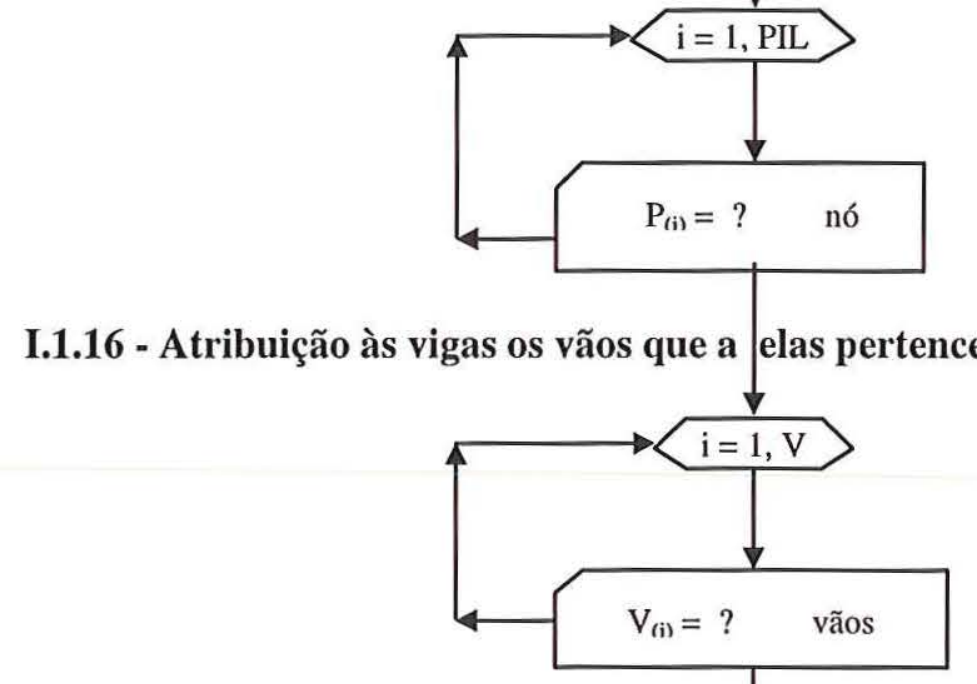

I.1.17 - Atribuição de base elástica aos elementos de barra

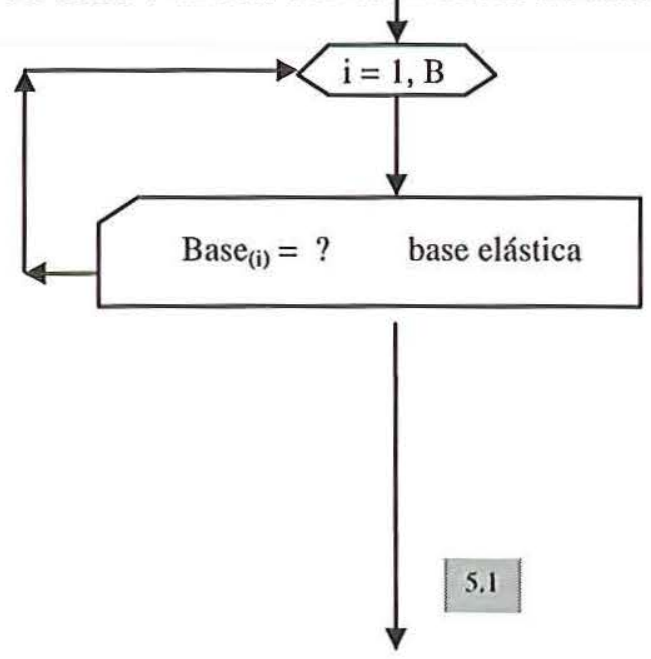


I.1.18 - Identificador de continuidade da $\mid \begin{aligned} & 5.1 \\ & \text { viga no processo de otimização }\end{aligned}$

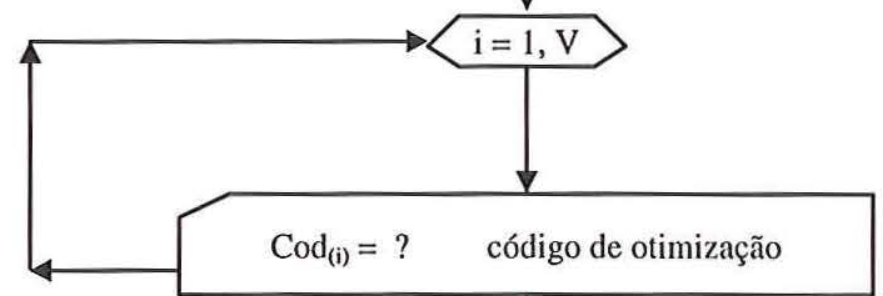

I.2 - Dados necessários ao software

I.2.1 - Altura mínima para as vigas

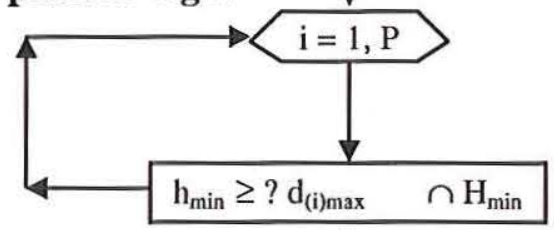

I.2.2 - Inércia inicial para os elementos de barra - Estádio I

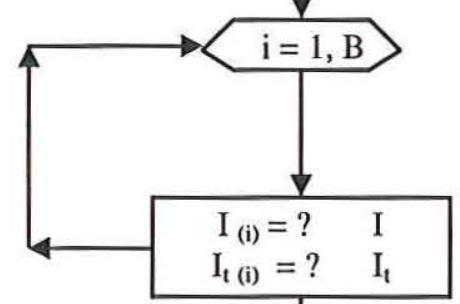

I.2.3 - Vão das vigas

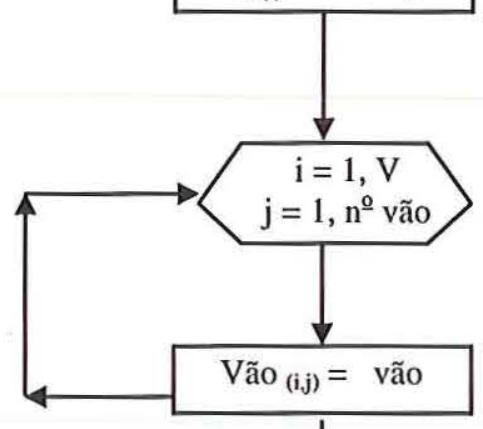

I.2.4 - Custo inicial da estrutura - volume de concreto + área de forma

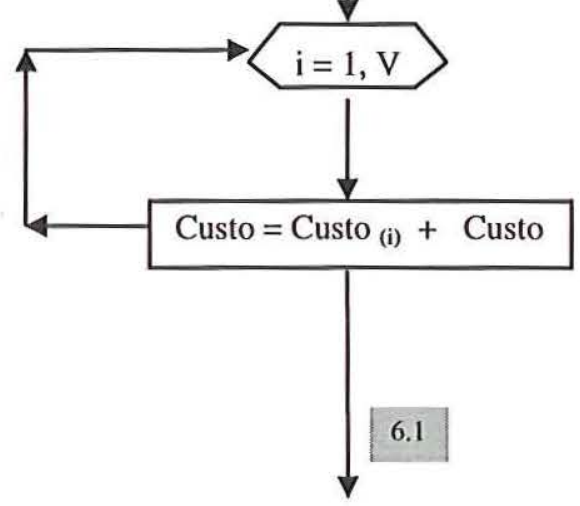


I.3 - Impressão dos dados da estrutura $\mid \begin{aligned} & 6.1 \\ & \text { ARQUIVO.ENT }\end{aligned}$

Identificação da estrutura

Nome do arquivo

Características dos materiais

Número de nós

Número de elementos de placa

Número de elementos de barra

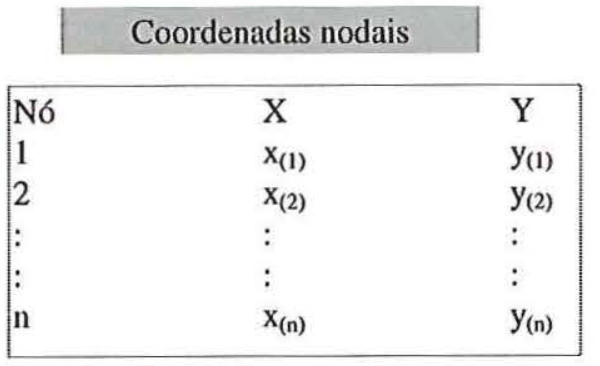

\begin{tabular}{|c|c|c|c|}
\hline & \multicolumn{3}{|c|}{ Vinculações nodais } \\
\hline No & $\mathrm{Rz}$ & $\theta x$ & $\theta y$ \\
\hline 1 & $R z_{(1)}$ & $\theta x_{(1)}$ & $\theta y_{(1)}$ \\
\hline 2 & $R z_{(2)}$ & $\theta \mathrm{x}_{(2)}$ & $\theta y_{(2)}$ \\
\hline : & : & : & : \\
\hline : & : & : & : \\
\hline n & $\mathrm{Rz}_{(\mathrm{n})}$ & $\theta x_{(n)}$ & $\theta y_{(n)}$ \\
\hline
\end{tabular}

Incidência dos elementos de placa

Incidência dos elementos de barra

\begin{tabular}{|lllll|}
\hline Elem. & Nó $_{1}$ & $\mathrm{No}_{2}$ & $\mathrm{Nó}_{3}$ & $\mathrm{Nó}_{4}$ \\
1 & nó $_{1(1)}$ & nó $_{2(1)}$ & nó $_{3(1)}$ & nó $_{4(1)}$ \\
2 & nó $_{1(2)}$ & nó $_{2(2)}$ & nó $_{3(2)}$ & nó \\
$4(2)$ \\
$:$ & $:$ & $:$ & $:$ & $:$ \\
$:$ & $:$ & $:$ & $:$ & $:$ \\
p & nó $_{1(\mathrm{p})}$ & nó $_{2(\mathrm{p})}$ & nó $_{3}(\mathrm{p})$ & nó $_{4(\mathrm{p})}$ \\
\hline
\end{tabular}

\begin{tabular}{|lll}
\hline Elem. & Nó $_{\mathrm{i}}$ & Nó $_{\mathrm{f}}$ \\
1 & nó $_{\mathrm{i}(1)}$ & nó $_{\mathrm{f}(1)}$ \\
2 & nó $_{(\mathrm{i}(2)}$ & nó $_{\mathrm{f}(2)}$ \\
$:$ & $:$ & $\vdots$ \\
$\mathrm{b}$ & $\vdots$ & $:$ \\
& nó $_{\mathrm{i}(\mathrm{b})}$ & nó $_{\mathrm{f}(\mathrm{b})}$
\end{tabular}

Características dos elementos de placa

Características iniciais dos elementos de barra

\begin{tabular}{|ll|}
\hline Elem. & espessura \\
1 & esp.(1) \\
2 & esp.(2) \\
$:$ & $:$ \\
$:$ & $:$ \\
$p$ & esp.(p) \\
\hline
\end{tabular}

Elementos associados às vigas

\begin{tabular}{|lll} 
Elem. & $\mathrm{Ix}$ & $\mathrm{Iy}$ \\
1 & $\mathrm{Ix}_{(1)}$ & $\mathrm{Iy}_{(1)}$ \\
2 & $\mathrm{Ix}_{(2)}$ & $\mathrm{Iy}_{(2)}$ \\
$:$ & $\vdots$ & $\vdots$ \\
$:$ & $:$ & $\vdots$ \\
$\mathrm{b}$ & $\mathrm{Ix}_{(\mathrm{b})}$ & $\mathrm{Iy}_{(\mathrm{b})}$
\end{tabular}

\begin{tabular}{|ll|}
\hline Viga & elemento $_{1}$ \\
2 & $\operatorname{elem}_{(1)} \ldots \operatorname{elem}_{(i)}$ \\
$:$ & $\vdots$ \\
$:$ & $\vdots$ \\
$v$ & $\operatorname{elem}_{(1)} \ldots$ elem(i) \\
\hline
\end{tabular}

Vãos associados às vigas

\begin{tabular}{|c|c|c|c|c|c|c|c|c|}
\hline \multicolumn{3}{|c|}{ Carregamento nodal } & & \multicolumn{3}{|c|}{ Carregamento na barra } & \multicolumn{2}{|c|}{ Carregamento na placa } \\
\hline Nó & $\mathrm{Fz}$ & $\mathrm{Mx}$ & My & Elem. & Q & $\mathrm{Mt}$ & Elem. & Q \\
\hline 1 & $\mathrm{Fz}_{(1)}$ & $\mathrm{Mx}_{(1)}$ & $\mathrm{My}_{(1)}$ & 1 & $\mathrm{Q}_{(1)}$ & $\mathrm{Mt}_{(1)}$ & 1 & $\mathrm{Q}_{(1)}$ \\
\hline 2 & $\mathrm{Fz}_{(2)}$ & $\mathrm{Mx}_{(2)}$ & $\mathrm{My}_{(2)}$ & 2 & $\mathrm{Q}_{(2)}$ & $\mathrm{Mt}_{(2)}$ & 2 & $\mathrm{Q}_{(2)}$ \\
\hline : & : & : & : & : & : & : & : & : \\
\hline : & : & : & : & : & : & : & : & : \\
\hline n & $\mathrm{Fz}_{(\mathrm{n})}$ & $\mathrm{Mx}_{(\mathrm{n})}$ & $\mathrm{My}_{(\mathrm{n})}$ & b & $Q_{(b)}$ & $\mathrm{Mt}_{(\mathrm{b})}$ & $\mathrm{p}$ & $Q_{(p)}$ \\
\hline
\end{tabular}




\section{I.4 - Impressão dos dados para plotagem da estrutura - ARQUIVO.PLT \\ Este arquivo será lido pelo programa SSPLOT para plotagem na tela da estrutura. \\ 7.1}

Número de nós - Número de elementos de placa - Número de elementos de barra

Coordenadas e vinculações nodais

\begin{tabular}{|llllll|}
\hline Nó & $\mathrm{X}$ & $\mathrm{Y}$ & $\mathrm{Rz}$ & $\theta \mathrm{x}$ & $\theta \mathrm{y}$ \\
1 & $\mathrm{x}_{(1)}$ & $\mathrm{y}_{(1)}$ & $\mathrm{Rz}_{(1)}$ & $\theta \mathrm{x}_{(1)}$ & $\theta \mathrm{y}_{(1)}$ \\
2 & $\mathrm{x}_{(2)}$ & $\mathrm{y}_{(2)}$ & $\mathrm{Rz}_{(2)}$ & $\theta \mathrm{x}_{(2)}$ & $\theta \mathrm{y}_{(2)}$ \\
$:$ & $:$ & $:$ & $:$ & $:$ & $:$ \\
$:$ & $:$ & $:$ & $:$ & $:$ & $:$ \\
$\mathrm{n}$ & $\mathrm{x}_{(\mathrm{n})}$ & $\mathrm{y}_{(\mathrm{n})}$ & $\mathrm{Rz}_{(\mathrm{n})}$ & $\theta \mathrm{x}_{(\mathrm{n})}$ & $\theta \mathrm{y}_{(\mathrm{n})}$ \\
\hline
\end{tabular}

Incidência dos elementos de placa

\begin{tabular}{|c|c|c|c|c|}
\hline Elem. & Nó & $\mathrm{Nó}_{2}$ & $\mathrm{No}_{3}$ & $\mathrm{Nó}_{4}$ \\
\hline 1 & nó ${ }_{1(1)}$ & nó ${ }_{2(1)}$ & nó $3(1)$ & ${ }^{n} \sigma_{4(1)}$ \\
\hline 2 & nó $_{1(2)}$ & nó $_{2(2)}$ & nó ${ }_{3(2)}$ & nó $_{4(2)}$ \\
\hline : & : & : & : & : \\
\hline : & : & : & : & : \\
\hline $\mathrm{p}$ & nó $\sigma_{1(p)}$ & ${ }^{n} \sigma_{2(\mathrm{p})}$ & nó $_{3(\mathrm{p})}$ & nó $_{4(\mathrm{p})}$ \\
\hline
\end{tabular}

Incidência dos elementos de barra

\begin{tabular}{|c|c|c|c|}
\hline $\begin{array}{l}\text { Elem. } \\
1 \\
2\end{array}$ & $\begin{array}{l}\text { Nó }_{i} \\
\text { nó } \\
\text { nó } \\
\text { i(1) }\end{array}$ & $\begin{array}{l}\text { Nóf }_{f} \\
\text { nóf(1) } \\
\text { nóf(2) }\end{array}$ & $\begin{array}{l}\text { Limitações do SSPLOT: } \\
\text { nós }=1800 \\
\text { - elementos de placa }=1800\end{array}$ \\
\hline$:$ & $\begin{array}{l}: \\
:\end{array}$ & $\begin{array}{l}: \\
:\end{array}$ & - elementos de barra $=1000$ \\
\hline
\end{tabular}

\section{I.5 - Impressão no ARQUIVO.OTI}

Nome do arquivo

Identificação da estrutura

Viga - bw - $h-A_{s}-A_{s}{ }^{\prime}-$ Flecha inicial - Flecha da seção 
I.6 - Cálculo da largura da semi-banda da matriz de rigidez global

I.7 - Início do "loop" de otimização das vigas - "loop" externo

Este loop apenas será interrompido quando o usuário fixar todas as alturas das vigas.

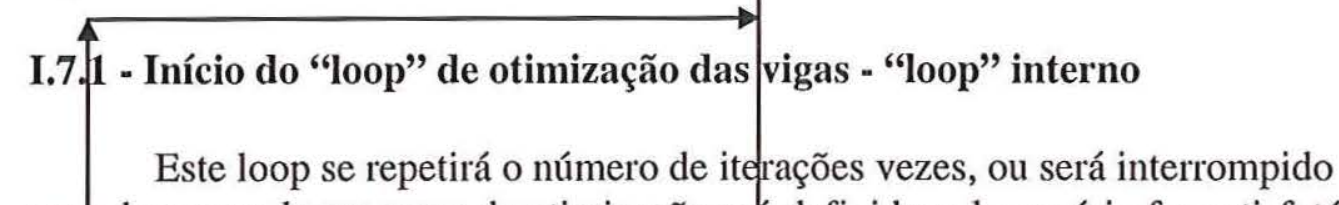

quando o erro do processo de otimização prę-definido pelo usuário for satisfatório.

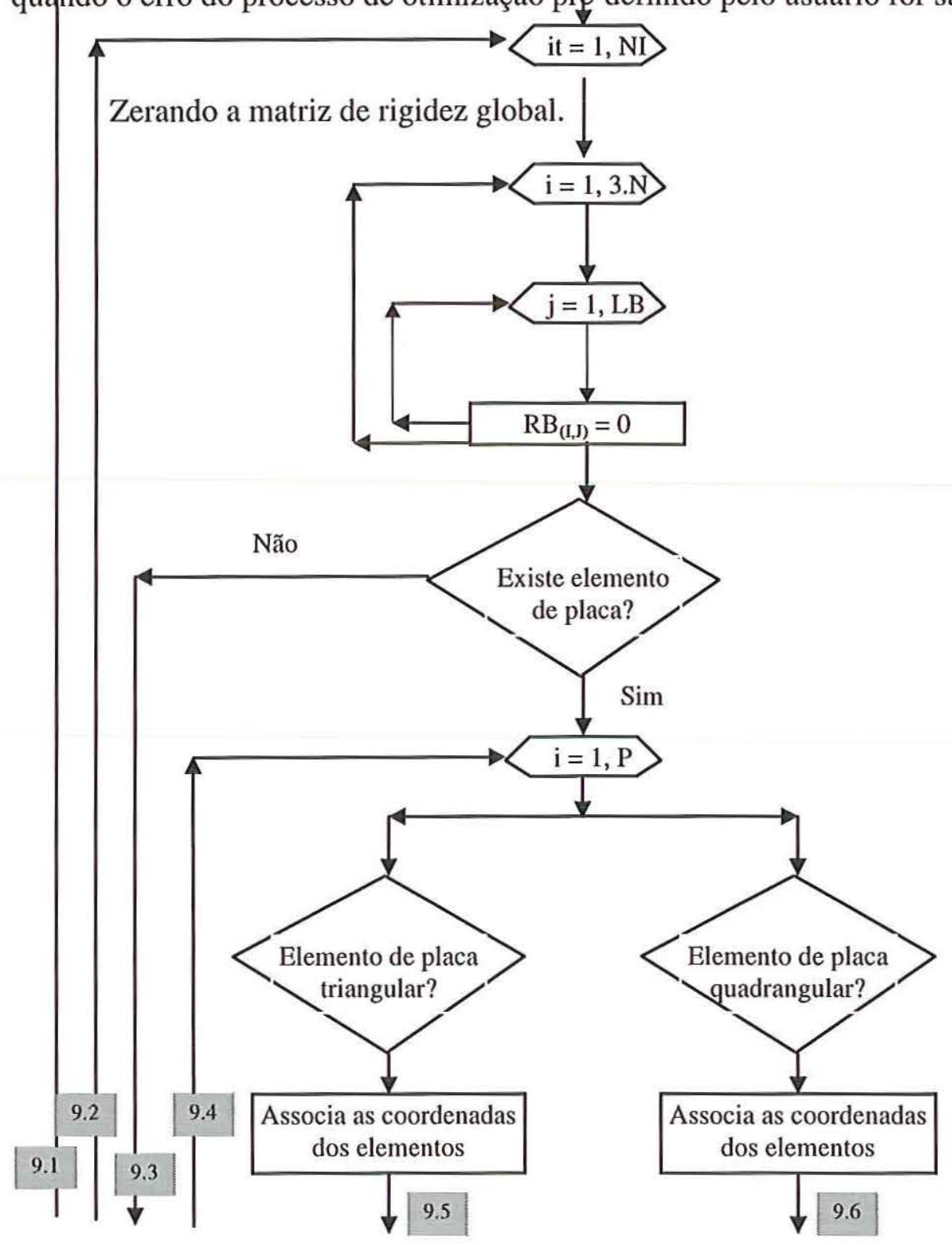


9.3

Subrotina - DKT

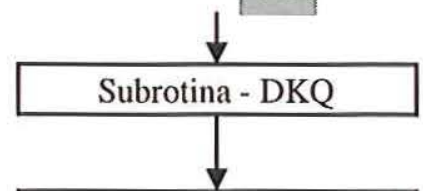

Área do triângulo quadrângulo

se Área $\leq 0 \rightarrow$ Fim se Área $\leq 0 \rightarrow$ Fim
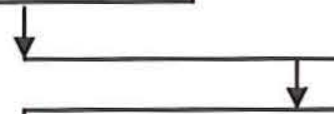

Carregamento nodal equivalente
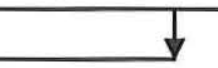

Contribuição do elemento de placa

na matriz de rigidez global - RB

\section{Existe elemento de}

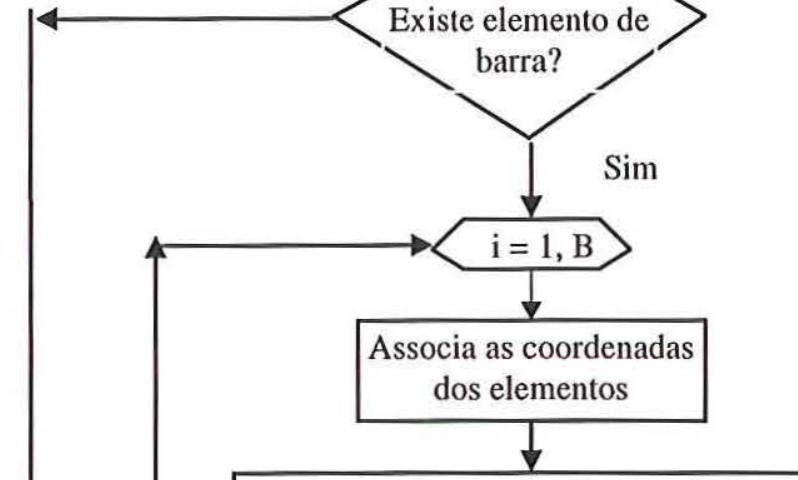

Determina o comprimento dos elementos $\mathrm{e} o$ ângulo entre $\mathrm{o}$ sistema de coordenadas locais e o de referência

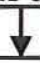

Carregamento nodal equivalente da barra nas coordenadas globais Subrotina - NOEO

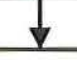

Matriz de rigidez do elemento nas coordenadas globais

Subrotina - BARGLO<smiles>C1CC2CCC12</smiles>

Contribuição do elemento de barra na matriz de rigidez global - RB dos nós (pilares) - RB 


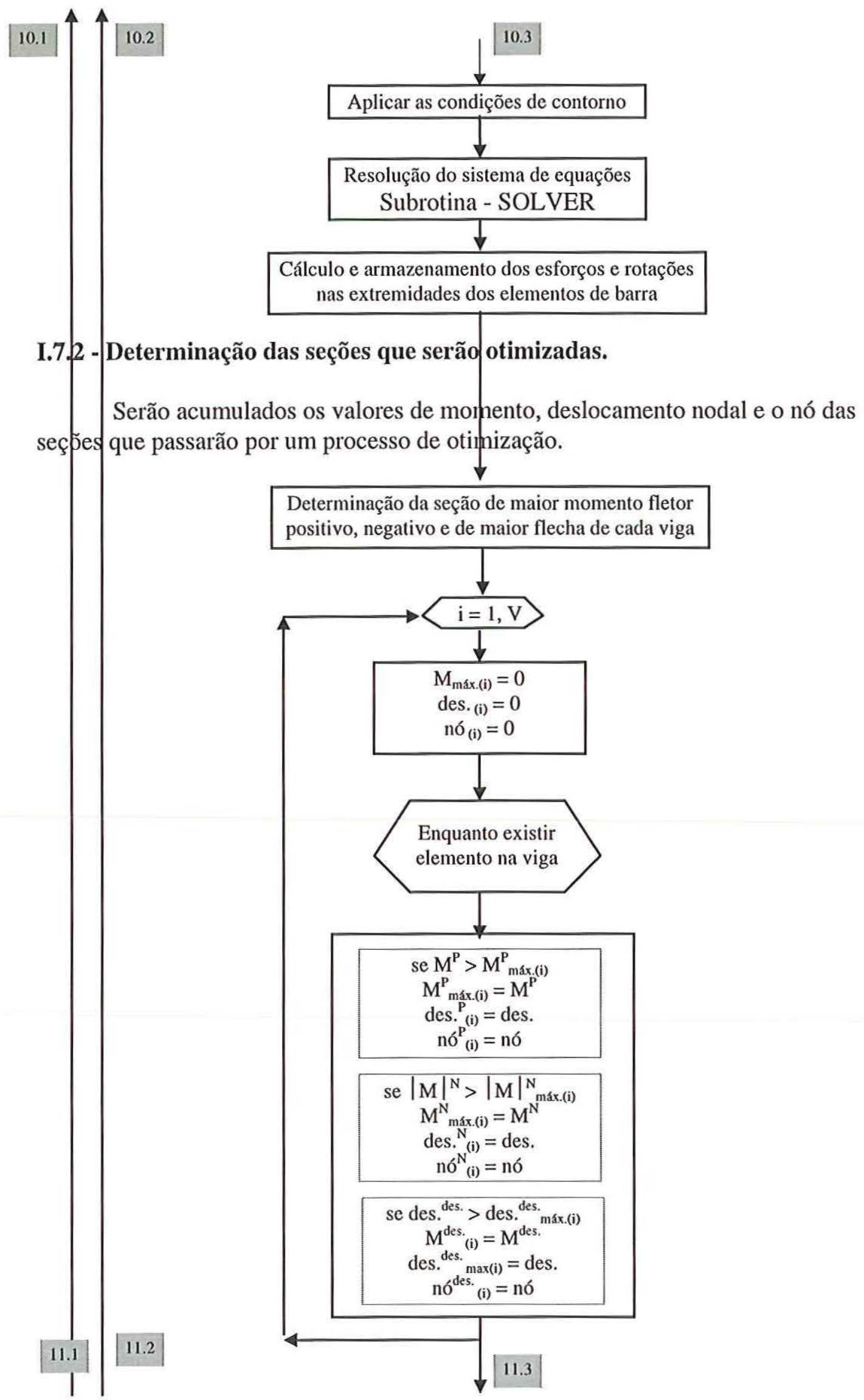




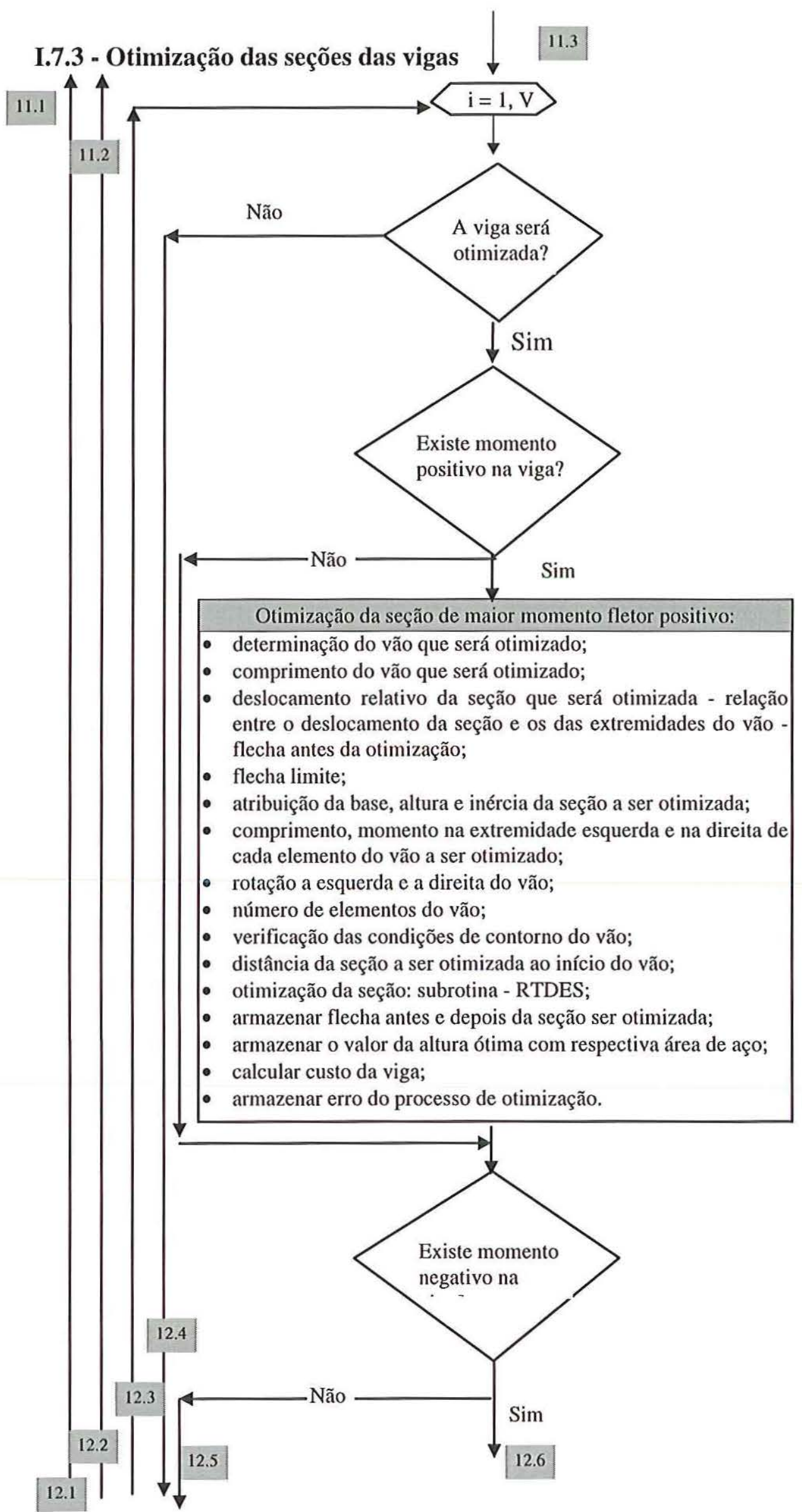




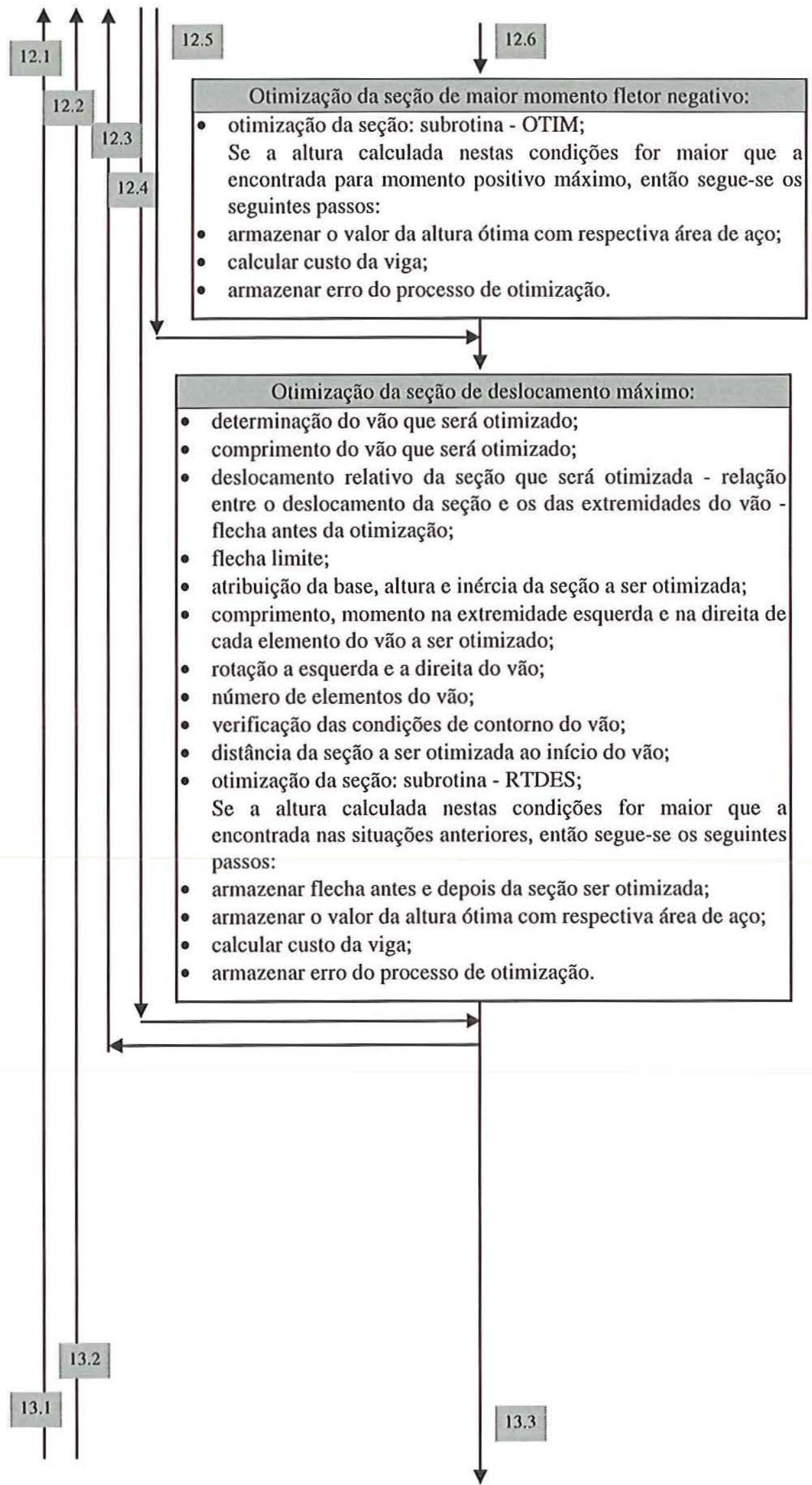




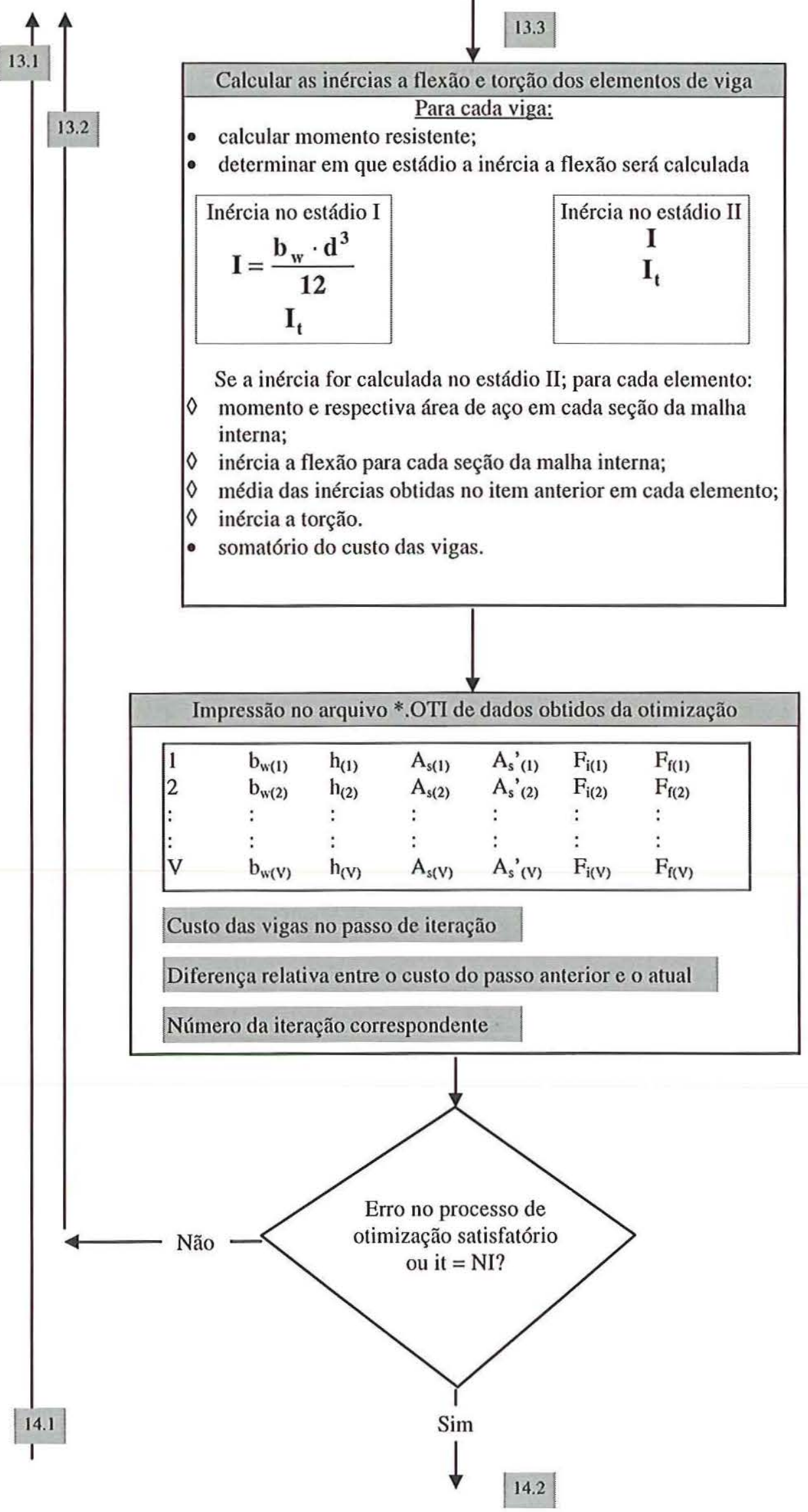




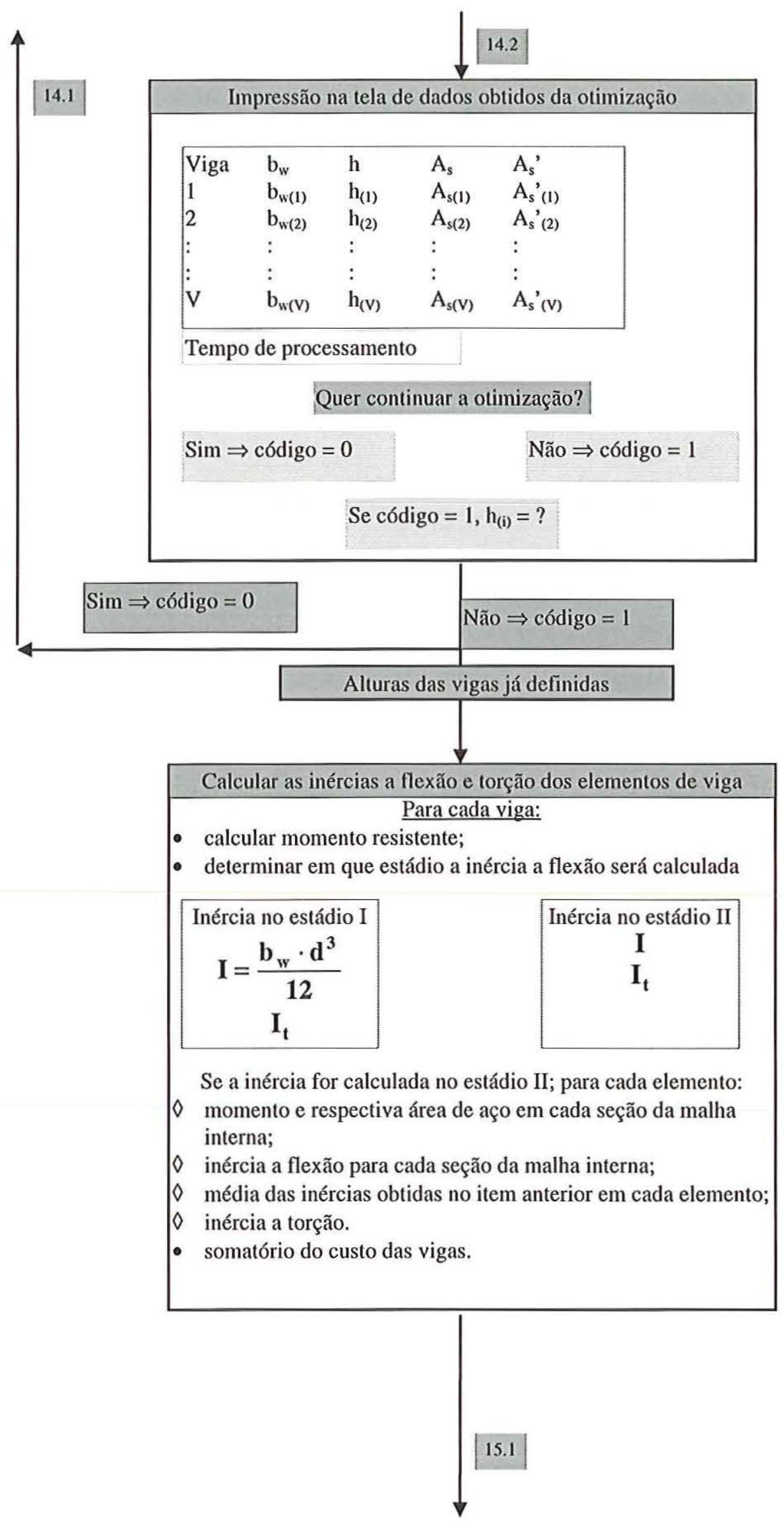




\section{I.8 - Correção das inércias dos elementos finitos de viga.}

Este loop se repetirá o número de iterações vezes, ou será interrompido quando o erro do processo de correção das ihércias pré-definido pelo usuário for satisfatório.

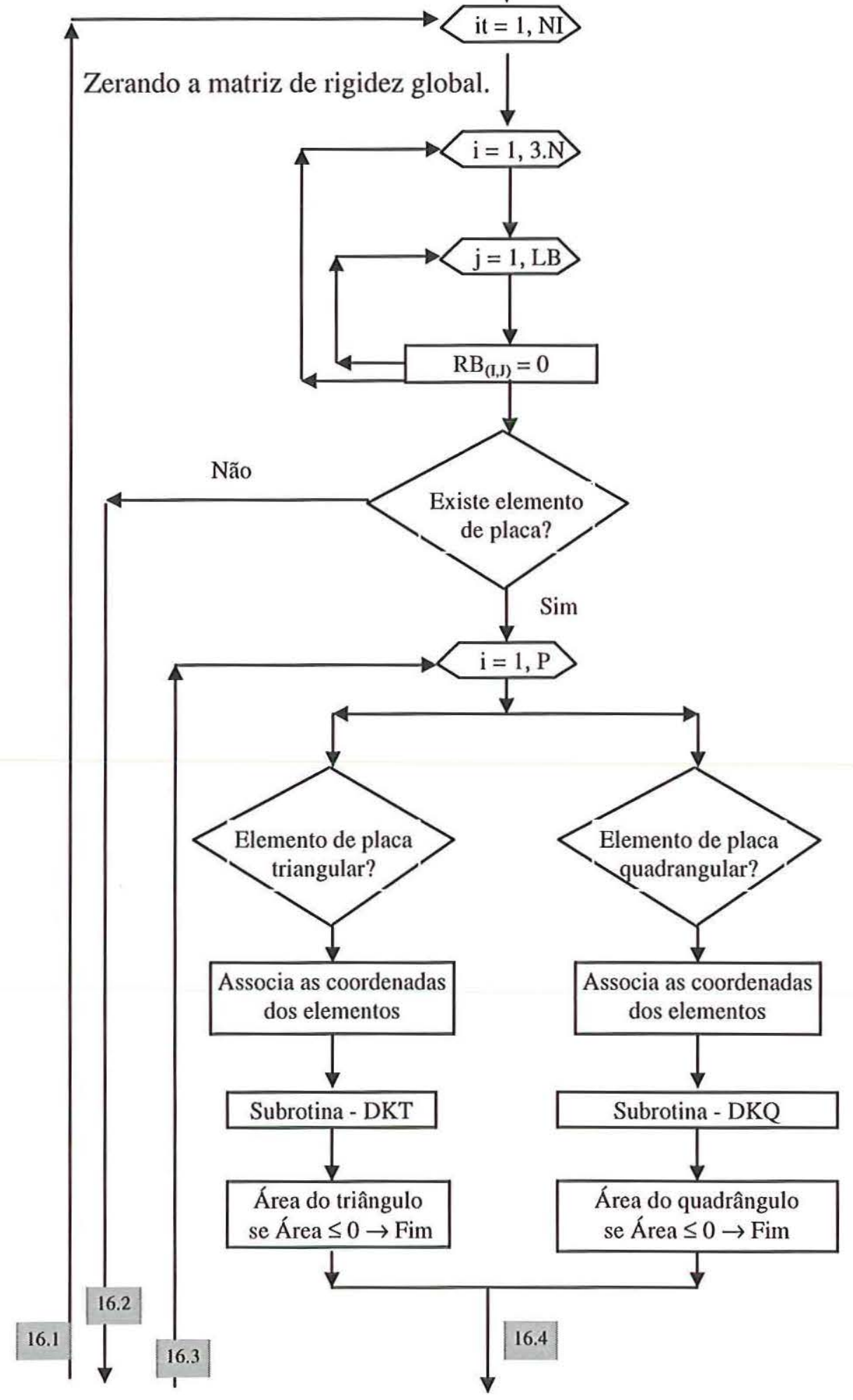




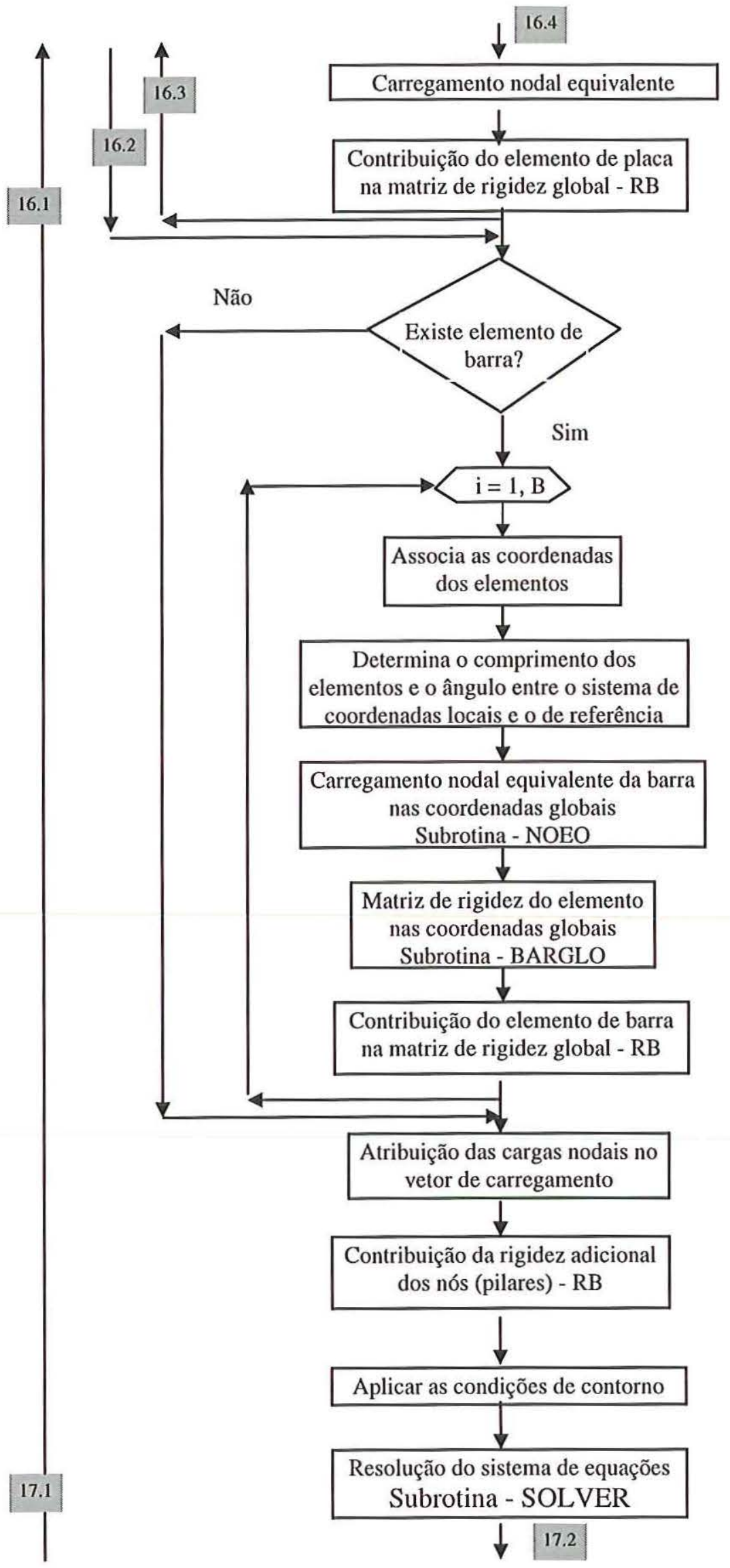




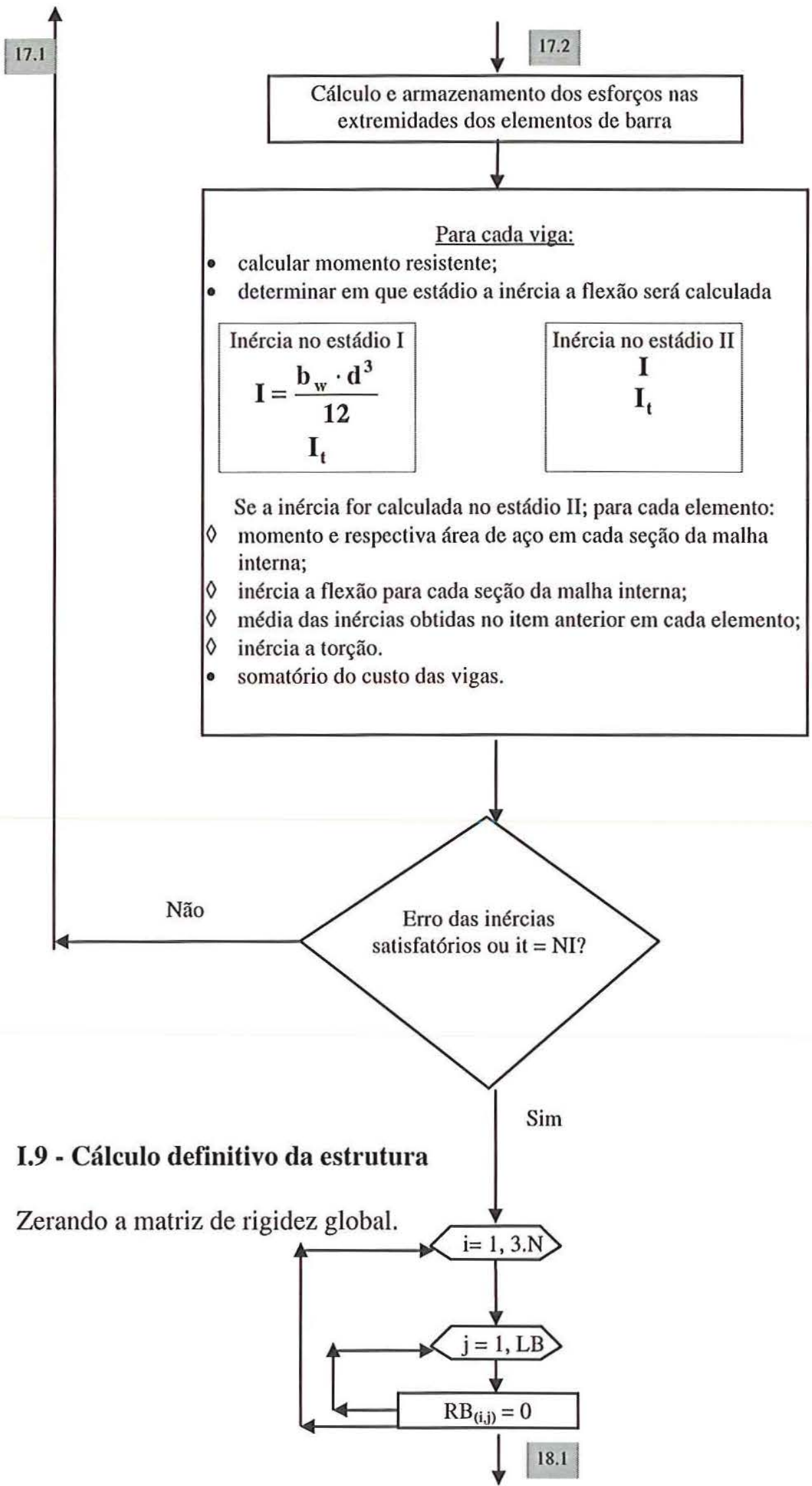




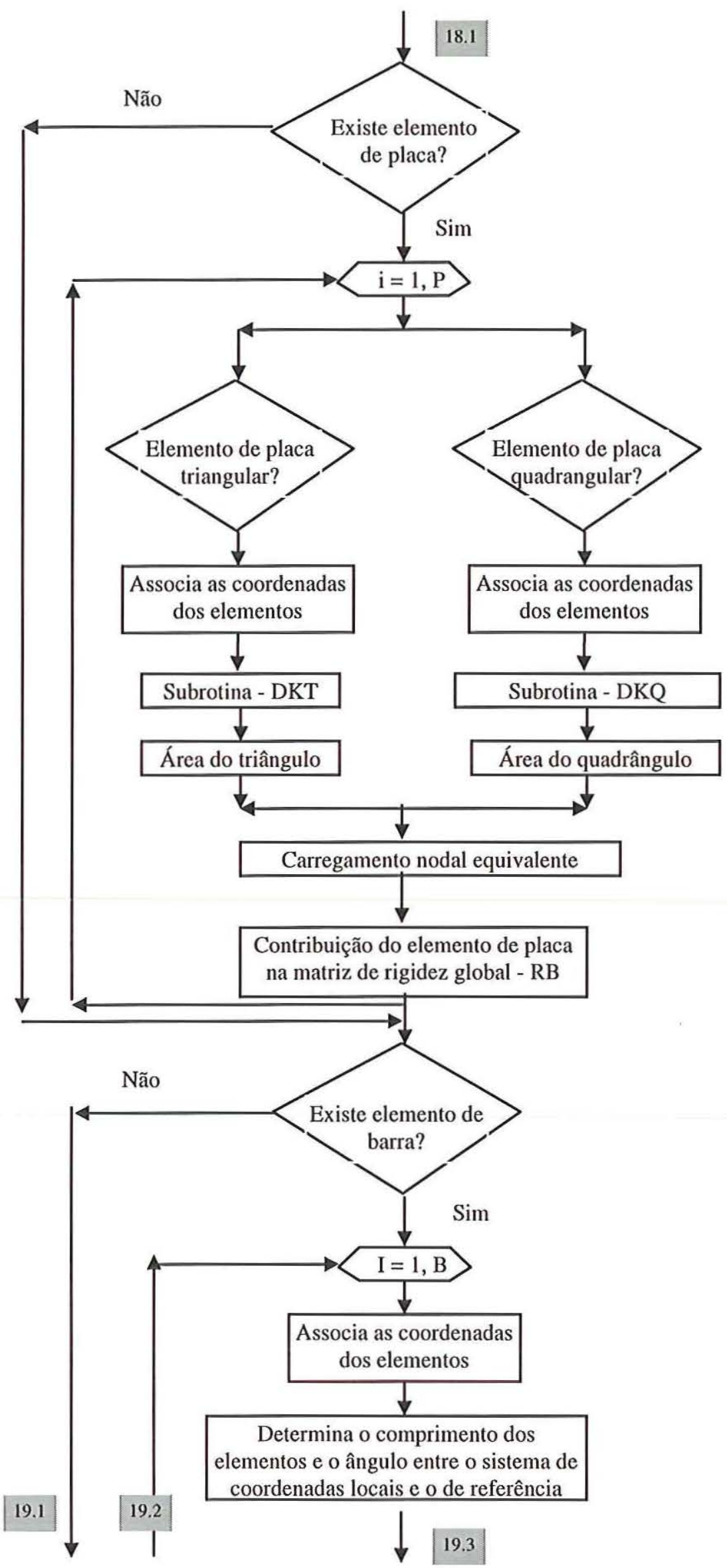




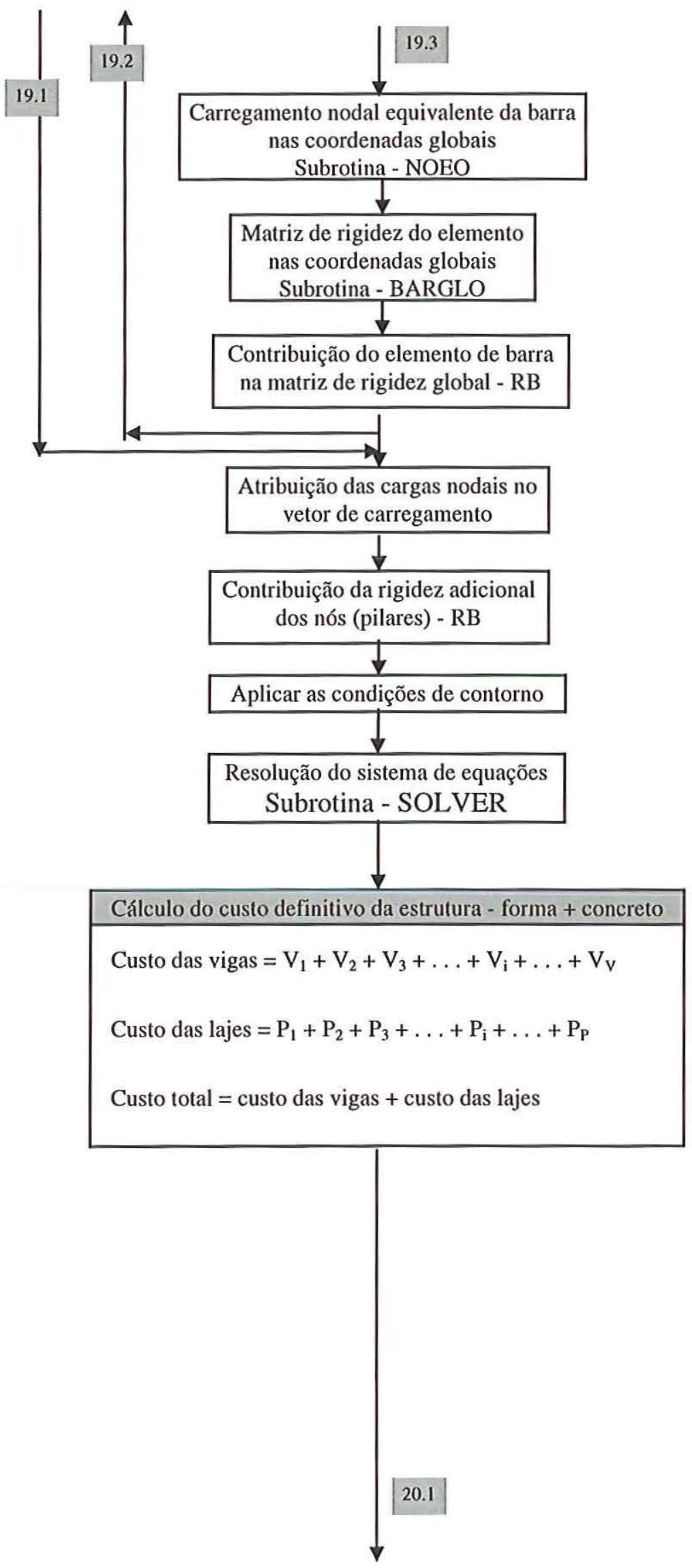




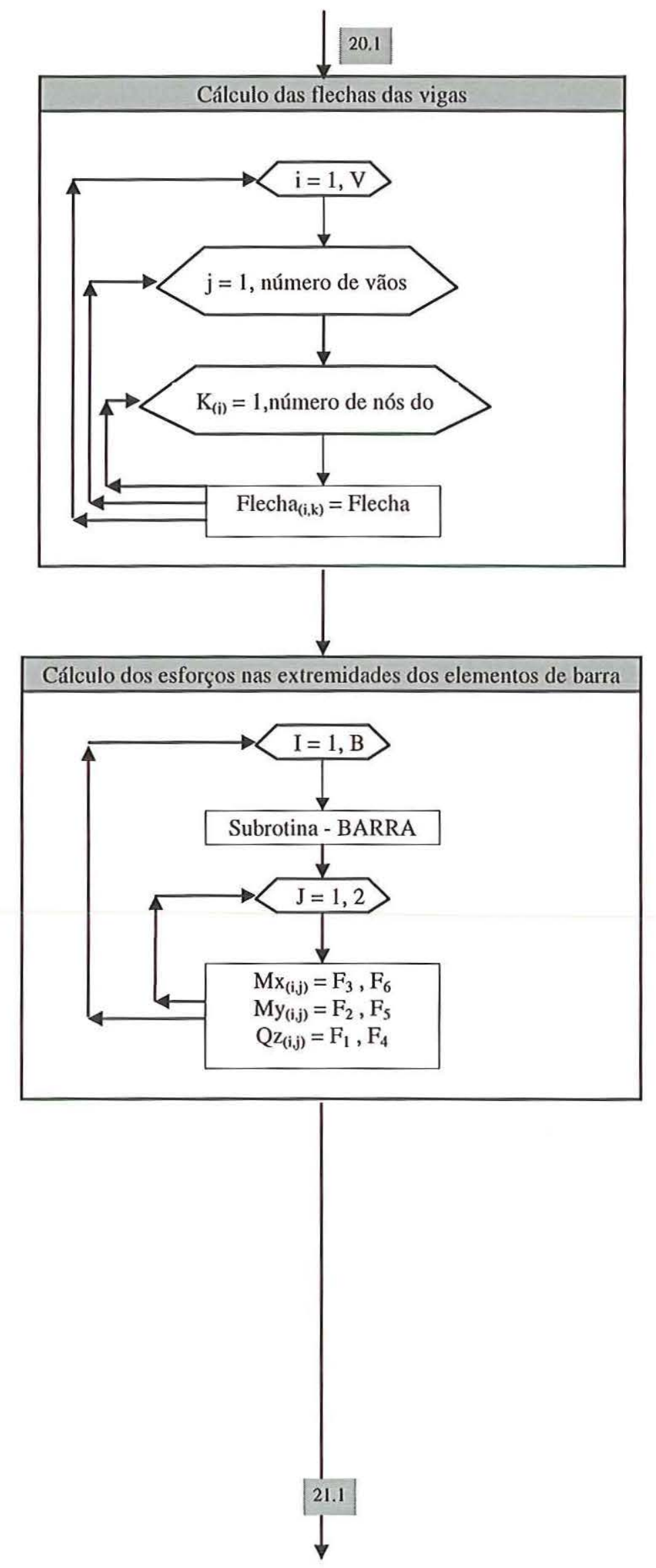




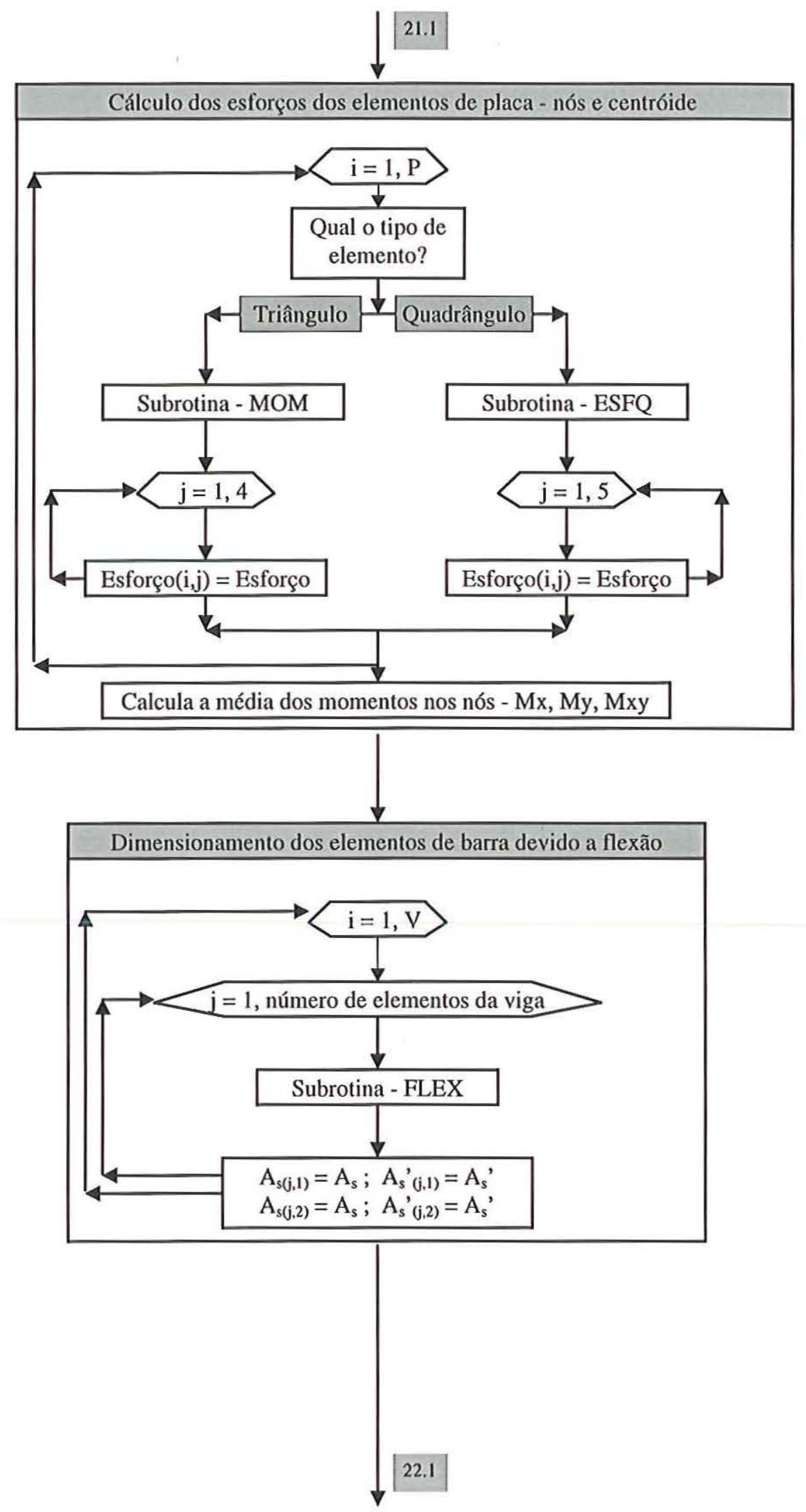


Impressão no arquivo " *.REA "

Nome do arquivo

Identificação da estrutura

Custo das vigas

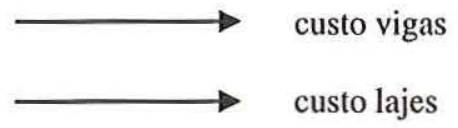

Custo das lajes

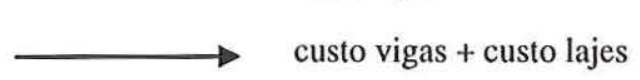

Custo total

Inércias a flexão dos elementos de barra

\begin{tabular}{|ll|}
\hline Elem. & Inércia \\
1 & $\mathrm{I}_{(1)}$ \\
2 & $\mathrm{I}_{(2)}$ \\
$:$ & $\vdots$ \\
$:$ & $\vdots$ \\
B & $\mathrm{I}_{(\mathrm{B})}$ \\
\hline
\end{tabular}

Flechas dos nós das vigas

Áreas de aço, devido a flexão, das barras

\begin{tabular}{|lll|}
\hline Viga & Elem. & $\mathrm{F}_{1}$ \\
1 & 1 & $\mathrm{~F}_{(1,1)}$ \\
1 & 2 & $\mathrm{~F}_{(1,2)}$ \\
1 & $:$ & $\vdots$ \\
1 & $\vdots$ & $:$ \\
2 & 1 & $\mathrm{~F}_{(2,1)}$ \\
2 & 2 & $\mathrm{~F}_{(2,2)}$ \\
$:$ & $:$ & $:$ \\
$:$ & $:$ & $:$ \\
$\mathrm{V}$ & 1 & $\mathrm{~F}_{(\mathrm{V}, 1)}$ \\
$\mathrm{V}$ & 2 & $\mathrm{~F}_{(\mathrm{V}, 2)}$ \\
$\mathrm{V}$ & $:$ & $:$ \\
$\mathrm{V}$ & $:$ & $:$ \\
\hline
\end{tabular}

\begin{tabular}{|lllll|}
\hline Viga & Elem. & Nó & $\mathrm{A}_{\mathrm{s}}$ & $\mathrm{A}_{\mathrm{s}}{ }^{\prime}$ \\
1 & 1 & $\mathrm{No}_{\mathrm{i}}$ & $\mathrm{A}_{\mathrm{s}(1,1)}$ & $\mathrm{A}_{\mathrm{s}}{ }^{\prime}(1,1)$ \\
1 & 1 & $\mathrm{No}_{\mathrm{f}}$ & $\mathrm{A}_{\mathrm{s}(1,2)}$ & $\mathrm{A}_{\mathrm{s}}^{\prime}(1,1)$ \\
1 & $:$ & $:$ & $:$ & $:$ \\
1 & $:$ & $:$ & $:$ & $:$ \\
2 & 1 & $\mathrm{Nó}_{\mathrm{i}}$ & $\mathrm{A}_{\mathrm{s}(2,1)}$ & $\mathrm{A}_{\mathrm{s}}{ }^{\prime}(1,1)$ \\
2 & 1 & $\mathrm{Nó}_{\mathrm{f}}$ & $\mathrm{A}_{\mathrm{s}(2,2)}$ & $\mathrm{A}_{\mathrm{s}}{ }^{\prime}(1,1)$ \\
$:$ & $:$ & $:$ & $:$ & $\vdots$ \\
$:$ & $:$ & $:$ & $:$ & $:$ \\
$\mathrm{V}$ & 1 & $\mathrm{No}_{\mathrm{i}}$ & $\mathrm{A}_{\mathrm{s}(\mathrm{V}, 1)}$ & $\mathrm{A}_{\mathrm{s}}{ }^{\prime}(1,1)$ \\
$\mathrm{V}$ & 1 & $\mathrm{No}_{\mathrm{f}}$ & $\mathrm{A}_{\mathrm{s}(\mathrm{V}, 2)}$ & $\mathrm{A}_{\mathrm{s}}^{\prime}(1,1)$ \\
$\mathrm{V}$ & $:$ & $:$ & $:$ & $:$ \\
$\mathrm{V}$ & $:$ & $:$ & $:$ & $:$ \\
\hline
\end{tabular}


Deslocamentos nodais

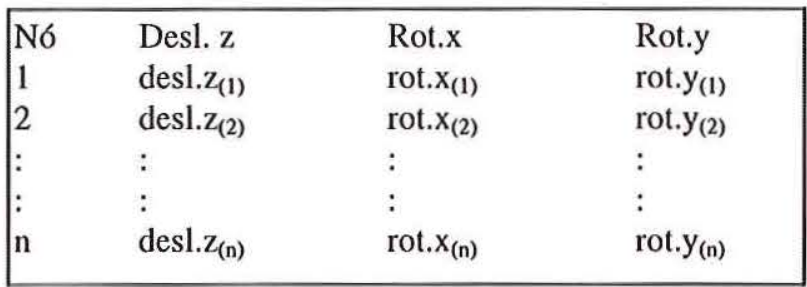

Esforços nas extremidades dos elementos de barra

\begin{tabular}{|c|c|c|c|c|}
\hline Elemento & Nó & $\mathrm{Fz}$ & $\mathrm{Mx}$ & My \\
\hline 1 & nó $_{\mathrm{i}(1)}$ & $\mathrm{Fz}_{\mathrm{i}(1)}$ & $M x_{i(1)}$ & $M y_{i(1)}$ \\
\hline 1 & nóf(1) & $\mathrm{Fz}_{\mathrm{f}(1)}$ & $\mathrm{Mx}_{\mathrm{f}(1)}$ & $\mathrm{My}_{\mathrm{f}(1)}$ \\
\hline 2 & nó $_{i(1)}$ & $\mathrm{FZ}_{\mathrm{i}(1)}$ & $M x_{i(1)}$ & $M y_{i(1)}$ \\
\hline 2 & nóf(1) & $\mathrm{FZ}_{\mathrm{f}(1)}$ & $\mathrm{Mx}_{\mathrm{f}(1)}$ & $\mathrm{My}_{\mathrm{f}(\mathrm{l})}$ \\
\hline : & : & : & : & : \\
\hline : & $:$ & $:$ & : & : \\
\hline B & $n \sigma_{i(B)}$ & $\mathrm{Fz}_{\mathrm{i}(\mathrm{B})}$ & $\mathrm{Mx}_{\mathrm{i}(\mathrm{B})}$ & $M y_{i(B)}$ \\
\hline B & nóf(B) & $\mathrm{Fz}_{\mathrm{f}(\mathrm{B})}$ & $\mathrm{Mx}_{\mathrm{f}(\mathrm{B})}$ & $\mathrm{My}_{\mathrm{f}(\mathrm{B})}$ \\
\hline
\end{tabular}

Momento no centróide dos elementos Momento médio nos nós - esforços nas placas

\begin{tabular}{|c|c|c|c|c|c|c|c|}
\hline Elem. & $\mathrm{Mx}$ & My & Mxy & Nó & $\mathrm{Mx}$ & My & Mxy \\
\hline 1 & $\mathrm{Mx}_{(1)}$ & $\mathrm{My}_{(1)}$ & $\mathrm{Mxy}_{(1)}$ & 1 & $\mathrm{Mx}_{(1)}$ & $\mathrm{My}_{(1)}$ & $\mathrm{Mxy}_{(1)}$ \\
\hline 2 & $\mathrm{Mx}_{(2)}$ & $\mathrm{My}_{(2)}$ & $\mathrm{Mxy}_{(2)}$ & 2 & $\mathrm{Mx}_{(2)}$ & $\mathrm{My}_{(2)}$ & $\mathrm{Mxy}_{(2)}$ \\
\hline : & : & : & : & : & : & : & : \\
\hline : & : & : & : & : & : & : & : \\
\hline $\mathrm{P}$ & $\mathrm{Mx}_{(\mathrm{p})}$ & $\mathrm{My}_{(\mathrm{p})}$ & $\mathrm{Mxy}_{(p)}$ & $\mathrm{N}$ & $\mathrm{Mx}_{(\mathrm{N})}$ & $\mathrm{My}_{(\mathrm{N})}$ & $\mathrm{Mxy}_{(\mathrm{N})}$ \\
\hline
\end{tabular}

Reações de apoio

\begin{tabular}{|llll|}
\hline$N o ́$ & Direção Z & Direção X & Direção $\mathrm{Y}$ \\
1 & $\mathrm{Rz}_{(1)}$ & $\mathrm{Rx}_{(1)}$ & $\mathrm{Ry}_{(1)}$ \\
2 & $\mathrm{Rz}_{(2)}$ & $\mathrm{Rx}_{(2)}$ & $\mathrm{Ry}_{(2)}$ \\
$:$ & & $:$ & $\vdots$ \\
$:$ & & $\vdots$ & $\vdots$ \\
$\mathrm{N}$ & $\mathrm{Rz}_{(\mathrm{N})}$ & $\mathrm{Rx}_{(\mathrm{N})}$ & $\mathrm{Ry}_{(\mathrm{N})}$ \\
\hline
\end{tabular}

Somatório das reações verticais $-\mathrm{Rz}_{(1)}+\mathrm{Rz_{(2) }}+\ldots+\mathrm{R} \mathrm{z}_{(\mathrm{N})}$ 


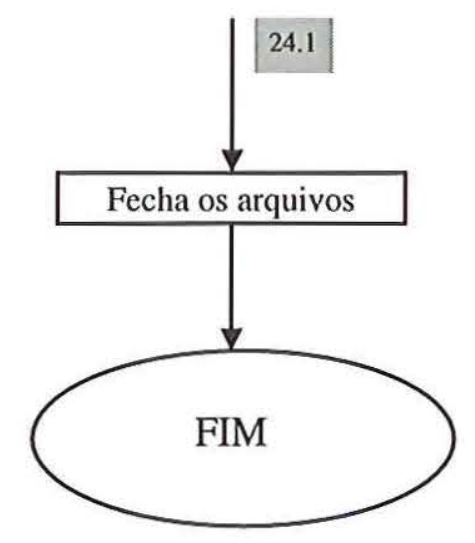

\section{I.2 - FLUXOGRAMA - SUBROTINAS}

\section{I.2.1 - Subrotina BARRA}

Esta subrotina visa ao cálculo dos esforços nas extremidades dos elementos de barra.

\section{Início}

\section{Variáveis de entrada e saída}

- comprimento do elemento;

- seno entre o eixo $\mathrm{x}$ do sistema de coordenadas locais e o eixo $\mathrm{x}$ do sistema de referência;

- cosseno entre o eixo $\mathrm{x}$ do sistema de coordenadas locais e o eixo $\mathrm{x}$ do sistema de referência;

- módulo de elasticidade longitudinal do material;

- coeficiente de Poisson;

- momento de inércia a torção e a flexão;

- momento de torção e ação transversal uniformemente distribuídos na barra;

- deslocamentos $\mathrm{U}_{1}, \mathrm{U}_{2}, \mathrm{U}_{3}, \mathrm{U}_{4}, \mathrm{U}_{5}, \mathrm{U}_{6}$, nas coordenadas globais;

- esforços nas extremidades dos elementos nas coordenadas locais;

- rotações nas extremidades dos elementos.

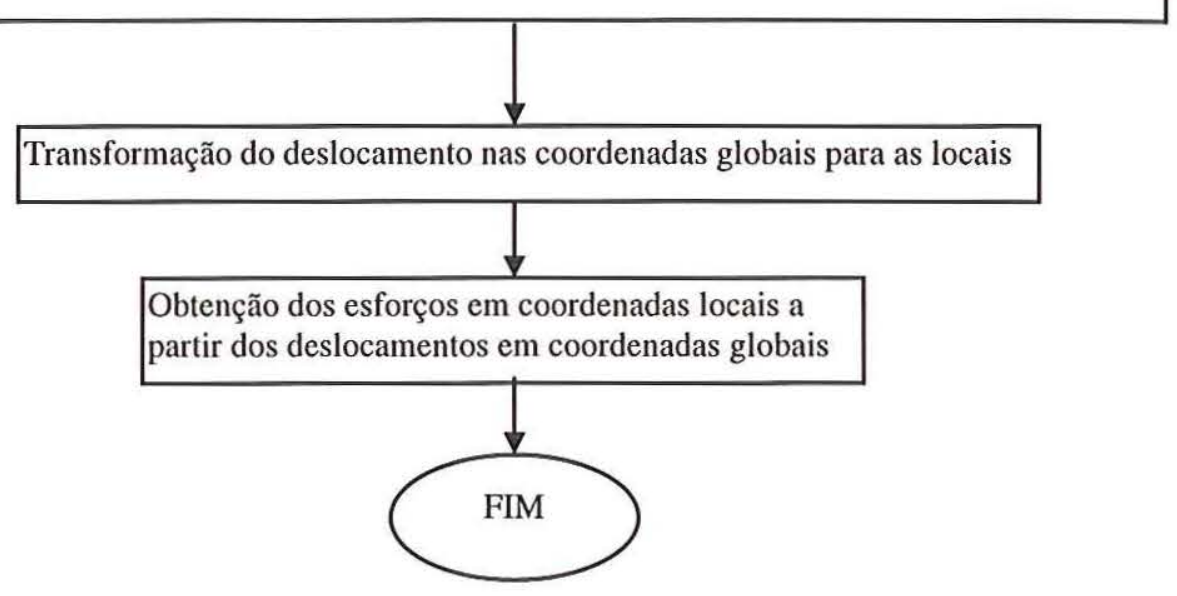




\section{I.2.2 - Subrotina BAND}

Nesta subrotina, pretende-se determinar a largura da semi-banda da matriz de rigidez global.

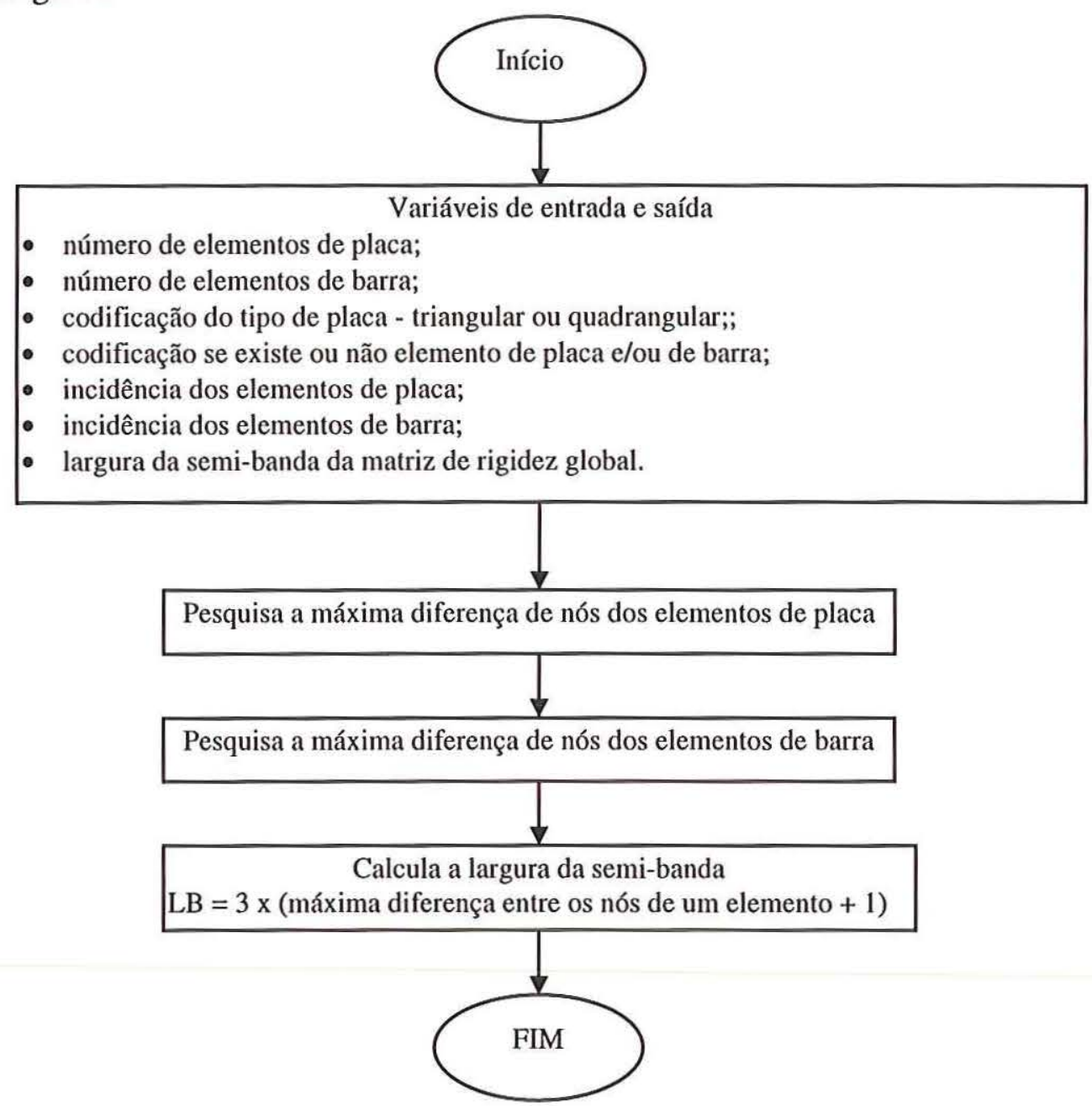

\section{I.2.3 - Subrotina MATD}

Pretende-se determinar a matriz das leis constitutivas com as propriedades elásticas do material - elemento de placa.

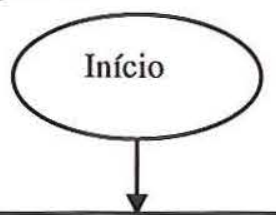

Variáveis de entrada e saída

- módulo de elasticidade longitudinal do material;

- coeficiente de Poisson;

- espessura da placa;

- matriz com propriedades elásticas do material. 


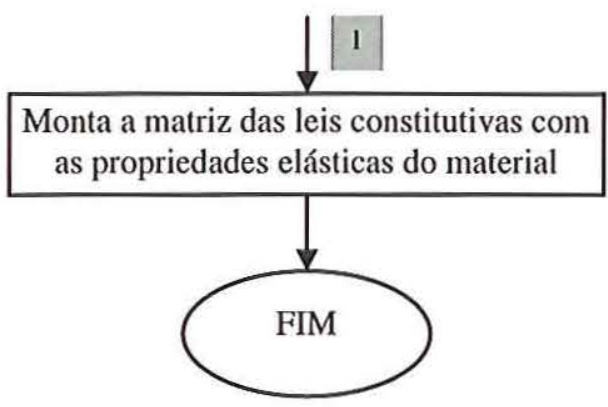

\section{I.2.4 - Subrotina DKQ}

Esta subrotina é responsável pela contribuição da matriz de rigidez do elemento de placa quadrangular na matriz de rigidez global, utilizando para isso condensação estática. Quatro elementos de placa triangulares passam a ser apenas um elemento quadrangular, eliminando o nó central comum aos quatro elementos.

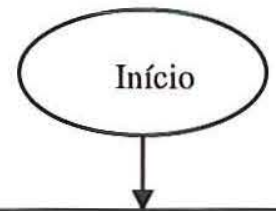

Variáveis de entrada e saída

- carregamento uniformemente distribuído na área do elemento de placa;

- espessura da placa;

- módulo de elasticidade longitudinal do material;

- coeficiente de Poisson;

- coordenadas do elemento;

- matriz de rigidez do elemento nas coordenadas globais - RG;

- forças nodais equivalentes nas coordenadas globais $-\mathrm{F}^{0}$.

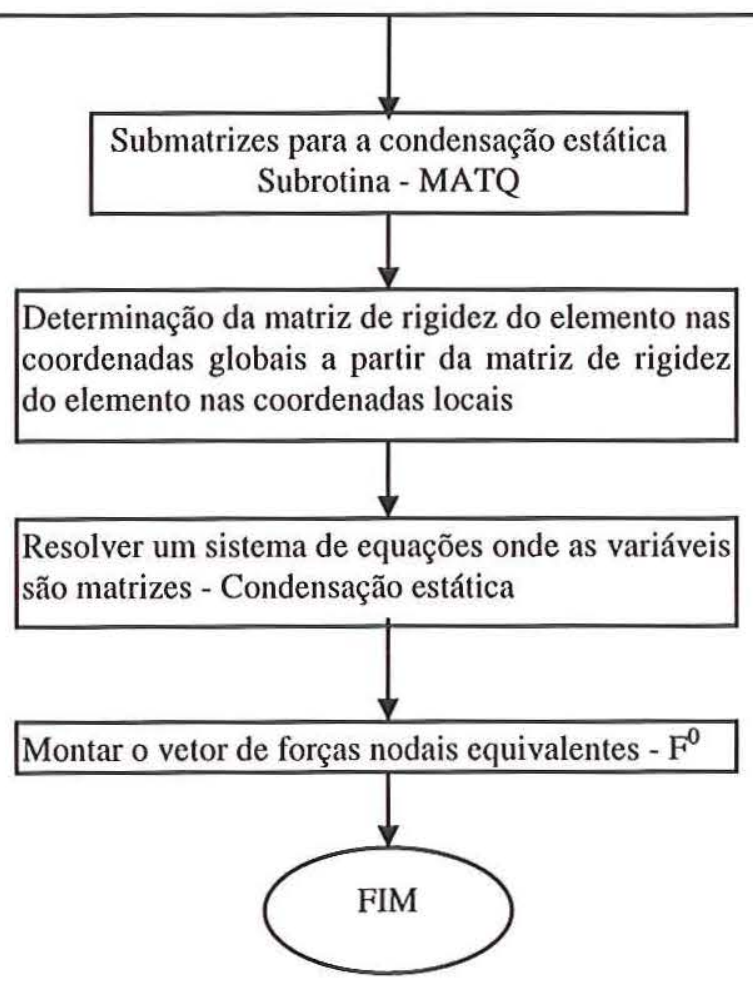




\section{I.2.5 - Subrotina BARGLO}

Fornece a matriz de rigidez dos elementos de barra nas coordenadas globais.

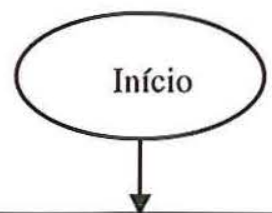

Variáveis de entrada e saída

- incidência do elemento de barra;

- comprimento do elemento;

- seno e cosseno do eixo $\mathrm{x}$ no sistema de coordenadas globais com o eixo $\mathrm{x}$ do sistema de coordenas locais;

- módulo de elasticidade longitudinal do material;

- coeficiente de Poisson;

- inércia a torção e a flexão;

- coeficiente de mola uniformemente distribuído no elemento;

- matriz de rigidez do elemento nas coordenadas globais - RV.

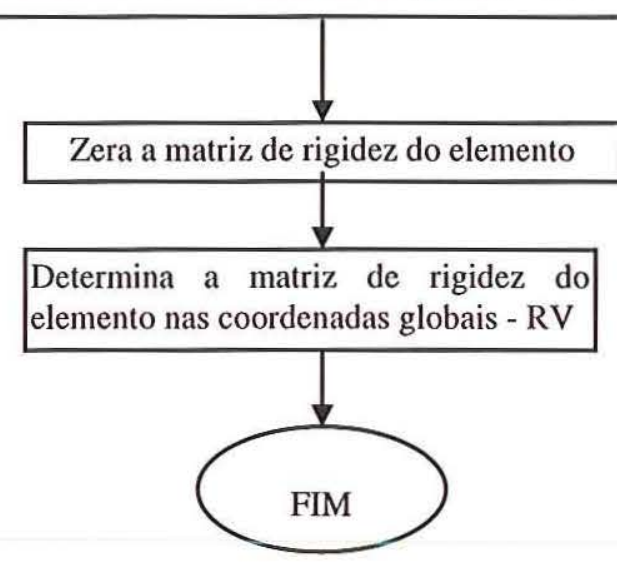

\section{I.2.6 - Subrotina SOLVER}

Resolve um sistema de equações lineares, obtendo os deslocamentos nodais da estrutura.

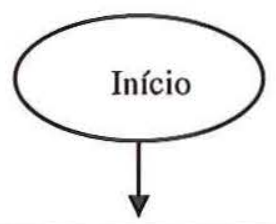

Variáveis de entrada e saída

- número de nós;

- largura da semi-banda;

- matriz de rigidez global [RB];

- vetor de esforços nodais - $\{\mathrm{P}\}$;

- vetor de deslocamentos - $\{\mathrm{U}\}$. 


\section{I.2.7 - Subrotina DKT}

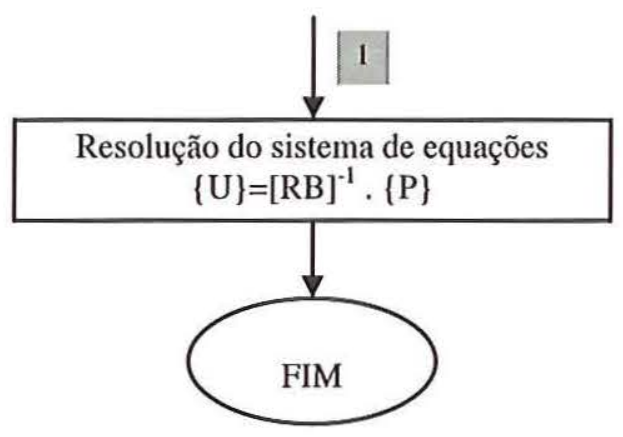

Responsável pela matriz de rigidez do elemento de placa triangular nas coordenadas globais.

\section{Início}

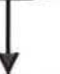

Variáveis de entrada e saída

- espessura da placa;

- módulo de elasticidade longitudinal do material;

- coeficiente de Poisson;

- coordenadas do elemento;

- matriz de rigidez do elemento nas coordenadas globais - RE.

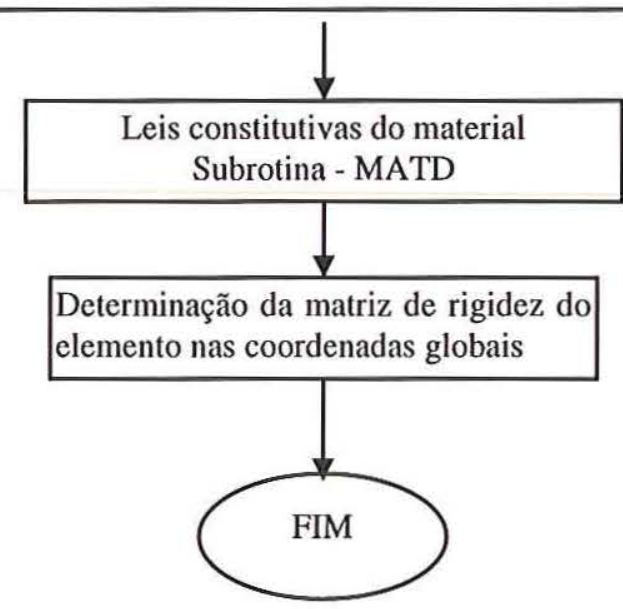

\section{I.2.8 - Subrotina NOEQ}

Cálculo do carregamento nodal equivalente do elemento de barra. 


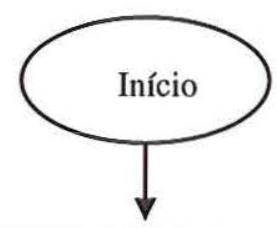

Variáveis de entrada e saída

- comprimento do elemento;

- seno e cosseno do eixo x no sistema de coordenadas globais com o eixo $\mathrm{x}$ do sistema de coordenas locais;

- carga transversal uniformemente distribuída no elemento;

- momento de torção uniformemente distribuído no elemento;

- vetor de carga nodal equivalente.

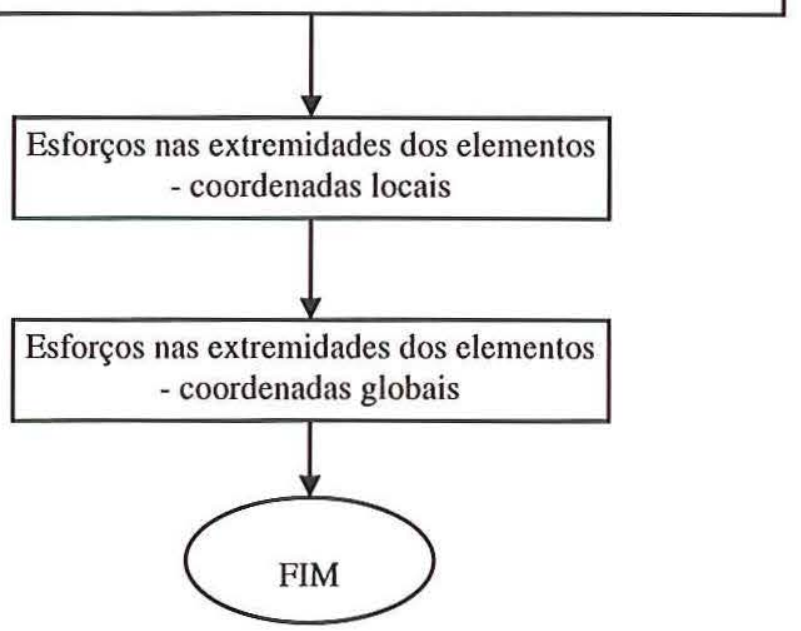

\section{I.2.9 - Subrotina MOM}

Calcula o momento nos nós e no centróide dos elementos de placa triangular.

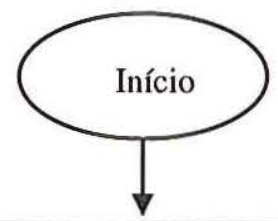

Variáveis de entrada e saída

- espessura da placa;

- módulo de elasticidade longitudinal do material;

- coeficiente de Poisson;

- coordenadas do elemento;

- deslocamentos dos nós do elemento nas coordenadas globais;

- momentos nos nós e centróide do elemento - Mx, My, Mxy.

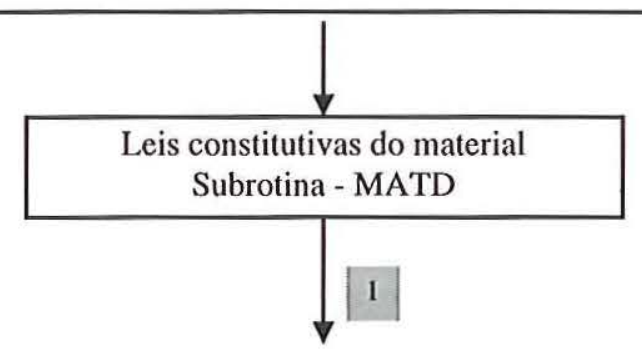




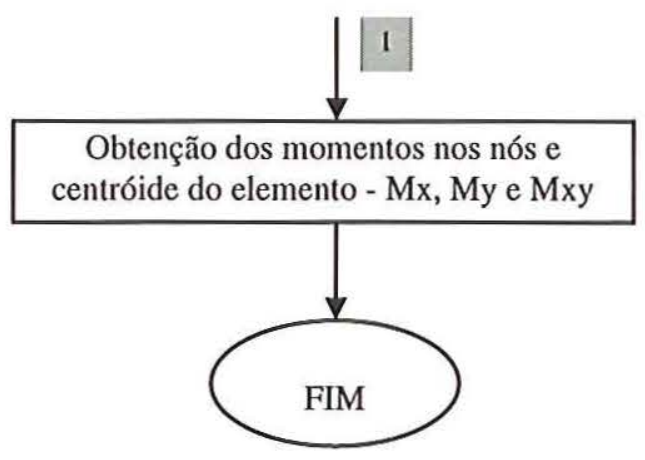

\section{I.2.10 - Subrotina ESFQ}

Cálculo dos esforços no elemento de placa quadrangular.

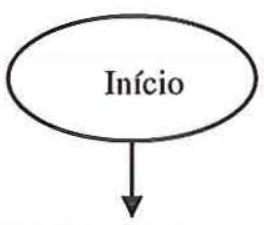

Variáveis de entrada e saída

- carregamento transversal aplicado uniformemente na placa;

- espessura da placa;

- módulo de elasticidade longitudinal do material;

- coeficiente de Poisson;

- coordenadas do elemento;

- deslocamentos dos nós do elemento nas coordenadas globais;

- momentos nos nós e centróide do elemento - Mx, My e Mxy.

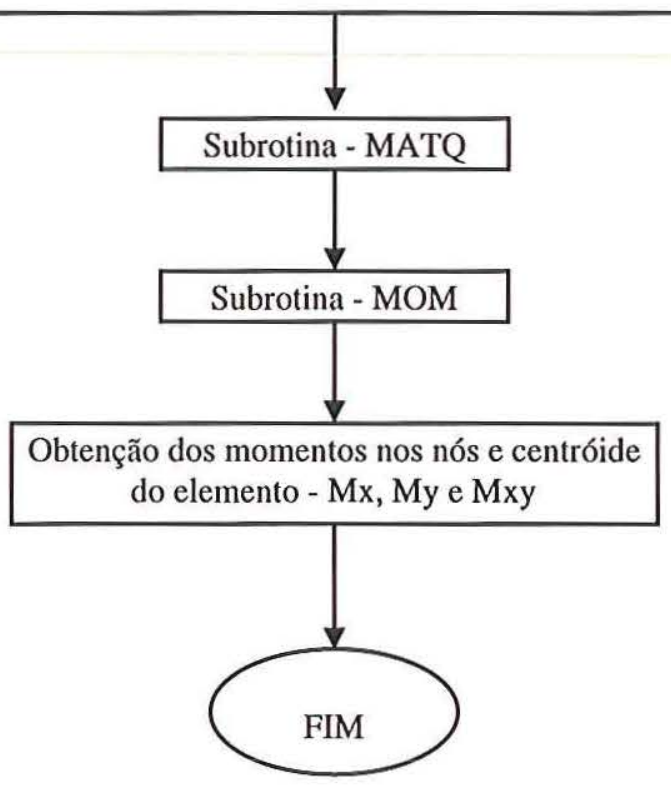




\section{I.2.11 - Subrotina MATQ}

Obtenção de sub-matrizes para a condensação estática e da matriz de rigidez do quadrângulo (12×12).

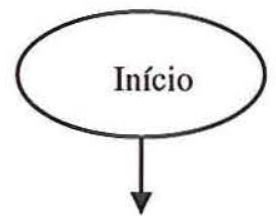

Variáveis de entrada e saída

- carregamento transversal aplicado uniformemente na placa;

- espessura da placa;

- módulo de elasticidade longitudinal do material;

- coeficiente de Poisson;

- coordenadas do elemento;

- vetores e matrizes auxiliares para a condensação estática do carregamento e da matriz de rigidez respectivamente;

- vetor de forças nodais equivalente;

- matriz de rigidez do elemento antes da condensação estática;

- matriz de rigidez do elemento já feita a condensação estática.

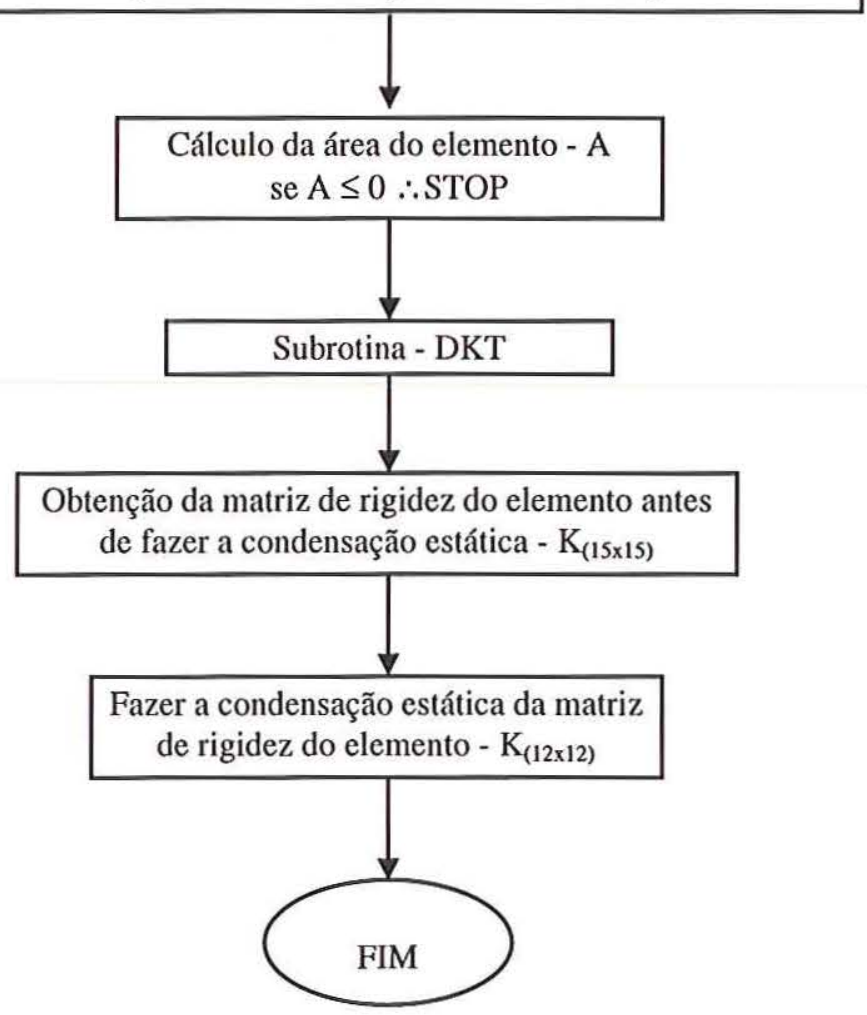




\section{I.2.12 - Subrotina OTIM}

Nesta subrotina, é feita a otimização de uma seção transversal de concreto armado sujeita às restrições explicitadas no presente trabalho com exceção da restrição de deslocamento que será imposta em outra subrotina como será visto posteriormente.

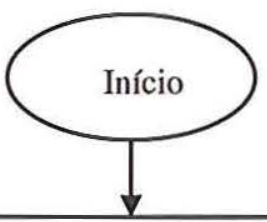

\section{Variáveis de entrada e saída}

- altura útil da seção transversal de concreto;

- área de aço à tração e à compressão devido à flexão da peça;

- custo dos materiais;

- resistência de cálculo do aço e do concreto;

- máxima taxa geométrica de armadura;

- base da seção transversal;

- deformação máxima do aço e do concreto;

- peso específico do aço;

- momento fletor de cálculo;

- distância entre o centro de gravidade da armadura positiva e a face da seção transversal de concreto mais comprimida (d');

- custo da seção transversal por unidade de comprimento - aço, forma e concreto;

- custo da seção transversal por unidade de comprimento - forma e concreto;

- cobrimento das armaduras.

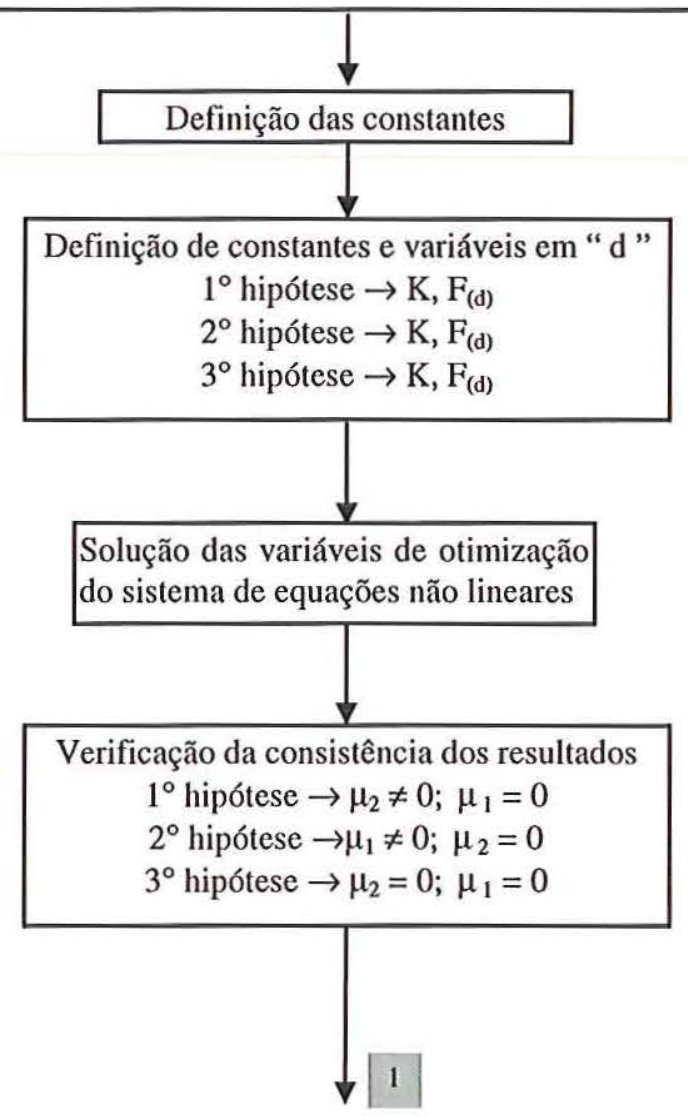




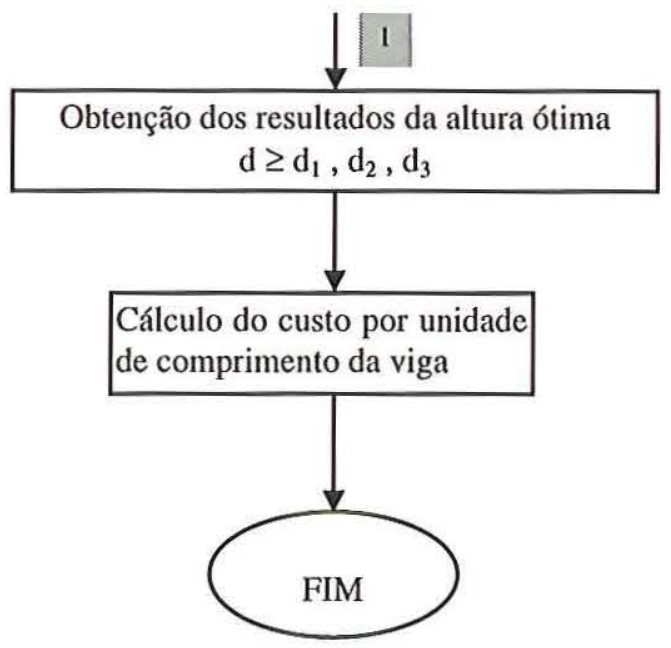

\section{I.2.13 - Subrotina FLEX}

Dimensiona uma seção transversal de concreto armado sujeita a esforço de flexão.

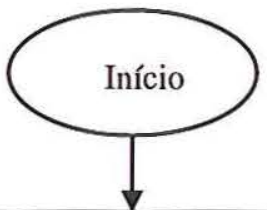

Variáveis de entrada e saída

- resistência de cálculo do aço e do concreto;

- módulo de elasticidade longitudinal do aço;

- altura útil da seção transversal de concreto;

- distância entre o centro de gravidade da armadura positiva e a face da seção transversal de concreto mais comprimida (d');

- base da seção transversal;

- momento fletor de cálculo;

- área de aço a tração e a compressão devido a flexão da peça.

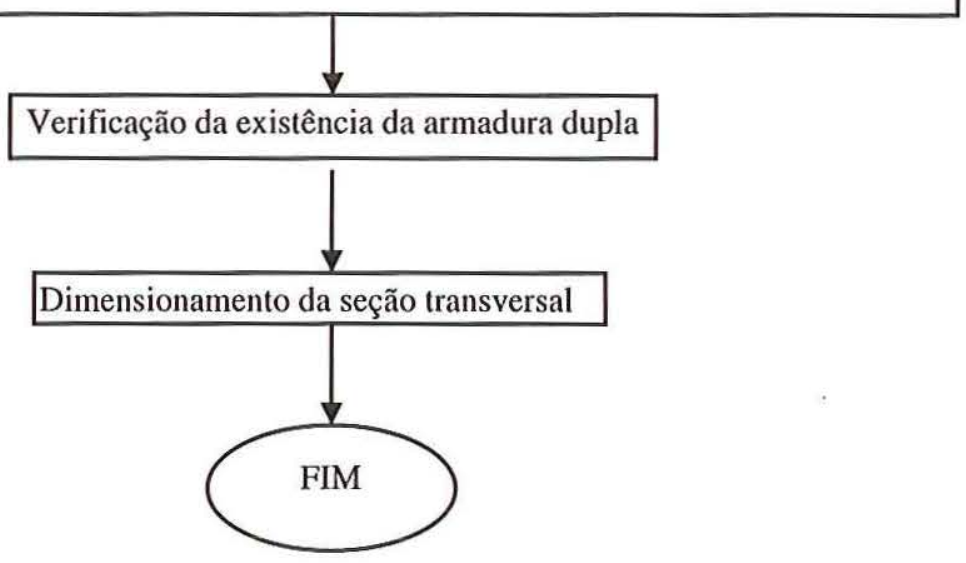




\section{I.2.14 - Subrotina RTDES}

Nesta subrotina é imposta a restrição de deslocamento na otimização da viga de concreto armado.

Início

Variáveis de entrada e saída

- custo dos materiais;

- resistência de cálculo do aço e do concreto;

- módulo de elasticidade longitudinal do concreto e do aço;

- base da seção transversal;

- altura útil da seção transversal de concreto, antes e depois desta restrição;

- distância entre o centro de gravidade da armadura positiva e a face da seção transversal de concreto mais comprimida (d');

- peso específico do aço;

- percentagem máxima de armadura em relação a área de concreto;

- deformação máxima do aço e do concreto;

- momento fletor de cálculo;

- flecha limite do tramo ou vão da viga;

- área de aço a tração e a compressão devido a flexão da peça;

- custo da seção transversal por unidade de comprimento - aço, forma e concreto;

- flecha inicial da viga na seção a ser otimizada;

- código se a inércia a flexão será calculada no estádio I ou II;

- custo da seção transversal por unidade de comprimento - forma e concreto;

- momento fletor nas extremidades esquerda e direita de cada elemento do vão a ser otimizado;

- número de elementos finitos do vão;

- número de elementos finitos entre a extremidade esquerda do vão e a seção a ser otimizada;

- comprimento do vão;

- comprimento de cada elemento finito do vão;

- distância da seção a ser otimizada à extremidade esquerda do vão;

- flecha após a seção ser otimizada;

- número de divisões internas do elemento finito;

- resistência característica do concreto à tração;

- cobrimento das armaduras;

- rotação à esquerda e à direita do vão a ser otimizado;

- codificação se o vão está em balanço ou é biapoiado;

- altura mínima da viga;

- coeficiente de majoração dos esforços $\left(\gamma_{f}\right)$.

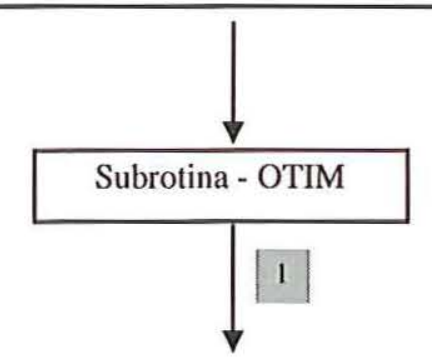




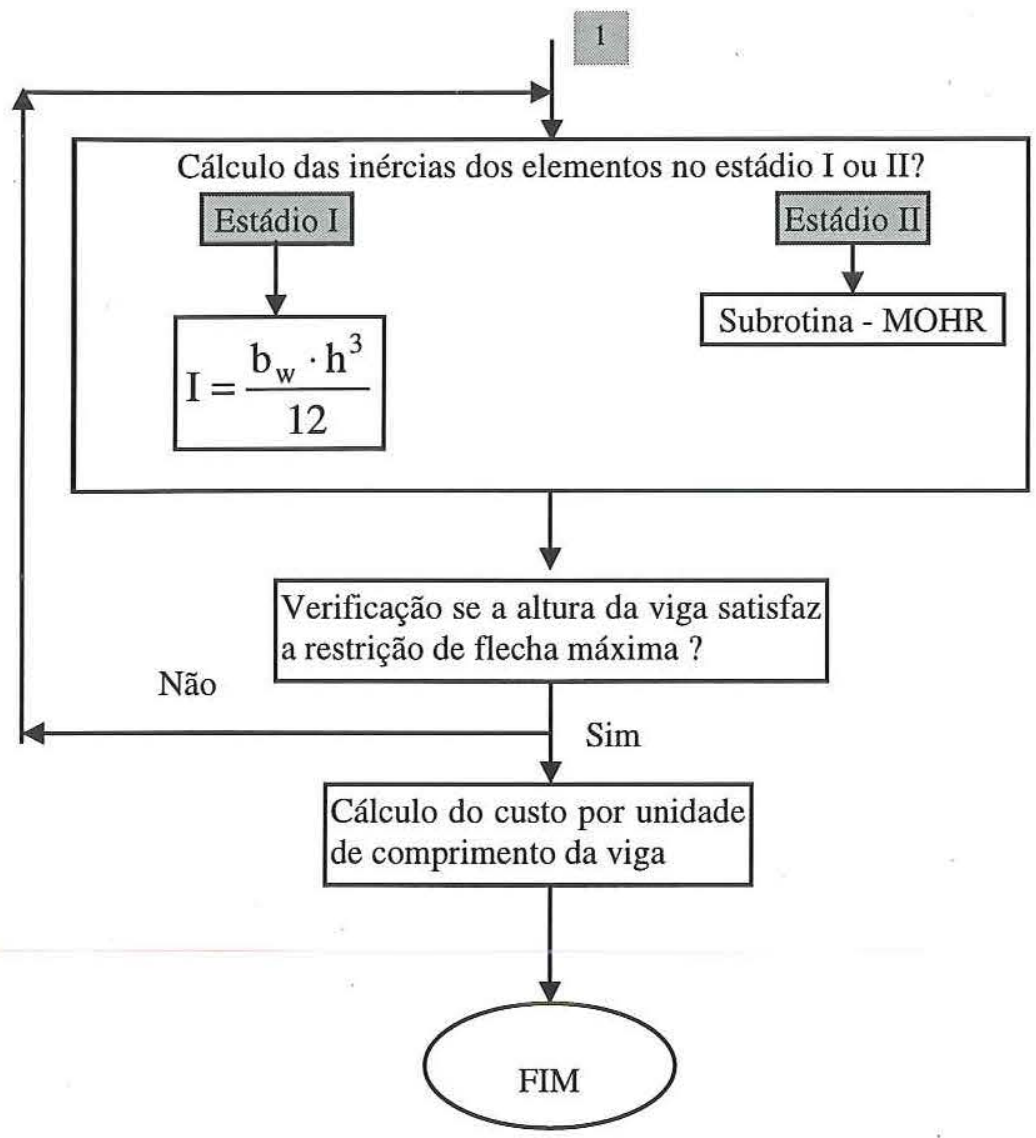

\section{I.2.15 - Subrotina MOHR}

Calcula-se a flecha de uma viga com inércia qualquer sujeita a momentos fletores concentrados aplicados ao longo de seu comprimento. A viga é composta apenas por um tramo que pode ser biapoiado com momentos aplicados nas extremidades ou um balanço. 


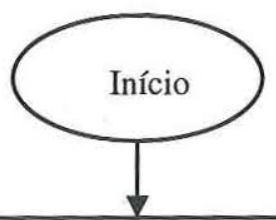

Variáveis de entrada e saída

- resistência do aço e do concreto (fyd, fcd, fct);

- módulo de elasticidade longitudinal do concreto e do aço;

- base da seção transversal;

- altura útil da seção transversal de concreto, antes e depois desta restrição;

- distância entre o centro de gravidade da armadura positiva e a face da seção transversal de concreto mais comprimida (d');

- momento fletor nas extremidades esquerda e direita de cada elemento do vão a ser otimizado;

- número de elementos finitos do vão;

- número de elementos finitos entre a extremidade esquerda do vão e a seção a ser otimizada;

- comprimento do vão;

- comprimento de cada elemento finito do vão;

- distância da seção a ser otimizada a extremidade esquerda do vão;

- flecha após a seção ser otimizada;

- número de divisões internas do elemento finito;

- rotação a esquerda e a direita do vão a ser otimizado;

- codificação se o vão está em balanço ou é biapoiado;

- cobrimento das armaduras;

- coeficiente de majoração dos esforços $\left(\gamma_{\mathrm{f}}\right)$.

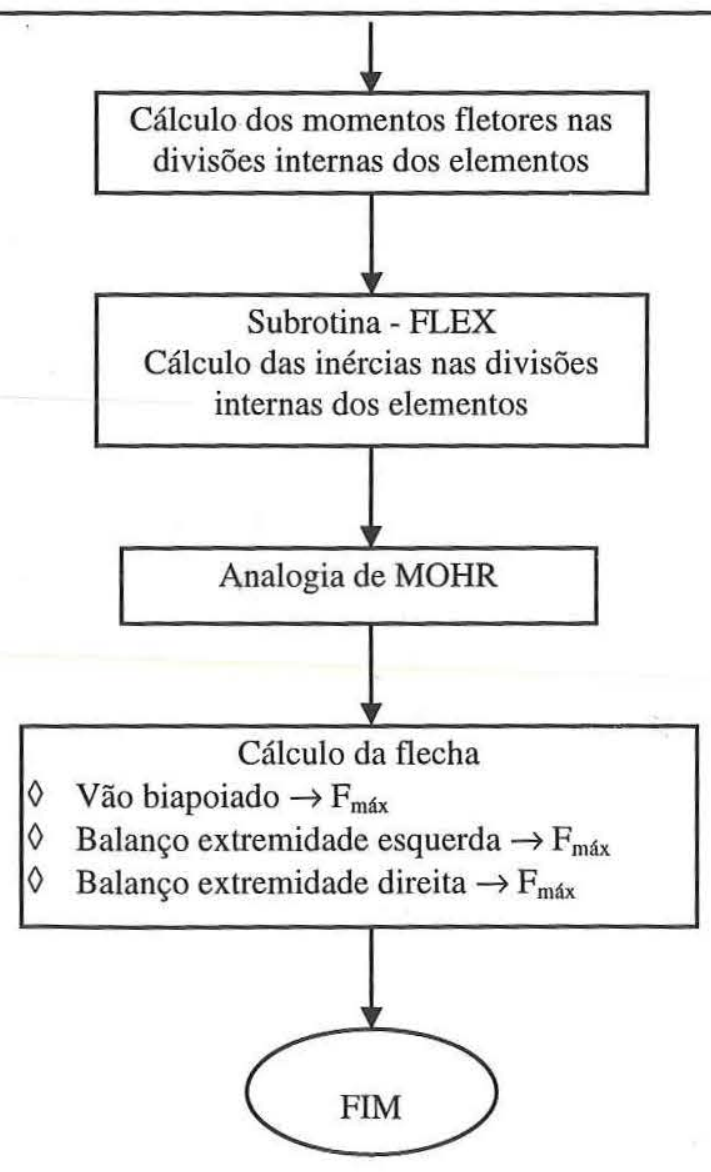

